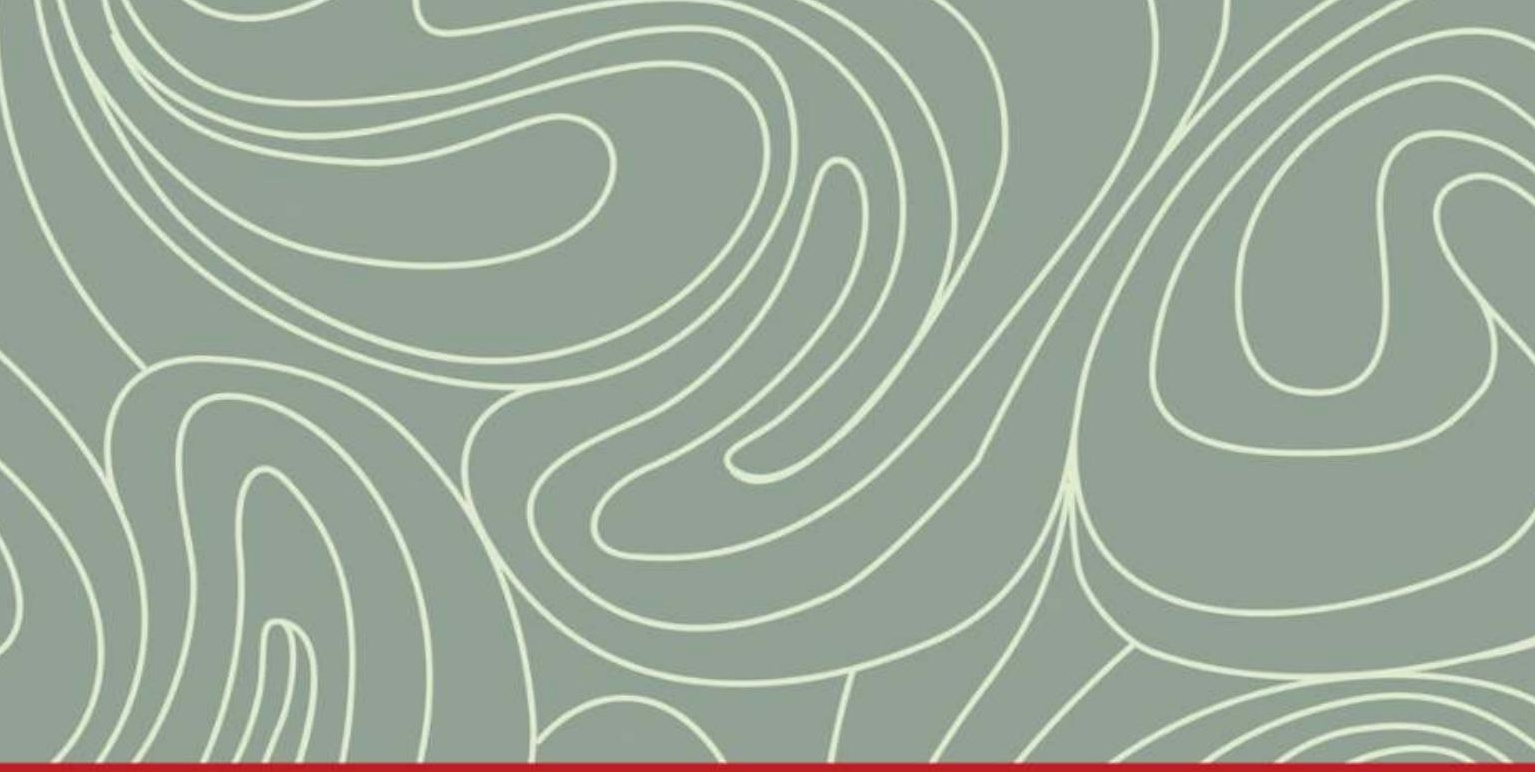

Routledge Research in Legal Philosopby

\title{
PROCEDURAL JUSTICE AND RELATIONAL THEORY
}

\section{EMPIRICAL, PHILOSOPHICAL, AND LEGAL PERSPECTIVES}

Edited by

Denise Meyerson, Catriona Mackenzie, and Therese MacDermott

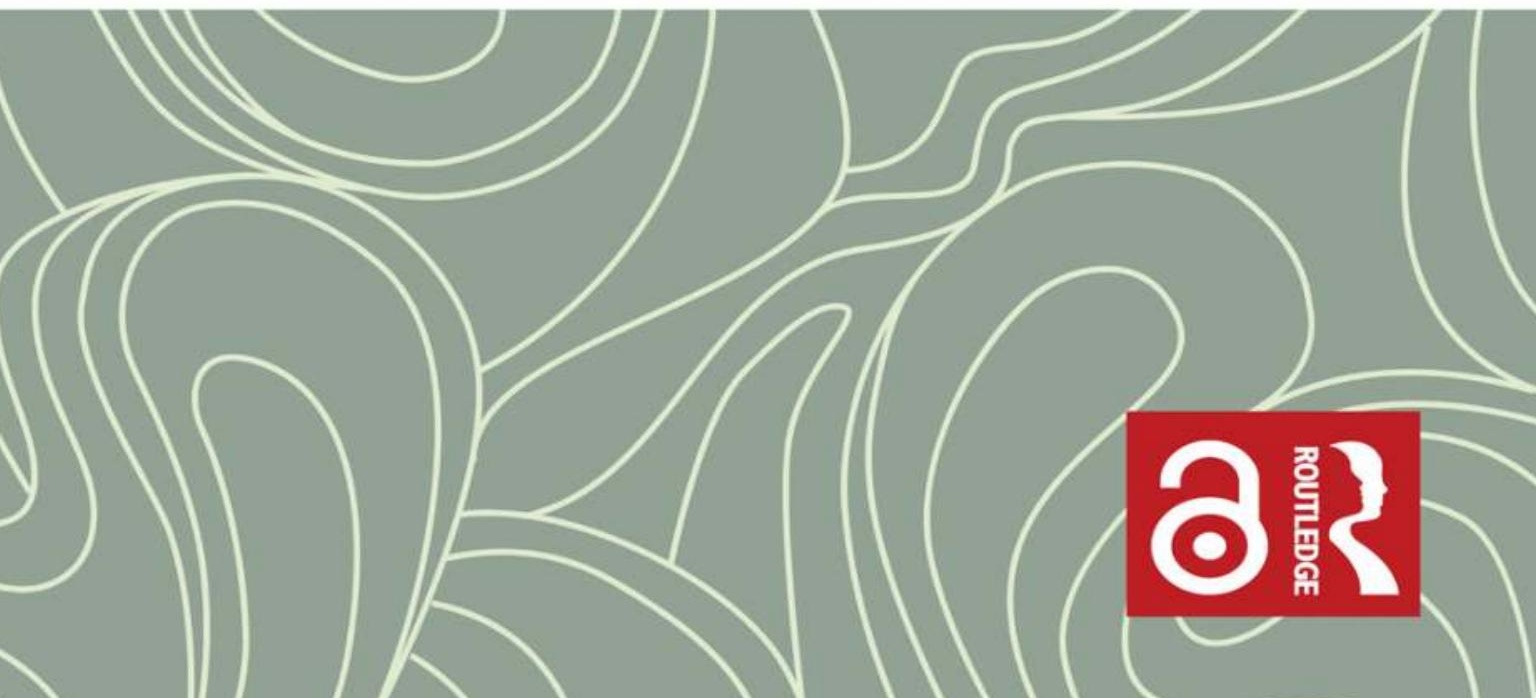




\section{Procedural Justice and Relational Theory}

This book bridges a scholarly divide between empirical and normative theorising about procedural justice in the context of relations of power between citizens and the state.

Empirical research establishes that people's understanding of procedural justice is shaped by relational factors. A central premise of this volume is that this research is significant but needs to be complemented by normative theorising that draws on relational theories of ethics and justice to explain the moral significance of procedures and make normative sense of people's concerns about relational factors. The chapters in Part I provide comprehensive reviews of empirical studies of procedural justice in policing, courts and prisons. Part II explores empirical and normative perspectives on procedural justice and legitimacy. Part III examines philosophical approaches to procedural justice. Part IV considers the implications of a relational perspective for the design of procedures in a range of legal contexts.

This collection will be of interest to a wide academic readership in philosophy, law, psychology, and criminology.

Denise Meyerson, Macquarie Law School, Macquarie University, Sydney

Catriona Mackenzie, Department of Philosophy, Macquarie University, Sydney

Therese MacDermott, Macquarie Law School, Macquarie University, Sydney 


\section{Routledge Research in Legal Philosophy}

Procedural Justice and Relational Theory

Empirical, Philosophical, and Legal Perspectives

Edited by Denise Meyerson, Catriona Mackenzie, and Therese MacDermott 


\section{Procedural Justice and Relational Theory}

Empirical, Philosophical, and Legal Perspectives

Edited by Denise Meyerson,

Catriona Mackenzie, and Therese MacDermott 
First published 2021

by Routledge

2 Park Square, Milton Park, Abingdon, Oxon OXI4 4RN

and by Routledge

52 Vanderbilt Avenue, New York, NY 10017

Routledge is an imprint of the Taylor \& Francis Group, an informa business

(C) 2021 selection and editorial matter, Denise Meyerson, Catriona Mackenzie, and Therese MacDermott; individual chapters, the contributors

The right of Denise Meyerson, Catriona Mackenzie, and Therese MacDermott to be identified as the authors of the editorial material, and of the authors for their individual chapters, has been asserted in accordance with Sections 77 and 78 of the Copyright, Designs and Patents Act 1988.

The Open Access version of this book, available at www.taylorfrancis.com, has been made available under a Creative Commons Attribution-Non Commercial-No Derivatives 4.0 license.

Trademark notice: Product or corporate names may be trademarks or registered trademarks, and are used only for identification and explanation without intent to infringe.

British Library Cataloguing-in-Publication Data

A catalogue record for this book is available from the British Library

Library of Congress Cataloging-in-Publication Data

A catalog record has been requested for this book

ISBN: 978-0-367-32172-7 (hbk)

ISBN: 978-0-367-56517-6 (pbk)

ISBN: 978-0-429-31724-8 (ebk)

DOI: $10.4324 / 9780429317248$

Typeset in Galliard

by Deanta Global Publishing Services, Chennai, India 


\section{Contents}

List of contributors vii

Acknowledgements ix

Introduction: Procedural justice in law, psychology,

and philosophy

DENISE MEYERSON, CATRIONA MACKENZIE, AND THERESE MACDERMOTT

\section{PART I}

Procedural justice in policing, courts, and prisons:

Empirical reviews

1 The empirical study of procedural justice policing in Australia: Highlights and challenges

2 Procedural fairness and jury satisfaction: An analysis of relational dimensions

JANE GOODMAN-DELAHUNTY, DAVID TAIT, AND NATALIE MARTSCHUK

3 Procedural justice in corrections

\section{PART II}

Procedural justice and legitimacy: Empirical and normative perspectives 


\section{vi Contents}

5 Procedure-content interaction in attitudes to law and in the value of the rule of law: An empirical and philosophical collaboration

NOAM GUR AND JONATHAN JACKSON

6 Legal legitimacy and the relevance of participatory procedures 141 SARAH SORIAL

\section{PART III}

The concept of procedural justice: Philosophical perspectives

7 The inadequacy of instrumentalist theories of procedural justice 159 DENISE MEYERSON

8 The many facets of procedural justice in legal proceedings EMANUELA CEVA

9 Procedural justice, relational equality, and self-respect CATRIONA MACKENZIE

\section{PART IV}

Implications and applications: Legal institutions and the exercise of legal authority

10 Racial profiling as pejorative discrimination

11 Administrative discretion and governing relationships: Situating procedural fairness KRISTEN RUNDLE

12 The framing of tribunal procedures: A question of balance or a participation-centred approach? 


\section{Contributors}

Julie Barkworth is a Lecturer in the School of Criminology and Criminal Justice and Griffith Criminology Institute at Griffith University. She has research interests in procedural justice, cooperation and compliance behaviour, defiance and resistance to authority, policing, policing vulnerability, corrections, and prisoner well-being.

Anthony Bottoms is Emeritus Wolfson Professor of Criminology at the University of Cambridge and Honorary Professor of Criminology at the University of Sheffield. He is also a Fellow of the British Academy.

Emanuela Ceva is Professor of Political Theory at the University of Geneva. She works on conflict and justice, democracy, and corruption.

Jane Goodman-Delahunty is Professor of Forensic and Legal Psychology at Charles Sturt University and a Member of the New South Wales Civil and Administrative Tribunal. Her empirical legal studies foster evidence-based decisions to promote social, procedural, and distributive justice.

Noam Gur is a Senior Lecturer in Law and Co-Director of the Centre for Law and Society in a Global Context at Queen Mary University of London. He specialises in jurisprudence and has further research interests in political theory and in tort law.

Jonathan Jackson is a Professor of Research Methodology at the London School of Economics and an Honorary Professor at the University of Sydney Law School. He is a criminologist working at the intersection of psychology and law.

Therese MacDermott is a Professor at Macquarie Law School, with research interests in the areas of dispute resolution, employment rights, equality, and anti-discrimination law. Her professional engagement with legal practice and tribunal processes has facilitated the focus of her research on evaluating the utility and accessibility of statutory rights. 


\section{viii Contributors}

Catriona Mackenzie is a Distinguished Professor in Philosophy at Macquarie University and a Fellow of the Australian Academy of Humanities. Her research interests lie at the intersection of ethics, applied ethics, moral psychology, and feminist philosophy.

Natalie Martschuk is a Research Associate at Charles Sturt University, Australia. Her research focuses on effectiveness of interviewing strategies, procedural justice, decision- making, and witness reliability and credibility. Previously, she practiced as a psychologist at the State Hospital for Forensic Psychiatry (Stendal, Germany).

Denise Meyerson is a Professor of Law at the Macquarie Law School, Macquarie University, and a Fellow of the Australian Academy of Law. Her research interests lie at the intersection of human rights law, legal philosophy, and political philosophy.

Kristina Murphy is a Professor of Criminology and an Australian Research Council Future Fellow at the Griffith Criminology Institute, Griffith University. Her current research projects explore the importance of procedural justice in the context of policing crime victims, and immigrant, ethnic minority, and Muslim communities in Australia. Her focus is on how procedural justice in policing can improve police-community relations.

Kristen Rundle is a Professor and Co-Director of the Centre for Comparative Constitutional Studies at Melbourne Law School. She teaches and researches in the fields of legal theory and administrative law.

Natalie Stoljar is an Associate Professor in the Department of Philosophy at McGill University. Her research is principally in three areas: feminist philosophy, social and political philosophy, and the philosophy of law.

Sarah Sorial is an Associate Professor in Law at Macquarie University. Her research is primarily at the intersection of philosophy and law, with a specific focus on the limits of free speech, the importance of democratic deliberation, and the place of rights in liberal democracies.

David Tait is Professor of Justice Research at Western Sydney University. He has led four Australian Research Council funded research projects about court environments, technologies, and processes and is currently developing immersive virtual courts.

Justice Tankebe is a Lecturer in Criminology at the University of Cambridge. His research interests are in policing and illegitimacy, procedural and distributive injustice, institutional distrust, corruption, and vigilantism. 


\section{Acknowledgements}

We would like to thank the contributors to this volume whose enthusiasm for this project and hard work made it possible. Wendy Carlton provided outstanding editorial assistance. Her eagle eye for detail in matters of consistency, referencing, style, and formatting made the task of the editors immeasurably easier. We are also grateful to Alison Kirk, our editor at Routledge, for her encouragement and friendly support throughout this project. The editors' research for this volume was funded by the Australian Government through the Australian Research Council's Discovery Project funding scheme (DP1701009600: 'A Relational Theory of Procedural Justice'). We are very grateful to the Australian Research Council for its support. The origins of the volume lie in a workshop funded by the Australian Research Council and the Macquarie University Research Centre for Agency, Values and Ethics. This workshop, which was held at Macquarie University in September 2018, brought together moral and legal philosophers, lawyers, social psychologists and criminologists to explore the topic of procedural justice. Earlier versions of some of the chapters in this volume were presented at the workshop and the productive discussion among the participants greatly enriched the final product. Each of us would also like to acknowledge the time and commitment our fellow editors put into bringing this project to fruition.

$$
\begin{array}{r}
\text { Denise Meyerson, Macquarie } \\
\text { University, Sydney } \\
\text { Catriona Mackenzie, Macquarie } \\
\text { University, Sydney } \\
\text { Therese MacDermott, Macquarie } \\
\text { University, Sydney } \\
\text { April } 2020
\end{array}
$$




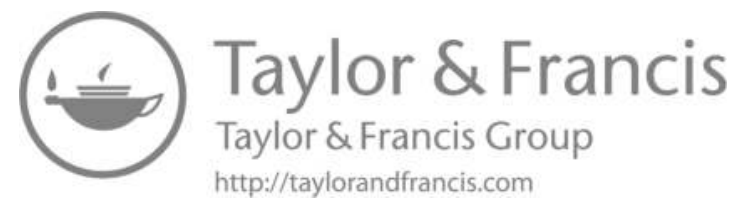




\title{
Introduction
}

\section{Procedural justice in law, psychology, and philosophy}

\author{
Denise Meyerson, Catriona Mackenzie, and \\ Therese MacDermott
}

\subsection{Introduction $^{1}$}

What procedures should officials use as a matter of justice when they apply and enforce the law or exercise discretion vested in them by the law? ${ }^{2}$ This is an important question of political morality, since procedurally just treatment at the hands of officials is a precondition for the justifiable exercise of state power. Yet legal theorists and philosophers have paid surprisingly little attention to addressing this question. This contrasts with the extensive philosophical literature exploring substantive forms of justice, such as distributive justice and rectificatory justice (Bayles 1990, p. 1), and with the recognition of the importance of procedures in other areas of philosophical inquiry, such as meta-ethics and political philosophy (e.g. in the field of democratic theory). The philosophical neglect of procedural justice is all the more striking in light of the attention the concept has attracted in other disciplines. Social psychologists in particular have undertaken extensive empirical research on procedural justice in legal, policing, and organisational contexts. A central finding of this research is that people care as much about procedures as about outcomes, and that their understanding of procedural justice is shaped by relational factors, such as the attitudes expressed by authorities in interacting with them. The premise of this volume is that the empirical research into the psychology of procedural justice is significant. However, this research needs to be complemented by normative theorising that explains the moral significance of procedures and makes normative sense of people's concerns about relational factors.

This volume contributes to the field of applied legal philosophy by initiating an interdisciplinary exchange between moral philosophers, lawyers, legal theorists, psychologists, and criminologists on the topic of procedural justice in legal contexts. In particular, given the importance of relational factors according to the research in social psychology, a central focus of the volume is to investigate procedural justice from the perspective of relational theories of ethics and justice, and to explore the implications of this perspective for the design of legal procedures.

One of the challenges posed by interdisciplinary exchange of this kind is that scholars from different disciplines can use the same concepts with subtly or sometimes substantially different meanings, leading to misunderstanding and

DOI: $10.4324 / 9780429317248-1$ 


\section{Denise Meyerson et al.}

miscommunication. One of our aims in this introduction is to try to avert potential misunderstandings by explaining some differences between the way lawyers, legal theorists, social psychologists, and philosophers understand certain key concepts. In Section 2, we provide an overview of some key concepts and relevant background literature on procedural justice in law, legal theory, social psychology, and philosophy. In Section 3, we provide a brief overview of the structure of the volume and summarise the contents of each chapter.

\subsection{Key concepts for understanding procedural justice}

Procedural justice is, of course, a central legal concept (usually under the name of 'procedural fairness', 'natural justice' or 'procedural due process', depending on the jurisdiction). ${ }^{3}$ However, this volume is not centrally concerned with the law's approach to procedural justice as a doctrinal matter (the analysis of legal concepts, rules, and practices). Instead, it approaches procedural justice from a more critical, normative perspective.

As an example of the law's approach, consider the hearing rule, which is one of the two classic rules of procedural fairness recognised by the common law, the other being the rule against bias. The hearing rule imposes a legal obligation on certain decision-makers (whether in the exercise of judicial or administrative power) to give individuals a 'fair opportunity' to advance their case. Doctrinal treatments of the rule are concerned mainly with determining to which decisions and decision-makers the rule applies and analysing its content when it does apply. Since the rule applies in the majority of cases, the latter tends to be the 'real and practical question' (Galligan 1996, p. 358). The key consideration here is that the hearing rule is very generally framed, and the courts have emphasised that its content is flexible, saying that its requirements are more or less stringent, depending on the circumstances of the particular case. Thus, the rule has a 'chameleon-like' nature (Kioa v West (1985) 159 CLR 550, 612). For instance, the courts have held that fairness to affected persons sometimes requires a full-blown oral hearing with legal representation (e.g. in the circumstances of a criminal trial), but that in other circumstances (e.g. high-volume administrative matters, such as the refusal of a licence renewal), a pared-back hearing based solely on written submissions will suffice. From the doctrinal perspective, then, the focus is on close, particularised analysis of whether a person has had an adequate opportunity to be involved in the decision-making process in light of all the surrounding circumstances. By contrast, deeper moral questions about the justifiability of the hearing rule are of less interest. As DJ Galligan says, 'the courts tend not to enter into direct discussion of why the hearing principle is a fundamental requirement of procedural fairness' (1996, p. 354). Instead, the reason for this is often taken to be self-evident, as in Justice Fortescue's frequently quoted statement in Dr Bentley's Case that 'God himself would not condemn Adam for his transgression until he had called him to know what he could say in his defence ... Such proceeding is agreeable to justice' (The King v Chancellor of Cambridge (1723) I Str 557, 2 Ld Raym 1334, $8 \operatorname{Mod} 148,164)$. 
By contrast, a normative approach is in search of the most defensible theory of procedural justice from a philosophical point of view. Such a theory answers deeper moral questions about the procedures that officials should use when they apply the law, enforce the law, or make discretionary decisions, and it also suggests ways in which procedural rules and practices should be reformed if they diverge from the relevant normative standards. For instance, while it is no doubt more 'agreeable to justice' to determine questions of guilt and innocence by allowing accused persons to defend themselves as opposed to, say, tossing a coin, a normative theory will ask why this is the case. Is it, for instance, because a hearing makes it more likely that the rules of the criminal law will be accurately applied? Or does a hearing also serve non-instrumental values and, if so, what form do they take? Consider also the problem of bias. What sort of bias is offensive to procedural justice? Personal bias is obviously a breach of procedural justice, but what should we say about more insidious, systemic forms of bias in, for instance, bureaucracies and the police force (see Galligan 1996, pp. 438-439)? Why, for example, is it morally problematic if government officials treat welfare recipients with disrespect or operate with the assumption that they are undeserving? Or, as Natalie Stoljar asks in her contribution to this volume, why might the use of racial profiling by police be inherently morally problematic? A normative theory of procedural justice is necessary to answer these questions.

To the extent that legal theorists and philosophers have sought to develop normative theories of procedural justice, the literature is dominated by instrumental and dignitarian accounts. Instrumental accounts take the outcomes-oriented view that the only purpose of procedures is to lead to outcomes that uphold substantive legal rights. Ronald Dworkin is an influential defender of the instrumentalist view, as is John Rawls. Dworkin believes that people who are mistakenly denied their legal rights suffer injustice or 'moral harm' (1985, p. 80) and that procedural justice consists in the use of procedures that guard against this form of injustice. Dworkin makes clear that he believes that there is no moral harm other than the harm of a mistaken decision (pp. 102-103). This implies that the only reason to insist on a procedure such as a hearing is if it guards against legal error. Rawls takes a related view, saying that procedural justice in criminal trials consists in the use of procedures that lead to the correct result most of the time (1971, p. 86 ), and that due process is 'a process reasonably designed to ascertain the truth' (1971, p. 239). Richard Posner's economic approach to procedural justice (1973) is also a form of instrumentalism, although, unlike Dworkin and Rawls, Posner does not regard the erroneous deprivation of legal rights as a form of injustice to individuals. Instead, he is concerned only about the fact that legal error makes it more difficult to achieve the aims of the substantive law. This is a social cost, not a moral cost. Furthermore, since accurate procedures are expensive and therefore have their own social cost, Posner is willing to trade off the social benefits of accuracy-promoting procedures against their costs. In this volume, Emanuela Ceva, Denise Meyerson, and Kristen Rundle develop critiques of instrumental accounts.

By contrast with instrumentalists, dignitarians such as Antony Duff and Jeremy Waldron maintain that certain procedures have an inherent value that 
is independent of any contribution they make to arriving at legally correct outcomes. They argue that this independent 'process value' is the value of respect for dignity in the Kantian sense of rational agency. In their view, procedural justice requires respect for people as active subjects, not passive objects-ends, not means. This involves respecting them as people who can reason and explain themselves (Duff et al. 2007; Waldron 2011). Thus, dignitarians argue that denying defendants a hearing would fail to respect their rational agency and be unjust in itself, even when their guilt is certain, and an accurate verdict can be arrived at without their participation.

One of the aims of this volume is to present an alternative to instrumentalist and dignitarian accounts of procedural justice. This alternative, relational account is inspired by both relational theory in ethics and political philosophy and by relational accounts of procedural justice in social psychology and criminology. Relational theory is informed by feminist critique of the excessively individualistic and rationalistic focus of much contemporary ethics and philosophy (see, e.g., Mackenzie \& Stoljar 2000). In contrast to dominant assumptions of atomistic individualism and rationalism, relational theorists maintain that ethics and political philosophy should pay more attention to the relational dimensions of human agency and identity. This includes attending to the social, embodied, and emotional dimensions of human agency, as well as taking seriously the ways that our individual identities are constituted by our interpersonal, familial, and social relationships, by our social group memberships, and by enculturation into specific linguistic and political communities. Relational theory also draws attention to the impact of unjust social hierarchies on individual agency and identity. Applied to the context of procedural justice, while a relational account agrees with the dignitarians about the importance of respect, it rejects their emphasis on rational agency, arguing for an expanded conception of agency as social, embodied, and emotional as well as rational. It also highlights the critical role of social relationships in fostering respect and self-respect, and the ways in which these attitudes can be undermined by social injustice, oppression, and inequality.

As far as the empirical research on procedural justice undertaken by social psychologists is concerned, some key aspects are worth highlighting. One of the significant findings is that processes matter to people. In fact, the experience of having been treated fairly can be as important as outcome favourability (whether the outcome leads to personal gain) and outcome fairness (whether the outcome is deserved). This proposition, described as 'counter-intuitive' by Steven Blader and Tom Tyler (2003, p. 747), has been widely confirmed in a range of empirical studies. It is not that people are happy to lose, but they are more likely to be willing to accept such a loss if they feel they were treated fairly (Tyler 2007, p. 26). Second, people do not typically associate procedural justice with procedures that maximise their chances of achieving a desired outcome. Instead, they interpret procedures as conveying information about their relationship with authorities, and they understand procedural justice in terms of relational criteria. Four factors in particular are central to people's assessments of procedural fairness: 
respect, trustworthiness, neutrality, and voice (Tyler 2007, p. 30). Respect refers to people's sense that they have been treated with respect and dignity in their interactions with authorities and in the context of decision-making processes. Trustworthiness refers to people's assessments of whether or not authorities can be trusted to behave fairly towards them, both in the context of a particular decision-making process and in future interactions with them or members of their social group. Neutrality refers to people's assessments of whether authorities are impartial and even-handed in their dealings with them, rather than biased against them for personal reasons or on the basis of group characteristics, such as gender, race, ethnicity, or religion. Voice refers to people's perceptions that authorities have provided them with opportunities to participate in the decision-making process and to voice their points of view. If people feel that they have been treated with respect by authorities, if they perceive these authorities to be trustworthy and neutral, and if they are given opportunities to participate in the decisionmaking process, they are more likely to judge that process as fair. Conversely, people are likely to experience a sense of injustice if their treatment fails to satisfy these criteria, even if they accept that the flaws in their treatment made no material difference to the outcome. A final key finding from the empirical studies is that the experience of procedurally just treatment fosters belief in the legitimacy of authorities and promotes law-abiding behaviour (Tyler 2009).

As to why the experience of procedural justice should have such powerful attitudinal and behavioural effects, the most prominent explanation is the group value model originally developed by Tom Tyler and Allan Lind. According to this model, people seek out social group connections and are highly motivated to 'understand, maintain and improve the social bonds that exist within groups'. Further, 'people are concerned about their status in groups because high status within a valued group validates their own self-identity' (Tyler \& Lind 1992, p. 141). Procedures come into this picture via the fact that people interpret satisfactory treatment at the hands of group authorities as a sign that they have value and status within their group. The experience of fair treatment therefore validates their self-identity and promotes a sense of self-worth or self-respect (Tyler \& Lind 1992, pp. 139-141; Tyler \& Blader 2000, pp. 90-92, 171, 185187). In short, it is identity processes that drive our interest in procedures and explain why procedural justice fosters belief in the legitimacy of authorities and promotes law-abiding behaviour (Murphy 2017, p. 48). Several chapters in this volume elaborate on these various aspects of the empirical research and further them in the specific contexts of policing (Kristina Murphy), jury reforms and trial innovations (Jane Goodman-Delahunty, David Tait, and Natalie Martschuk), and prisons (Julie Barkworth).

This set of claims is central to what social psychologists refer to as a 'relational' model of procedural justice. Relational models are often contrasted with both social exchange and distributive models. Social exchange theories posit self-interest as people's primary motivation for engaging in social interactions and social relationships, and hence claim that people assess the value of social relationships 


\section{Denise Meyerson et al.}

in terms of the costs and benefits to themselves of those relationships. Applied to the context of procedural justice, social exchange theories hold that people assess decisions and procedures according to the personal outcome favourability or otherwise of those decisions, and the personal transactions costs or benefits of the procedures (Tyler \& Lind 1992, pp. 119-121). In contrast, group value theory, which underpins relational models of procedural justice, emphasises the importance of social group membership for individual identity and its role in psychological motivation. In common with relational models, distributive models of procedural justice claim that people assess authorities and procedures in terms of fairness, rather than self-interest. However, distributive models claim that people assess fairness in terms of outcome distribution, for example, how the outcome they receive compares to the outcome others receive, or whether the outcome falls short of their expectations (Tyler \& Lind 1992, pp. 121-122). Relational models, by contrast, as discussed above, hold that judgements about fairness are linked to procedures even more than outcomes. In their contribution to this volume, Anthony Bottoms and Justice Tankebe suggest that this contrast may have been overstated by relational models, and propose a procedural justice framework that incorporates both procedural and distributive notions of fairness.

The social psychology literature is expressly descriptive, rather than normative in the philosophical sense. It offers a descriptive and explanatory account of people's beliefs and attitudes, not an account of the moral value of procedures, such as the instrumental, dignitarian, and relational accounts proposed by philosophers, as discussed above. Kjell Törnblom, for instance, contrasts a social psychological approach to justice, which involves the scientific investigation of people's perceptions of justice, with philosophers' normative arguments about which political or economic system is most just (1992, pp. 177, 190). In the context of discussing legitimacy, Tom Tyler likewise explains that a social scientific perspective on legitimacy uses psychological methods of data collection to investigate the factors that cause people to feel under a sense of obligation to obey the law, while a normative or philosophical perspective asks whether people ought to defer to legal authorities and obey the law. Tyler explains that he takes the social scientific perspective on legitimacy and is not concerned with normative or philosophical issues (2003, p. 285; 2006, pp. 286-287). Social psychologists therefore understand legitimacy in a descriptive or sociological sense; namely, that an institution or authority is legitimate if those who are subject to it perceive it as legitimate, or as having the moral right to exercise authority. Philosophers, by contrast, understand legitimacy as a normative concept. An institution or authority is normatively legitimate if in fact it does have the moral right to exercise authority over those it governs and is therefore entitled to their allegiance (see, e.g., Levitov 2016 for a helpful discussion of this distinction). In their contribution to this volume, Noam Gur and Jonathan Jackson explain how legitimacy in the descriptive sense is measured, and how the felt duty to obey the law interacts with the belief that specific laws are morally justifiable, in this way strengthening people's motive to obey the law. In her chapter, Catriona Mackenzie addresses 
the question of whether the four elements of procedural justice identified in the empirical literature might satisfy the criteria for both descriptive and normative legitimacy.

However, although the social psychology literature is not normative in the philosophical sense, social psychologists do use the term 'normative'. They also use the term 'instrumental', although again not in the way in which philosophers use it, viz. to describe a particular normative approach to the value of procedures. Instead, social psychologists use 'normative' and 'instrumental' as opposites. As Bottoms and Tankebe explain in their chapter in this volume, social scientists use 'normative' and 'instrumental' to distinguish between different kinds of motivations for law-abiding behaviour. People may obey the law in order to avoid punishment (an 'instrumental' explanation based on self-interest), or they may obey the law because they believe that legal authorities are legitimate and entitled to be obeyed (a 'normative' explanation). Murphy's chapter in this volume elaborates on this distinction between instrumental and normative explanations of compliance. The distinctive feature of this use of the word 'normative' is that it is used merely to report on, not endorse, people's normative judgements. It is therefore consistent with the social scientists' descriptive methodology.

Murphy makes a further distinction between instrumental and normative justifications for treating people in ways that satisfy the four procedural justice desiderata of respect, neutrality, trustworthiness, and voice. Many social scientists see procedural justice as a strategy for engineering legal compliance. Their approach is informed by findings which show (i) that people who believe that authorities have a right to be obeyed are more likely to comply with the law than people who are motivated by self-interest, and (ii) that the experience of procedural justice is a powerful factor in activating the normative judgement that authorities have such a right. This is known as the 'procedural justice effect' (Tyler 1987, p. 333). Combining these findings, social scientists argue that the cheapest and most effective way to secure obedience to the law is for officials to exercise power in a way that satisfies people's procedural expectations. For instance, Riël Vermunt and Kjell Törnblom explain that psychologists apply 'social psychological knowledge ... about justice processes ... for the purpose of reducing conflict' (2007, p. 10). Tyler and Yuen Huo describe this justification for procedural justice as 'psychological jurisprudence', saying that it 'provides a distinctly empirical, rather than normative perspective on the problems presented by the law' (2002, p. 209). It can also be described as an 'instrumental' justification, because procedural justice is viewed as a technique or tool for encouraging law-abiding behaviour. By contrast, normative justifications for procedural justice of the kind discussed above would see procedural justice as a moral requirement whether or not it promotes compliance.

It is also important to be aware of both commonalities and differences in the way social psychologists and political philosophers use the term 'relational'. In common is the idea that human beings are fundamentally social creatures and that people's identities and sense of self, including attitudes of self-respect and 


\section{Denise Meyerson et al.}

self-worth, are bound up with their interpersonal relationships. As mentioned previously, social psychologists in the field of procedural justice elaborate this idea in terms of group value theory. According to this theory, people are motivated to bond with their group because positive messages about their status within the group support their sense of self-worth and validate their self-identity. For this reason, people are very attentive to cues and messages that convey information about their social group status. Group value theory is thus a descriptive hypothesis about what motivates human social behaviour.

While relational theory in ethics and political philosophy is also premised on the view that humans are fundamentally social creatures, as discussed above, it is underpinned by both normative and methodological concerns. The normative focus of relational theory is the critique of various forms of social oppression, inequality, and injustice and their effects on the lives of individual members of minority social groups. Connected with this normative concern, relational theory rejects the methodological individualism that characterises much philosophical theorising. The term 'methodological individualism' refers to a set of theoretical assumptions about social groups and the relationship between individuals and the groups to which they belong. In particular, methodological individualism eschews explanations of social phenomena and individual behaviour that make reference to social groups and the structural constraints imposed by group membership on individual action, choice and behaviour (Cudd 2006, p. 46). By contrast, relational theories argue that a focus on social groups and the social dynamics of power is critical for understanding how the actions, choices, and behaviour of individual members of minority social groups are constrained and shaped by oppression and inequality.

The differences between the sense in which social psychologists and philosophers use the term 'relational' are therefore twofold. The project of relational theory in social psychology is descriptive and explanatory: it aims to describe and analyse the psychological effects of interpersonal relationships and social group dynamics on individuals' identities. The project of relational theory in ethics and political philosophy is normative analysis: it aims to provide a normative critique of social oppression and inequality and their impact on individuals' lives. This difference in aim explains a further respect in which the social psychology and philosophical literatures differ in the context of theorising about procedural justice. Empirical research in social psychology has identified the importance of the four relational factors of respect, neutrality, trustworthiness, and voice for people's perceptions of procedural justice and seeks to provide a descriptive explanation and analysis, in terms of group value theory, of why these four factors matter to people. Taking this empirical research as its starting point, philosophers influenced by relational theory in ethics and political philosophy seek to explain the normative significance of these four factors. Thus, the chapters in this volume by Ceva, Mackenzie, Stoljar, and Sorial seek to show why the relational factors identified in the empirical literature are normatively significant. 
The relational account of procedural justice that emerges from this volume has implications for the design of legal procedures. Tyler identifies one of the core aims of the legal system as being that people's disputes are managed in ways that lead them to accept and be willing to abide by the decisions made by the courts' (Tyler 2007, p. 26). In this way, procedurally just legal processes can foster faith in legal institutions and willingness to comply with the decisions made by such institutions. A key factor in bringing this about is the existence of participatory processes that are appropriate to the issue under consideration. A number of contributions to this volume (see Sorial and Therese MacDermott in particular) examine the form in which legal procedures should be structured so that individuals have the sense that they were afforded a genuine opportunity to tell their story, that an unbiased decision-maker took the time to consider their point of view, and that the decision-maker tried to act fairly towards all parties. MacDermott also identifies the need for mechanisms to be built into dispute resolution frameworks to provide individuals with appropriate support and adequate explanations to enable them to take part fully in legal decision-making processes affecting them.

Like many institutions of government, legal authorities are continually under pressure to provide their services in ways that are timely and cost-efficient. As a former Chief Justice of the High Court of Australia observed, '[t]here is a tendency in some quarters to regard procedural fairness as a species of ethics ornamentation, a moral luxury which is a drag on efficient decision-making' (French 2010 , p. 2). However, contributions to this volume emphasise that the participation that is at the core of procedural justice is what confers legitimacy on decision-making processes and fosters compliance with the law. Hence, although resource constraints make it impossible to provide perfect procedures, participation is a fundamental requirement that cannot simply be balanced away in the service of timeliness and efficiency. There is also a tendency to minimise the need for extensive procedures when claims are of low monetary value. This type of approach fails to acknowledge the crucial relational dynamics that need to be addressed in resolving any dispute, irrespective of the monetary amount at stake.

In addition, there are certain situations, such as the exercise of policy-based administrative discretion or racial profiling in policing, where the legal rules of procedural fairness may not be regarded as applicable. However, the chapters by Rundle and Stoljar in this volume show that a relational perspective can explain why it is not simply the legal form in which power is exercised that dictates whether procedural justice considerations should apply. The same can be said of forms of alternative dispute resolution that seek to resolve disputes through less formal means than are available to parties when an adjudicative process such as a hearing or trial is conducted. ${ }^{4}$

This brief analysis of key concepts in procedural justice research highlights why procedural justice matters and why an interdisciplinary approach to the topic is necessary and timely. In the following section, we provide an overview of the contributions made by the chapters in this volume to advancing this interdisciplinary research agenda. 


\subsection{Chapter overview}

Part I, 'Procedural justice in policing, courts, and prisons: empirical reviews', explores psychological perspectives on procedural justice, using a range of empirical studies in the contexts of policing, juries and courtrooms, and correctional facilities.

In Chapter 1, Kristina Murphy provides a comprehensive survey of the Australian procedural justice policing scholarship. She explores ways of measuring procedural justice, explains why police should be concerned with it, and outlines the challenges involved in undertaking empirical work of this nature. Murphy's chapter explains that procedurally just treatment in a policing context matters primarily because it promotes perceptions of legitimacy and fosters the belief that police and laws ought to be obeyed. Murphy is particularly interested in what motivates people to volunteer information and engage in other citizen-initiated contact with police, and the implications of this for police relations with vulnerable population groups and marginalised communities. Murphy argues that procedurally just treatment by police can create positive messages for communities who are uncertain about the treatment they might receive from the police and about their acceptance in society. This can in turn contribute to initiatives that rely on harnessing the support of communities in voluntarily cooperating with the police, for instance, by reporting terror threats. In terms of challenges, Murphy mentions the cost of quality sampling and measurement issues, as well as the difficulty of embedding procedural justice in policing practices and the risk that such an approach may be seen as soft on crime. She concludes with some reflections on the future direction of procedural justice policing, including its importance for police interactions with vulnerable groups, such as those who experience domestic violence.

In Chapter 2, Jane Goodman-Delahunty, David Tait, and Natalie Martschuk examine jury reform efforts based on the four key principles of procedural justice (respect, trustworthiness, voice, and neutrality). They also discuss ways of showing respect to the accused that can have an indirect effect on juries. First, the authors examine ways in which the physical environment of the courtroom and the jury room can be designed to reduce juror discomfort (respectful treatment) and enhance jury neutrality. For instance, there is evidence suggesting that the accused should not be isolated in a dock, since confinement within an enclosed space may encourage the jury to believe the accused is dangerous. Second, the authors discuss a range of matters relevant to trust in the jury, such as the exclusion of probative evidence from trials. They point out that from a procedural justice perspective the exclusion of evidence conveys a lack of trust in the jury, and they refer to empirical studies suggesting that jurors exposed to evidence of the kind that is traditionally excluded do not engage in prejudicial reasoning. By contrast, the innovative introduction of 'question trails' to guide jury deliberations reflects trust in the capacities of jurors. Third, the authors discuss studies that show that many jurors ignore judicial directions that forbid internet research. These findings have led to innovations that allow jurors to participate 
more actively in trials, such as allowing juries to take notes and to submit questions to witnesses and the court. These interventions speak primarily to the procedural justice interest in voice. Finally, the authors address issues of legitimacy. They discuss empirical research that shows that most jurors express a high degree of confidence in the criminal justice process and that legal professionals strongly support juries as an institution.

In Chapter 3, Julie Barkworth examines how procedural justice might be utilised in interactions between prisoners and staff. She focuses on two issues that are critical to the prison environment-prisoner well-being and compliance-related behaviour. Barkworth makes reference to a broad range of empirical studies that illustrate the links between perceived fairness of staff behaviour and improved prisoner perceptions of staff legitimacy as well as the willingness of prisoners to comply with prison rules. In terms of challenges, Barkworth refers to discrepancies that can arise when empirical studies use varied measurement approaches to assessing both procedural justice and legitimacy. She also points to the limitations of cross-sectional research designs that only provide a snapshot of interactions with prison authorities at a particular point in time, and do not separate the influence of procedural justice from the influence of social and cultural factors such as poverty, family, isolation, and other forms of social dysfunction. As for future research, Barkworth identifies the need to expand the scope of research beyond high-security male prisons to include female prisoners, prisoners held in other correctional environments such as low-risk facilities, and prisoners subjected to periods of incarceration of varying lengths. She also highlights the lack of research regarding how prison staff perceive procedural justice and its value in the correctional context.

The chapters in Part II, 'Procedural justice and legitimacy: empirical and normative perspectives', discuss empirical and theoretical approaches to legitimacy and participation.

Chapter 4, by Anthony Bottoms and Justice Tankebe, seeks to explicate the relationship between procedural justice and legitimacy, and to show why both concepts should be understood as social/relational and contextual. The starting point for Bottoms and Tankebe's analysis of legitimacy is the claim (derived from Bernard Williams) that power is legitimate to the extent that power-holders honour citizens' 'basic legitimation expectations'. They suggest that one way of understanding Tyler's analysis of the connection between procedural justice and legitimacy is that the four procedural justice factors could be understood as basic legitimation expectations. However, while agreeing that procedural justice is important for legitimacy, Bottoms and Tankebe argue that there is both empirical and conceptual support for their view (elaborated in Bottoms \& Tankebe 2012,2017 ) that citizens assess the legitimacy of criminal justice authorities with reference to three additional basic legitimation expectations. These are lawfulness (that authorities exercise power and act within the boundaries of the law); distributive justice (that justice outcomes are fairly distributed among different social groups); and effectiveness (that criminal justice agencies are effective in the 


\section{Denise Meyerson et al.}

performance of their duties). Notably, they claim that the importance of these factors can vary in different social and situational contexts, and therefore that no single factor best promotes legitimacy in every context. Bottoms and Tankebe's second main concern is to draw attention to the influence of social/relational and contextual variables on judgements of legitimacy. In support of this claim, they cite a number of studies showing that judgements of legitimacy vary depending on a range of such variables, including people's core normative and political values, and social and cultural backgrounds. They also discuss the evidence that experiences of social exclusion, marginalisation, or powerlessness, for example, on the grounds of race, social class, or gender, significantly influence judgements of legitimacy and can result in pervasive cynicism about legal authorities. Additionally, they suggest that citizens' prior interactions with authorities, the stakes involved in a specific interaction, and whether the interaction was initiated by the citizen or by the police (e.g. in random stop and frisk activities), all have an impact on judgements of legitimacy. Bottoms and Tankebe conclude that procedural justice research should attend more closely to the complex contextual variability of judgements of legitimacy.

In Chapter 5, Noam Gur and Jonathan Jackson analyse interactions between procedure and content from both empirical and normative perspectives. They discuss empirical survey data about people's attitudes to law, explaining that two factors are important predictors of legal compliance. The first is people's belief that they have a content-independent moral duty to obey the law (which is an element of descriptive or perceived legitimacy and itself strongly predicted by public perceptions of procedural justice in the operation of police and courts). The second factor is people's moral assessment of the content of specific laws (sometimes called their 'personal morality'). Furthermore, Gur and Jackson claim that these two factors interact, in the sense that a felt content-independent duty to obey the law does not merely add to the motivational force of the belief that specific laws are morally justifiable but strengthens it, and vice versa. In short, perceptions of fair treatment at the hands of the police and courts promote legitimacy and influence law-abiding behaviour, but this influence is greater when people approve of the moral content of legal requirements. So far as Gur and Jackson's parallel normative argument is concerned, they adopt Fuller's 'procedural' conception of the rule of law, according to which the rule of law depends on certain formal features of law, such as its generality, clarity, and prospectivity, as well as on congruence between the enacted rules and their application. An on-going debate concerns whether observance of Fuller's principles has intrinsic moral value regardless of the content of the law, or whether his principles merely supply a 'recipe' for lawmakers, whether good or bad, to achieve their aims efficiently. Gur and Jackson argue that neither position is correct. They defend a 'hybrid' position involving both content and procedure, according to which Fuller's principles have an expressive moral quality, but the extent to which their expressive effect materialises is sensitive to the moral quality of the law's content. Thus, they conclude that the expressive value of rule-of-law adherence will be enhanced when the content of the law is morally defensible. 
In Chapter 6, Sarah Sorial draws on procedural theories of law and democracy in developing a normative account of the relevance of participation for legitimacy and compliance with the law. Building on the notion of 'legitimacy as dialogue' (Bottoms \& Tankebe 2012), she recasts the relationship between the citizen and the state as dialogical and relational in nature. Sorial argues that participatory procedures give citizens an opportunity to engage in law-making processes that make them parties to the legal norms binding them, thereby conferring legitimacy and bringing about compliance with the law. Her account focuses on the unique features of legitimacy in democratic societies and the kinds of opportunities they offer for participation in elections, law-making, and a variety of decision-making processes ranging from criminal trials to commissions of inquiry. In the context of being heard in one's own defence in a criminal trial, Sorial identifies some core features of a participatory procedure that confer legitimacy. These include hearing from the person whose interests are at stake, giving their arguments due consideration in arriving at a decision, and supporting decisions with good reasons that all participants can accept. In addition, she argues that dialogical aspects of the trial process that involve public scrutiny and deliberation contribute to the recognition of courts as just institutions whose decisions should be respected. These aspects include the justificatory nature of reason-giving, the fact that court proceedings are open to the public, and the potential involvement of citizens as jurors.

The chapters in Part III, 'The concept of procedural justice: philosophical perspectives' discuss a range of philosophical approaches to procedural justice from a normative perspective. In Chapter 7, Denise Meyerson explores the concept of procedural justice in the adjudicative context, asking what procedures officials should use when they apply legal rules. Is it an entirely instrumental matter, dependent solely on the capacity of procedures to lead to accurate legal results, or can procedures also be just for intrinsic reasons? Meyerson argues against two versions of instrumentalism-economic theories, which see procedural justice as a matter of balancing the value of accuracy-promoting procedures against their monetary costs in an effort to maximise wealth, and outcome-based theories, which hold that individuals are entitled as a matter of fairness to procedures that are suited to enforce their legal rights. She argues that economic theories fail to take our legal rights seriously. Meyerson divides outcome-based theories into theories that maintain that procedural justice consists in the use of procedures that are guaranteed to produce correct results (e.g. Galligan) and theories that are satisfied with something less (e.g. Rawls and Dworkin). Although Galligan takes our legal rights with utmost seriousness, Meyerson argues that this comes at a price: since procedural perfection is unachievable in the real world, Galligan's understanding of procedural justice is utopian. Dworkin and Rawls avoid this problem by conceding that just procedures are not capable of perfectly protecting our legal rights. Dworkin regards procedures as unjust only when the risk of error is distributed unfairly, and Rawls regards them as unjust only when the risk of error is too high. Although Meyerson thinks that Dworkin and Rawls are right to concede that procedural justice should not be identified with procedural 


\section{Denise Meyerson et al.}

perfection, she argues that this concession undermines their commitment to instrumentalism. If real-world procedures are capable of enforcing our legal rights only imperfectly, why, asks Meyerson, should we accept that this anaemic form of procedural protection exhausts what individuals are entitled to as a matter of fairness? She concludes that it is more plausible to infer that procedures must matter intrinsically as well as instrumentally.

Chapter 8, by Emanuela Ceva, aims to explain the normative value of the principle of due process in criminal trials. She considers three possible explanations of the normative value of this principle. The first, instrumental, explanation focuses on the epistemic value of due process. According to this explanation, due process is valuable to the extent that it plays a crucial epistemic role in enabling the relevant facts to be revealed. Insofar as they facilitate the revelation of the truth, criminal proceedings are just. Ceva argues that this instrumental explanation locates the normative value of due process in a value that is extrinsic to the process itself, namely in the truth of the facts that the process aims to reveal. The second explanation holds that due process derives its value from its expressive role in publicly acknowledging the normative status of the participants. Just as the value of democratic processes of decision-making lies in their public expression and recognition of the status of citizens as equal political agents, so too legal proceedings informed by the principle of due process express important institutional messages of respect for participants. As the empirical literature on procedural justice shows, these messages play a critical role in supporting participants' sense of self-respect. While acknowledging that both the epistemic and expressive explanations highlight important normative dimensions of due process, Ceva argues that neither explanation can explain its inherent value. Her alternative explanation, which she refers to as 'interactive justice', locates this value in the structural properties or 'constitutive rules' of the process. These establish what people who participate in the process can claim against and owe to each other. Drawing on dignitarian views, she argues that the constitutive rules of due process confer a special dignitary status on participants, the status of right holders and claim makers. Thus, due process as an instantiation of procedural justice does not simply express, but rather bestows, normative status on participants.

In Chapter 9, Catriona Mackenzie discusses different justifications for why officials should embed procedural justice in their interactions with citizens. Empirical approaches typically focus on the claim that procedural justice is more effective than other methods of law enforcement, such as deterrence-based strategies that rely on coercion or reward mechanisms. However, Mackenzie argues that this instrumental explanation needs to be supplemented by a normative argument, explaining why social institutions and their representatives are morally obliged to treat citizens in a procedurally just manner. Mackenzie draws on recent work in political philosophy on relational equality to develop this argument. Relational egalitarians argue that justice is not just a matter of distributive fairness; it is also fundamentally about social equality. One of the central concerns of relational egalitarian theory is to explain the normative obligations of state institutions with 
respect to citizens subject to their power. These include ensuring that processes and authorities express respect for the moral and social equality of all persons and that the exercise of power by authorities is regarded as legitimate. Mechanisms must also be in place for enabling persons subject to power to hold institutions and authorities publicly accountable and to voice their concerns and interests. Mackenzie argues that these claims dovetail with and give normative substance to the concerns about social standing and fair treatment in the empirical research on procedural justice. Relational egalitarian theory also provides normative support for citizens' expectations that they should be treated fairly and with respect. Relational egalitarian theory has much in common with Ceva's interactive theory of procedural justice. However, while sympathetic to Ceva's central claims, Mackenzie suggests that Ceva's theory is more dignitarian than relational, insofar as it emphasises rational agency as the basis of obligations of respect. To explain the difference between these approaches, Mackenzie draws on feminist analysis of the relational and emotional dimensions of respect and self-respect. She suggests that this analysis resonates with group value theory, and provides a complementary explanation of why people are so sensitive to the messages about their status conveyed by group processes and by how they are treated by persons in positions of authority. It also underscores the normative connections between social equality and self-respect. In conclusion, Mackenzie suggests that if her argument is persuasive it shows why institutions that satisfy citizens' expectations for fair and respectful treatment will count not only as descriptively but also as normatively legitimate.

Part IV, 'Implications and applications: legal institutions and the exercise of legal authority', explores the implications and relevance of a relational approach to procedural justice for particular legal contexts.

Chapter 10, by Natalie Stoljar, considers whether the use of racial profiling in policing contexts constitutes morally unjust discrimination. Drawing on the empirical literature on procedural justice, her first aim is to critically appraise consequentialist arguments in favour of racial profiling. Stoljar argues that since racial profiling is perceived by targeted groups as unfairly singling them out it undermines legitimacy and erodes compliance. This calls into question consequentialist arguments to the effect that racial profiling can sometimes be justified on the basis of the alleged social benefit of increased security. She also rejects the consequentialist claim that the benefits of profiling outweigh its costs, allegedly because in a racist society profiling adds only minimally to the harm already suffered by targeted groups. This claim, she argues, misunderstands both the extent and type of harm suffered by targeted groups, especially the magnitude of the process-related harms brought about by profiling. These harms are highlighted in the empirical literature, which seems to provide support for consequentialist arguments against profiling. Stoljar's second aim is to develop a new, non-consequentialist objection to racial profiling. Some philosophers have argued that because racial profiling is based on non-spurious statistical correlations between racialised groups and criminality, the practice of profiling is not intrinsically disrespectful to those groups. 
Stoljar challenges this argument, drawing on recent philosophical work on striking property generics. These 'pick out essentialised kinds and attribute a disposition to have the negative property (i.e. criminality, being a terrorist) to the nature of each member of the kind' (p. 226). This implicit positing of an untrue association between certain social groups and negative properties is inconsistent with respect, because it makes a moral mistake about the personhood of each profiled person (as well as about members of the whole group). Thus, profiling violates the state's obligation to treat citizens with equal respect and constitutes morally unjust discrimination. In conclusion, Stoljar proposes that the feeling by members of targeted groups that the criminal justice system is unfair and disrespectful is justified, because 'profiling actually does constitute disrespectful treatment' (p. 228).

In Chapter 11, Kristen Rundle shifts the focus of attention to procedural fairness in discretionary contexts. As she points out, the demands of procedural fairness in circumstances of administrative discretion have not attracted the same attention as procedural fairness in the rule-based, adjudicative context. The key difference is that in the adjudicative context, the relationship between officials and legal subjects is framed by pre-existing rules to which both officials and subjects are subordinate. By contrast, in the discretionary context, officials are free to make a choice between possible courses of action. This raises the question of whether officials have any procedural obligations in such circumstances. This question is even more acute when an official is required to act in the public interest when deciding how an individual should be treated (for instance, in deciding whether to release a prisoner on parole). Rundle argues that procedural fairness is, in fact, of great importance even when there is a policy element to the exercise of discretion. In her view, this form of decision-making encourages an extreme turn towards the repository of power and away from the individual's perspective. The value of procedural fairness, for Rundle, is that it supplies a 'relational correction' to this 'stark asymmetry' by obliging the official to engage with the agency of the person subject to the discretion. Since Rundle also defends a conception of the rule of law influenced by Lon Fuller, in terms of which the rule of law depends on the quality of governing relationships between those who exercise power and those subject to it, she draws the conclusion that procedural fairness makes it possible for discretionary power to be exercised in a way that meets the demands of the rule of law. For Rundle, then, procedural fairness in the administrative context has a wider significance that goes beyond the interests of individuals in fair treatment, important though these interests are.

The final chapter, by Therese MacDermott, examines the nature of procedures adopted by Australian tribunals in dealing predominantly with civil matters. Tribunals are generally regarded as operating as a forum for affordable justice and are vested with considerable procedural flexibility, where the 'just, quick and cheap resolution' of the issues in dispute is often part of a tribunal's statutory mandate. The idea that these three competing factors should be balanced is regularly adopted in the decision-making of tribunals and in the judgements of appellant courts called upon to evaluate the procedural practices of other legal 
institutions. MacDermott considers whether a balancing approach meets the requirements of justice. She argues instead for an approach, informed by relational theory, based on the importance of participation. In her view, affording the opportunity for participation takes substantial priority over factors of cost or efficiency. MacDermott also examines whether a just resolution can be achieved in a forum that encourages self-representation if tribunals do not adequately fulfil their obligations to help parties understand the procedures in which they are involved.

\section{Notes}

1 The editors' research for this volume was funded by the Australian Government through the Australian Research Council's Discovery Project funding scheme (DP1701009600: 'A Relational Theory of Procedural Justice').

2 This volume is concerned only with questions of procedural justice arising out of relationships between citizens and the state and we use the term 'officials' to refer to individuals on whom the state has conferred official authority. We also categorise all such individuals as 'officials'. The volume's primary focus is on the procedural obligations of judges, tribunal members, administrative officials, and police and correctional authorities.

3 Most contributors to this volume refer to 'procedural justice'. However, some authors refer to 'procedural fairness' or use these terms interchangeably.

4 MacDermott and Meyerson (2018) have argued elsewhere that there are sound normative reasons for taking people's relational concerns into account in the alternative dispute resolution context.

\section{References}

Bayles, MD 1990, Procedural justice: allocating to individuals, Kluwer Academic Publishers, Dordrecht.

Blader, SL \& Tyler, TR 2003, 'A four-component model of procedural justice: defining the meaning of a "fair" process', Personality and Social Psychology Bulletin, vol. 29, no. 6, pp. 747-758.

Bottoms, AE \& Tankebe, J 2012, 'Beyond procedural justice: a dialogic approach to legitimacy in criminal justice', Journal of Criminal Law and Criminology, vol. 102, no. 1, pp. 119-170.

Bottoms, AE \& Tankebe, J 2017, 'Police legitimacy and the authority of the state', in A du Bois-Pedain, M Ulväng, \& P Asp (eds), Criminal law and the authority of the state, Hart Publishing, Oxford.

Cudd, A 2006. Analyzing oppression, Oxford University Press, New York.

Duff, A, Farmer, L, Marshall, S, \& Tadros, V 2007, The trial on trial, vol. 3, Hart Publishing, Oxford/Portland, OR.

Dworkin, R 1985, 'Principle, policy, procedure', in A matter of principle, Harvard University Press, Cambridge, MA.

French, R 2010, 'Procedural fairness-indispensable to justice?' Sir Anthony Mason Lecture, University of Melbourne Law School, available at https://www.hcourt. gov.au/assets/publications/speeches/current-justices/frenchcj/frenchcj07octl $0 . \mathrm{pdf}$ 
Galligan, DJ 1996, Due process and fair procedures: a study of administrative procedures, Clarendon Press, Oxford.

Levitov, A 2016, 'Normative legitimacy and the state', retrieved from Oxford Handbooks Online, DOI: 10.1093/oxfordhb/9780199935307.013.131, online publication date October 2016.

MacDermott, T \& Meyerson, D 2018, 'Australian tribunals and alternative dispute resolution: a procedural justice perspective', Civil Justice Quarterly, vol. 37, no. 4, pp. 443-462.

Mackenzie, C \& Stoljar, N (eds) 2000, Relational autonomy: feminist perspectives on autonomy, agency and the social self, Oxford University Press, New York.

Murphy, K 2017, 'Procedural justice and its role in promoting voluntary compliance', in P Drahos (ed.), Regulatory theory: foundations and applications, ANU Press, Canberra, ACT.

Posner, RA 1973, 'An economic approach to legal procedure and judicial administration', Journal of Legal Studies, vol. 2, no. 2, pp. 399-458.

Rawls, J 1971, A theory of justice, Oxford University Press, Oxford.

Törnblom, K 1992, 'The social psychology of distributive justice', in KR Scherer (ed.), Justice: interdisciplinary perspectives, Cambridge University Press, Cambridge.

Tyler, TR 1987, 'Conditions leading to value-expressive effects in judgments of procedural justice: a test of four models', Journal of Personality and Social Psychology, vol. 52, no. 2, pp. 333-344.

Tyler, TR 2003, 'Procedural justice, legitimacy and the effective rule of law', Crime and Justice, vol. 30, pp. 283-357.

Tyler, TR 2006, Why people obey the law, Princeton University Press, Princeton, NJ.

Tyler, TR 2007, 'Procedural justice and the courts', Court Review: The Journal of the American Judges Association, vol. 44, no. 1/2, pp. 26-31.

Tyler, TR 2009, 'Legitimacy and criminal justice: the benefits of self-regulation', Ohio State Journal of Criminal Law, vol. 7, no. 1, pp. 307-359.

Tyler, TR \& Blader SL, 2000, Cooperation in groups: procedural justice, social identity, and cooperative behaviour, Psychology Press, New York.

Tyler, TR \& Lind, EA 1992, 'A relational model of authority in groups', Advances in Experimental Social Psychology, vol. 25, pp. 115-191.

Tyler, TR \& Huo, YJ 2002, Trust in the law: encouraging public cooperation with the police and courts, Russell Sage Foundation, New York.

Vermunt, R \& Törnblom, K 2007, 'Distributive and procedural justice', in K Törnblom and R Vermunt (eds), Distributive and procedural justice: research and social applications, Ashgate, Aldershot.

Waldron, J 2011, 'The rule of law and the importance of procedure', in JE Fleming (ed.), Getting to the rule of law, New York University Press, New York/London. 


\section{Part I}

Procedural justice in policing, courts, and prisons Empirical reviews 


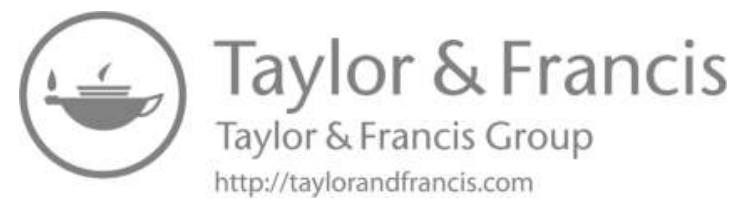




\title{
1 The empirical study of procedural justice policing in Australia
}

\author{
Highlights and challenges
}

\author{
Kristina Murphy
}

\subsection{Introduction ${ }^{1}$}

In 2014, US President Barack Obama established a Presidential Task Force on $21^{s t}$ Century Policing. This was borne out of concern over the mounting tensions between America's police and racial minority communities. Numerous police shootings of unarmed black men pointed to a widespread cultural problem of racism in American police agencies. The violent Black Lives Matter Protests that occurred in the US in 2020 reveal this problem has still not been resolved. The President's Task Force released its final report in 2015 (President's Task Force 2015). The report cited research-including Australian research-espousing the virtues of procedural justice policing. Procedural justice policing is a style of policing that emphasises the fair and respectful treatment of citizens. The report cited evidence linking police use of procedural justice to citizens' enhanced trust and confidence in the police. At the same time, the report also recognised the normative importance of procedural justice for policing, highlighting that 'trust between law enforcement agencies and the people they protect and serve is essential in a democracy' (p. 1). Thus, the Task Force recommended that procedural justice should be a guiding principle on which quality policing should be based.

In Australia, a long history of strained relationships between police and minority communities also exists. Chan (1997, pp. 108-115) explored police-minority relations in NSW in the mid-1990s and noted-as in the US - that the culture of the NSW Police Service supported widespread racism toward minority communities. Australian police agencies have since made a concerted effort to recognise the value of procedural justice for improving police-community relations. The Queensland Police Service (2017) specifies, as a key research priority, the strengthening of its relationship with the community and highlights procedural justice as important for achieving this goal. However, as evidenced by the 2020 Black Lives Matter protests that occurred in Australia issues regarding police racism still remain in Australia.

Since the release of the President's Task Force report in 2015, the empirical study of procedural justice in policing has proliferated exponentially. Scholars have sought to measure public perceptions of the police, with the aim of ascertaining the value of procedural justice for improving citizen experiences with

DOI: $10.4324 / 9780429317248-3$ 


\section{Kristina Murphy}

police (e.g. Nix et al. 2015). Some scholars have also focused on whether police officers can be trained to support and be procedurally just in interactions with the public (e.g. Skogan, van Craen \& Hennessy 2015), and others have sought to understand the situational contexts under which procedural justice policing matters most to citizens (e.g. Wolfe et al. 2016).

Prior to this new wave of empirical research, a large number of procedural justice policing studies had already emerged from Australia, including studies with minority communities. This chapter presents an overview of the procedural justice policing scholarship that has been undertaken in Australia both before and after the Presidential Task Force released its final report. Drawing on these Australian studies, the chapter will discuss how procedural justice has typically been measured in Australian research and why the police should be concerned with procedural justice. The chapter then highlights key empirical findings from Australian research. Overall, findings show that procedural justice is important to Australians and can strengthen positive relations between the police and the public. Finally, the challenges associated with undertaking empirical research of this nature will be discussed before some reflections are made about the future direction of procedural justice policing research. Before doing this, the following sections provide an overview of what procedural justice is and why procedural justice has gained prominence in policing research.

\subsection{What is procedural justice policing?}

Procedural justice in policing refers to the quality of the interpersonal treatment people receive from police and the fairness of the procedures police use to make decisions (see Tyler 1990, p. 7). Tyler (1990, p. 7) noted that four key elements are required for a police-citizen interaction to be considered as procedurally just. These four elements are: trustworthiness; respectful treatment; neutrality; and voice. A police officer who displays sincerity in being helpful, honest and open, and who acts consistently and in the best interests of citizens is an officer who will be viewed as trustworthy. Respectful treatment refers to police behaviour that displays respect for people's rights and exemplifies dignified and polite treatment. People are particularly sensitive to signs that they are being treated respectfully by police, and they respond very negatively to signs of rude behaviour. In fact, rude behaviour from police typically attracts the largest number of citizen complaints in Australia each year (Porter \& Prenzler 2017, p. 874). Police convey neutrality when they treat all individuals and groups in the community equally, and refrain from acting on biases or pre-existing views about people when making decisions. The over- or under-policing of certain communities can be perceived as police not providing neutral treatment across society (Tyler \& Wakslak 2004, p. 254). Finally, voice refers to the ability of citizens to have a say in a situation that involves them. Having the opportunity to air a concern or explain one's side of the story to a police officer before a decision is made, and being genuinely listened to, are indicators of procedural justice. Being consulted in police 
decision-making processes also constitutes an important element of voice. For example, research on Muslim communities shows that the provision of voice is an extremely important feature of Muslims' interactions with police in counterterrorism. A major criticism that Muslims have of police engagement efforts is that police do little in the way of consulting Muslims or involving Muslims in genuine discussions about how radicalisation in the Muslim community should be dealt with (Cherney \& Murphy 2016, p. 491).

\subsubsection{Deterrence versus procedural justice?}

Policing is grounded on a deterrence-based model of crime control, where the focus is on detecting and apprehending lawbreakers (Mazerolle et al. 2014, p. 57). A deterrence-based model of policing assumes that people are rational actors who will be deterred from disobeying police or breaking the law because the consequences of being non-compliant will be detrimental to their welfare. In other words, people weigh up the costs and benefits of obeying police or the law. If the perceived costs of non-compliance outweigh the perceived benefits, then compliance will be the rational choice. A deterrence-based model assumes that police can best promote law-abiding behaviour through displaying power, effective enforcement and creating severe sanctions for non-compliance (Nagin 2013, pp. 205-206).

The problem with a deterrence-based policing approach, however, is it cannot explain why people still comply with police and the law when there is little chance of being detected breaking the law or when sanctions for non-compliance are minimal (Murphy, Bradford \& Jackson 2015, p. 103). It also cannot explain why contact with the criminal justice system can increase re-offending. Anwar and Loughran (2011, p. 673), for example, noted that persistent offenders respond differently to deterrence. They showed that serious offenders reported being less concerned with sanction risk when compared to less persistent offenders. Deterrence perspectives are particularly problematic when explaining discretionary forms of law-related behaviour. Discretionary law-related behaviours include contacting police to report a crime or victimisation, or assisting police in crime prevention activities. Discretionary law-related behaviours are essential to the effective operation of the criminal justice system. Without such forms of behaviour, crimes would not be identified, witnesses would not come forward to provide evidence, and police would be unable to work with communities to promote and maintain order. Deciding not to engage in these behaviours will not-in most cases-result in a sanction. Yet most people engage willingly in these types of discretionary behaviour. At the same time, research with marginalised groups (e.g. crime victims, racial/ethnic minorities, those living in high crime neighbourhoods) finds these groups often avoid contact with police even in times of need (e.g. Murphy \& Barkworth 2014, p. 178). Using the threat of punishment with individuals who do not engage in discretionary activities is likely to exacerbate disengagement. 


\section{Kristina Murphy}

Procedural justice scholars have therefore responded to the limitations of deterrence-based policing by arguing that most people cooperate and comply with legal authorities and laws because they believe it is right to do so, not because they fear the consequences of doing otherwise. For discretionary forms of law-abiding behaviour, procedural justice scholars suggest that concerns about fair treatment and respect are likely to be particularly salient in motivating people's decisions to engage with police.

According to the procedural justice perspective, law-related behaviour is driven by normative and relational concerns, not instrumental concerns. Here, people cooperate and comply because they believe in the legitimacy of police and believe police and laws are entitled to be obeyed. In other words, the procedural justice perspective is underpinned by the normative assumption that authorities who treat people fairly have earned their rightful position to govern others, are entitled to be regarded as legitimate and have the right to request law-abiding behaviour from citizens (e.g. Hinds \& Murphy 2007, p. 27). Studies demonstrate that an authority's legitimacy can be damaged when an authority behaves badly. An authority that abuses its power or treats its citizens poorly will be distrusted by the community, resulting in an unwillingness of citizens to volunteer information, or to cooperate or comply with the authority and its laws (e.g. Murphy, Mazerolle \& Bennett 2014, p. 408).

\subsection{Why should procedural justice be of concern to police?}

There are three main reasons why police should be concerned with procedural justice. The first reason is based on an instrumental argument. Mazerolle et al. (2014, p. 3-5) argue that authorities that govern with procedural justice will be better able to foster compliance and discretionary cooperation from citizens and will have to rely less heavily on deterrence. It has also been suggested that procedurally just dialogue is a more low-cost and time-efficient strategy for obtaining compliance when compared to deterrence (Drahos \& Krygier 2017, p. 5). Put simply, procedural justice can be cheaper and more effective than deterrence. An instrumental argument has appeal for police agencies because they are increasingly being tasked to do more with less.

The second reason why police should be concerned with procedural justice is based on a normative argument. 'A widely shared normative expectation about the appropriate use of legal power is that justice officials should act in accordance with the principles of fair treatment and impartial decision-making' (Trinkner, Jackson \& Tyler 2018, p. 281). Police have a moral obligation to exercise their authority in a procedurally fair way, irrespective of any instrumental benefit such an approach may have in facilitating their role in maintaining cooperation and compliance. In other words, procedural justice should be viewed as a common good in itself. While authorities can view procedural justice as an instrumental tool to gain cooperation or compliance from citizens, citizens have clear expectations of how police should behave in interactions with the community. As noted 
earlier, citizens confer legitimacy upon an authority if authorities act in ways that adhere to the values and expectations of the community. Procedurally just treatment helps to engender the sense among citizens that police are legitimate and entitled to be obeyed. Hence, authorities should commit to being procedurally just because it is expected of them and because it is the right thing to do.

The third reason why procedural justice should be of concern to police is based on a relational argument. This relational argument is most pertinent to the theme of this book. The relational perspective suggests that procedural justice is important because it strengthens the social bonds and relationships between authorities and those they govern. Exercising authority in a procedurally just way communicates status and value to those on the receiving end of the actions of authorities. Braithwaite (2017, p. 33) suggests that all forms of regulation pose a threat to people's freedom. As such, how authorities wield their power can have negative or positive consequences for social relations. Procedural justice is thought to strengthen relationships because it communicates information about citizens' value and standing within society (Tyler \& Blader 2000, p. 15). People place importance on procedurally just treatment because it communicates important information about the quality of the relationship between police and citizens. Procedural features like trustworthiness, neutrality, respectful treatment and voice convey important symbolic information about identity, belonging and position in society (Bradford, Murphy \& Jackson 2014, p. 528). The experience of procedural justice thus promotes connection to the authority and the group it represents. People in turn feel more obligated to support and cooperate with the authorities of the groups to which they belong (Bradford, Murphy, \& Jackson 2014 , p. 528). While procedural justice is related to positive social identities and inclusion, unjust treatment from authorities can have negative consequences for identity formation (Tyler \& Blader 2000, p. 15). Those who feel they have been treated in a procedurally unjust way by authorities will view such treatment as reflective of their worth and status in the eyes of that authority. As important representatives of the state, the treatment that police convey toward an individual can also signal how society in general views them. Procedurally unjust treatment signals social exclusion. Social exclusion in turn can result in disengagement from society and its social institutions.

Empirical research also highlights the importance of emotion for understanding why procedural justice matters to people. Felt injustice and unfair treatment at the hands of authorities can trigger strong emotional responses in people, most notably anger. In fact, the discrete emotions of happiness, joy, anger, frustration, guilt, and anxiety have all been linked to perceptions of procedural justice and injustice (for a review see Barkworth \& Murphy 2015). This suggests that experiencing procedural injustice from police can damage people's relationship with police due to the negative emotions it can elicit. Hence, procedural justice is important from a relational point of view because it can improve relationships between police and the public and can reduce the hostility individuals direct toward police. 


\subsection{How is procedural justice policing typically measured in empirical research?}

Having established what procedural justice policing is and why police should care about procedural justice, this section presents an overview of how Australian scholars have typically measured procedural justice policing in their research. The vast majority of published procedural justice studies have made use of quantitative-based survey methodology. This is the case for both Australian research and research conducted elsewhere. Hence, this section focuses specifically on how procedural justice has been measured in survey-based research.

It should be highlighted that the measurement of procedural justice in empirical studies has proven to be a source of much debate and criticism. A number of academics have argued that procedural justice research inconsistently operationalises key constructs and has done little to evaluate the construct validity of existing measures (e.g. Gau 2011, p. 489; Reisig, Bratton, \& Gertz 2007, p. 1006). ${ }^{2}$ These authors note that measures of procedural justice have often differed substantially between studies. Concern has also been raised about whether measured variables actually reflect their stated concept. Rightly so, these critics argue that when measures are inconsistent between studies, or do not measure what is intended, this can lead to misleading, inaccurate, and conflicting conclusions across different studies. Fortunately, these criticisms can be overcome by utilising similar measures across different studies and by performing statistical techniques on survey data to assess whether different concepts in a study are statistically reliable and have construct validity.

Importantly, almost all of the procedural justice studies undertaken and published by key Australian scholars Kristina Murphy, Adrian Cherney, Elise Sargeant, Lorraine Mazerolle, Emma Antrobus, Sarah Bennett and Natasha Madon have avoided these measurement issues. These scholars typically use similar and standardised measures of procedural justice across their studies. These scholars also use factor analytic statistical techniques to ensure that their procedural justice measures are reliable, have construct validity, and are conceptually distinct from other measures incorporated in the study (i.e. the procedural justice measure is conceptually distinct from measures of police legitimacy, trust in police, satisfaction with police, willingness to cooperate with police, etc.).

Table 1.1 presents the commonly used survey items that have been used to measure procedural justice in surveys conducted in Australia. These items were originally adapted from Tyler's (1990) seminal work in the US, and have been refined and improved over time for use in Australia. These procedural justice measures include a 5-point Likert scale response format, where survey participants indicate their agreement or disagreement to several statements (e.g. 'Police treat people with dignity and respect': 1 = strongly disagree, 2 = disagree, 3 = neither disagree nor agree, $4=$ agree, $5=$ strongly agree). These statements assess citizens' perceptions of police use of procedural justice, either in general terms or in response to a specific encounter with a police officer. Thus, they are subjective assessments rather than objective assessments of the treatment received 
Table 1.1 Survey Items Used to Measure Perceptions of Procedural Justice Policing in Australia

General Procedural Justice Measures

Based on your experiences or perceptions indicate whether you agree or disagree with the following statements:

- Police try to be fair when making decisions $(\mathrm{T})$

- Police treat people fairly $(\mathrm{T})$

- Police treat people with dignity and respect $(\mathrm{R})$

- Police are always polite when dealing with people (R)

- Police listen to people before making decisions $(\mathrm{V})$

- Police make decisions based upon facts, not their personal biases or opinions $(\mathrm{N})$

- Police respect people's rights when decisions are made $(\mathrm{R})$

Cronbach's alpha $=0.89$

OR

\section{When dealing with people in your community}

- Police give people a chance to express their views before making decisions $(\mathrm{V})$

- Police make their decisions based upon facts, not their personal opinions (N)

- Police apply the law consistently to everyone, regardless of who they are (N)

- Police consider people's views when deciding what to do $(\mathrm{V})$

- Police take account of the needs and concerns of the people they deal with $(\mathrm{V})$

- Police respect people's rights (R)

- Police treat people with dignity and respect $(\mathrm{R})$

- Police treat people fairly (T)

- Police try to be fair when making decisions $(\mathrm{T})$

- Police are polite when dealing with people (R)
Encounter Specific Procedural Justice

Measures

Thinking about your most recent

encounter with police, do you think:

- The police officer treated me with dignity and respect $(\mathrm{R})$

- The police officer was polite when dealing with me (R)

- The police officer was fair $(\mathrm{T})$

- The police officer gave me the opportunity to express my views $(\mathrm{V})$

- The police officer listened to me (V)

- The police officer made decisions based upon facts, not their personal biases or opinions $(\mathrm{N})$

Cronbach's alpha $=0.88$

Cronbach's alpha $=0.95$

$\mathrm{T}=$ trustworthiness $; \mathrm{R}=$ respectful treatment $\mathrm{N}$ = neutrality; $\mathrm{V}=$ voice 
from police. Best practice measures of procedural justice typically include several questions canvassing the four elements of procedural justice (i.e. trustworthiness, respectful treatment, neutrality, voice) which are combined to create an overall procedural justice scale. To test the construct validity of a scale and its reliability, measures are tested via factor analysis and a Cronbach alpha calculation. ${ }^{3}$ Cronbach alpha scores between 0.8 and 1.0 indicate an internally reliable scale.

\subsection{Procedural justice policing research in Australia: findings and highlights}

The previous section discussed how procedural justice is typically measured in Australian surveys. The findings from Australian procedural justice policing studies are presented in this section. At the time of writing this chapter, 48 Australian studies had been published in journals or book chapters. ${ }^{4}$ The 48 studies are organised as follows: (a) procedural justice studies with general population samples (including the early published Australian studies); (b) studies undertaken with vulnerable communities (i.e. youth, crime victims, ethnic/racial minorities); (c) counter-terrorism policing studies; (d) neighbourhood-level studies; and (e) applied policing studies. The Appendix to this chapter provides a full list of the authors responsible for these five groups of studies.

\subsubsection{Studies undertaken with general population samples}

Throughout the 1990s and early 2000s, Tom Tyler and his colleagues empirically tested the importance of procedural justice policing to American citizens' evaluations of police. That survey research revealed that Americans' procedural justice perceptions were strongly and positively associated with their perceptions of the legitimacy of police, their satisfaction with police, their willingness to cooperate with police, and their willingness to comply with laws. It was also found that procedural justice, not instrumental factors (i.e. personal outcomes; perceived ability of police to detect and prevent crime), dominated Americans' concerns when predicting these outcomes (e.g. Tyler 1990, p. 102; Sunshine \& Tyler 2003, pp. 525-528). Such findings were viewed as important because they highlighted the fact that police could directly influence public sentiment and behaviour through the way they treated people.

In the mid-2000s, Hinds and Murphy (2007, p. 31) pointed out that the generalisability of the US-based research was unknown. Due to the dearth of procedural justice policing studies outside the US, it was unclear whether the findings linking procedural justice to citizens' enhanced perceptions of police legitimacy, satisfaction with police, and willingness to cooperate with police and comply with laws could be replicated in jurisdictions outside the US. The aim of the early Australian procedural justice policing work, therefore, was to test for the first time the applicability and generalisability of the procedural justice framework in a non-US context. 
Six of the early Australian studies were published between 2007 and 2009 by Kristina Murphy and/or Lyn Hinds. Each of these six studies utilised survey data collected from adult citizens from the general population. Three of the six papers simply sought to replicate key findings from the US, investigating specifically whether citizens' perceptions of procedural justice were positively associated with: (a) perceptions of police legitimacy (Hinds \& Murphy, 2007), (b) satisfaction with police (Hinds 2009a; Hinds \& Murphy 2007), and c) willingness to cooperate with police (Murphy, Hinds, \& Fleming 2008). The studies also examined whether procedural justice concerns, not police effectiveness concerns, dominated citizens' evaluations of police. The other three papers (Murphy 2009a, 2009b; Murphy, Tyler, \& Curtis 2009) examined the contextual effects of procedural justice, investigating specifically whether procedural justice effects could vary across groups or situations. Overall, the six early studies confirmed the salience and generalisability of the American procedural justice literature to Australian policing. In each study, procedural justice policing perceptions were positively associated with legitimacy, satisfaction, or self-reported cooperation/ compliance levels.

Three notable findings were obtained from the early Australian research. First, Hinds and Murphy (2007, p. 36) revealed that relative to Americans, Australians placed more weight on instrumental concerns when evaluating the police. Specifically, while procedural justice still mattered more to Australians, respondents also focused strongly on whether police were effective. Second, these effects varied across policing context (e.g. Murphy 2009a, p. 172). Murphy (2009a) found that Australians focused most on procedural justice concerns and less on police effectiveness concerns when they were involved in police-initiated contacts. In contrast, when involved in citizen-initiated contacts with police, Australians focused most on police effectiveness and less on procedural justice concerns. Third, the Murphy (2009b) and Murphy et al. (2009) studies revealed that psychological factors could moderate the effect of procedural justice on citizens' evaluations of police. For example, Murphy (2009b, p. 18) found that peoples' propensity to act emotionally to events influenced their receptiveness to procedural justice; specifically, procedural justice resulted in lower defiance levels toward police for those Australians who were low in emotionality. For those who were high in emotionality, procedural justice had little effect in reducing defiance.

'Most procedural justice scholars assume that procedural justice effects are always positive or "invariant" across people, groups and contexts' (Murphy 2017a, p. 430). Certainly, much of the empirical procedural justice policing research has revealed that procedural justice matters equally to people from different demographic groups (e.g. Wolfe et al. 2016, p. 253). The Australian findings cited above reveal, however, that procedural justice effects can vary.

There are several explanations for why differences have been observed in Australia but not in the US research. Two are offered here. The US research examined differences in procedural justice effects between demographic groups. Those studies did not consider the potential influence of individual-level psychological 
factors and how these can shape people's receptiveness to procedural justice. In the justice literature, it has been proposed that justice is a subjective-affective construct (van den Bos, 2003, p. 483). This suggests that justice perceptions result from how people feel emotionally after experiencing justice or injustice. It follows that individual differences in a person's personality or predispositions should influence how they respond to procedural justice and injustice. Indeed, the Murphy (2009b, p. 18) study cited above confirmed that emotional disposition did influence how Australians reacted to procedural justice.

It also makes sense from a psychological point of view that people will focus more on procedural justice in police-initiated contacts, while concerns about the effectiveness of police should dominate in citizen-initiated contacts. Policeinitiated contacts tend not to be entered into voluntarily. Hence, they can be perceived by individuals in a suspicious or adversarial way. The more adversarial nature of police-initiated encounters can evoke unpleasant emotions and uncertainty regarding how the event will unfold. To reduce feelings of uncertainty, people tend to focus on relational aspects of encounters with authorities. In other words, they place greater emphasis on signs they are being treated justly by authorities. When people contact police for assistance, in contrast, the hope is that police will take action that results in a positive outcome for the individual. The emphasis here is likely to be on whether police are effective in dealing with the citizen's concerns. While procedural justice is also appreciated in this context, the primary concern will be with the officer dealing with the issue at hand.

Following the publication of the six early Australian studies, five additional papers using general population samples were published. These five studies sought to further understand when and why procedural justice mattered to Australian citizens. Four of the five studies focused on the relational properties of procedural justice and its ability to enhance identity and reduce negative emotions and defiance. Bradford, Murphy, and Jackson (2014, p. 538) revealed that procedural justice enhanced Australians' identity as law-abiding citizens, with those who identified more strongly as law-abiding perceiving police as more legitimate and entitled to be obeyed. Barkworth and Murphy (2015, p. 268) confirmed that procedural justice could reduce negative affect, and Murphy (2016, p. 101) showed that procedural justice could reduce defiance toward police. Using longitudinal survey data, Sargeant, Murphy, and Madon (2017, p. 131) also demonstrated that if citizens held defiant attitudes toward police when entering into an interaction this had an impact on their perceptions of procedural justice and, in turn, their satisfaction with the encounter (p. 132).

\subsubsection{Studies undertaken with vulnerable communities}

The second group of procedural justice studies in Australia focused on the importance of procedural justice to vulnerable population groups. This work built upon the early Australian studies presented in the previous section and aimed to better understand the different contexts under which procedural justice policing was effective or ineffective. 
Of the 15 studies published in this group, four focused on youth (Hinds 2007; Hinds 2009b; Murphy 2015; Bates, Allen \& Watson 2016), four focused on crime victims (Elliott, Thomas \& Ogloff 2011, 2012; Murphy \& Barkworth 2014; Barkworth \& Murphy 2016), one focused on the LGBTI community (Miles-Johnson 2013), and six focused on ethnic/racial minority communities(see Appendix for a full list of these authors). Almost all of these studies confirmed that procedural justice policing was positively associated with citizens' trust in police, their perceptions of the police as legitimate, their satisfaction with the police, or their willingness to voluntarily cooperate with the police. However, one study revealed that procedural justice policing had a negative effect on ethnic minorities' cooperation with police (Murphy \& Cherney 2011, p. 248). Sargeant, Murphy, and Cherney's (2014, p. 513) study also revealed that procedural justice had little impact in building Vietnamese immigrants' trust in police, but it mattered a great deal for Indian immigrants and non-minority respondents. For Vietnamese immigrants, concerns regarding police effectiveness dominated their trust in police.

In other studies, Murphy and Barkworth (2014, pp. 193-194) also revealed that procedural justice had a stronger positive effect for certain types of crime victim (i.e. domestic violence, burglary, vandalism victims), while for other types of crime victim (i.e. motor theft victims) the perceived effectiveness of police mattered more when deciding to report future victimisation. Murphy (2015, p. 53 ) also revealed that young people placed more importance on procedural justice than adults, and Madon, Murphy, and Sargeant (2017, p. 624) found that procedural justice mattered most to disengaged individuals when evaluating the legitimacy of the police. Finally, Murphy (2013, p. 193) revealed that ethnic minorities who identified more strongly with their ethnic identity placed more importance on procedural justice when deciding to trust the police. Together, these studies challenge the view that all population groups respond equally to procedural justice; that is, that procedural justice effects are invariant across different demographic groups.

Each of the studies cited above provided explanations for the differing effects of procedural justice across groups. While there is no space in this chapter to go through all the explanations, two noteworthy suggestions are offered. For the studies involving ethnic minority and immigrant groups, the finding that procedural justice mattered little to some groups can be explained by examining the historical and cultural legacies of some minority groups. For some migrant groups, immigration to Australia was driven by a need to flee war or communist regimes (e.g. Vietnamese immigrants). Given their experiences of war and oppression, immigrants from these types of countries may place more attention on the ability of police in their host country to keep them safe; whether they are treated respectfully or not is of less concern. Procedural justice studies conducted in African contexts show similar findings. Tankebe (2009, p. 1265) showed that people in Ghana placed little importance on procedural justice when judging the legitimacy of police, instead focusing on whether the police were effective. Tankebe argued that police effectiveness becomes particularly important to people when personal security is of concern. 


\section{Kristina Murphy}

When explaining why some groups may be more positively affected by procedural justice than others, we can draw from prior research in non-policing domains. Prior research suggests that when people feel more uncertain about how authorities might view or treat them, procedural justice concerns become particularly salient (Van den Bos 2003, p. 483). This again points to the important relational aspects of procedural justice. Procedural justice can act as an uncertainty reducer (DeCremer, Brebels \& Sedikides, 2008, p. 1524), allaying people's anxiety about how authorities view them. This is because procedural justice can promote relationships between those in authority and those they govern. Prior psychological research on prejudice also reveals that minority group members who identify strongly with their own minority group are more sensitive to signs of discrimination and bias (Operario \& Fiske 2001, p. 550). Identifying strongly with a minority group heightens expectations of unfair treatment and injustice. It might be the case that youth, those who see their ethnicity as more central to their identity, those who feel more disengaged, and domestic violence victims, may feel particularly anxious and uncertain about how police might view them; and this explains why they responded more positively to procedural justice in the Australian studies.

\subsubsection{Counter-terrorism policing studies}

Emerging from the Australian procedural justice work on ethnic minority communities was the next wave of Australian research, examining procedural justice concerns in the counter-terrorism policing context. While terrorism can be perpetrated by any group or individual, the focus of the Australian studies centred on Muslim communities. Research abroad had revealed that police struggle to engage Muslim communities in counter-terrorism due to Muslims reporting suspicion and resentment of counter-terrorism policing and laws, and due to Muslims feeling stigmatised by the association of Islam with terrorism (Innes 2006, p. 237).

In a series of seven studies, Adrian Cherney and Kristina Murphy, and others (Cherney \& Murphy 2013, 2017; Madon, Murphy \& Cherney 2017; Murphy \& Cherney 2017; Murphy, Madon \& Cherney 2017, 2020; Murphy, Cherney \& Teston 2019), found that procedural justice policing was extremely important to Muslims living in Australia. Using survey data collected from 800 Muslims living in Brisbane, Sydney, and Melbourne, Cherney and Murphy (2017) confirmed that many Muslims did feel stigmatised by Australia's policing response to Islamist-inspired terrorism (p. 1026). They also revealed that when counterterrorism police were perceived to be adhering to procedural justice principles, Muslims trusted the police more and were more willing to report terror threats to them (p. 1031). In one recent study, Murphy, Madon, and Cherney (2020, p. 370) revealed that procedural justice was particularly important for promoting a willingness to report terror threats to police for those Muslims who felt most stigmatised. These findings again highlight the relational aspects of procedural justice. DeCremer and Sedikides $(2005$, p. 157) showed that when people hold greater doubts about their inclusiveness in a group they will be more sensitive 
to signs of procedural justice and injustice. Those who feel more stigmatised by others are likely to hold greater doubts about their acceptance in society. Through their interactions with the police, Muslims can construe their perceived worth and standing within the broader community by how the police treat them; as procedural justice conveys to highly stigmatised individuals that police value them and value their input in the fight against terrorism. Overall, these studies revealed that even in the challenging domain of counter-terrorism policingwhere Muslims feel highly stigmatised, and police are often viewed with high levels of suspicion and scepticism by Muslims-procedural justice can promote closer relationships and mutual trust.

\subsubsection{Neighbourbood-level studies}

In the fourth group of studies, Sargeant, Mazerolle, and Wickes (2016), Sargeant and Kochel (2018), and Antrobus et al. (2015) considered community-level factors for understanding how police are perceived in Australia. A long history of US-based research demonstrates that 'place' matters when explaining people's views of police (e.g. Reisig \& Parks 2000, p. 607; Weitzer 1999, p. 841). Unlike in the US, the Australian studies revealed that attitudes toward police and their perceived use of procedural justice varied little between neighbourhoods (although Sargeant and Kochel (2018, p. 832) did reveal that neighbourhood characteristics and procedural justice perceptions both explained the variation in Australians' willingness to cooperate with police). Two explanations are offered for why neighbourhood factors may matter less in Australia. First, policing in Australia operates in a very centralised manner at a state and territory level. Thus, each state and territory police agency has a single policing function. By contrast, policing is much more fragmented in the US. There are over 14,000 policing agencies across three levels of government (county, state, and federal) (FBI 2004), with agencies at each level being responsible for a different function. Australia's centralised policing model means less potential for interagency rivalry and greater intrastate consistency in policing roles, legal responsibilities, service delivery, and performance criteria. Second, violent crime rates across suburbs in Australia tend to be significantly lower than in the US and vary less between suburbs. In the US, many neighbourhoods are also characterised by enduring levels of violent crime. Police in these high crime American neighbourhoods often adopt a very different approach to those in low crime neighbourhoods; they typically rely more heavily on the use of force, and they place a strong emphasis on deterrence (Weitzer 1999 , p. 822). Unsurprisingly, community attitudes toward police therefore vary greatly in the US between high and low crime neighbourhoods.

\subsubsection{Applied policing studies}

The final collection of studies from Australia canvass collaborative work undertaken between academics and police agencies, most notably the Queensland Police Service. Murphy (2017b, p. 54) recently noted 'a burgeoning area of study 


\section{Kristina Murphy}

in the procedural justice field has involved researchers working closely with regulators to evaluate procedural justice effects in applied settings'. The Australian studies: (a) assessed how police officers perceived the efficacy of procedural justice, (b) tested whether police could be trained to be more procedurally just in encounters with the public, and (c) used randomised controlled trials to evaluate the effects of procedural justice policing in the field. Randomised controlled trials can overcome some of the limitations of survey research by clarifying the causal relationships between predictor variables (e.g. procedural justice) and outcome variables (e.g. trust in police). Twelve Australian studies have been published in this area to date (see Appendix for the full list of studies).

In general, the studies revealed that training police officers to be more procedurally just in encounters with the public (i.e. training them how to be more respectful, to allow citizens a voice, to be neutral in encounters, and to express trustworthy motives) had a positive effect on how the public perceived their interactions with police. Specifically, the studies revealed that providing training to police about the importance of procedural justice did enhance citizens' trust in police (Murphy, Mazerolle, \& Bennett, 2014, p. 405); perceptions that police were legitimate (e.g. Sargeant et al. 2016, p. 797); satisfaction with a police encounter (e.g., Mazerolle et al. 2012, pp. 358-359); and willingness to cooperate with police (e.g. Murphy et al. 2014, pp. 417-418). Importantly, the studies also revealed that training police in procedural justice made police more aware of their own behaviour (e.g. Bates et al. 2015, p. 442) and influenced their attitudes regarding the efficacy of procedural justice (e.g. Bond, Murphy \& Porter 2015, p. 229).

\subsection{Reflections on the challenges of doing empirically based procedural justice research and directions for future research}

This final section provides a brief discussion of the challenges associated with doing empirically based procedural justice research. Following this will be some reflections on where empirical research on procedural justice policing might be headed in the future.

There are several challenges associated with doing empirical procedural justice research. The first challenge relates to the cost of quality sampling. Applied survey research can be very expensive and can be prohibitive to many researchers. If one's aim is to extrapolate findings to the wider population and to inform actual police practice, it is important to ensure that the target sample being studied is as representative as possible of the population from which it is drawn, and that sufficient numbers have been sampled to provide reliable results. Otherwise the validity of one's findings and conclusions can be challenged. Recruiting a large representative sample can be particularly challenging when surveying small hard-to-reach minority communities or where language or cultural barriers exist. To access such groups, researchers typically require the services of a reputable third party survey provider that specialises in recruiting culturally and linguistically diverse population groups. These research companies have the resources to 
employ and train non-English speakers to recruit and interview participants, but they come with a significant economic outlay to the researcher, which can be prohibitive for many researchers.

The second challenge relates to measurement. As already noted, many studies in the procedural justice field have been criticised for failing to pay attention to measurement issues. The conclusions drawn from studies can be questioned if measured constructs have not been rigorously created or validated. While the vast majority of Australian studies cited in this chapter did pay attention to measurement issues, some did not. Often scholars who indirectly study procedural justice make use of available survey datasets that were not originally designed to measure procedural justice or its associated constructs. This practice must be avoided as unreliable measures can produce results that conflict with prior research.

Third, embedding procedural justice into actual police work is not without its challenges. Organisational factors operating within police agencies (e.g. lack of resources, or a culture that opposes the use of procedural justice) can inhibit the reliable uptake of strategies that draw on a procedural justice-based policing model. External factors pertaining to the public and political demands on police can also undermine innovation in policing. When police are placed under increasing pressure to achieve value for money in service delivery, anything that adds to the time they spend on their duties (i.e. procedural justice initiatives such as taking time to build trust, allowing citizens a voice, etc.) may be set aside as it distracts them from detecting and apprehending criminals. Media and political discourse surrounding crime control and the need to 'get tough' on crime, and the dominance of the deterrence-based model of policing, are likely to be other significant barriers to the uptake of procedural justice policing. Procedural justice may be perceived as the 'soft on crime' approach despite research revealing that it benefits police in both a relational and instrumental sense. As Mazerolle et al. $(2014$, p. 70$)$ argue, changing police culture to adopt procedural justice into service delivery 'requires organizational support, training, and willingness on the part of police' to adopt and test procedural justice in different operational settings. As the Black Lives Matter Movement also highlights, police need to pay due attention to procedural justice if they wish to improve relations with Australia's ethnic and racial minority communities.

The procedural justice research described in this chapter has made important contributions to policing in Australia. Sarre (2016, pp. 7-8) notes it as one of the top ten 'big bangs' that have made a difference to Australian policing in the past three decades. With this in mind, it is worth mentioning some future directions that research on procedural justice policing might take. First, procedural justice is particularly important for vulnerable groups. Domestic violence victims, for example, place a great deal of importance on procedural justice when deciding whether to report future victimisations to police. There is still more to learn about how and when procedural justice policing can improve the quality of life and justice needs of victims of violent crime. Likewise, ethnic/racial minorities respond very well to police adhering to procedural justice. There is still more to learn about how, when and why minority groups respond to procedural justice. 
Second, there are still unanswered questions regarding whether procedural justice actually changes people's compliance behaviour. The vast majority of procedural justice studies rely on survey methods. The associations made between self-reported views and behaviour in these studies obscure the causal relationships between variables. It is unclear, for example, whether procedural justice results in greater compliance with the law or whether those who are more compliant rate police as more procedurally just. Therefore, demonstrating that there is a measurable impact of procedural justice on actual legal compliance behaviour is a matter for further study. Third, scholars have begun to focus attention on police and how they think about procedural justice and its effectiveness, their willingness to use it in the field, and the barriers to its implementation. More of this type of research is warranted as changing police officers' attitudes to procedural justice can influence how police provide their service to the community. Finally, police increasingly rely on the use of technology to do their work. It is unclear, for example, what impact the rollout of body-worn video cameras has on street-level policing and frontline police-citizen interactions. Examining the impact of the use of technology in policing on public perceptions of procedural justice is an area ripe for study.

\subsection{Conclusion}

To conclude, this chapter has provided a summary of the significant body of procedural justice policing research undertaken in Australia. The chapter has discussed how procedural justice has been defined and operationalised in Australian research and how the empirical study of procedural justice reveals that procedural justice policing can have a number of positive instrumental, normative, and relational benefits for police and the public. While this research has not been without its limitations and challenges, it appears on balance that procedural justice policing offers police agencies the opportunity to improve their relationship with the public. The groundswell of interest in procedural justice policing research is yet to wane, and so this chapter concluded with some reflections on possible future directions for the field. Police have the power to change their relationship with the public. Adhering to procedural justice principles enables police to move from a relationship based on deterrence and coercion, to one based on reassuring the public that they are there to serve their communities.

\section{Appendix}

The appendix presents a list of the 48 published Australian procedural justice policing studies canvassed in this chapter.

\section{Studies with general population samples}

Hinds \& Murphy (2007)

Murphy, Hinds \& Fleming (2008)

Hinds (2009a)

Murphy (2009a) 
Murphy (2009b)

Murphy, Tyler \& Curtis (2009)

Bradford, Murphy \& Jackson (2014)

Barkworth \& Murphy (2015)

Murphy, Sargeant \& Cherney (2015)

Murphy (2016)

Sargeant, Murphy \& Madon (2017)

\section{Counter-terrorism policing studies}

Cherney \& Murphy (2013)

Cherney \& Murphy (2017)

Madon, Murphy \& Cherney (2017)

Murphy, Madon \& Cherney (2017)

Murphy \& Cherney (2017)

Murphy, Madon \& Cherney (2018)

Murphy, Cherney \& Teston (2019)

\section{Vulnerable community studies}

Hinds (2007)

Hinds (2009b)

Murphy \& Cherney (2011)

Elliott, Thomas \& Ogloff (2011)

Elliott, Thomas \& Ogloff (2012)

Murphy \& Cherney (2012)

Miles-Johnson (2013)

Murphy (2013)

Murphy \& Barkworth (2014)

Sargeant, Murphy \& Cherney (2014)

Murphy (2015)

Bates, Allen \& Watson (2016)

Barkworth \& Murphy (2016)

Murphy \& Cherney (2017)

Madon, Murphy \& Sargeant (2017)

\section{Neighborbood-level studies}

Antrobus, Bradford, Murphy \& Sargeant (2015)

Sargeant, Mazerolle \& Wickes (2016)

Sargeant \& Kochel (2018)

\section{Applied policing studies}

Mazerolle, Bennett, Antrobus \& Eggins (2012)

Mazerolle, Antrobus, Bennett \& Tyler (2013) 
Murphy, Mazerolle \& Bennett (2014)

Bond, Murphy \& Porter (2015)

Bates, Antrobus, Bennett \& Martin (2015)

Fildes, Murphy \& Porter (2016)

Sargeant, Antrobus, Murphy, Bennett \& Mazerolle (2016)

Antrobus \& Pilloto (2016)

Murphy (2017a)

Bennett, Newman \& Sydes (2017)

Murphy \& Mazerolle (2018)

Antrobus, Thompson \& Ariel (2019)

\section{Notes}

1 I acknowledge the funding support of the Australian Research Council (Grant Number FT180100139).

2 Construct validity refers to the degree to which something measures what it claims, or purports, to be measuring.

3 Cronbach's alpha is a statistical calculation performed on survey data and is a measure of internal consistency; that is, it measures how closely related a set of items are as a group. It is considered to be a measure of scale reliability.

4 Additional papers have been written in Australia but they were discussion pieces, relied on qualitative interview data, were contained in conference proceedings, or examined the relevance of procedural justice in non-policing contexts. Hence, they are not reviewed in this chapter.

\section{References}

Antrobus, E, Bradford, B, Murphy, K \& Sargeant, E 2015, 'Community norms, procedural justice, and the public's perceptions of police legitimacy', Journal of Contemporary Criminal Justice, vol. 31, no. 2, pp. 151-170.

Antrobus, E \& Pilotto, A 2016, 'Improving forensic responses to residential burglaries: results of a randomized controlled trial', Journal of Experimental Criminology, vol. 12, no. 3, pp. 319-345.

Antrobus, E, Thompson, I \& Ariel, B 2019, 'Procedural justice training for police recruits: results of a randomized controlled trial', Journal of Experimental Criminology, vol. 15, no. 1, pp. 29-53.

Anwar, S \& Loughran, T 2011, 'Testing a Bayesian learning theory of deterrence among serious juvenile offenders', Criminology, vol. 49, no. 3, pp. 667-698.

Barkworth, J \& Murphy, K 2015, 'Procedural justice policing and citizen compliance behavior: the importance of emotion', Psychology, Crime and Law, vol. 21, no. 3, pp. 254-273.

Barkworth, J \& Murphy, K 2016, 'System contact and procedural justice policing: improving quality of life outcomes for victims of crime', International Review of Victimology, vol. 22, no. 2, pp. 105-122.

Bates, L, Allen, S \& Watson, B 2016, 'The influence of the elements of procedural justice and speed camera enforcement on young novice driver self-reported speeding', Accident Analysis and Prevention, vol. 92, pp. 34-42. 
Bates, L, Antrobus, E, Bennett, S \& Martin, P 2015, 'Comparing police and public perceptions of a routine traffic encounter', Police Quarterly, vol. 18, no. 4, pp. 442-468.

Bennett, S, Newman, M \& Sydes, M 2017, 'Mobile police community office: a vehicle for reducing crime, crime harm and enhancing police legitimacy?', Journal of Experimental Criminology, vol. 13, no. 3, pp. 417-428.

Bond, C, Murphy, K \& Porter, L 2015, 'Procedural justice in policing: the first phase of an Australian longitudinal study of officer attitudes and intentions', Crime, Law and Social Change, vol. 64, no. 4-5, pp. 229-245.

Bradford, B, Murphy, K \& Jackson, J 2014, 'Officers as mirrors: policing, procedural justice and the (re)production of social identity', British Journal of Criminology, vol. 54 , no. 4 , pp. $527-550$.

Braithwaite, V 2017, 'Closing the gap between regulation and the community', in P Drahos (ed.), Regulatory theory: foundations and applications, pp. 25-42, ANU Press, Canberra, ACT.

Chan, J 1997, Changing police culture: policing in a multicultural society, Cambridge University Press, Cambridge.

Cherney, A \& Murphy, K 2013, 'Policing terrorism with procedural justice: the role of police legitimacy and law legitimacy', The Australian and New Zealand Journal of Criminology, vol. 46, no. 3, pp. 403-421.

Cherney, A \& Murphy, K 2016, 'Being a 'suspect community' in a post 9/11 world The impact of the war on terror on Muslim communities in Australia', Australian and New Zealand Journal of Criminology, vol. 49, no. 4, pp. 480-496.

Cherney, A \& Murphy, K 2017, 'Police and community cooperation in counterterrorism: evidence and insights from Australia', Studies in Conflict and Terrorism, vol. 40, no. 12, pp. 1023-1037.

DeCremer, D, Brebels, L \& Sedikides, C 2008, 'Being uncertain about what? Procedural fairness effects as a function of general uncertainty and belongingness uncertainty', Journal of Experimental Social Psychology, vol. 44, no. 6, pp. 1520-1525.

DeCremer, D \& Sedikides, C 2005, 'Self-uncertainty and responsiveness to procedural justice', Journal of Experimental Social Psychology, vol. 41, no. 2, pp. 157-173.

Drahos, P \& Krygier, M 2017, 'Regulation, institutions and networks', in P Drahos (ed.), Regulatory theory: foundations and applications, pp. 1-24, ANU Press, Canberra, ACT.

Elliott, I, Thomas, S \& Ogloff, J 2011, 'Procedural justice in contacts with the police: testing a relational model of authority in a mixed methods study', Psychology, Public Policy and Law, vol. 17, no. 4, pp. 592-610.

Elliott, I, Thomas, S \& Ogloff, J 2012, 'Procedural justice in contacts with the police: the perspective of victims of crime', Police Practice and Research, vol. 13, no. 5, pp. 437-449.

Federal Bureau of Investigation 2004, 'Crime in the United States, 2003', US Department of Justice, Washington, DC.

Fildes, A, Murphy, K \& Porter, L 2016, 'Police officer procedural justice selfassessments: do they change across recruit training and operational experience?', Policing and Society, vol. 29, no. 2, pp. 188-203.

Gau, J 2011, 'The convergent and discriminant validity of procedural justice and police legitimacy: an empirical test of core theoretical propositions', Journal of Criminal Justice, vol. 39, no. 6, pp. 489-4. 
Hinds, L 2007, 'Building police-youth relationships: the importance of procedural justice', Youth Justice, vol. 7, no. 3, pp. 195-209.

Hinds, L 2009a, 'Public satisfaction with police: the influence of general attitudes and police-citizen encounters', International Journal of Police Science and Management, vol. 11, no. 1, pp. 54-66.

Hinds, L 2009b, 'Youth, police legitimacy and informal contact', Journal of Police and Criminal Psychology, vol. 24, no. 1, pp. 10-21.

Hinds, L \& Murphy, K 2007, 'Public satisfaction with police: using procedural justice to improve police legitimacy', The Australian and New Zealand Journal of Criminology, vol. 40, no. 1, pp. 27-42.

Innes, M 2006, 'Policing uncertainty: countering terror through community intelligence and democratic policing', Annals of the American Academy of Political and Social Science, vol. 605, no. 1, pp. 222-241.

Jackson, J, Bradford, B, Stanko, B \& Hohl, K 2012, Just authority: trust in the police in England and Wales, Routledge, Oxon.

Madon, N, Murphy, K \& Cherney, A 2017, 'Promoting community collaboration in counter-terrorism: do social identities and perceptions of legitimacy mediate reactions to procedural justice policing?', British Journal of Criminology, vol. 57, no. 5 pp. 1144-1164.

Madon, N, Murphy, K \& Sargeant, E 2017, 'Promoting police legitimacy among disengaged minority groups: does procedural justice matter more?', Criminology and Criminal Justice, vol. 17, no. 5, pp. 624-642.

Mazerolle, L, Antrobus, E, Bennett, S \& Tyler, T 2013, 'Shaping citizen perceptions of police legitimacy: a randomized field trial of procedural justice', Criminology, vol. 51, no. 1, pp. 33-64.

Mazerolle, L, Bennett, S, Antrobus, E \& Eggins, E 2012, 'Procedural justice, routine encounters and citizen perceptions of police: main findings from the Queensland Community Engagement Trial (QCET)', Journal of Experimental Criminology, vol. 8 , no. 4 , pp. 343-367.

Mazerolle, L, Sargeant, E, Cherney, A, Bennett, S, Murphy, K, Antrobus, E \& Martin, P 2014, Procedural justice and legitimacy in policing, Springer Briefs, New York.

Miles-Johnson, T 2013, 'Confidence and trust in police: how sexual identity difference shapes perceptions of police', Current Issues in Criminal Justice, vol. 25, no. 2, pp. 685-702.

Murphy, K 2009a, 'Public satisfaction with police: the importance of procedural justice and police performance in police-citizen encounters', The Australian and New Zealand Journal of Criminology, vol. 42, no. 2, pp. 159-178.

Murphy, K 2009b, 'Procedural justice and affect intensity: understanding reactions to regulatory authorities', Social Justice Research, vol. 22, no. 1, pp. 1-30.

Murphy, K 2013, 'Policing at the margins: fostering trust and cooperation among ethnic minority groups', Journal of Policing, Intelligence and Counter terrorism, vol. 8 , no. 2 , pp. 184-199.

Murphy, K 2015, 'Does procedural justice matter to youth? Comparing adults' and youths' willingness to collaborate with police', Policing and Society, vol. 25, no. 1 , pp. 53-76.

Murphy, K 2016, 'Turning defiance into compliance with procedural justice', Regulation and Governance, vol. 10, no. 1, pp. 93-109.

Murphy, K 2017a, 'Challenging the invariance thesis: procedural justice policing and the moderating influence of trust on citizens' obligation to obey police', Journal of Experimental Criminology, vol. 13, no. 3, pp. 429-437. 
Murphy, K 2017b, 'Procedural justice and its role in promoting voluntary compliance', in P Drahos (ed.), Regulatory theory: foundations and applications, pp. 43-58, ANU Press, Canberra, ACT.

Murphy, K \& Barkworth, J 2014, 'Victim willingness to report crime to police: does procedural justice or outcome matter most?', Victims and Offenders, vol. 9, no. 2, pp. 178-204.

Murphy, K, Bradford, B \& Jackson, J 2015, 'Motivating compliance behavior among offenders: procedural justice or deterrence?', Criminal Justice and Behavior, vol. 43 , no. 1, pp. 102-118.

Murphy, K \& Cherney, A 2011, 'Fostering cooperation with the police: how do ethnic minorities in Australia respond to procedural justice-based policing?', The Australian and New Zealand Journal of Criminology, vol. 44, no. 2, pp. 235-257.

Murphy, K \& Cherney, A 2012, 'Understanding cooperation with police in a diverse society', British Journal of Criminology, vol. 52, no. 1, pp. 181-201.

Murphy, K \& Cherney, A 2017, 'Policing marginalized groups in a diverse society: using procedural justice to promote group belongingness and trust in police', in D Oberwittler \& S Roche (eds), Police-citizen relations across the world, pp. 153-174, Routledge, London.

Murphy, K, Cherney, A \& Teston, M 2019, 'Promoting Muslims' willingness to report terror threats to police: testing competing theories of procedural justice', Justice Quarterly, vol. 36, no. 4, pp. 594-619.

Murphy, K, Hinds, L \& Fleming, J 2008, 'Encouraging public cooperation and support for police', Policing and Society, vol. 18, no. 2, pp. 136-155.

Murphy, K, Madon, N \& Cherney, A 2017, 'Promoting Muslims' cooperation with police in counter-terrorism: the interaction between procedural justice, police legitimacy and law legitimacy', Policing: An International Journal, vol. 40, no. 3, pp. 544-559.

Murphy, K, Madon, N \& Cherney, A 2020, 'Reporting threats of terrorism: stigmatisation, procedural justice and policing Muslims in Australia', Policing and Society, vol. 30, no. 4, pp. 361-377.

Murphy, K \& Mazerolle, L 2018, 'Policing immigrants: using a randomized control trial of procedural justice policing to promote trust and cooperation', The Australian and New Zealand Journal of Criminology, vol. 51, no. 1, pp. 3-22.

Murphy, K, Mazerolle, L \& Bennett, S 2014, 'Promoting trust in police: findings from a randomized experimental field trial of procedural justice policing', Policing and Society, vol. 24, no. 4, pp. 405-424.

Murphy, K, Sargeant, E \& Cherney, A 2015, 'Procedural justice, police performance and cooperation with police: does social identity matter?', European Journal of Criminology, vol. 12, no. 6, pp. 719-738.

Murphy, K \& Tyler, T 2008, 'Procedural justice and compliance behaviour: the mediating role of emotions', European Journal of Criminology, vol. 38, no. 4, pp. 652-668.

Murphy, K, Tyler, T \& Curtis, A 2009, 'Nurturing regulatory compliance: is procedural justice effective when people question the legitimacy of the law?', Regulation and Governance, vol. 3, no. 1, pp. 1-26.

Nagin, D 2013, 'Deterrence in the twenty-first century', Crime and Justice, vol. 42, no. 1, pp. 199-263.

Nix, J, Wolfe, S, Rojek, J \& Kaminski, R 2015, 'Trust in the police: the influence of procedural justice and perceived collective efficacy', Crime and Delinquency, vol. 61, no. 4, pp. 610-640. 
Operario, D \& Fiske, S 2001, 'Ethnic identity moderates perceptions of prejudice', Personality and Social Psychology, vol. 27, no. 5, pp. 550-561.

Porter, L \& Prenzler, T 2017, 'Police officer gender and excessive force complaints: an Australian Study', Policing and Society, vol. 27, no. 8, pp. 865-883.

President's Task Force on 21 st Century Policing 2015, Final report of the President's task force on 21st century policing, Office of Community Oriented Policing Services, Washington, DC.

Queensland Police Service 2017, Queensland police service research priorities 20172018, viewed 4th April 2019. Available at: https://www.police.qld.gov.au/corpo ratedocs/research/Documents/QPS\%20Research\%20Priorities\%202017\%20-\% 202018.pdf

Reisig, M, Bratton, J \& Gertz, M 2007, 'The construct validity and refinement of process-based policing measures', Criminal Justice and Behavior, vol. 34, no. 8, pp. 1005-1028.

Reisig, M \& Parks, R 2000, 'Experience, quality of life and neighborhood context: a hierarchical analysis of satisfaction with police', Justice Quarterly, vol. 17, no. 3, pp. 607-630.

Sargeant, E, Antrobus, E, Murphy, K, Bennett, S \& Mazerolle, L 2016, 'Social identity and procedural justice in police encounters with the public: results from a randomised controlled trial', Policing and Society, vol. 26, no. 7, pp. 789-803.

Sargeant, E \& Kochel, T 2018, 'Re-examining the normative, expressive, and instrumental models: how do feelings of insecurity condition the willingness to cooperate with police in different contexts?', Policing and Society, vol. 28, no. 7, pp. 823-840.

Sargeant, E, Mazerolle, L \& Wickes, R 2016, 'Trust in police and the neighbourhood context: a study of policing in Melbourne', Police Science, vol. 1, no. 2, pp. 10-16.

Sargeant, E, Murphy, K \& Cherney, A 2014, 'Ethnicity, trust and cooperation with police: testing the dominance of the process-based model', European Journal of Criminology, vol. 11, no. 4, pp. 500-524.

Sargeant, E, Murphy, K \& Madon, N 2017, 'Is dissatisfaction with police inevitable? Testing an integrated model of motivational postures and procedural justice in police-citizen encounters', Police, Practice and Research, vol. 19, no 2, pp. $125-137$.

Sarre, R \& Prenzler, T 2016, “Ten big bangs" in theory and practice that have made a difference to Australian policing in the last three decades', Salus Journal, vol. 4, no. 2 , pp. 1-18.

Skogan, W, van Craen, M \& Hennessy, C 2015, 'Training police for procedural justice', Journal of Experimental Criminology, vol. 11, no. 3, pp. 319-334.

Sunshine, J \& Tyler, T 2003, 'The role of procedural justice and legitimacy in shaping public support for policing', Law and Society Review, vol. 37, no. 3, pp. 513-547.

Tankebe, J 2009, 'Public cooperation with the police in Ghana: does procedural fairness matter?’, Criminology, vol. 47, no. 4, pp. 1265-1293.

Trinkner, R, Jackson, J \& Tyler, T 2018, 'Bounded authority: expanding “appropriate” police behavior beyond procedural justice', Law and Human Behavior, vol. 42, no. 3, pp. 280-293.

Tyler, T 1990, Why people obey the law, Yale University Press, New Haven.

Tyler, T \& Blader, S 2000, Cooperation in groups, Routledge, New York. 
Tyler, T \& Wakslak, C 2004, 'Profiling and police legitimacy: procedural justice, attributions of motive and acceptance of police authority', Criminology, vol. 42, no. 2 , pp. 253-282.

Van den Bos, K 2003, 'On the subjective quality of social justice: the role of affect as information in the psychology of justice judgements', Journal of Personality and Social Psychology, vol. 85, no. 3, pp. 482-498.

Weitzer, R 1999, 'Citizen perceptions of police misconduct: race and neighborhood context', Justice Quarterly, vol. 16, no. 4, pp. 819-846.

Wolfe, S, Nix, J, Kaminski, R \& Rojek, J 2016, 'Is the effect of procedural justice on police legitimacy invariant? Testing the generality of procedural justice and competing antecedents of legitimacy', Journal of Quantitative Criminology, vol. 32 , no. 2 , pp. $253-282$. 


\title{
2 Procedural fairness and jury satisfaction
}

\section{An analysis of relational dimensions}

\author{
Jane Goodman-Delahunty, David Tait, \\ and Natalie Martschuk
}

\subsection{Introduction}

Challenges faced by juries in performing their duties are well documented. These include the unfamiliarity and gravity of the assignment, the absence of guidance on key tasks, inadequate remuneration, working with strangers, and grappling with highly technical legalese (Goodman-Delahunty et al. 2008; Peter-Hagene, Salerno \& Phalen 2019). Criticisms of jury competence are perennial, and rely on dominant narratives, many of which have been exposed as myths (Bornstein \& Greene 2017). Unsurprisingly, avoidance of jury duty is a common response to a jury summons (Sams, Neal \& Brodsky 2013, p. 4). Jury reforms in this context are constant, and not necessarily evidence-based.

Most jury reform efforts centre on judicial directions, and are often ad hoc (Clough et al. 2019, p. 1). This focus derives from an outmoded model of jury information processing - a judicial myth that juries understand and adhere to every direction from the court, so all that has to be done is modify the directions to accomplish new judicial objectives. As more judges come to accept that juries struggle to understand and apply legal jury instructions, reliance on linguistic simplification to remedy the communication problem is diminishing. For example, during his tenure as Chair of the NSW Law Reform Commission, Justice Wood led initiatives to increase the participation of citizens on juries and supported a range of interventions to improve communications between courts and juries (Goodman-Delahunty 2015, p. 58). Contemporary reforms incorporate a paradigm shift that respectfully acknowledges jurors' active engagement as fact-finders:

It is true that, in modern times, it is seen as important that the jury be accorded respect, and not treated as passive recipients or mere observers of the trial process.

(Tootle v R (2017) 94 NSWLR 430 [59] (Simpson JA))

This chapter examines research on jury reforms and trial innovations related to procedural fairness to juries and to the accused. 


\subsubsection{Procedural fairness in jury trials}

A leading social psychological theory applied in the justice sector draws on the Group Value Relational Model (Tyler 1989) to support policies and practices that focus on interpersonal relational values. Procedural Justice Theory contends that the behaviour of an authority figure is evaluated in terms of what it communicates regarding the social relationship between the individual citizen and the authority. Thus, the manner in which disputes are handled has an important influence upon people's evaluations of their experiences in court and of the criminal justice process. Some research has explored ways in which procedural justice can be incorporated into courts. Notably, these findings

do not apply only to litigants or other members of the public who come to court (the 'clients' of the court system). They also apply to the people who work within the court system ... and the same principles that can be used to design efforts to deal with the public also apply to efforts to design effective approaches to dealing with the people working within the criminal justice system.

(Tyler 2008, p. 29)

Another important factor is the perceived legitimacy of the laws and confidence in the justice system - a factor that seems to be directly associated with perceived procedural justice (Murphy 2018; Murphy, Tyler \& Curtis 2009).

The four key principles or tenets of procedural justice are respect, trustworthiness, neutrality, and voice (Tyler 1989, 2008). We consider these four concepts in turn, both their direct effects on juries, and to a lesser extent, to the accused with an indirect effect on juries.

In its original formulation, respectful treatment refers to the treatment of citizens with professionalism and dignity. Respect could refer to the consideration the judge shows the jury: acknowledging their contribution, providing clear instructions, giving the jury comfort breaks, and giving them opportunities to ask questions when appropriate. Additionally, respect could refer to democratic practice in the jury room: civil discourse, taking turns to speak, and attempting to incorporate diverse perspectives into a common view. In this chapter, we focus on the respect shown to the accused by the way they are accommodated in court and the consequential effects on juries. A more general issue this raises is the way the design of court facilities incorporates principles affording dignity to different participants.

Trustworthiness refers to the public perception of courts' openness, sincerity, and motivation to serve the best interests of the jury and community. The notion of trustworthiness could draw attention to the integrity and credibility of judges in the eyes of jurors, but could also refer to how the public think about the jury system itself and particular verdicts.

Neutrality is the perceived absence of biased treatment. In one sense juries should be neutral. Clearly, jurors should not pre-judge a matter and should come 
with an open mind to the case-unlike early English juries where prior knowledge of the matter was precisely what was required. Jurors are expected, however, to bring common sense. Further, as members of a diverse community, jurors come with a range of expectations, preconceptions, and biases. Potentially this is an advantage, in that the jury deliberation can provide an opportunity for jurors to challenge each other and bring their different experiences of life to assess the credibility of witnesses and the accused to decide how much of their evidence to accept. However, this may sometimes be wishful thinking. Jurors may share stereotyped views about members of minority or disadvantaged populations; they may (often unconsciously) apply assumptions about how a mother should react to the loss of a child, how people of a particular ethnic group treat women, or how priests can be expected to behave with children.

Voice refers to citizens' sense of being heard and having their input valued (Goodman-Delahunty 2010, pp. 404-405). As such, voice is the one aspect of procedural justice that seems least relevant to the role of the jury. For the most part, jurors silently and passively observe the criminal trial (Dann \& Hans 2004, p. 12). They do not disagree openly with the judge, talk to the witnesses in the corridor, talk to fellow jurors as they listen to the evidence, or 'friend' the prosecutor or the defence lawyer on Facebook. Indeed, jurors who do any of these things could find themselves in trouble. When they sit on a jury trial, the normal forms of voice that jurors use in their everyday lives are closed to them. Yet voice is fundamental to jury deliberation, and to the oral process that is a public trial. What witnesses say on the stand constitutes the raw material for the jury to consider and evaluate in order to make their findings of fact. In doing so, the jury finally gets their chance to use their voice, as they review, assess, deliberate, and try to reach consensus. Yet it is a constrained voice. Common law juries almost never give reasons for their decision. Voice for the accused in a jury trial also takes an unusual form, namely the right to remain silent, a right that many counsels advise their clients to exercise. For the jury this may mean that they do not hear 'both' sides of a case; they hear mostly the prosecution evidence and have to decide if it reaches the standard prescribed by the court.

The four elements identified in the procedural justice literature shine light on some aspects of jury trials. We distinguish respectful treatment of jurors and the perceived legitimacy of jury trials in general from fairness to the accused. We deal with each of these in turn as we review contemporary jury interventions in the following sections. Chief among these are innovations to enhance the physical environment and quality of technology in courtrooms (Section 2.2); to entrust juries with evidence presumed to be prejudicial and supplement jury directions with fact-based question trails (Section 2.3); and to increase jury participation in the trial (Section 2.4). Finally, we discuss legitimacy of the jury and confidence in the jury system.

\subsection{Procedural justice through the physical environment}

An extensive body of research examines how juries make decisions. By contrast, relatively little research explores how jurors are influenced by elements of their environment, such as the design of the courtroom or jury room, the placement of 
the accused, or the technology used in court. Attention to these aspects of the jury experience centres on two procedural justice tenets, namely, respect and neutrality.

Several studies have documented the physical discomfort that many jurors experience in poorly designed, physically inadequate jury boxes, and cramped deliberation rooms with no spaces to relax or unwind (Goodman-Delahunty et al. 2008, p. 108). Australian and New Zealand judges reported that the poor courtroom acoustics made communication difficult (Clough et al. 2019, p. 54). In one Sydney courtroom, a large pillar blocks visual contact between witnesses and jurors, so the jury has to view the witness on a video screen. While some of the research uses experimental methods, it is more difficult to access realistic courtroom environments than psychology laboratories more commonly used to explore other jury-related issues.

\subsubsection{Jurors: respectful jury facilities}

\section{The courtroom}

The courtroom has not always been a safe and comfortable place for jurors. English courtrooms were typically cold, draughty, and, at least until the nineteenth century, rife with infectious diseases. Court officials and architects came to believe that a well-designed courtroom was essential to evoke the right emotional responses in jurors, a principle expressed in the nineteenth-century re-design of the Palais de Justice in Paris:

In a nondescript courtroom, cold and mean, the architecture cannot help the juror to comprehend the gravity of his role, the weight of the terrible responsibility that he assumes. In a room in which the forms, proportions and decorations are out of the ordinary, able to astonish and surprise, his emotions are different, he feels that he has been removed from his milieu to an exceptional, abnormal situation.

(Narjoux cited in Taylor 1993, p. 101)

The ideal courtroom was therefore conceptualised as one that took jurors out of their everyday lives to assume the 'terrible responsibility' of their office. As for forms, proportions and decorations being 'out of the ordinary', school children perform worse when visual stimulation in the environment is high, so jurors may be similarly distracted by overly ornate courtrooms (Barrett et al. 2015, p. 129).

Designing respectful jury spaces in the modern courtroom, more prosaically, focuses on providing comfortable spaces that allow jurors to concentrate on their task (Ingham \& Spencer 1977) describe similar aspects in medical waiting rooms). As the design standards for the Western Australian justice system specify:

Jurors should be extended the comfort and courtesies appropriate to people who must concentrate and remain alert for what can in some cases be for extended periods of time.

(Government of Western Australia 2017, p. 68) 
Other design features of the courtroom may reflect the level of respect with which the justice system treats the jury, and may potentially affect jurors' ability to listen attentively to the evidence and contribute to a more relaxed, or conversely stressed, jury. While there are few studies that document how more respectful spaces improve jury performance-specifically how listening more attentively is likely to render a more accurate verdict-we can draw tentative conclusions from research carried out with other groups in other workplaces. For example, in other workplaces, good lighting, thermal comfort, and an absence of noise has been found to contribute to increased comfort and less tired workers (Vischer 2007). We also know that students are more likely to keep 'on task' when they have full-spectrum lighting (Pulay 2015, p. 74). Attention to lighting may likewise be important for jurors' comfort and ability to attend to the trial. Another study has demonstrated that perceived privacy increases satisfaction with the work environment (Ruijter 2006, p. 7). For jurors, an innovation to address privacy could include modesty panels in front of the first row of jury seats.

\section{The jury room}

Special areas for juries to deliberate were not necessary for Greek or Roman juries, who voted immediately after hearing the evidence. Nor were they always available for English juries until the eighteenth century-jurors usually huddled together to reach their decision without retiring. But juries did not deliberate for long. Juries in seventeenth-century England typically heard between 12 and 20 cases in a day (Phillips \& Thomas 1986, p. 207). If they could not agree, it was standard practice until 1870 to lock them up overnight 'without meat, drink, fire and tobacco' (Phillips \& Thomas 1986, p. 210).

With longer trials and more evidence to sort through, jury rooms began to become more comfortable, and juror treatment more respectful. Jury facilities built since the 1990s in three Australian states were rated by jurors more favourably than those in older courthouses. Satisfaction with the comfort of the jury room ranged from a high of $73 \%$ for the 5 -year-old Victorian County Court in Melbourne to a low of $26 \%$ for the Downing Centre in Sydney, converted from a department store in 1985 (Goodman-Delahunty et al. 2008, p. 138). Features of jury rooms with considerable variation between older and newer courts included direct access to outdoor space (garden or balcony) and natural ventilation (access and quality) (Goodman-Delahunty et al. 2008, pp. 119-121). Architectural enhancements such as these have a measurable impact on juror satisfaction, and convey greater respect shown to jurors by the justice system.

The design of furniture in the jury room may impact the ability of individual jurors to have their say-to voice-during deliberation. The position of jurors at a rectangular jury table influences power dynamics and interactions among jurors, with the person seated at the head of the table most likely to be voted foreperson, and people seated at right angles more likely to interact with each other than with those either across the table or alongside (Sommer 1959, p. 401). 
A round or square table might produce more equal interactions (Sommer 1961, p. 108). To address some of these concerns, a report to the Western Australian Law Reform Commission recommended replacing rectangular with round tables for jury deliberation (Kennedy \& Tait 1999, p. 1050). Size constraints in many jury rooms made this impractical, so new jury rooms tend to provide an oval table for jury use. Whether this type of deliberation space gives more voice to less confident jurors or produces mutual respect is largely unknown.

\subsubsection{The accused: neutral spaces in the courtroom for the accused}

How the accused is accommodated in the courtroom can influence jury perceptions of the accused, and consequently the fairness of the trial process and outcome. This issue has generated much judicial and academic commentary and a small number of experimental studies. Key questions are i) how the accused can be granted a voice in the trial proceedings (generally described as instructing counsel), and (ii) whether the placement of the accused in the courtroom conveys respect for their human dignity, and is perceived as neutral rather than prejudicial. The jury is, in a sense, the critical test for each of these.

Nineteenth-century juries tended to see the accused in a designated area variously known as a box, a dock, or bench (Anklagebank or banc des accusés). In European courts, the accused spoke and was questioned from this position; in common law countries, the accused moved to a witness stand. The use of a dock was challenged in a 1914 Pennsylvania case on the grounds that placement of the accused in a dock undermined his right to consult his lawyer (Commonwealth v Boyd, $246 \mathrm{~Pa} 529,535$ (1914)) and thereby his right to voice. Any form of visible constraint was ruled unacceptable in 1970 by the US Supreme Court in Illinois $v$ Allen (397 US 337, 344 (1970)) for undermining the right to dignity. Meanwhile, in 2005 the US Supreme Court held that any mark of restraint, including a dock, undermined the presumption of innocence and could create prejudice in the minds of jurors (Deck v Missouri, 554 US 622, IIIA (2005)). Similar shifts away from the use of an enclosed area for the accused occurred in Germany, Ireland, and Scandinavian countries, while Australia, the UK, and most of Central and Eastern Europe moved towards greater use of security docks of some sort (Tait 2011, p. 468, 478-479). But what evidence is there that isolating the accused in this way may compromise jury neutrality and jeopardise the fairness of the trial for the accused?

Generally, we associate people with the environment in which they appear-the ecological contamination hypothesis (Werthman \& Piliavin 1967, p. 56), or the 'room with a cue' (Gosling et al. 2002, p. 387). Thus, confining accused persons within the courtroom may signal to the jury that they are dangerous. One field experimental study, using a terrorism scenario and mock jurors in a high-security counter-terrorism courtroom, revealed that the accused was about 1.8 times more likely to be convicted (and to appear 'dangerous') if he was seated in a dock, compared to being seated beside his lawyer at the bar table (Rossner et al. 2017). The dock provided a 'box with a cue' for the jury telling them that the accused 
was guilty. A subsequent mock jury study, using a dog-fighting scenario and a low-security courtroom, replicated this finding (Tait et al. 2017). If the accused person was seated in a dock in the courtroom, he was 1.7 times more likely to be convicted for that matter than when sitting alongside his lawyer in court, or in a remote location. These studies support the US Supreme Court's assertion that any form of visible constraint of the accused can be prejudicial.

Fairness for the accused may also potentially be threatened by another aspect of court design - the relative position of the two parties. A fundamental principle of an adversarial contest, such as a trial, is equality of arms. This includes whether either party is given a physical position in court that affords them a symbolic advantage. In older French courts, the Avocat général, the prosecutor, typically sits on a throne, in a red gown fringed with ermine, and, when standing, is the tallest person in the room. By contrast, the defence lawyer is located in the well of the court, usually dressed in black. The cue provided to the jury by this placement could be that the voice of the prosecutor counts more than the voice of the defence lawyer. Largely for this reason, newer French courts tend to place the two parties at the same level. Differences in common law courts are more subtle, but the lawyer whose table is closest to the jury might have an advantage by virtue of proximity.

\subsection{Procedural justice through the management of evidence and jury directions}

A series of innovations in jury trials centres on the trustworthiness of juries and their neutrality. These include procedural features such as management of the evidence to which juries are exposed, to avoid bias, and greater attention to the capacities and welfare of juries, reflected in jury instructions on the law, and the availability of counselling services for jurors.

\subsubsection{Exclusion of prejudicial information}

To ensure the right of the accused to a fair trial, a number of jury procedures have been implemented to avoid the risk of verdicts based on unfair prejudice. This includes the exclusion from a trial of relevant probative evidence. This is more critical in jury systems that follow the English model, with lay jurors deliberating on their own. In most mixed-panel jury systems where jurors and judges deliberate together, wider tolerance is given to evidence admitted during the trial, including evidence about prior convictions of the accused. Exclusion of such information may, however, demonstrate a lack of trust in the jury. In some cases, evidence that is withheld from the jury is available to the trial judge in a judge-alone trial, and the extent to which this evidence may be unfairly prejudicial is not empirically validated. For example, judges would typically not allow jurors to see beheading videos that the prosecution argues are relevant to a case, although the judge may view them themselves in a judge-only trial (Goodman-Delahunty 2017). 
Studies of real jurors in Australia and New Zealand indicate that jurors often believe that they do not get all the relevant evidence they need to arrive at a fair and impartial decision (Horan 2012; Young, Cameron \& Tinsley 1999), particularly in word-against-word cases. Juries are often frustrated by what they perceive as gaps in the trial evidence, and by the application of evidentiary rules that preclude courts and lawyers from placing all salient probative facts before them. For instance, evidence from multiple complainants about their experiences with the same defendant is often excluded to ensure that juries do not engage in impermissible reasoning that is unfairly prejudicial to the accused. This issue was investigated in a realistic live controlled jury simulation study using examples of institutional child sexual abuse by a repeat offender. Mock jurors attended either (a) a standard trial including one complainant; (b) a trial in which additional evidence about grooming behaviour and four uncharged acts of sexual abuse against the same complainant were provided; or (c) a trial in which additional evidence about four uncharged acts by the accused against two additional victims was presented (Goodman-Delahunty \& Martschuk 2020). The major finding was that juries exposed to evidence of additional sexual misconduct by the same perpetrator (tendency evidence) did not engage in unfairly prejudicial reasoning. Jury observations and content analyses of deliberations showed that exposure to evidence of prior offending by the accused did not cause juries to lower the standard of proof or render verdicts that were emotionally driven, illogical, based on accumulation of evidence, or confusion of charged and uncharged acts.

From a procedural justice standpoint, the admission of probative background evidence conveys trust in the jury and respect for their conscientiousness in avoiding bias. Withholding this information not only frustrates juries, but conveys disrespect by insinuating their verdicts are untrustworthy, prone to bias and unfair prejudice. Among the actions that jurors may engage in when they perceive gaps in the relevant information needed to reach a fair decision is to resort to social media to conduct extra-curial research, e.g. internet searches, to which we now turn.

\subsubsection{Jury directions probibiting internet research}

Typically, juries receive judicial directions that forbid internet research accompanied by information about the consequential criminal penalties. For example, section 68C of the Jury Act 1977 (NSW) prohibits a juror from seeking information about the accused or any matters relevant to the trial, and punishes violations with a sentence of up to two years in prison. Academics, legal practitioners, and judges (Sweeney 2011) have acknowledged that the traditional paradigm of judicial instructions with a threat of sanctions is premised on passive pre-internet jurors, but does not work reliably with contemporary active, information-seeking, internet-aware jurors.

Internationally, since access to this technology became widespread, the number of 'Google mistrials' burgeoned. In one Florida drug trial, 9 out of 12 jurors admitted conducting internet research on the case (Blackman \& Brickman 2011, p. 2). 
In high profile trials and in trials where information about the trial is posted on the internet, more jurors are prone to violate the judicial direction (HannafordAgor, Rottman \& Waters 2012, p. 3).

Research with US juries serving on 35 trials revealed that most jurors wanted to use the internet to conduct research to assist them in their jury duties because they were accustomed to using social media in this way on a daily basis (Hannaford-Agor, Rottman \& Waters 2012, p. 6). Approximately one-third of jurors misunderstand the scope of the judicial admonition regarding social media (Hannaford-Agor, Rottman \& Waters 2012, p. 6). This was often because 'Googling' was not regarded as an activity comprising 'research', but was perceived as something more informal, and an exercise of juror engagement or voice. Other jurors believed that using the internet to obtain general information was not prohibited because they understood the prohibited conduct to apply to searches for specific information pertaining to the parties and the particular case (Hannaford-Agor, Rottman \& Waters 2012, p. 6). For instance, many jurors did not recognise that use of the internet to check definitions of terms that were not explained by witnesses or legal counsel constitutes proscribed 'research' because they regard this as non-prejudicial, neutral extrinsic information, necessary to perform their duties.

Researchers have attributed juror non-compliance with judicial directions to several factors. Some emphasise that the judicial direction is counter-intuitive to contemporary jurors, who are accustomed to reliance on the internet (Waters \& Hannaford-Agor 2014, pp. 2735, 2737). Contemporary jurors rely extensively on the internet to inform their decision-making in other aspects of their lives, such as health care, finances, and education. From the individual juror's perspective, such research aims to produce a more trustworthy, well-informed verdict. From the point of view of public confidence in justice, however, it suggests that the integrity of the jury process and the authority of judges could be diminished.

An Australian field study explored what motivated jurors to engage in internet and other independent investigations. A total of $78 \mathrm{New}$ South Wales jurors who served on criminal trials in the period 2005-2006 and 2011 were interviewed. Results disclosed that it is the conscientious jurors who feel most compelled to conduct independent research to reach a fairer and well-informed decision (Hunter 2013, p. 37). A major case-related factor explaining jurors' compulsion to conduct research is incomplete or insufficient evidence. Jurors knowingly defy judicial directions to refrain from independent research because they perceive a higher duty to return a more robust and trustworthy verdict, and are more prone to do so when the evidence presented at trial seems incomplete (Horan 2012, pp. 166-167).

Courts responding to jury use of the internet should respect the need by jurors, especially conscientious jurors, for more information. Allowing juries to submit questions to the court or to witnesses is an innovation proposed to reduce independent juror investigations and internet use (Hoffmeister 2015, p. 994). This innovation (discussed below) increases jury participation in trials, reflects respect for and trust in juries, and increases their voice. 


\subsubsection{Aiding jury decision-making with questions}

After decades of research confirming that juries often struggle to understand and apply legal directions provided at the conclusion of a trial (Peter-Hagene, Salerno \& Phalen 2019, p. 353), a number of jurisdictions have experimented with an innovation that removes this burden from jurors and focuses on their fact-finding abilities. By embedding the law and relevant facts in a series of questions that are posed to juries, called a 'question trail' (Spivak, Ogloff \& Clough 2019, p. 443), the need to provide juries with lengthy instructions on legal definitions and principles is obviated. Among logistic advantages of this approach are that it could shorten deliberation times, thereby reducing demands on court space and resources. However, the primary objective is to encourage the jury to handle the evidence in a systematic way that will allow them to reach a fair decision. In other words, juries are trusted to understand what the evidence is and how it is relevant to the choice they have to make.

Nowadays, more judges are adopting fact-based directions (Clough et al. 2019, p. 50). For example, this approach is routine in New Zealand courts. Evidence about the benefits of this approach comes from a realistic trial simulation with 403 mock jurors who deliberated to a verdict using standard judicial directions or standard directions accompanied by a question trail (Goodman-Delahunty, Cossins \& Martschuk 2016, pp. 222-230). Results showed that question trail use increased the efficiency of jury decision-making and reduced deliberation time. Jurors who used the question trail reported significantly less cognitive effort to reach a unanimous verdict than those who did not. Content analyses of jury deliberations revealed that mock jurors given a question trail spent more time on discussion of the charges, judicial principles, and instructions than jurors given traditional jury directions.

Similarly, mock jurors reported expending less cognitive effort to evaluate the defence case when assisted by the question trail. Such effects are either logistical (less time taken), or provide psychological benefits for the jurors themselves (reduced cognitive load). Whether the decisions made are fairer to the accused is yet to be established. It is possible, for example, in matters where the jury may be considering nullification, where they consider the prosecution is over-zealous or the law is unjust, that a question trail may act as a constraint on their voice.

\subsubsection{Juror counselling}

Increasingly, courts acknowledge that jury participation may come with a cost, as the experience of jury service can cause some jurors significant stress and anxiety. This is due to a number of factors, including unfamiliarity with the task, the burden of isolation and secrecy, uncertainty, financial insecurity, the explicit or traumatic nature of the evidence (Goodman-Delahunty 2017, p. 91), conflicts with other jurors, and the gravity of consequences of a life-altering verdict.

The dominant jurisprudential concern has been the extent of discomfort while evidence is displayed, rather than the impact on a juror's subsequent wellbeing 
and decision-making, or the types of procedural measures to ensure psychological support for jurors, so that juror stress can be avoided or minimised. Surprisingly, a survey of judges in Australia and New Zealand revealed that not all courts inform jurors of the availability of juror counselling services, and that some judges were unaware of available services within their own courts (Clough et al. 2019, p. 55).

Favourable cues to the trustworthiness of authorities come from indications that their intentions are benevolent, caring, and sincere in trying to do what is best for the people with whom they are dealing (Murphy 2018). Contemporary courts are showing more genuine concern for the welfare of jurors, in line with the procedural tenet of trust. They are educating judges and juries to better recognise symptoms of psychological distress, informing them of available counselling services, and providing trial debriefing after a case closes to assist jurors in dealing with the aftermath of jury service (Report of the Standing Committee on Justice and Human Rights 2018, pp. 19-24). Arguably, these measures also reflect a more respectful treatment of juries and increase their satisfaction with jury duty (Miller \& Bornstein 2013, pp. 252, 254, 256).

\subsection{Procedural justice through increased jury participation}

Enabling jurors to participate more actively in a trial increases the procedural justice tenet of voice. Examples of trial procedures that expanded jurors' voice are notetaking and allowing jurors to submit questions to witnesses.

\subsubsection{Taking notes}

The role of juries as observant bystanders during a trial is largely passive. Nevertheless, there are some small shifts to increase jury participation during the trial. Allowing, or more strongly encouraging, jurors to take notes is one practice that has been adopted in many jurisdictions. This assists jurors to keep track of the evidence, particularly over a long trial, rather than relying on the necessarily selective summing up of counsel to remind them of the main lines of argument and points of evidence. In some older courtrooms on a hot afternoon, any manual activity, including notetaking, may help jurors to remain alert and awake. Notetaking can assist jurors to ask questions of witnesses. However, the main benefit of juror notetaking is the expectation that it will assist in deliberation. When jurors take notes, this makes it more likely that important evidence is discussed around the jury table. In addition, faulty memories of some jurors are corrected by reference to contemporaneous notes taken by others. Given that one of the claimed advantages of the jury system is the way the selection process may result in jurors with rather different backgrounds and views being able to challenge each other's prejudices, it is expected that they will similarly be able to correct and challenge each other's notes.

That at least is the theory. In practice, any improvement in the collective memory resulting from juror notetaking is 'modest' (Dann \& Hans 2004, p. 14), although jurors tend to believe the practice improves their recall and judges are 
strongly in favour of it. However, there are no reported downsides to the practice, such as lengthening the deliberation process or giving more weight in the jury room to the views of those who chose to take notes. Jurors who took notes were likely to recall more legally relevant facts (Hope, Eales \& Mirashi 2014, p. 325 ). Whether case outcomes are impacted by notetaking is unclear. In a recent study using a criminal vignette, whether mock jurors took notes made no difference to verdict, verdict certainty or verdict satisfaction (Thorley, Baxter \& Lorek 2016, p. 567). Perhaps civil verdicts may be more susceptible to the influence of notetaking. Mock jurors who took notes distinguished between the legal situations of plaintiffs better than those who did not (Foster, Horowitz \& Bourgeois 1994, p. 576). In another study, damage awards from mock juries who did not take notes were higher than those from their counterparts who did (Horowitz \& Bordens 2002, pp. 383-384).

There are several forms in which notes may be taken. Jurors are likely to take more complete notes if they are given organisational cues in the form of a structured notebook with headings than if they write their notes freestyle (Thorley, Baxter \& Lorek 2016, p. 568). When jurors structured their own notebooks in a systematic way, they had better recall than jurors who were less organised (Rosenhan, Eisner \& Robinson 1994, pp. 58-59). On the other hand, better notes do not necessarily translate into the ability to retrieve information subsequently (Thorley, Baxter \& Lorek 2016, p. 569). Retrieval of information may improve with the use of tablets rather than paper to take notes. With an evidence book on tablets, some jurisdictions allow jurors to add their own notes in digital form, avoiding the need for two different technologies. This has two important consequences, both of which have yet to be studied in detail. The first is that the notes may tag or highlight the evidence, providing not so much a summary as an interpretation or cue. Second, having an evidence book in digital form allows the original evidence to form the basis of jury deliberation, with the annotations providing speedy access to the relevant place in the evidence book. Juries tend to find information more quickly on iPads than paper evidence books (McDonald et al. 2015), and with the additional cues provided by annotations, this process may be hastened still further.

There are some questions about the efficacy of these studies. For example, the effectiveness of notetaking may be greater in real trials than those reported for mock juries. Most mock jury studies are necessarily limited in time, with the length of performance typically about 30 minutes, compared to the typical trial which would run for anywhere from three days to six months. It is easier to recall something that one saw 15 minutes ago than six months ago. Further, mock trial scenarios tend to be ordered and parsimonious, whereas real trials are often confusing and repetitive. With many short mock trials, the failure to obtain significant improvements in memory simply reflects the fact that most participants are already near the top of the range.

In terms of the four elements of procedural justice outlined above, notetaking is relevant to all. It facilitates a voice for jurors, making the opportunity to ask questions of witnesses less stressful (compared to relying solely on memory), as 
well as allowing less confident jurors a prop to use in deliberation. In a mixed jury system, having notes might balance the scales a little, giving lay jurors some written material to access during deliberation to counter the advantage given professional jurors who have read the written dossier. The very act of writing notes empowers the jurors to select the evidence they consider relevant and provide their own interpretation of what they hear rather than relying on the unmediated statements of counsel (or the judge). The opportunity to take notes is a small mark of the respect accorded to the jury by the court; it assumes the members of the jury are not just competent in oral communication, but literate in written communication as well. Jury neutrality may be enhanced if notetaking reduces errors or omissions when recalling the evidence in deliberations. However, while taking notes necessarily involves the selection of what is most relevant, jurors are more likely to write down what they hear as they hear it, allowing them to cross-check what others say later. In the jury room this prompted memory aid may contribute to greater weight being given to the evidence adduced in court, at the expense of retrospective hunches, prejudicial comments, or other statements that could violate neutrality.

\subsubsection{Asking questions}

Traditionally, courts dealt with questions from juries that arose in the course of their post-trial deliberations, often simply by advising the jury to reread the jury directions. Starting in the late 1990s, courts experimented by allowing jurors to submit questions during the trial at the conclusion of a witness examination, after the counsel's presentation of the evidence (Heuer \& Penrod 1994; Mott 2003). Among the noted benefits were that jurors were better informed, thus less prone to bias. An analysis of the frequency and type of questions asked by jurors in North American trials revealed that the mean number per trial was 16 questions, although juries posed twice as many questions in criminal than civil trials. The researcher observed that the questions were intended to enhance the jury role as neutral fact-finder (Mott 2003, p. 119), in line with the procedural justice tenet of neutrality. This innovation was also rated as more respectful of jurors, by regarding them as 'intelligent and contributing members of the justice system' (Mott 2003, p. 1120). Jurors' questions fell into three major categories, seeking clarification of (a) legal standards; (b) the parties' or witnesses' motives; and (c) evidence. A smaller proportion of questions were about legal procedures or the meaning of legal directions. Conversely, if jurors are discouraged from asking questions they may perceive themselves as bystanders and more passive participants in jury trials, which may increase their dissatisfaction with the justice process (Horan 2012).

\subsection{The legitimacy of the jury}

Perceived procedural justice shapes satisfaction with the justice process (Murphy 2018), because it increases the perceived legitimacy of the laws. The perceived legitimacy of the jury is reflected in confidence in the jury system by the public, jurors, and legal practitioners. 


\subsubsection{Confidence of jurors in justice}

One claimed benefit of the jury system, or more particularly participating in the system as a juror, is that it will increase citizen confidence in the justice process. Jurors will, it is claimed, see for themselves how the system works, and develop an enhanced respect for the rule of law. This increased awareness would not relate to one trial or one judge, but to the system as a whole. Perceived legitimacy of the justice process could translate into greater support for judges and courts, and less criticism of the system as a whole when citizens disagree with the outcome of one trial.

Overall, Australian jurors have a moderate degree of confidence in the criminal justice process, as shown in a large-scale study of Australian jury-eligible citizens (Goodman-Delahunty, Cossins \& Martschuk 2016) using the Pretrial Juror Attitude Questionnaire (Lecci \& Myers 2008). Compared to jurors in the United Kingdom (Furnham \& Alison 1994) or the United States (Chapdelaine \& Griffin 1997), Australians held more pro-prosecution attitudes (Goodman-Delahunty, Martschuk \& Cheung 2020). This is a measure of the trustworthiness of one element of the criminal justice process, but given the items used to measure it, is likely to diminish another key feature of the justice system-the presumption of innocence.

At the same time, jurors' exposure to and contact with the court may influence their confidence in the criminal justice process (Diamond 1993). Despite initial reluctance to serve on juries, at the completion of their service, most jurors express a high degree of satisfaction (Cutler \& Hughes 2001; Matthews, Hancock \& Briggs 2004). For instance, a survey of empanelled and non-empanelled jurors in three different states in Australia showed that more extensive participation in the court process (non-empanelled jurors versus empanelled jurors discharged before deliberation versus empanelled jurors who deliberated to a verdict) was associated with significantly higher satisfaction with their jury experience and increased confidence in the criminal justice process (O'Brien et al. 2008). These findings were replicated in an experimental simulation with jury-eligible participants, showing consensus that deliberation assisted them in reaching a verdict and increased their confidence in the verdict (Goodman-Delahunty, Cossins \& Martschuk 2016, pp. 236-237). One possible reason is that individual jurors in a diverse group may have relevant knowledge and experience to assist others with complex evidence or difficult legal constructs, leading to overall better performance of the group (Horan 2012). In addition, participation in deliberation, actively giving jurors from diverse backgrounds a voice in the justice process, increases citizens' commitment to the jury system and the legitimacy of the criminal justice process (Cornwell \& Hans 2011; Hans, Gastil \& Feller 2014).

\subsubsection{Confidence of legal professionals in the jury system}

A procedural justice analysis of juries cannot look simply at how juries themselves feel or respond. In terms of neutrality and trust, it also matters how juries are perceived by the public. Research on confidence in juries within the criminal 
justice process has shown that legal professionals who work most closely with juries have higher confidence in their abilities than those who do not. Justice Wood, who served as Chief Judge at Common Law in New South Wales, Australia, for eight years, remarked on how this experience, during which he was deeply engaged with juries in the most serious criminal cases, left him with strong confidence in the jury system as opposed to judge-alone trials (GoodmanDelahunty 2015 , p. 58). For these reasons, he opposed the weakening of or abolition of juries.

We investigated the extent to which legal professionals (prosecutors, criminal defence lawyers, judges, and jury administrators) endorsed jury trials using a sample of key stakeholders in the criminal justice system in three Australian states (Goodman-Delahunty et al. 2008). These legal professionals expressed significantly greater confidence in juries $(84 \%)$ than judges $(73 \%)$. All were asked whether they personally would choose a jury or a judge-alone trial, first, if they were the victim of a crime, and second if they were the accused. Results revealed a preference for trial by jury in both roles, but stronger if the participant were the accused. This degree of support for juries as an institution indicates that legal professionals see juries as legitimate. Since they are the group that works in close contact with juries, this provides some assurance that the jury is likely to survive, at least in common law countries.

\subsection{Conclusion}

This review has examined different aspects of procedural fairness in jury trials, using the four-fold-category developed by Tyler. Increased respect for jurors themselves has taken the form of better accommodation. Jury neutrality has been enhanced by the placement of the accused in court. Trust in the jury has been augmented by reforms more sensitive to the capacity and conscientiousness of juries as fact-finders, such as doctrines on the exclusion of prejudicial material, the management of internet research by jurors, uses of question trails to guide jury deliberations, and counselling services for distressed jurors. Greater voice for juries is demonstrated by increased opportunities for trial participation, such as the chance to take notes and ask questions. On the other hand, some changes have compromised jury neutrality. In countries such as the UK, Australia, and France, caging the accused in court runs the risk of prejudicing the jury against the accused.

Overall, this review suggests that enhanced relational contact between courts and juries yields increases in jurors' positive civic attitudes, willingness to serve, as well as satisfaction with the justice process. Increases in jury participation have enhanced the legitimacy of the criminal justice process. The support of legal professionals for the jury shows confidence in the jury system. The findings support the view that improved relational engagement in the criminal justice system through managerial practices and innovations that apply procedural justice tenets is critical to the effectiveness, legitimacy, and retention of the petit jury. 


\section{References}

Barrett, P, Davies, F, Zhang, Y \& Barrett, L 2015, 'The impact of classroom design on pupils' learning: final results of a holistic, multi-level analysis', Building and Environment, vol. 89, pp. 118-133.

Blackman, J \& Brickman, E 2011, 'Let's talk: addressing the challenges of internetera jurors', The Jury Expert, vol. 25, no. 2, pp. 1-11.

Bornstein, BH \& Greene, E 2017, The jury under fire: myth, controversy, and reform, Oxford University Press, New York.

Chapdelaine, A \& Griffin, SF 1997, 'Beliefs of guilt and recommended sentence as a function of juror bias in the OJ Simpson trial', Journal of Social Issues, vol. 53, no. 3 , pp. 477-485.

Clough, J, Spivak, B, Ogloff, JRP, Ruffles, J, Goodman-Delahunty, J \& Young, W 2019, The jury project 10 years on: practices of Australian and New Zealand judges, Australasian Institute of Judicial Administration, Melbourne, VIC.

Cornwell, E \& Hans, V 2011, 'Representation through participation: a multilevel analysis of jury deliberations', Law and Society Review, vol. 45, no. 3, pp. 667-698.

Cutler, BL \& Hughes, DM 2001, 'Judging jury service: results of the North Carolina administrative office of the courts juror survey', Behavioural Sciences and the Law, vol. 19, no. 2, pp. 305-320.

Dann, BM \& Hans, VP 2004, 'Recent evaluative research on jury trial innovations', Court Review, vol. 41, no. 1, pp. 12-19.

Diamond, SS 1993, 'What jurors think: expectations and reactions of citizens who serve as jurors', in RE Litan (ed.), Verdict: assessing the civil jury system, Brookings Institute, Washington, DC, pp. 282-305.

FosterLee, L, Horowitz, IA \& Bourgeois, M 1994, 'Effects of notetaking on verdicts and evidence processing in a civil trial', Law and Human Behavior, vol. 18, no. 5, pp. 567-578.

Furnham, A \& Alison, L 1994, 'Theories of crime, attitudes to punishment and juror bias amongst police, offenders and the general public', Personality and Individual Differences, vol. 17, no. 1, pp. 35-48.

Goodman-Delahunty, J 2010, 'Four ingredients: new recipes for procedural justice in Australian policing', Policing: A Journal of Policing and Practice, vol. 4, no. 4, pp. 403-410.

Goodman-Delahunty, J 2015, 'The Honourable James R Wood AO QC: New South Wales Supreme Court judge', in D Lowe and DK Das (eds), Trends in the judiciary: interviews with judges across the globe (vol. 2), CRC Press, New York, pp. 57-76.

Goodman-Delahunty, J 2017, 'Assessing unfair prejudice from extremist images in terrorism trials', in D Tait \& J Goodman-Delahunty (eds), Juries, science and popular culture in the age of terror, Palgrave MacMillan, London, pp. 87-121.

Goodman-Delahunty, J, Brewer, N, Clough, J, Horan, J, Ogloff, JRP, Tait, D \& Pratley, J 2008, Practices, policies and procedures that influence juror satisfaction in Australia, Research and public policy series report no. 87, Australian Institute of Criminology Research and Public Policy Series, Canberra, ACT.

Goodman-Delahunty, J, Cossins, A \& Martschuk, N 2016, Jury reasoning in joint and separate trials of institutional child sexual abuse: an empirical study, Royal Commission into Institutional Responses to Child Sexual Abuse report, Sydney. 
Goodman-Delahunty, J \& Martschuk, N 2020, 'Mock jury and juror responses to uncharged acts of sexual misconduct: advances in the assessment of unfair prejudice', Zeitschrift für Psychologie, vol. 228, pp. 199-209.

Goodman-Delahunty, J, Martschuk, N \& Cheung, S 2020, 'Juror bias, demographic correlates, and verdict: findings from a large Australian sample', Unpublished manuscript.

Gosling, SD, Ko, SJ, Mannarelli, T \&Morris, ME 2002, 'A room with a cue: personality judgments based on offices and bedrooms', Journal of Personality and Social Psychology, vol. 82, no. 3, pp. 379-398.

Government of Western Australia 2017, 'Department of justice, design brief for courthouses in Western Australia', viewed 3 October 2019. Available at https:// courts.justice.wa.gov.au/_files/courts_design_brief.pdf

Hannaford-Agor, P, Rottman, D \& Waters, NL 2012, Juror and jury use of new media: a baseline exploration, National Center for State Courts, Williamsburg, VA.

Hans, VP, Gastil, J \& Feller, T 2014, 'Deliberative democracy and the American civil jury', Journal of Empirical Legal Studies, vol. 11, no. 4, pp. 697-717.

Heuer, L \& Penrod, S 1994, 'Juror notetaking and question asking during trials: a national field experiment', Law \& Human Behavior, vol. 18, pp. 121-150.

Hoffmeister, T 2015, 'Preventing juror misconduct in a digital world', Chicago-Kent Law Review, vol. 90, no. 3, pp. 981-1000.

Hope, L, Eales, N \& Mirashi, A 2014, 'Assisting jurors: promoting recall of trial information through the use of a trial ordered notebook', Legal and Criminological Psychology, vol. 9, no. 2, pp. 316-331.

Horan, J 2012, Juries in the twenty first century, Federation Press, Sydney.

Horowitz, IA \& Bordens, KS 2002, 'The effects of jury size, evidence complexity, and note taking on jury process and performance in a civil trial', Journal of Applied Psychology, vol. 87, no. 1, pp. 121-130.

Hunter, J 2013, Jurors' notions of justice: an empirical study of motivations to investigate \& obedience to judicial directions, UNSW Jury Study, Law \& Justice Foundation, Sydney, NSW.

Ingham, B \& Spencer, C 1997, 'Do comfortable chairs and soft lights in the waiting area really help reduce anxiety and improve the practice's image?', Health Psychology Update, vol. 28, pp. 17-20.

Kennedy, L \& Tait, D 1999, Court perspectives: architecture, psychology and Western Australian law reform, Western Australian Law Reform Commission, Perth, WA.

Lecci, L \& Myers, B 2008, 'Individual differences in attitudes relevant to juror decision making: development and validation of the pre-trial juror attitude questionnaire (PJAQ)', Journal of Applied Social Psychology, vol. 38, no. 8, pp. 2010-2238.

Matthews, R, Hancock, L \& Briggs, D 2004, Juror's perceptions, understanding, confidence and satisfaction in the jury system: a study of six courts, Home Office online report 05/04, Home Office, London.

McDonald, LW, Tait, D, Gelb, K, Rossner, M \& McKimmie, BM 2015, 'Digital evidence in the jury room: the impact of mobile technology on the jury', Current Issues in Criminal Justice, vol. 27, no. 2, pp. 179-194.

Miller, MK \& Bornstein, BH 2013, 'The experience of jurors: reducing stress and enhancing satisfaction', in MK Miller and BH Bornstein (eds), Stress, trauma, and wellbeing in the legal system, Oxford University Press, New York, pp. 247-267.

Mott, NL 2003, "The current debate on juror questions: "To ask or not to ask, that is the question", Chicago-Kent Law Review, vol. 78, pp. 1099-1125. 
Murphy, K 2018, 'Procedural justice, legitimacy, and policing', in G Bruinsma \& D Weisburd (eds), Encyclopedia of criminology and criminal justice, Springer, New York, pp. 4024-4034.

Murphy, K, Tyler, TR, and Curtis, A 2009, 'Does procedural justice help authorities when people question the underlying legitimacy of the law?', Regulations of Governance, vol. 3, no. 1, pp. 1-26.

O’Brien, K, Goodman-Delahunty, J, Clough, J \& Pratley, J 2008, 'Factors affecting juror satisfaction and confidence in New South Wales, Victoria and South Australia', Trends and Issues in Crime and Criminal Justice no. 354, Australian Institute of Criminology, Canberra, ACT.

Peter-Hagene, LC, Salerno, JM \& Phalen, H 2019, 'Jury decision making', in N Brewer and AB Douglass (eds), Psychological science and the Law, The Guilford Press, New York, pp. 395-416.

Phillips, JA \& Thomas, C 1986, 'Jurors v. judges in later Stuart England: the Penn/ Mead trial and Bushell's case', Law \& Inequality, vol. 4, no. 1, pp. 189-229.

Pulay, AS 2015, 'The impact of the correlated color temperature of fluorescent lighting and its influence on student on-task behavior in an elementary school classroom', PhD thesis, Oregon State University, Oregon.

Rosenhan, DL, Eisner, SL \& Robinson, RJ 1994, 'Notetaking can aid juror recall', Law and Human Behavior, vol. 18, no. 1, pp. 53-61.

Rossner, M, Tait, D, McKimmie, B \& Sarre, R 2017, 'The dock on trial: courtroom design and the presumption of innocence', Journal of Law and Society, vol. 44, no. 3, pp. 317-344.

Ruijter, RTM 2006, 'The effect of open-plan office designs on employees: a study on hair cortisol, functional', Master's thesis, Vrije Universiteit Amsterdam, Amsterdam.

Sams, D, Neal, T \& Brodsky, S 2013, 'Avoiding jury duty: psychological and legal perspectives', The Jury Expert, vol. 25, no. 1, pp. 4-8.

Sommer, R 1959, 'Studies in personal space', Sociometry, vol. 22, no. 3, pp. 247-260.

Sommer, R 1961, 'Leadership and group geography', Sociometry, vol. 24, no. 1, pp. 99-110.

Spivak, B, Ogloff, JRP and Clough, J 2019, 'Asking the right questions: examining the efficacy of question trails as a method of improving lay comprehension and application of legal concepts', Psychiatry, Psychology and Law, vol. 26, no. 3, pp. 441-456.

Sweeney, DM 2011, 'Worlds collide: the digital native enters the jury box', Reynolds Courts \& Media Law Journal, vol. 1, no. 2, pp. 121-146.

Tait, D 2011, 'Glass cages in the dock?: presenting the defendant to the jury', ChicagoKent Law Review, vol. 86, no. 2, pp. 467-495.

Tait, D, McKimmie, B, Sarre, R, Jones, D, McDonald, LW \& Gelb, K 2017, 'Towards a distributed courtroom', Research report, The Court of the Future Network, viewed 3 November 2019, https://courtofthefuture.org/publications/towardsdistributed-courtroom/

Taylor, KF 1993, In the theater of criminal justice: the Palais de Justice in second empire Paris, Princeton University Press, Princeton, NJ.

The Standing Committee on Justice and Human Rights 2018, Improving support for jurors in Canada, House of Commons, Quebec.

Thorley, C, Baxter, RE \& Lorek, J 2016, 'The impact of note taking style and note availability at retrieval on mock jurors' recall and recognition of trial information', Memory, vol. 24, no. 4, pp. 560-574. 


\section{Jane Goodman-Delahunty et al.}

Tyler, TR 1989, 'The psychology of procedural justice: a test of the group-value model', Journal of Personality and Social Psychology, vol. 57, no. 5, pp. 830-838

Tyler, TR 2008, 'Procedural justice and the courts', Court Review, vol. 44, no. 1, pp. 26-31.

Vischer, JC 2007, 'The effects of the physical environment on job performance: towards a theoretical model of workspace stress', Stress and Health, vol. 23, no. 3, pp. 175-184.

Waters, NL \& Hannaford-Agor, P 2014, 'Jury impartiality in the modern era', in G Bruinsma \& D Weisburd (eds), Encyclopedia of criminology and criminal justice, Springer, New York, pp. 2735-2745.

Werthman, C \& Piliavin, I 1967, 'Gang members and the police', in D Bordua (ed.), The police: six sociological essays, Wiley, New York, pp. 56-98.

Young, W, Cameron, N \& Tinsley, Y 1999, 'Juries in criminal trials, part two-a summary of research findings', New Zealand Law Commission, vol. 2, 26. 


\title{
3 Procedural justice in corrections
}

\author{
Julie Barkworth
}

\subsection{Introduction}

Prison provides an environment that exposes people to a range of physical and psychological conflicts, and prison staff are faced with managing these conflicts. Prisoners, particularly those who do not feel equipped to defend themselves, are likely to experience fear and anxiety as a result of increasing frustrations in an environment that is often overcrowded and where boredom is at a peak (Molleman \& Van Ginneken 2015; Sykes 1958; Toch 1997). Gresham Sykes' (1958) pioneering research on prison social life identified certain 'pains' experienced by prisoners that were considered acceptable and unavoidable consequences of imprisonment. The pains or deprivations identified by Sykes included the losses of liberty, heterosexual relationships, goods and services, autonomy, and security. In more recent times, with the introduction of visitation programmes, incentives and earned privileges schemes, and single-cell accommodation, ${ }^{1}$ some of the traditional pains of imprisonment have been reduced, but they remain present. With a changing prison environment also comes new pains. For example, Crewe (2011a) identified pains of uncertainty and indeterminacy, psychological assessment and self-government. Liebling, Arnold, and Straub (2011) identified pains relating to trust, fear, safety, re-making identity (for survival in prison and then for public acceptance upon release), humanity, relationships and fairness, power and security, hope, meaning making progress, and getting out of prison.

The primary goals of prison staff are to maintain a safe and secure prison environment, provide prisoners with 'care with humanity', provide opportunities for prisoners to address their offending behaviour, and to assist with the day-today operations of the prison (Liebling, Price, \& Bottoms 1999, p. 37). Staff are therefore able to help mitigate some of the pains of imprisonment previously identified through the way they perform their duties. However, meeting these goals within such a complex organisation and with prisoners who may have serious behavioural or psychological problems requires staff to be equipped with a range of skills and approaches for achieving successful outcomes. Procedural justice has recently been proposed as a method by which prison staff can meet these goals in their interactions with prisoners. Research undertaken in a range of regulatory contexts (e.g. taxation, policing, courts) has linked procedural justice

DOI: $10.4324 / 9780429317248-5$ 
with citizens' enhanced emotional well-being, quality of life, the degree to which they perceive authorities as legitimate, and their willingness to cooperate with authorities and comply with the rules and laws enforced by those authorities (e.g. Barkworth \& Murphy 2015, 2016; Jackson et al. 2012; Murphy \& Tyler 2008; Sunshine \& Tyler 2003; Tyler \& Huo 2002). However, only a limited number of studies have examined the relationship between procedural justice (or related concepts), prisoners' well-being, and compliance behaviour (e.g. Barkworth 2018; Beijersbergen et al. 2014, 2015, 2016; Brunton-Smith \& McCarthy 2016; Jenness \& Calavita 2018; Reisig \& Mesko 2009; Weinrath 2016). Considering the potential negative consequences the prison environment can have on prisoners, and the importance of staff-prisoner relationships for ameliorating the situation, finding ways to enhance these relationships is increasingly at the forefront of penology research. Research in the corrections context allows for a unique look at the importance of procedural justice, given that prisoners and prison staff interact on a daily basis, as opposed to the sporadic nature of interactions between authorities and citizens in non-correctional contexts.

This chapter provides an overview of the implications of procedural justice for prisoners' well-being and compliance-related behaviour. Section 3.2 presents an overview of the two key issues prisoners and prison staff are often faced with daily: prisoner well-being, which is often affected due to the nature of the prison environment, and prisoner compliance behaviour (including how staff may go about enforcing compliance). Section 3.3 provides an overview of Tyler's (1990) model of procedural justice, with consideration given as to how procedural justice might be utilised in interactions between prisoners and prison staff. Section 4 then introduces the empirical research conducted to date that examines the link between procedural justice, prisoners' well-being, and reduced psychological distress (see Section 3.4.1), between procedural justice and perceived legitimacy, cooperation, and compliance (see Section 3.4.2) and additional studies examining procedural justice in the context of prisoner grievance processes and in relation to interactions with offender supervisors (see Section 3.4.3). Section 3.5 highlights limitations of the research conducted to date and provides suggestions for future research directions before presenting conclusions in Section 3.6. Overall, the research demonstrates positive outcomes for prisoners and prison authorities when prison staff behave in a procedurally just manner.

\subsection{Two key issues in the prison environment: prisoner well-being and compliance}

Prisoners must undergo significant adjustments when entering prison in order to adapt to and cope with prison life. A significant body of research has shown that prisoners are at increased risk of experiencing depression, anxiety, and stress when compared to the general population (e.g. Gullone, Jones, \& Cummins 2000; Schneider et al. 2011). These risks can be attributed to their experiences of the quality of prison life as a result of reduced activity, support, feelings of safety, and visits from family and friends (Toch 1997; Wooldredge 1999). 
As a result of heightened levels of anxiety, fear, and depression, prisoners are also more likely to experience suicide ideation, with suicide rates among this population higher than in the general population (Fazel, Grann, Kling, \& Hawton 2011, p. 193). How staff interact with and respond to prisoners may subsequently influence the way prisoners react. Staff-prisoner relationships are arguably at 'the heart of prison work' (Liebling \& Price 2001, p. 75). Therefore, staff can ultimately act as a protective factor against prisoner distress and suicidal ideation (Daniel 2006). The respect, fairness, and humanity shown in positive staff-prisoner relationships have been linked with lower levels of stress and improved quality of life and prisoner well-being (Liebling 2011; Liebling, assisted by Arnold 2004; Molleman \& Van Ginneken 2015; Slotboom, Kruttshnitt, Bijleveld, \& Menting 2011).

In addition to acting as a protective factor, what staff do and the way in which they do it can have important implications for the type of order they establish and the chances of successfully implementing the right type of order (Sparks, Bottoms, \& Hay 1996). Order within prisons is clearly important for maintaining a safe and secure environment for both prisoners and staff. Prison staff are greatly outnumbered by prisoners in any correctional facility, indicating that prisoners could overpower staff if they chose to do so (Cressey 1961). As a result, prison provides an environment where force is more likely to be used to enforce rules and regain control. However, the use of excessive force may lead to detrimental psychological consequences for prisoners, or result in increased acts of rulebreaking, resistance, and retribution, particularly by those who already do not view the regime as legitimate (Jackson, Tyler, Bradford, Taylor, \& Shiner 2010, p. 5). Jackson et al. (2010, p. 5) therefore suggest that it may be even more important in the prison environment than elsewhere to find alternatives to the use of coercive power and excessive force, particularly for encouraging voluntary cooperation with staff and willing compliance with prison rules. Given that procedural justice has produced a number of positive outcomes regarding well-being and compliance when examined in a range of regulatory contexts (as outlined in Section 3.1), scholars have more recently begun to consider the potential benefits of procedural justice in the context of prison staff interactions with prisoners.

\subsection{What is procedural justice and what might it look like in prison?}

Procedural justice is commonly understood as the perceived fairness of the treatment received and the perceived fairness of procedures used during a decisionmaking process (Blader \& Tyler 2003, p. 748). Early procedural justice scholars (e.g. Thibaut \& Walker 1975) examined third-party disputes and argued that people placed greater importance on receiving a favourable outcome and what they needed to do to achieve that outcome than on the treatment they received; that is, they were motivated by instrumental concerns. According to Thibaut and Walker (1975) procedural justice is important to people because it allows them to take control of the decision-making process and therefore have influence over the 
outcome of this process. Tyler (1990), however, argues that people are more concerned with how they feel they are being treated rather than with outcomes; that is, they are motivated by relational concerns. Tyler argues that procedural justice matters because it communicates to people that they are valued and respected by those in authority, and subsequently their self-worth is strengthened. Tyler's model of procedural justice incorporates four key elements of respect, neutrality, voice and trustworthiness.

Respectful treatment involves treating people with respect, dignity, and politeness (Tyler \& Lind 1992, p. 141). Pilling (1992, p. 6) has suggested that within a prison environment respectful treatment might be demonstrated by staff referring to prisoners by their preferred name, addressing them in a courteous manner, and asking them to do something rather than ordering them to do so. ${ }^{3}$ In contrast, disrespectful treatment might involve referring to prisoners by numbers, not acknowledging them as they pass by, or not making an effort to get to know them as individuals.

Neutrality refers to making decisions using a consistent set of rules and procedures, rather than basing decisions on personal opinions or prejudices (Tyler \& Fagan 2008 , p. 239). Tyler (2010, p. 130) argues that there are ample opportunities within a prison environment for decisions to be made based on personal prejudice given the nature of those being governed; however, he also acknowledges this is an environment with specifically defined rules upon which authorities can base and explain their decisions. In general, neutrality within the prison environment is important for the consistent and fair application of rules to all prisoners, and for clearly justifying and explaining exceptions to those rules when discretion is utilised.

Voice allows individuals an opportunity to explain their side of the story before a decision is made (Tyler 2010, pp. 129-130). For prisoners, this means being given an opportunity to state their case when a conflict has arisen and having an opportunity to participate in both formal and informal processes that allow prisoners to contribute to decisions made about their time spent in incarceration (Tyler 2010, p. 129). Crewe (201la, p. 514) highlights the fact that prisoners are often frustrated at not being given an opportunity to contribute to decisions about categorisation or release, and this can subsequently result in them feeling they are not being treated with the respect due to them as a person.

Finally, trustworthiness refers to an authority communicating to the individuals they govern that they are acting in their best interests and that they are open and honest in their interactions (Tyler 2007, p. 31). When people perceive authority as trustworthy, they are more willing to conform to the group norms that authority represents (Boeckmann \& Tyler 2002, p. 2071). Prison staff may be able to display trustworthiness by expressing a genuine interest in prisoners' well-being, recognising signs of potential psychological struggles, and checking in with them to see how they are doing. Liebling and Price (2001) noted that prison staff are often hesitant to completely trust prisoners and struggle with the conflict of demonstrating care while maintaining security and order; however, 
when staff can maintain a balance between these roles, they are more likely to maintain positive and trustworthy relationships with prisoners.

Liebling and Arnold (2004) spent considerable time in prisons to identify what makes some prisons better than others at providing a safe and secure environment, focusing on what works best rather than what does not work. They suggested that prison quality had not been previously satisfactorily defined in official measures of the prison, arguing that an important aspect of prison quality is the concept of moral performance and that 'prisons should perform well because it is important to treat human beings well' (p. 473). Liebling and Arnold's study of 'what matters' in prison identified that the moral performance of a prison refers to 'those aspects of a prisoner's mainly interpersonal and material treatment that render a term of imprisonment more or less dehumanising and/or painful' (p. 473). What mattered to prisoners were positive staff-prisoner relationships. This includes staff who treated prisoners with respect, humanity, and fairness, and staff who improved safety and order within the prison. Therefore, when prison staff engage in procedurally just practices, such as treating prisoners with respect and dignity, being consistent in how decisions are made, giving prisoners a chance to state their case, and demonstrating concern and understanding, they are more likely to be seen as fair in their interactions with prisoners (Tyler 2010).

\subsection{Empirical research on prisoner perceptions of procedural justice}

Examining the concept of procedural fairness in corrections has emerged out of two bodies of research: the first from penology scholars (e.g. Liebling \& Arnold 2004; Sparks et al. 1996) and the second from procedural justice scholars (e.g. Barkworth 2018; Reisig \& Mesko 2009). Each body of research considers related concepts around fairness and respect while employing varying measures of each. The research from penology scholars has largely focused on Liebling and Arnold's (2004) study of prison quality and the importance of staff-prisoner relationships for building a healthy and well-functioning prison. As mentioned above, many of the concepts that arose out of Liebling and Arnold's study align with Tyler's (1990) model of procedural justice (e.g. respect, fairness, humanity). Tyler's model of procedural justice has been widely employed across many regulatory contexts, but there is only a small collection of recent studies that have specifically examined its importance in the corrections context. Each of the studies arising from these two bodies of research will be considered in the following sections.

\subsubsection{Well-being and psychological distress}

Liebling and Arnold's (2004) study of prison quality did not specifically examine procedural justice; however, it did identify a range of elements commonly considered part of procedural justice. Their study utilised an Appreciative Inquiry approach to determine 'what matters' to both prisoners and prison staff across 
five prisons in England and Wales. The findings of this approach were then used to develop a quality of life survey that was administered to 512 prisoners and 121 prison staff. The authors found that prisoners' perceptions of the quality of prison life were based on whether they viewed relationships with prison staff as positive. Prisoners who perceived staff were treating them with respect, humanity, and fairness, and who considered staff-prisoner relationships to be balanced, were also likely to indicate they had trust in prison staff and felt they were trusted by staff. This trust was the result of prisoner experiences with staff who were honest, responsible, and confident. Their study highlighted that positive staff-prisoner relationships were related to prisoner views of fairness and humanity, which in turn were related to enhanced prisoner well-being. A later study by Liebling (2011) found that diminutions in perceived respect, fairness, and humanity in staff-prisoner interactions were subsequently associated with heightened levels of stress related to prisoner suicide rates.

Similarly, Slotboom et al. (2011) administered a survey to 251 female Dutch prisoners to examine links between staff treatment and prisoners' psychological distress. Prisoners who felt they were treated disrespectfully reported more depressive symptoms, irritability, post-traumatic stress disorders, and thoughts of self-harm. These studies indicate the importance of the procedural justice element of respectful treatment for reducing prisoners' psychological distress.

Researchers from the Netherlands carried out a longitudinal study from 2010 to 2011 , which sought to examine the importance of procedural justice for prisoner well-being (Beijersbergen et al. 2014). A self-report survey was administered to a total of 824 prisoners who had been in pre-trial detention for three weeks. The survey was then administered again after three months. Elements of procedural justice as measured by Liebling and Arnold (2004) were used by Beijersbergen et al. (2014). They included fairness, respect, humanity, and relationships with prison staff (similar sub-scales were also used by Mol \& Henneken-Hordijk 2008). ${ }^{4}$ Prisoner mental health was assessed with a psychometric assessment. Prisoners who reported positive perceptions of procedural justice after three weeks in custody also reported fewer mental health problems three months later (Beijersbergen et al. 2014). While both Liebling and Arnold (2004) and Beijersbergen et al. (2014) referred to Tyler's (1990) model of procedural justice in their respective studies, neither indicated the measures were specifically derived from Tyler's work.

Barkworth (2018) was the first to specifically apply Tyler's four-factor model of procedural justice in a study considering prisoners' well-being and psychological distress. Procedural justice was therefore measured as respect, trustworthiness, neutrality, and voice. Well-being was measured according to Liebling and Arnold's (2004) measure of well-being, which tapped into whether prisoners considered their experience of prison as painful or feeling like a punishment. Finally, psychological distress was measured using the Kessler-10 (k10) assessment tool. It assessed prisoners' self-reported depressive and anxiety symptoms. Key findings from Barkworth's study revealed that perceived procedural justice 
was positively related to higher levels of prisoner well-being and lower levels of psychological distress.

\subsubsection{Legitimacy, cooperation and compliance}

Several early prison studies also examined the relationship between procedural justice perceptions and legitimacy judgements, cooperation, and compliance. Across these studies, legitimacy tended to be measured in a variety of ways that assessed prisoners' feelings of obligation to obey prison staff, their trust in prison staff, and whether their morals and values aligned with prison staff. When staff, who act as representatives of the institution, are perceived as legitimate, so too is the prison regime or the institution itself (e.g. Brunton-Smith \& McCarthy 2016, p. 9; Sparks \& Bottoms 1995). Sparks et al. (1996, p. 307) consider an authority's use of fair procedures as a 'representation dimension' of encounters and treatment and suggest that prisoners will comply with rules if they a) believe it is right and proper that a prison has rules and laws and b) that the prison officers enforcing those rules are fair in their means of exercising power and therefore can command authority. Hence, prisoners who perceive prison staff and the prison regime to be legitimate also believe the prison should have rules, and those rules should be followed.

Early studies considered the link between fair treatment and legitimacy and between fair treatment, legitimacy, and compliance. For example, Ahmad (1996, cited in Liebling \& Arnold 2004) used structured interview data from 230 prisoners in the UK to examine the fairness of prison life. Prisoners indicated that interpersonal aspects of fairness, such as being treated with respect by staff, and being treated with understanding, concern, and equality, were most important to prisoners. Ahmad also found that prisoner perceptions of staff fairness were also related to regime fairness, which can be linked to views of legitimacy. Butler and Maruna (2009) further found that prisoners were more likely to feel victimised by an authority and were less likely to take responsibility for their actions when they felt treated with disrespect.

Perhaps most notable is the work of Sparks et al. (1996), who conducted extensive fieldwork in two maximum-security prisons in the UK (Long Lartin and Albany). Over six weeks, Sparks and colleagues observed daily routines, engaged in informal discussions with prisoners and staff, and conducted interviews with 83 prisoners and 66 staff. Official data regarding prisoner population characteristics and recorded incidents was also utilised. Long Lartin was viewed as a more relaxed prison with less reported staff-prisoner conflict, and was therefore seen as the more legitimate of the two prisons examined. The relaxed environment of Long Lartin was generally attributed to steps taken to improve the loss of autonomy (e.g. prisoners allowed to wear their own clothes rather than a uniform) and loss of liberty (e.g. more freedom to move around corridors at certain times). Prisoners indicated that good staff were those who helped them, did not promise something they could not deliver, had a sense of humour, and were 
not antagonistic. It was found that prisoners had particularly positive perceptions of staff who treated them with respect and decency. In general, the day-to-day actions of prison staff partially influenced the perceived fairness of those staff, with prisoners who viewed staff as fair also indicating they were more willing to comply with officer directives and prison rules. However, Long Lartin staff were seen to take a more flexible rather than consistent approach to order and control, which was a source of anxiety for some prisoners as they were uncertain as to how far they could go or what was expected of them. In the end, though, prisoners saw this as a 'mutually acceptable compromise' (p. 173). Based on key findings from their study, Sparks et al. highlighted the importance of legitimacy for encouraging compliance, and supported Woolf's (1991) argument that legitimacy can be achieved through prison staff behaving in a procedurally just manner.

In Slovenia, Hacin and Meško (2018) used qualitative interview data from 193 male and female prisoners to examine perceptions of fairness and staff legitimacy (e.g. prisoners' feelings of obligation to follow the rules and instructions imposed by prison staff and prisoners' acceptance of decisions made by prison staff even if they disagreed). They also studied differences between instrumental motives (e.g. avoiding punishment/receiving rewards) and normative motives (e.g. attitudes based on values and beliefs) for compliance. In general, prisoners felt prison staff were professional and treated them with respect but still felt obliged to obey staff and comply with rules even if they did not like how they were treated. Hacin and Meško argued:

Instrumental compliance is considered as the first step toward establishing legitimacy in a prison environment. It is unreasonable to expect that prisoners, who are defined by their fundamental conflict with the state, would internalise the norms of prison workers, whom they consider the direct representatives of the criminal justice system, immediately upon their arrival to prison.

They further claimed '[ $\mathrm{t}]$ he transition from prisoners' instrumental compliance to normative compliance is possible when relations between prison staff and prisoners are based on respect, legality, and fairness' (p. 16). This study provides further support for staff using procedural justice practices to encourage normative compliance, but indicates that additional research into understanding the various reasons why prisoners comply with prison rules should be conducted.

A range of studies considering prisoners' perceptions of the legitimacy of prison staff and compliance behaviour has also been developed out of Liebling and Arnold's (2004) prison quality work (e.g. Beijersbergen et al. 2015, 2016; Brunton-Smith \& McCarthy 2016). Liebling and Arnold, specifically found that perceived fairness of staff, prison rules, and decision-making influenced perceptions of order and control in prison, highlighting that staff-prisoner relationships and the idea of procedural justice are important for regulating the prison environment. 
As part of the Prison Project carried out in the Netherlands from 2010-2011, Beijersbergen et al. $(2015,2016)$ examined the link between procedural justice and prisoners' anger and misconduct (Study 1), and between procedural justice and prisoners' perceptions of legitimacy and likelihood of re-conviction (Study 2). Here, Beijersbergen et al.'s measure of procedural justice was created from four sub-scales relating to fairness, respect, humanity, and relationships with officers. In the first study, prisoner misconduct was measured using both self-report compliance data and official prison disciplinary reports (Beijersbergen et al. 2015). The results showed that prisoners who felt fairly treated three weeks into their time in detention were less likely to engage in misconduct three months later. The authors also confirmed that if prisoners received disciplinary action during the first three weeks of detention this had no impact on whether prisoners felt fairly treated by staff three months later. The study further showed that anger mediated the relationship between perceived procedural justice and subsequent misconduct; that is, those who felt unfairly treated by prison staff early in their detention were more likely to report feeling angry three months later and were therefore more likely to engage in misconduct. In the second study, Beijersbergen et al. (2016) utilised both survey and re-conviction data from 1,241 prisoners to examine the relationship between perceptions of procedural justice during their time in detention, the perceived legitimacy of the criminal justice system, and post-release offending behaviour. The study highlighted a significant link between positive perceptions of procedural justice and a reduced likelihood of re-conviction 18 months after release. Prisoners' perceptions of the legitimacy of the criminal justice system were not found to mediate this relationship. Overall, the findings from the Prison Project demonstrated that procedural justice (as per Liebling and Arnold's (2004) conceptualisation) is important for prisoners' behavioural outcomes, including misconduct within prison and likelihood of post-release offending.

Another study utilising Liebling and Arnold's (2004) measures was conducted by Brunton-Smith and McCarthy (2016) in England and Wales. Their study considered the role of both prison-level and individual-level characteristics to determine prisoners' perceptions of staff legitimacy. The legitimacy measure was taken at the individual level using data from the Surveying Prisoner Crime Reduction (SPCR) project, which included 3,000 prisoners sentenced to between one month and four years from 2005 to 2006 in England and Wales. Prisoners were surveyed within the first two to five weeks of entering prison and again within four weeks prior to release. The legitimacy measure covered prisoner perceptions of staff-prisoner relationships, trust (in staff and by staff), perceptions of fair treatment and support from staff, and perceptions of staff honesty and integrity. The procedural justice measure utilised data from the 2005 to 2009 round of the 'Measuring the Quality of Prison Life' (MQPL) survey (see Liebling, Hulley \& Crewe 2012 for further details of MQPL). An overall summary measure of procedural justice for each prison was utilised, which captured the fairness of the prison (e.g. consistent treatment from staff) and whether procedures were in place for prisoners to express their views during decision-making processes. The study did 
not measure individual prisoners' perceptions of procedural justice, but instead merged the individual-level measure of legitimacy and prison-level measure of procedural justice into one dataset. Brunton-Smith and McCarthy utilised multilevel modelling to demonstrate that when a prison was viewed as procedurally just, prisoners' perceptions of staff legitimacy were higher. In other words, those residing in prisons where the systems in place to respond to problems were seen to be clearer and fairer were more likely to perceive the prison as more legitimate (as per their views of staff legitimacy).

It should be noted here that the procedural justice and legitimacy measures used by Brunton-Smith and McCarthy are not typical of those used in similar research. For example, the legitimacy measure covered aspects around fair treatment, staff-prisoner relationships, humanity, and support that are often incorporated in measures of procedural justice; on the other hand, the procedural justice measure placed greater emphasis on procedures and privileges that are not often examined as part of common procedural justice measures. Interpreting the findings of this study should therefore be done with these variations in mind.

The studies discussed thus far demonstrated the importance of the perceived fairness of staff and prisons for improving prisoner perceptions of staff legitimacy and their willingness to comply with the prisons' rules. While these studies often refer to procedural justice in regard to measuring respect, fairness, and relationships; only a few recent studies have specifically incorporated Tyler's (1990) fourfactor model of procedural justice. For example, Weinrath (2016) conducted in-depth interviews with 38 prisoners and 24 correctional staff in four Western Canadian prisons to examine perceptions of procedural justice and legitimacy within staff-prisoner relationships. Weinrath found that when prisoners viewed staff behaviour as being consistent with the principles of procedural justice, they were more likely to perceive those staff as legitimate. In particular, prisoners felt that being treated with respect was the most important element of procedural justice. Weinrath's study identified the importance of procedural justice for improving staff-prisoner relationships and the perceived legitimacy of staff.

One of the first empirical studies to examine the relationship between prisoner perceptions of procedural justice, the perceived legitimacy of prison staff, and prisoner misconduct was conducted by Reisig and Mesko (2009) in a highsecurity Slovenian prison. They utilised self-report survey data collected in structured face-to-face interviews and official records from the six months following the interviews to capture both self-report and official measures of misconduct. Legitimacy was measured as a prisoner's sense of obligation to obey staff, and procedural justice incorporated the four key elements of respect, neutrality, voice, and trustworthiness. The results demonstrated that when prisoners viewed staff as more procedurally just, they were less likely to later engage in behavioural misconduct (the finding was supported with both self-report and official data). Interestingly, no relationship was found between perceptions of procedural justice and perceived legitimacy, or between legitimacy and prisoner misconduct. The findings from Reisig and Mesko's study suggest it is the perceived fairness of treatment that matters most for encouraging prisoner compliance. 
A recent study in Australia has also sought to empirically examine the effect of prisoner perceptions of procedural justice on the perceived legitimacy of staff (i.e. obligation to obey staff and accept staff decisions), on prisoners' cooperation, and on compliance behaviour (Barkworth 2018). Procedural justice captured Tyler's (1990) four key elements of respect, neutrality, voice, and trustworthiness. Legitimacy was measured as prisoners' sense of obligation to obey prison staff. Cooperation referred to prisoners' willingness to provide information to staff about the goings-on in prison. Compliance captured prisoners' willingness to follow the prison rules (self-report) and the number of breaches they had received (official data). It was found that prisoners who perceived staff as being procedurally just were more likely to also perceive them as legitimate and were more willing to cooperate with staff and comply with prison rules (supported with both self-report and official data).

Barkworth and Murphy (2019) further examined whether perceptions of procedural justice relate to prisoners' social distancing from staff and their subsequent compliance behaviour. Here, social distancing was operationalised using Braithwaite's (2003) motivational posturing styles that include commitment, capitulation, resistance, disengagement, and game-playing. The findings showed that prisoners who viewed staff as more procedurally just were more likely to subscribe to deferent postures of commitment and capitulation, and less likely to subscribe to defiant postures of resistance, disengagement, and game-playing. It was also found that those with deferent postures were more willing to comply with prison rules than those with defiant postures. These studies further support the positive implications for prisoners' behaviour through prison staff employing procedural justice practices.

The procedural justice perspective highlights the importance of normative compliance. Normative compliance occurs when people consider that rules and laws align with their own personal values, and when the authorities who enforce those rules and laws are seen as just and moral (Tyler 2007, p. 161). A particularly important factor for encouraging normative compliance is the perceived legitimacy of the authority charged with enforcing the rules and laws to be followed (Liebling \& Arnold 2004; Sparks et al. 1996; Tyler 1990). An authority is seen as legitimate when it is perceived as being entitled to make decisions and when people feel obligated to follow those decisions (Sunshine \& Tyler 2003; Tyler 1997). Legitimacy is considered most important for encouraging both cooperation and compliance behaviour because it is 'ethically more desirable, more cost-effective, and ultimately more durable than systems maintained "down the barrel of a gun"' (Jackson et al. 2010, p. 4). Sparks et al. (1996, p. 307) refer to the 'representational dimension' of people's encounters with criminal justice agencies: prisoners will comply partly because they believe a prison should have rules and laws, and partly because the staff enforcing those rules and laws are fair in how they exercise power and can therefore command authority.

Ultimately, procedural justice is important for building legitimacy and encouraging subsequent cooperation and compliance behaviour. Tyler (2003, p. 306) argues that when people view authorities as exercising power through 


\section{Julie Barkworth}

fair procedures, they are more likely to adopt the social values those authorities represent, which subsequently helps create and maintain a self-regulating and law-abiding society. Tyler and Blader $(2003$, p. 353) further argue that these social values represent what people feel they should do, and therefore 'reflect feelings of responsibility and obligation to follow group rules and the orders of group leaders'.

One of the key theoretical explanations for why procedural justice has a positive association with cooperation and compliance behaviour is Tyler and Blader's (2003) Group Engagement Model. The model is based on relational concerns and suggests that people's identification, or sense of belongingness, with a group is shaped through procedural justice. In this sense, people value being treated with respect and fairness and being given a voice as it communicates to them that they are valued and respected members of a group. Tyler and Blader (2003, p. 353) argue that 'Groups help to define who people are and help them to evaluate their status'. Hence, people feel good about themselves through associations with groups they perceive as having high status (Tyler \& Blader 2003). What should be considered in this context is whether prisoners attribute high status to prison staff and whether they are more likely to identify with prison staff rather than other prisoners. This is where using procedural justice practices may be particularly important; that is, prisoners may be more likely to perceive staff as having high status and may be more likely to identify with those staff when they perceive them to be procedurally just.

\subsubsection{Additional procedural justice studies}

Although not specifically examining prisoners' psychological and behavioural outcomes, it is important to mention additional research on procedural justice in the corrections context. For example, Jenness and Calavita (2018) compared prisoners' satisfaction with the process (procedural justice) and outcome (substantive justice) of grievances filed, for example, around staff misconduct, contesting a serious disciplinary violation or complaint about prison classification. Here, it was found that the outcome received was more important for prisoners' satisfaction than how the process was handled; that is, even those who considered the grievance to be adequately managed were unlikely to be satisfied with an unfavourable outcome. This particular finding opposes what is often found in the policing literature, that people can accept an unfavourable outcome if they believe that outcome has been arrived at through fair treatment and procedures (e.g. Tyler \& Huo 2002; Barkworth \& Murphy 2015). The authors did offer several explanations for their findings, including that prison is a high stakes environment and when the stakes are high it is more likely that perceptions of procedure and outcome will be combined (Heinz 1985 cited in Jenness \& Calavita 2018, p. 48). However, the findings do suggest that prisoners tend to place greater importance on instrumental concerns when an outcome has a direct impact on them. The conflicting findings from this study, compared to what is often found 
in the policing context, suggests that additional research into understanding prison grievance processes could be done.

Much of the research to date has focused on prisoner perceptions of interactions with correctional officers. However, a recent study by Bickers, Crewe, and Mitchell (2019) examined prisoner perceptions of procedural justice during interactions with offender supervisors (i.e. those responsible for risk assessments). It highlighted that staff involved in risk assessment were seen as unqualified to make such decisions and therefore lacked legitimacy (Crewe 2009, 2011b). Bickers et al. found that prisoner perceptions of procedural justice were low with regard to staff involved in risk assessment, which had negative impacts on developing positive relationships. Bickers et al. (2019, p. 17) argued that when staff prioritise actuarial risk assessments over developing quality relationships a range of negative outcomes is likely, including disengaging from offender supervisors, withholding information, and bypassing formal management systems. They suggested that all staff working with prisoners should have a clear understanding of the key elements of procedural justice.

\subsection{Limitations of the current research and future directions}

This chapter has reviewed the research conducted to date on prisoner perceptions of procedural justice and subsequent psychological and behavioural outcomes. The research discussed in this chapter is not, however, without limitations. For example, there are variations in how procedural justice and legitimacy have been measured across different studies. On the one hand, several studies have utilised measures based on Liebling and Arnold's (2004) work on prison quality, incorporating elements of respect, fairness, humanity, and staff-prisoner relationships (e.g. Beijersbergen et al. 2014, 2015, 2016; Brunton-Smith \& McCarthy 2016). Others more specifically considered Tyler's (1990) model of procedural justice, examining the key elements of respect, trustworthiness, neutrality, and voice (e.g. Barkworth 2018; Reisig \& Mesko 2009; Weinrath 2016). Some measured legitimacy as felt obligation to obey prison staff (e.g. Barkworth 2018; Hacin \& Meško 2018; Reisig \& Mesko 2009), while others incorporated trust, fair treatment from staff, and perceptions of staff honesty and integrity in their measure of legitimacy (e.g. Brunton-Smith \& McCarthy 2016). Such differences in how both procedural justice and legitimacy have been measured means caution should be observed when considering the variations in findings across studies.

Most of the research has also only been conducted in high-security male prisons (e.g. Barkworth 2018; Beijersbergen et al. 2014, 2015, 2016; Liebling \& Arnold 2004; Reisig \& Mesko 2009; Sparks et al. 1996), and has largely been limited by the use of cross-sectional research designs, which only provide a snapshot of what is happening at one point in time. Cross-sectional research designs do not consider whether it is procedural justice that influences outcome variables (such as well-being, psychological distress, legitimacy, or cooperation and compliance) or 
whether prisoners have pre-existing mental health conditions, attitudes, or behavioural tendencies that influence their perceptions of procedural justice. Nagin and Telep $(2017$, p. 7 ) argue that perceptions of procedural justice and legitimacy are likely the result of a lifetime of influences based on culture, community, and family, rather than just one or more interactions with an authority. They further argue that it would be particularly difficult in disadvantaged communities to separate the influence of procedural justice on legitimacy and compliance from influences such as extreme poverty, racial isolation, and various forms of social dysfunction. Nagin and Telep $(2017$, p. 12) therefore argue that alternate common causes and reverse causality may be responsible for the links found between perceptions of procedural justice, perceived legitimacy, and compliance. In other words, those who are compliant to begin with are more likely to view an authority as procedurally just and legitimate, which then influences subsequent compliance behaviour. Beijersbergen et al. (2015) did, however, conduct a cross-lagged analysis and found that positive perceptions of procedural justice measured within three weeks of entering prison were related to fewer instances of misconduct three months later, although misconduct during the first three weeks of incarceration was not related to perceptions of procedural justice three months later. This study provides the first evidence from a corrections context that procedural justice influences compliance, but compliance does not influence perceptions of procedural justice. Longitudinal research designs are needed in order to determine any changes in prisoners' perceptions, conditions, attitudes, and behaviour that occur over time. Beijersbergen et al.'s $(2014,2015,2016)$ Prison Project is the only longitudinal study to examine perceptions of procedural justice on prisoners' mental health, misconduct behaviour, and likelihood of re-conviction after release. Their research, however, is limited by the fact that it only examined prisoners who had spent a maximum of three months in pre-trial detention, and therefore did not further consider the impacts that long-term incarceration may have on individuals.

Future research should further examine Tyler's (1990) model of procedural justice, as well as address methodological issues, including: the use of longitudinal designs; controlling for cultural, community and familial differences, and previous experiences with authorities; and evaluating an experimental manipulation of procedural justice. Future research should also consider perceptions of procedural justice from female prisoners, prisoners who have spent varying lengths of time in prison, those from medium, low, and work camp facilities, and those who have varying histories with engagement with criminal justice authorities. Finally, very little research has considered prison staff perspectives on procedural justice in corrections. Only a couple of studies have turned their attention to examining how prison staff perceive procedural justice and their willingness to use it (e.g. Lambert, Hogan, \& Barton-Bellessa 2011; Meško, Hacin, Tankebe, \& Fields 2017; Trammell et al. 2018). Additional research is needed to understand whether staff see value in using such practices; what barriers they may face in implementing procedural justice practices; and the potential risks they may associate with the use of such practices (e.g. whether it may make staff vulnerable to forming inappropriate relationships with prisoners). Given that prison staff are 
responsible for creating and maintaining positive relationships with prisoners that can enhance prisoner well-being and assist with keeping order, it is important to understand the role of procedural justice from their perspective.

\subsection{Conclusion}

Prison staff play an important role in creating a safe, secure, and well-functioning prison through improving prisoner psychological well-being and maintaining prison order. It is therefore vital for staff to find ways to ensure positive outcomes for prisoners, with procedural justice identified as a key way to achieve such a goal. This is important because the way in which staff treat prisoners can most easily be changed and implemented. The research reviewed in this chapter has shown that procedural justice can have positive outcomes for both prisoners and prisons. For example, procedural justice was related to enhanced prisoner wellbeing and reduced psychological distress. In addition, perceptions of procedural justice were related to the perceived legitimacy of prisons and prison staff, as well as an increased willingness to voluntarily cooperate with staff and comply with prison rules. While the research examining procedural justice in the corrections context has produced some promising findings, there is evidently much more research that can be undertaken in this area.

\section{Notes}

1 While single-cell accommodation has been introduced, over-crowding is still a consistent issue in prisons.

2 It should be noted that the correct referencing of this source is Liebling, assisted by Arnold 2004, as noted here; however, for ease of reading, this source will be cited as Liebling and Arnold 2004 from this point on.

3 It should be noted that prisons are hierarchical institutions and by their very nature may require staff to enforce prison rules through a range of methods including ordering prisoners to comply and using force when they do not comply. The suggestion to ask a prisoner to do something rather than ordering them to do so should be a first-step approach when circumstances do not require anything more authoritative or forceful (e.g. prisoner is going about their day-to-day activities and not causing any problems).

4 The study by Mol and Henneken-Hordijk (2008) has not been discussed as it was only published in Dutch.

\section{References}

Barkworth, J 2018, 'Prisons, procedural justice and motivational posturing: examining prisoners' well-being and compliance behaviour' (Unpublished doctoral dissertation), Griffith University, Brisbane, QLD.

Barkworth, J \& Murphy, K 2015, 'Procedural justice policing and citizen compliance behaviour: the importance of emotion', Psychology, Crime \& Law, vol. 21, no. 3, pp. 254-273. doi: 10.1080/1068316X.2014.951649

Barkworth, J \& Murphy, K 2016, 'System contact and procedural justice policing: improving quality of life outcomes for victims of crime', International Review of Victimology, vol. 22, no. 2, pp. 105-122. doi: 10.1177/0269758015627044 
Barkworth, J \& Murphy, K 2019, 'Procedural justice, posturing and defiant action: exploring prisoner reactions to prison authority', Justice Quarterly. Advanced online publication. doi: 10.1080/07418825.2019.1666905

Beijersbergen, KA, Dirkzwager, AJE, Eichelsheim, VI, Van der Laan, PH \& Nieuwbeerta, P 2014, 'Procedural justice and prisoners' mental health problems: a longitudinal study', Criminal Behaviour and Mental Health, vol. 24, no. 2, pp. 100-112. doi: 10.1002/cbm.1881

Beijersbergen, KA, Dirkzwager, AJE, Eichelsheim, VI, Van der Laan, PH \& Nieuwbeerta, P 2015, 'Procedural justice, anger, and prisoners' misconduct: a longitudinal study', Criminal Justice and Behaviour, vol. 42, no. 2, pp. 196-218. doi: $10.1177 / 0093854814550710$

Beijersbergen, KA, Dirkzwager, AJE \& Nieuwbeerta, P 2016, 'Reoffending after release: does procedural justice during imprisonment matter?', Criminal Justice and Behavior, vol. 43 , no. 1, pp. 63-82.

Bickers, I, Crewe, B \& Mitchell, RJ 2019, 'Offender supervision, prisoners and procedural justice', The Howard Journal, vol. 58, no. 4, pp. 1-19. doi: 10.1111/ hojo. 12343

Blader, SL \& Tyler, TR 2003, 'A four-component model of procedural justice: defining the meaning of a "fair" process', Personality and Social Psychology Bulletin, vol. 29 , no. 6 , pp. 747-758. doi: $10.1177 / 0146167203252811$

Boeckmann, RJ \& Tyler, TR 2002, 'Trust, respect, and the psychology of political engagement', Journal of Applied Social Psychology, vol. 32, no. 10, pp. 2067-2088.

Braithwaite, V 2003, 'Dancing with tax authorities: motivational postures and noncompliant actions', in V Braithwaite (ed.), Taxing democracy: understanding tax avoidance and evasion, Aldershot, Ashgate.

Brunton-Smith, I \& McCarthy, DJ 2016, 'Prison legitimacy and procedural fairness: a multi-level examination of prisoners in England and Wales', Justice Quarterly, vol. 33, no. 6, pp. 1029-1054. doi: 10.1080/07418825.2015.1023215

Butler, M \& Maruna, S 2009, 'The impact of disrespect on prisoners' aggression: outcomes of experimentally inducing violence-supportive cognitions', Psychology, Crime and Law, vol. 15, no. 2-3, pp. 235-250. doi: 10.1080/10683160802190970

Cressey, D (ed.) 1961, The prison: studies in institutional organizational change, Holt, Rinehart and Winston, New York.

Crewe, B 2009, The prisoner society: power, adaptation and social life in an English prison, Oxford University Press, Oxford.

Crewe, B 2011a, 'Depth, weight, tightness: revisiting the pains of imprisonment', Punishment and Society, vol. 13, no. 5, pp. 509-529. doi: 10.1177/1462474 511422172

Crewe, B 2011b, 'Soft power in prison: implications for staff-prisoner relationships, liberty and legitimacy, European Journal of Criminology, vol. 8, no. 6, pp. 455-468.

Daniel, AE 2006, 'Preventing suicide in prison: a collaborative responsibility of administrative, custodial, and clinical staff', The Journal of the American Academy of Psychiatry and the Law, vol. 34, no. 2, pp. 165-175.

Fazel, S, Grann, M, Kling, B \& Hawton, K 2011, 'Prison suicide in 12 countries: an ecological study of 861 suicides during 2003-2007', Social Psychiatry, vol. 46, pp. 191-195. doi: 10.1007/s00127-010-0184-4

Gullone, E, Jones, T \& Cummins, R 2000, 'Coping styles and prison experience as predictors of psychological well-being in male prisoners', Psychiatry, Psychology and Law, vol. 7, no. 2, pp. 170-181. doi: 10.1080/13218710009524983 
Hacin, R \& Meško, G 2018, 'Prisoners' perception of legitimacy of the prison staff: a qualitative study in Slovene prisons', International Journal of Offender Therapy and Comparative Criminology, vol. 62, no. 13, pp. 4332-4350. doi: $10.1177 / 0306624 X 18758896$

Jackson, J, Bradford, B, Hough, M, Myhill, A, Quinton, P \& Tyler, TR 2012, 'Why do people comply with the law?: legitimacy and the influence of legal institutions', British Journal of Criminology, vol. 52, no. 6, pp. 1051-1071.

Jackson, J, Tyler, TR, Bradford, B, Taylor, D \& Shiner, M 2010, 'Legitimacy and procedural justice in prisons', Prison Service Journal, vol. 191, pp. 4-10.

Jenness, V \& Calavita, K 2018, 'It depends on the outcome: prisoners, grievances, and perceptions of justice', Law \& Society Review, vol. 52, no. 1, pp. 41-71.

Lambert, EG, Hogan, NL \& Barton-Bellessa, SM 2011, 'The association between perceptions of distributive justice and procedural justice with support of treatment and support of punishment among correctional staff', Journal of Offender Rehabilitation, vol.50,no.4,pp. 202-220.doi: 10.1080/10509674.2011.552586

Liebling, A 2011, 'Moral performance, inhuman and degrading treatment, and prison pain', Punishment \& Society, vol. 13, no. 5, pp. 530-550. doi: $10.1177 / 1462474511422159$

Liebling, A, assisted by Arnold, H 2004, Prisons and their moral performance: a study of values, quality, and prison life, Oxford University Press, Oxford.

Liebling, A, Arnold, H \& Straub, C 2011, An exploration of staff-prisoner relationships at HMP Whitemoor: 12 years on, Cambridge Institute of Criminology, Prison Research Centre, Cambridge.

Liebling, A, Hulley, S \& Crewe, B 2012, 'Conceptualising and measuring the quality of prison life', in D Gadd, S Karstedt \& SF Messner (eds), The SAGE handbook of criminological research methods, Sage, London.

Liebling, A \& Price, D 2001, The prison officer, Leyhill, Prison Service and Waterside Press.

Liebling, A, Price, D \& Bottoms, A 1999, An exploration of staff-prisoner relationships at HMP Whitemoor, Institute of Criminology, Cambridge.

Mesko, G, Hacin, R, Tankebe, J \& Fields, C 2017, 'Self-legitimacy, organisational commitment and commitment to fair treatment of prisoners: an empirical study of prison officers in Slovenia', European Journal of Crime, Criminal Law and Criminal Justice, vol. 25, pp. 11-30.

Mol, GD \& Henneken-Hordijk, I 2008, 'Gedetineerd in Nederland 2007', Een survey onder alle gedetineerden in het Nederlandse gevangeniswezen, Dienst Justitiele Inrichtingen, Den Haag. [Mol, GD \& Henneken-Hordijk, I 2008, Imprisonment in the Netherlands 2007. A survey among all prisoners in Dutch correctional facilities, The Hague, The Netherlands, Ministry of Security and Justice, National Agency of Correctional Institutions.]

Molleman, T \& Van Ginneken, EFJC 2015, 'A multi-level analysis of the relationship between cell sharing, staff-prisoner relationships, and prisoners' perceptions of prison quality', International Journal of Offender Therapy and Comparative Criminology, vol. 59, no. 10, pp. 1029-1046. doi: 10.1177/0306624X14525912

Murphy, K \& Tyler, T 2008, 'Procedural justice and compliance behaviour: the mediating role of emotions', European Journal of Social Psychology, vol. 38, pp. 652-668. doi: 10.1002/ejsp.502

Nagin, DS \& Telep, CW 2017, 'Procedural justice and legal compliance', Annual Review of Law and Social Science, vol. 13, pp. 5-28. 
Pilling, J 1992, 'Back to basics: relationships in the prison service', in Home Office (ed.), Perspectives on prison: a collection of views on prison life and running prisons, HMSO, London.

Reisig, MD \& Mesko, G 2009, 'Procedural justice, legitimacy and prisoner misconduct', Psychology, Crime \& Law, vol. 15, no. 1, pp. 41-59. doi: $10.1080 / 10683160802089768$

Schneider, K, Richters, J, Butler, T, Yap, L, Richards, A, Grant, L \& Smith, A 2011, 'Psychological distress and experience of sexual and physical assault among Australian prisoners', Criminal Behaviour and Mental Health, vol. 21, no. 5, pp. 333-349.

Slotboom, AM, Kruttschnitt, C, Bijleveld, C \& Menting, B 2011, 'Psychological wellbeing of incarcerated women in the Netherlands: importation or deprivation?', Punishment \& Society, vol. 13, no. 2, pp. 176-197.

Sparks, R \& Bottoms, A 1995, 'Legitimacy and order in prisons', The British Journal of Sociology, vol. 46, no. 1, pp. 45-62.

Sparks, R, Bottoms, A \& Hay, W 1996, Prisons and the problem of order, Clarendon, Oxford.

Sunshine, J \& Tyler, TR 2003, 'The role of procedural justice and legitimacy in shaping public support for policing', Law \& Society Review, vol. 37, no. 3, pp. 513-547.

Sykes, GM 1958, The society of captives, Princeton University Press, Princeton, NJ.

Thibaut, J \& Walker, L 1975, Procedural justice, Erlbaum, Mahwah, NJ.

Toch, H 1997, Corrections: a humanistic approach, Harrow and Heston, New York.

Trammell, R, Cook, AR, Marquez, MVD, Hinkle, P, Protze, LM \& Rodriguez, N 2018, 'From procedural justice to procedural injustice: understanding prison staff and inmate conflict', The Howard Journal, vol. 57, no. 4, pp. 537-555. doi: $10.1111 /$ hojo. 12285

Tyler, TR 1990/2006, Why people obey the law, Yale University Press, New Haven.

Tyler, TR 1997, 'The psychology of legitimacy: a relational perspective on voluntary deference to authorities', Personality and Social Psychology Review, vol. 1, no. 4, pp. 323-345. doi: $10.1207 /$ s15327957pspr0104_4

Tyler, TR 2003, 'Procedural justice, legitimacy, and the effective rule of law', Crime and Justice, vol. 30, pp. 283-357.

Tyler, TR 2007, 'Procedural justice and the courts', Court Review: The Journal of the American Judges Association, vol. 44, no. 1/2, pp. 26-31. Available at https://di gitalcommons.unl.edu/ajacourtreview/217

Tyler, TR 2010, 'Legitimacy in corrections: policy implications', Criminology \& Public Policy, vol. 9, no. 1, pp. 127-134.

Tyler, TR \& Blader, SL 2003, 'The group engagement model: procedural justice, social identity, and cooperative behavior', Personality and Social Psychology Review, vol. 7, no. 4, pp. 349-361.

Tyler, TR \& Fagan, J 2008, 'Legitimacy and cooperation: why do people help the police fight crime in their communities', Journal of Criminal Law and Criminology, vol. 6, pp. 231-275.

Tyler, TR \& Huo, YJ 2002, Trust in the law, Russell-Sage, New York.

Tyler, TR \& Lind, EA 1992, 'A relational model of authority in groups', Advances in Experimental Social Psychology, vol. 25, pp. 115-191. 
Weinrath, M 2016, Behind the walls: inmates and correctional officers on the state of Canadian prisons, University of British Columbia Press, Vancouver, Canada.

Wooldredge, JD 1999, 'Inmate experiences and psychological wellbeing', Criminal Justice and Behavior, vol. 26, no. 2, pp. 235-250. doi: $10.1177 / 0093854899026002005$

Woolf, Lord Justice 1991, Prison disturbances, April 1990, HMSO, London. 


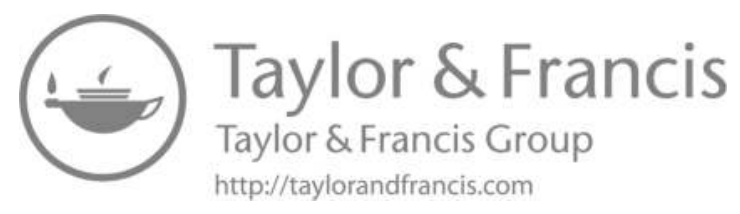




\section{Part II}

Procedural justice and legitimacy

Empirical and normative perspectives 


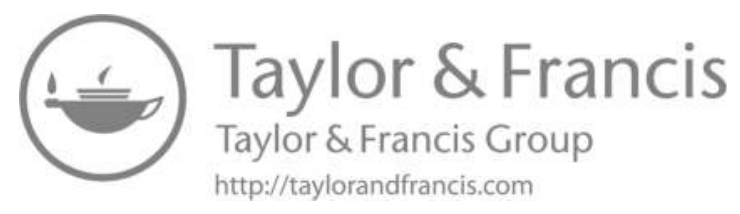




\title{
4 Procedural justice, legitimacy, and social contexts
}

\author{
Anthony Bottoms and Justice Tankebe
}

\subsection{Introduction}

Most people can remember occasions when they have been treated unfairly by an authority figure-for example, a teacher, a boss, a police officer, an airport official, or a referee in a sports game. Perhaps that person refused to listen to what we were trying to explain to them; or perhaps they seemed to have already made up their mind without considering all the facts; or perhaps they made belittling personal remarks about us, or made an unkind joke at our expense. We might also remember occasions when the reverse has happened, and an authority figure has treated us very courteously and with a concern for our well-being, or has gone out of her way to master all the facts and carefully explain her decision.

In the world of academia, these matters are described as 'procedural justice' (or injustice), and there is now a large and rather technical literature on this topic. It is therefore worth reminding ourselves that this literature concerns an everyday phenomenon, of which we all have experience. That being the case, procedural justice (or injustice) is delivered in a wide variety of social contexts. It has to be said, however, that the empirical research literature on procedural justice (hereafter, 'PJ') has not always taken adequate account of the social contexts of the encounters that it seeks to study. We are therefore pleased to have been asked to contribute to a volume that, among other things, is seeking to redress this imbalance.

Within criminology, a further feature of the academic literature on PJ is that much of it is closely linked to analyses of the legitimacy of criminal justice authorities. Thus, it is very commonly claimed that when such authorities act with procedural justice, this enhances their legitimacy in the eyes of those they are dealing with; and it is sometimes claimed that PJ is the most important factor promoting such legitimacy.

Against this background, the analysis in this chapter will be developed in two main sections and a conclusion. In Section 4.2, we discuss PJ within the context of its relation to the legitimacy of criminal justice institutions and personnel. In so doing, we pay particular attention to the meaning of 'PJ' and of 'legitimacy', and we argue that understanding of both concepts is enhanced by seeing them through the lens of a theory of 'basic legitimation expectations'. That theory

DOI: $10.4324 / 9780429317248-7$ 
also suggests that factors other than PJ might contribute to the legitimacy of criminal justice authorities. In Section 4.3, we emphasise the social embeddedness of procedural justice and legitimacy. This leads us to consider how a citizen's social background, and his or her prior experiences with legal authorities, might shape understandings of, and reactions to, a current encounter with an authority figure; how the particular situational context of the current encounter might also be important; and why a distinction between 'good' and 'right' relationships between citizens and legal authorities is relevant in the study of PJ. In the conclusion, we argue that the contextual variability demonstrated in Section 4.3 suggests that PJ scholarship should in future pay greater attention to the social circumstances in which PJ is delivered, and therefore also to qualitative research methods.

Throughout, we will in particular consider PJ and legitimacy in the context of policing because that has been the principal focus of the empirical research literature. However, where appropriate we also introduce evidence from other criminal justice contexts, especially prisons.

\subsection{Procedural justice and legitimacy}

It is central to our argument that both procedural justice and legitimacy are, in a double sense, normative concepts. Within the framework of social and legal philosophy, they are normative in the sense that they offer reasons why legal authorities should behave in certain ways. Within the framework of descriptive social science (which, for the most part, aims to be morally neutral in its study of social processes), they also provide normative as opposed to instrumental explanations of human behaviour. ${ }^{1}$

In thus emphasising the doubly normative character of PJ and legitimacy, we are influenced by the analyses of the legal philosopher Neil MacCormick (2007), who pointed out that, descriptively speaking, human beings are inescapably 'norm-users, whose interactions with each other depend on mutually recognizable patterns that can be articulated in terms of right versus wrong conduct, or of what one ought to do in a certain setting' (p. 20). Building on his understanding of the indispensability of norms to everyday life, MacCormick further claimed that the central characteristic of a modern legal system is that it is a form of 'institutional normative order'-that is, it comprises a complex set of social institutions that, among other things, embody and proclaim standards of 'right versus wrong conduct, or of what one ought to do in a certain setting' (p. 11).

\subsubsection{Conceptual issues}

If law is institutional normative order, it follows that any attempt to understand people's orientations to legal authorities must include some consideration of the normative status of those authorities (Beetham 1991/2013). 
This thought immediately introduces the concept of legitimacy. Legitimate power has been well described, within the framework of social science, as power that is 'acknowledged as rightful by relevant agents, who include power-holders and their staff, those subject to the power and third parties whose support or recognition may help confirm it' (Beetham 2013, p. 19, emphasis in original). ${ }^{2}$ Among these 'relevant agents', those subject to the power are perhaps of special significance because of their potential vulnerability. This point has been illuminated in a posthumously published essay by the philosopher Bernard Williams. Williams (2005) argues that the 'first political question' in any society is always the 'securing of order, protection, safety, trust and the conditions of co-operation', because without a solution to this question people cannot satisfactorily pursue everyday routine activities such as economic production, trade, child care, and education (p. 3). However, as Geoffrey Hawthorn (2005, p. xii) pointed out in his introduction to Williams' essays, if a ruler with no moral scruples has access to effective state power, then 'putting a stop to disorder is not difficult'; but in those circumstances a solution to the 'first question' might well generate a further problem - that of living under despotism. This is why, in Williams' analysis, it is always reasonable for those subject to state power to 'ask what the nature of the state's protection and its price are to be and why, and they will want a reasonable reply' (Hawthorn 2005, p. xii). Raising such questions is described by Williams as making 'Basic Legitimation Demands', or BLDs. These so-called 'demands' indicate the kind of conditions that citizens consider will allow them to acknowledge state power as 'rightful'. Given this, we think they are perhaps better described as 'expectations' rather than 'demands' (or BLEs rather than BLDs) - that is, they indicate the expectations that the citizens of a given state have of rightful power-holders. Williams argues that the difference between legitimate and illegitimate power lies in the ability of power-holders to honour citizens' BLEs, to a reasonable extent, in particular state contexts. ${ }^{3}$ Crucially, he also claims that what people consider a satisfactory 'legitimation story' (i.e. an account that satisfies their BLEs) is historically variable. This implies that we can only hypothesise, rather than determine a priori, what the structure of legitimacy might look like in any given society; and such structures will probably vary both historically and geographically (for example, they will likely be different in a medieval theocracy and a modern liberal democracy).

How does PJ fit into this kind of analysis? It is now standard for scholars interested in PJ to describe it as referring to four aspects of the exercise of authority. A useful summary of this framework has recently been provided by Tom Tyler and Tracey Meares (2019):

First, people want a voice. The public wants [authorities] to allow people to express their views or tell their side of the story before determining policies or making decisions. Second, people care about neutrality. People want [authorities] to act in a transparent and impartial manner by making decisions based upon facts, not prejudices. Neutrality is also related to whether 
[authorities] explain what their policies are, and how they are being applied. Third, people want interpersonal respect. This includes respect for people's rights as citizens and for their dignity as people ... Fourth, people care about trustworthy motives. It is important to people to feel that [authorities] are motivated to do what is good for the people in their community. ${ }^{4}$

(p. 74, emphasis added)

In light of Bernard Williams' analysis, it is interesting to note that this account is couched in terms of what people 'want' or 'care about' in their dealings with legal authorities. Given this, it seems reasonable to argue that Tom Tyler, the leading academic proponent of PJ in relation to criminal justice, is here in effect claiming that the four identified aspects of PJ constitute (at least in liberal democracies such as the United States) four aspects of a basic legitimation expectation that authorities will act with procedural justice. If that is correct, it is potentially an important conceptual linkage of PJ theory to legitimacy theory. However, it leaves open the question of whether citizens might also have Basic Legitimation Expectations concerning other matters, which might also need to be satisfied before the authority is regarded as fully legitimate.

Tom Tyler's work has primarily focused on empirical analyses. Ever since his seminal book, Why People Obey the Law (Tyler 1990/2006), he has argued for a sequence of empirical links between PJ and legal compliance, approximately as follows: the procedurally just treatment of citizens by criminal justice (CJ) agents will lead citizens to form positive perceptions of PJ by CJ agents; this in turn will mean that citizens are more likely to recognise CJ agents as legitimate authorities; and, finally, this recognition of legitimacy will lead citizens to an enhanced compliance with law. ${ }^{5}$

A key explanatory question arising from this proposed sequence is: why are citizens who form positive perceptions of PJ by CJ agents more likely to regard those authorities as legitimate? The principal explanation that has been put forward in the PJ literature is the so-called 'group value model', originally developed by Lind and Tyler (1988), which postulates that human beings are social creatures who derive part of their understanding of themselves from how they are valued (or otherwise) by other members of the social groups to which they belongfrom families to the state. ${ }^{6}$ Tyler $(1990 / 2006)$ applied this theory to procedural justice in legal contexts in the following way:

When people approach authorities, their social standing and feelings of security within the group are on the line. They may have an experience that reaffirms their belief that they are valued, protected members of society ... they may also have an experience that makes them feel less valued and protected than they would like to believe ... Dealing with authorities clearly raises issues far beyond those connected with the issue to be decided ... When the police harass members of minority groups, the poor or the young, they are communicating to those groups that they have marginal social status.

(pp. 175-176) 
In our view, this is a compelling normative explanation as to why the exercise of procedural justice by legal authorities is likely to contribute to attributions of legitimacy. ${ }^{7}$ As will shortly be seen, however, we believe that other factors also often contribute to these attributions.

\subsubsection{Assessing procedural justice}

A technical question of some importance concerns how researchers can best measure the concept of procedural justice. In some criminal justice contexts, such as courts, PJ can in principle be observed directly, because courts are open to the public. But the bulk of PJ research has focused on the police, and here matters are more complicated, because many interactions between police and citizens have few if any witnesses. Most empirical research on PJ in policing contexts has therefore measured PJ by survey questions to people who have had some contact with the police. In such surveys, respondents are asked about (among other things) their overall satisfaction with the encounter, whether the police officer allowed the citizen to have a voice, whether the officer was polite and treated the citizen with respect, and so on. This might be described as a measure of 'subjective PJ' or 'perceived PJ'.

Recently, several researchers have published studies that attempt to get closer to what actually happens when police meet citizens (see, for example, JonathanZamir et al. 2015; McCluskey et al. 2019; Nawaz \& Tankebe 2018). The most interesting, and the most challenging, of these studies is by Worden and McLean (2017) in Schenectady, New York. These authors studied 411 police-citizen encounters where, uniquely, data about the same encounter were available both from the citizen's recollections in a standard survey and from independent coding of a video recording of the incident. As expected, these two data sources were positively correlated; but, much more surprisingly, the correlation was only 'weak to moderate' (p. 134), so that observed 'procedural justice and injustice together explained no more than 12 per cent of the variations in citizens' subjective experience' of PJ (p. 179). We should not jump to too many conclusions from a single study, but methodologically speaking this result does suggest that scholars should be cautious, at present, before they too readily assume that what might be described as 'subjective PJ' is identical to 'independently observed PJ'.

But suppose it turns out, after a number of further research studies, that these two concepts are consistently shown to be only weakly connected? Here, it is important to recall that Tyler's (1990/2006) hypothesised causal sequence is that 'observed PJ' leads to 'perceived PJ' leads to 'citizens' attributions of legitimacy' (see previous discussion). That being so, a result of the kind described would have no impact on the bulk of research findings about the relationship between PJ and legitimacy (other than to substitute 'perceived PJ' for 'PJ'), because the hypothesis has always been that perceived PJ leads to attributions of legitimacy. What such a result would do, however, is to open up a fresh strand of empirical research into why citizens' recollections of PJ are sometimes different 
from what actually happened; in other words, it would raise important questions about how police behaviour is socially perceived by citizens. We will return to this issue in Section 4.3.1 below.

\subsubsection{The Bottoms-Tankebe approach to criminal justice legitimacy}

In previous publications on legitimacy and criminal justice, we have advanced a number of propositions, two of which are of relevance in the current context. First, in a 2012 paper, we argued that 'legitimacy needs to be perceived as always dialogic and relational in character' (emphasis added). We elaborated the point as follows:

those in power (or seeking power) in a given context make a claim to be the legitimate ruler(s); then members of the audience ${ }^{8}$ respond to this claim; the power-holder might adjust the nature of the claim in light of the audience's response; and this process repeats itself ... [I]t is more like a perpetual discussion, in which the content of power-holders' later claims will be affected by the nature of the audience response.

(Bottoms \& Tankebe, 2012, p. 129)

At the time that we wrote that paper, we were not aware of Bernard Williams' conceptualisation of the 'basic legitimation demand', but it is clear that seeing legitimation as a continuing dialogue is highly congruent with the 'BLD/BLE' approach. ${ }^{9}$

A second main claim in our previous work has been that, at least in democratic societies, it is possible to identify four Basic Legitimation Expectations that seem likely to contribute to the structure of legitimacy of criminal justice agencies. This claim has an empirical element, because each of these four BLEs has been shown empirically to contribute to perceptions of legitimacy in some situations. However, we also argue that these empirical findings are coherently related to the definition of legitimacy as power that is 'acknowledged as rightful' (Beetham 2013 , p. 19). This is because each of the four matters can be seen as being appropriately raised as BLEs when citizens ask criminal justice authorities 'what the nature of the state's protection and its price are to be, and why' (Hawthorn 2005, p. xii).

One of these four suggested BLEs is procedural justice; the others are the lawfulness, distributive justice, and effectiveness of the relevant authorities (Bottoms \& Tankebe 2017; Tankebe 2013). Lawfulness concerns authorities' adherence to the rule of law; more specifically, to an expectation that they will exercise only those powers that are explicitly provided in law, and that they will act within the relevant legal boundaries. Distributive justice concerns the perceived fairness of criminal justice agencies in allocating resources and making key decisions (police stops, sentencing, parole, etc.) with regard to relevant social groupings. These groupings include race, gender, social class, political affiliation, and offence type. 
Distributive justice therefore 'raises questions regarding the evenness with which law enforcement and sanction is applied-whether justice outcomes are distributed fairly' (Peffley \& Hurwitz 2010, p. 71, emphasis in original). Finally, effectiveness is concerned with public expectations that criminal justice agencies should be reasonably effective in performing the tasks that they have been assigned. Effectiveness might be called into question if, for example, the police seem unable to address public safety satisfactorily in a particular area, or if a parole board regularly releases people who then commit serious offences.

In the research literature, the most contentious of these four matters as contributors to attributions of legitimacy have been distributive justice and effectiveness, ${ }^{10}$ and the debates around this matter have been partly empirical and partly conceptual.

The empirical debate has focused on the question 'which factor(s) is/are most important in generating legitimacy'? Some PJ scholars have claimed that procedural justice is always or almost always the most important, but this claim is becoming increasingly hard to sustain. For example, as regards effectiveness, there are now a number of studies, especially from African countries where the state is often weak, suggesting that (congruently with Williams' 'first political question') effectiveness in providing basic social order, rather than procedural justice, is the primary concern for citizens seeking legitimate governance (Tankebe 2009; Bradford et al. 2014; Akinlabi 2018). Similarly, as later sections of this chapter will show, there is now clear evidence that in some circumstances distributive justice or injustice is a more powerful explanation of the observed social phenomena than is procedural justice or injustice. Our own reading of the evidence is that there is no one factor that best promotes legitimacy in every context; instead, the importance of factors can and does vary in different social contexts.

The second debatable issue is conceptual. It arises from the fact that effectiveness and distributive justice both contain an outcome-oriented dimension, which some scholars have seen as making them necessarily instrumental in focus, and therefore distinct from the normative concept of legitimacy (see, for example, Sunshine \& Tyler 2003, p. 514). In our view, however, such a position is conceptually problematic. Certainly, distributive justice and effectiveness include a concern with outcomes, but that does not make them simply instrumental. For social behaviour to be instrumental, it needs to be arrived at by considering the future consequences of the behaviour-usually the anticipated future benefits or costs (financial or otherwise). Attributions of legitimacy, however, are not forward-looking: they are judgements about the current normative status of power-holders (Beetham 1991/2013); hence, they describe a positive or negative assessment by citizens of a power-holder's current moral right to exercise power (Bottoms \& Tankebe 2012; Coicaud 2002). Using that criterion, a police service that seems either ineffective, or biased against a particular ethnic group, might reasonably be considered by some citizens to have lost the moral right to exercise power. ${ }^{11}$ For example, the main concern of the Black Lives Matter movement in the United States has not been the fairness of the processes leading to 
police decisions to shoot African Americans, nor even the legality of police violence. Rather, what drives this movement is a deep concern and resentment about the unfairness of the very disproportionate representation of African Americans as victims in fatal police-civilian encounters. Thus, their ethical stance is not based on an instrumental (cost-benefit) calculation of future outcomes; rather, it is rooted in a deep moral concern about the apparent disregard by many police services of the statement in the 1776 American Declaration of Independence that 'all [human beings] are created equal ... with certain unalienable rights ... [including those of] life, liberty and the pursuit of happiness'. Black people in the US are continuing to express a 'basic legitimation expectation' that their police services should honour this principle; that police often seem not to be doing so (distributive unfairness) is therefore very much a matter of normative, not instrumental, concern.

In order to avoid misunderstanding about our proposed fourfold legitimacy structure, some clarificatory comments about it might be helpful. In a recent paper on legitimacy in policing, we described the structure in this way:

Legitimacy dialogues are always contingent on specific features of the time and place in which they occur ... and this means that the specifics of legitimation and legitimacy can be very variable. We have however suggested the enduring importance of procedural justice, distributive justice, effectiveness and lawfulness as guides to the delivery of legitimate policing ... [F]irm evidence can be cited that a failure to deliver on any one of these four matters has on some occasions led to a legitimacy deficit for a public police service.

(Bottoms \& Tankebe 2017, p. 88)

Two points about this statement are worth emphasising. First, the approach taken is empirical, so no claim is made that these four matters will always contribute to citizens' perceptions of criminal justice legitimacy in every cultural context (in some situations, they may not ${ }^{12}$ ). Nor is it claimed that no other factors will ever contribute to criminal justice legitimacy (very likely, in some situations they will, especially as more research is conducted in non-Western contexts). The claim is simply that each of these matters has been shown empirically to contribute to the formation of citizens' views about criminal justice legitimacy; hence those interested in building improved legitimacy should always consider the potential relevance of each of these matters in their particular situation. Second, the structure does not assume that all of its proposed contributors carry equal weight. On the contrary, depending on the social context, one or more of them might be of greater or lesser importance.

Finally, we should note that a recent empirical study in the United States provides some encouraging support for our fourfold model. Kearns et al. (2019), having noted that the academic literature contains varied theoretical approaches to the understanding of legitimacy, decided to survey the general population on this question. They therefore asked 1,900 US residents the open-ended question: 
'When thinking about the police, what does “legitimacy" mean to you?' Answers were mostly short (mean $=6.2$ words), but the researchers were able to code the responses into seven distinct categories, which varied very little across different ethnic groups. ${ }^{13}$ Overall, the most frequently mentioned category was 'follows the law' (mentioned by $37 \%$ of respondents); the other categories were 'honesty' (19\%), 'fairness' (11\%), 'right to govern' (11\%), 'effective' (9\%), 'moral/do right' $(9 \%)$, and 'protection' (5\%). As the authors note, these categories explicitly include each of the four dimensions in the Bottoms-Tankebe model ['follows the law'; 'fairness' (procedural and distributive) ${ }^{14}$; and 'effective'], although the proportion of respondents choosing some of these dimensions was small. As we interpret them, the categories also include one item ('right to govern') that is very close to academic definitions of legitimacy; two items ('honesty' and 'moral/do right') that could be subsumed under the heading of procedural justice; and one item ('protection') that could be subsumed under effectiveness. Since the research question was open-ended, with no prompting, the results of this study offer support for the view that each element of our proposed fourfold structure is regarded as a basic legitimation expectation by at least a proportion of ordinary citizens.

\subsubsection{Comment}

This initial section has focused on trying to understand the concepts of procedural justice and legitimacy more fully, and to show how they might be related. But in doing so, we have also, directly or by implication, raised a number of matters that require us to understand these concepts as necessarily social and relational in character. Indeed, the concept of legitimacy itself makes no sense except against the background facts that, first, human beings always live in groups; and second that for these groups to function adequately, some people have to be given the power to make certain decisions on behalf of the group, in order to promote the safety and well-being of its members. ${ }^{15}$ In turn, this leads those without power to express some 'basic legitimation expectations' to the power-holders, in order to try to ensure that the character of the power being exercised does not become unjust, or otherwise inappropriate. If power-holders do start to behave in ways that citizens consider to be unjust, people will not feel that they are being treated with proper dignity as members of the group or society. All this being the case, both PJ and legitimacy are deeply social as well as normative concepts. It is therefore now necessary to explore in more detail some of their social features.

\subsection{Social and situational contexts}

Employing a terminology used in economic sociology, it is possible to categorise two broad approaches to social-scientific research: formalist and substantivist. A formalist approach to social action isolates individuals from their socio-historical contexts and attempts to analyse their actions in an atomised fashion. Granovetter (1985, p. 490) identifies three characteristics of the formalist position: the 
transactors are previously unacquainted; they are unlikely to transact again, and information about the activities of either is unlikely to reach others with whom they might transact in the future. A substantivist approach, on the other hand, emphasises the embeddedness of social actions within specific socio-historical settings and within 'concrete, ongoing systems of social relations' (Granovetter 1985, p. 487).

No procedural justice research has all the characteristics of the formalist position. Nevertheless, because much of the PJ literature is survey-based, some of it does have a tendency to treat interactions between legal authorities and civilians as 'spot' encounters, atomised and without history, and lacking much consideration of broader social contexts and the current situational framework. From our dialogic perspective of legitimacy, this is a mistake: as we have argued above, legitimacy dialogues are always contingent on specific features of the place and time in which they occur. A substantivist view is therefore consistent with the insights from political science that there are always social forces and processes that shape the nature and outcomes of legitimacy dialogues (see Dunn 2013). Those forces and processes might, of course, operate at macro-, meso- or micro-social levels. However, given the focus of this volume on procedural justice, it is appropriate in this chapter to consider especially what happens when there are actual encounters (or a deliberate avoidance of encounters) between authority figures and citizens. Accordingly, our focus here is on micro- and meso-social issues. ${ }^{16}$

Our substantivist discussion will work with the useful distinction drawn by Worden and McLean (2017, Figure 6, p. 83) between the influence of 'citizens' backgrounds' and the influence of the current 'situational context' in which legitimacy-relevant encounters occur.

\subsubsection{Citizens' backgrounds, procedural justice and legitimacy}

We begin by exploring the possible relevance of citizens' normative beliefs. In Why People Obey the Law, Tyler (1990/2006) identified two different types of internalised obligation to obey authorities. These are legitimacy, and what he called 'personal morality', which was described as differing from legitimacy because it is 'not a feeling of obligation to an external ... authority', but instead 'an internalized obligation to follow one's personal sense of what is morally right or wrong' (pp. 25-26). Despite this conceptual distinction, however, Tyler noted that in some circumstances these two kinds of obligation might be empirically linked, because an individual's personal morality (e.g. his or her political beliefs) 'may or may not' lead him or her to ascribe legitimacy to the authorities in a given situation (p. 26). Much of the literature has paid only limited attention to possible links of this kind, but recently this topic has been more actively considered.

An important analysis in this vein was conducted by Mehozay and Factor (2017), using data from over 52,000 respondents to the European Social Survey (which covers 27 countries). The authors hypothesised that beliefs about the legitimacy of the police derive, to a significant extent, from what they term 'core 
normative values (i.e. notions of the good and virtuous life) that stem from deeply embedded cultural orientations through which individuals operate in and interpret the world' (p. 154). Four such categories of 'deep values' were identified, and described as liberal; republican-communitarian; ethno-national and religious-traditional. The analysis of survey responses showed that perceptions of the legitimacy of police were positive for individuals holding liberal or republican-communitarian worldviews, but they were negative for those holding ethno-national normative values. ${ }^{17}$ The authors also conducted an analysis in which respondents' views were aggregated on a national basis, which showed some important differences by country, both in dominant normative values and in assessments of police legitimacy. The results of the study are described as providing preliminary support for the authors' main hypothesis. Importantly, however, it is argued that if the theory underpinning that hypothesis receives fuller substantiation, this will show that 'even optimal [police] procedural conduct or efficiency may not affect the attitudes of some populations' (p. 172). At a theoretical level, the authors also argue that the 'core normative values' that they describe 'are so embedded and internalized that they become a sort of habit', which, they suggest, might explain why they have received little attention in the criminological literature, because habit is a compliance mechanism that 'seems to be much ignored by [most] criminologists' (p. 171). ${ }^{18}$ Not dissimilar results have emerged from a French survey by Roché and Roux (2017), which explored how a general population sample judged 'police unfairness'. In a multivariate analysis, it was found that 'political attitudes and values emerged as the strongest predictors' (p. 524). More specifically, police were considered to be fairer by those holding right-wing political views, punitive attitudes, 'legalistic' values, and an intolerance towards crime.

However, the Roché-Roux study also raises a different issue about the possible influence of social background on judgements of legitimacy. A special subsample was drawn from those living in the large Seine-St. Denis area on the outskirts of Paris, which has a very high level of social deprivation, and a high proportion of ethnic minority and immigrant residents. Respondents from this area returned the lowest ratings on police fairness. But this result raises the fresh question: is the perceived police unfairness attributable to the cultural norms prevailing in this type of area, or to police behaviour in the area? Probably the answer is 'both', because in the survey both 'high police-initiated contact' and living in St. Denis were significantly associated with perceived police unfairness when other variables were controlled for. Similar findings emerged in a survey by Wesley Skogan (2006) in Chicago, where the dependent variable was confidence in the police; in this study, negative experiences with the police were statistically associated with lack of confidence, but so were 'neighbourhood dissatisfaction' and perceived problems in the area (drugs, social disorder). Most recently, after a complex and fascinating analysis of ethnicity and legitimacy in European Social Survey data, Bradford et al. (2018, pp. 69-70) report that while 'the experience of police activity seems to shape legitimacy in important ways', so too do 'economic, 
social and political marginalization', which in policy terms, they suggest, means that governments should consider not only improvements to policing, but also 'broader political responses to social exclusion'.

The analyses reported above clearly demonstrate that when citizens meet police officers, they do not do so with blank minds (and neither, of course, do the police come to such meetings in that fashion). The 'personal morality' which citizens bring to the meeting may be shaped, among other things, by their political or religious values; by their social status; by the culture and concerns of the area where they live; or by their previous experiences with the police. Given this, the question arises: do any of these background matters actually affect how citizens react in a specific encounter with police? The research evidence on this matter is still limited, but the answer to the question is clearly 'yes', as two studies - in different ways-help to illuminate.

The first of these studies provided evidence of a clear ethnic difference in citizens' reactions, based on their prior experiences with the police. Charles Epp and colleagues (2014) carried out research into police vehicle stops in the US, distinguishing between 'traffic-safety stops' and so-called 'investigative stops', in which officers target people whom they suspect of lawbreaking. The authors claim that, while officers shared with most ordinary citizens a bias against African Americans, this bias was not generally visible; however, it was apparent 'in the process of making investigatory stops' (p. 53). So, for example, a white woman living in a 'nice neighbourhood' is quoted as saying that she has been 'pulled over' much less often than her black neighbour and friend-'she's pulled over down at the corner more, and just asked "Do you live around here?"” (p. 122). By law, officers need a probable cause to order a stop, but the authors report that 'a minimal justification for the stop' is frequently voiced in African Americans' accounts of investigatory stops (p. 119). All this has significant consequences:

Most white drivers' narratives are of typical traffic-safety stops. White drivers never express a fear of the officer demanding to search the vehicle or make an arrest ... [By contrast] African American drivers ... focus on whether the stop was really about traffic enforcement or something else. Deana ... reported being 'scared' after being stopped twice within a few minutes 'for no reason, just to see where I was going', even though the officers were 'nice' and gave her no tickets ... Elizabeth ... characterized a stop as 'racial abuse' because the officers seemed less interested in the violation that they used to justify the stop-a late turn on a yellow light — than in checking her out and peering closely into her car.

(pp. 124-125)

The authors further report that it is common for African American drivers to express 'indignation' at the behaviour of 'polite but intrusively inquisitive officers' (p. 125), but that no such reaction was found among white drivers. Naturally, these matters are widely discussed among African Americans; and their 'shared 
knowledge of investigatory stops leads them to look carefully for signs that [their next] stop is an investigatory stop' (p. 120). Thus, there are very different immediate reactions when people are stopped. Epp et al. (2014) report that evaluations by whites are "framed within the range of typical possibilities in the "normal" traffic-safety stop: ticket versus warning'; by contrast, African Americans' evaluations 'are framed within a much wider range of possibilities: speeding stop versus intrusive investigation' (p. 126). It is also worth emphasising that, in this study, the indignation of African Americans subjected to investigatory stops was not mitigated by the politeness of officers; it was simply not the case that, as a former Chicago police chief once claimed, 'it's not what you do, it's how you do it' (Thacher 2019, p. 98). Procedural justice (including politeness) certainly matters, but so does non-discriminatory police practice (distributive justice). ${ }^{19}$

The second study was led by the late Peter ('Tank') Waddington, whose research team showed four video clips of real-life encounters between police and citizens (taken from BBC documentary programmes) to 34 focus groups in England. These groups were of varied age, ethnicity, and social status; for example, they included groups of Muslim women, mid-career professionals, and young offenders on probation. An early publication from the study describes in detail group members' reactions to just one of the video clips, which focused on a traffic stop by motorway police of a suspected car thief, and the aftermath of the stop as it became clear that the incident was more complex than the officers originally thought. The main conclusion was that the behaviour of the two police officers in this incident was often (although not invariably) assessed very differently by different people. ${ }^{20}$ What the authors described as 'issues of fairness and respect' surfaced repeatedly in the group discussions, but on many occasions different participants 'drew attention to the same occurrences within the video clip to justify entirely contradictory evaluations' (Waddington et al. 2015, p. 212). Further analysis showed that these divergent opinions 'could not readily be explained either by differences in the age, gender, ethnicity, or class composition of groups, or the purpose for which the group existed' (p. 221). The main reason for this perhaps surprising finding was that respondents

relied on their wider cognitive resources not only to interpret what they saw on screen, but also to infer what could not be seen and imagine past occurrences, current possibilities and future potentialities far removed from what they witnessed.

(p. 232, emphasis added)

This is valuable evidence that as citizens meet criminal justice authorities, they interpret the developing incident not only in terms of what is actually observed, but also in terms of inferences that-based on their background-they might draw about what they have seen. An example from a different videoed incident, reported in a later publication, is instructive in this regard. There was a general consensus that a police officer showed considerable patience when taking a 
statement from an elderly man who had just been robbed. However, during this process the officer looked at his wristwatch. In one group, this was interpreted by one observer as discourteous ('he was trying to rush it along'), but another thought the officer was fulfilling an administrative requirement to record the time on the statement (Waddington et al. 2017, p. 52).

There is much complexity here; and very possibly the issues identified by Waddington and colleagues might be related to Worden and McLean's (2017) findings of only a weak to moderate relationship between independently observed PJ and subjective PJ (see previous discussion). This is clearly an issue requiring further research.

\subsubsection{Situational contexts, procedural justice, and legitimacy}

We will explore the issue of situational contexts by considering the varying ways in which citizens meet police officers; the relationship between outcomes and judgements of PJ; and whether, in certain situations, people depart from the behaviour that might be expected in light of their 'deeply embedded core normative values' (Mehozay \& Factor 2017).

In the now extensive literature on assessments of PJ and legitimacy in policing encounters, it is frequently reported that contacts initiated by citizens themselves (often described as 'calls for service') are more positively evaluated than are policeinitiated contacts. Some useful detail is available from the Schenectady study by Worden and McLean (2017, Table 5, p. 138), where-it will be recalled-the available data included both 'observed' and 'subjective' measures of PJ for the same incidents. The authors conducted a series of regression analyses in which 'subjective procedural justice' was the dependent variable. In an early model, both observed procedural justice and observed procedural injustice were associated (in the expected directions) with subjective PJ, but so were encounters based on calls for service (positive) and arrests (negative) (Model II). Further analyses showed, first, that non-consensual stops and searches, either on the street or in a vehicle, were more negatively associated with PJ even than arrests ${ }^{21}$ (Models III and IV); and second that if the citizen had resisted the police during the encounter, he or she was particularly unlikely to perceive the encounter as procedurally just (Model V). In the final model (Model V), when all variables were included, observed procedural injustice still generated negative subjective perceptions of PJ, but observed procedural justice was no longer significant. The general picture that emerges from this survey is that citizens' perceptions of PJ seem to be inversely correlated with the police's use of coercive authority. This conclusion is supported by evidence from Waddington and colleagues' (2017) video clip analysis, which found that 'physical grappling with suspects' was 'not regarded with equanimity' by most members of the focus groups, especially when it involved more than one officer (p. 126). Since even the best police forces must, in order to do their job properly, sometimes use a degree of coercive authority (especially when dealing with citizen resistance, or with serious crimes ), these findings inevitably 
raise some policy dilemmas for police services: the uncomfortable truth seems to be that it is difficult to deliver optimal PJ when carrying out certain police tasks. ${ }^{22}$ However, it is important to note that by no means all police-initiated contact with citizens is coercive, and indeed community-oriented policing (COP) strategies explicitly set out to promote a different kind of proactive contact. A recent randomised field experiment yielded encouraging results as regards this type of contact; it was found that positive, non-enforcement COP visits by police to citizens' homes substantially improved public attitudes to the police, including legitimacy and willingness to cooperate, and these results were not limited to individuals with prior positive attitudes to the police (Peyton at al. 2019). Overall, therefore, the evidence suggests that the context of the police-citizen contact is an issue of some significance for subjective judgements of PJ and legitimacy.

Just as important as the above issues is the less well-explored situational issue of underenforcement; that is, situations where there is a lack of effective policing, although a credible 'basic legitimation expectation' for citizen protection is clearly present. A tragic example of this type of situation was described in an independent report into widespread child sexual abuse in the English town of Rotherham. The summary of the report makes clear the 'appalling nature of the abuse that [some] child victims suffered', which included 'being raped by multiple perpetrators [and] trafficked to other towns and cities'. The police, the inquiry concluded, 'gave no priority to [child sexual abuse], regarding many child victims with contempt'. Over a period of four years, three reports were made available to the police and the local government authority, and collectively these reports 'could not have been clearer in their description of the situation'. Unfortunately, however, the first report was 'effectively suppressed ... [while] the other two reports ... were ignored and no action was taken' (Jay 2014, p. 1). The victimised children and their families clearly considered that the police response lacked legitimacy. However, in making this judgement they were primarily concerned with the police's lack of effectiveness, and an apparent discrimination against this form of victimisation, rather than with a lack of procedural justice, although this was also present.

In the Rotherham example, those disadvantaged by underenforcement were socially powerless and vulnerable people. Alexandra Natapoff (2006) has argued that this structural characteristic is a recurring feature of underenforcement, which is

often linked with official discrimination ... legal failure, and the undemocratic treatment of the poor ... Conceived of as a form of public policy, underenforcement is a crucial distribution mechanism whereby the social good of lawfulness can be withheld.

The same author also notes that underenforcement can be observed not only (as in Rotherham) in weak state responses to victimisation, but also in weak 
responses to lawbreaking. This can take the familiar form of not pursuing cases against powerful people or corporations, but it can also occur when the lawbreakers are not powerful, but the offences they have committed have victimised vulnerable citizens. ${ }^{23}$

We turn now to a second aspect of social situations relevant to procedural justice and legitimacy, namely the relationship between process and outcome. Tyler and Meares (2019) have claimed that a 'central conclusion' of the research literature is that,

when people deal with authorities, their evaluations of the perceived fairness of the procedures through which authority is exercised influence legitimacy more strongly than does the perceived outcome of the encounter.

In our most recent joint paper, we endorsed this claim to the extent of saying that 'a powerful conclusion from the existing research is that ... citizens often prioritise procedural fairness' over perceived outcome favourability or fairness (Bottoms \& Tankebe 2017 , p. 75 , emphasis added). We also fully accept the encouraging evidence that fair procedures can act as a significant 'cushion of support against the potentially damaging effects of unfavorable outcomes' (Tyler $1990 / 2006$, p. 101). Nevertheless, and of relevance to the present discussion of situational differences, research has also shown that, in some circumstances, outcomes can matter rather more than the statement by Tyler and Meares would suggest; and three different issues are of relevance here.

First, do people actually know the outcomes delivered in other, similar, situations? For example, survey respondents who report having been the subject of a traffic stop might not know the outcomes for other stopped drivers-in which case, a claim of distributive unfairness of the outcome is hardly possible. By contrast, it has been shown that in long-term prisons-where news travels fast and the outcomes of most incidents are widely known-comparative outcome fairness is widely debated, and is of great importance (Sparks et al. 1996, pp. 303-311; discussed by Bottoms \& Tankebe 2012, p. 123). Second, some studies suggest that outcomes matter more to people's assessments of fairness when the stakes are high. For example, Jacobson et al. (2015) studied proceedings at an English Crown Court dealing with serious offences, where for defendants the potential consequences were usually much more serious than those at stake in most survey-based legitimacy research. The authors found that defendants were indeed interested in the fairness of procedures, but in the stark setting of the courtroom, the outcome of a case [conviction or acquittal; severity of sentence] ... is a crucial determinant of ... perceptions of legitimacy' (p. 166, emphasis added). Third, experience has confirmed Tyler's (1990/2006, p. 107) early speculation that "if a "fair" procedure continually delivers unfavorable outcomes, its fairness may ultimately come under scrutiny'. Exactly such a situation has been reported by Jenness and Calavita (2018) in a study of grievance procedures in California 
prisons, where 'prison officials ... uniformly lauded the [grievance] system as fair to prisoners' (p. 46) but where over 95\% of prisoners' grievances were denied (p. 45), creating considerable cynicism. From both their quantitative and qualitative analyses, the authors concluded that 'procedural justice does matter to ... prisoners'; however,

The prisoners in our study were above all concerned with how their grievance turned out-specifically, whether they were able to extract remedies from this institution that otherwise is responsible for so much daily deprivation. So dominant is this substantive dimension to their satisfaction that procedural dimensions are largely subordinate to it ... [In addition], the important relationship between outcome and satisfaction is further magnified when the stakes associated with the grievance are the highest.

(pp. 66-67).

None of the studies discussed in the previous paragraph argues that procedural justice was of no relevance in the situations that were researched. However, they all caution against assuming that procedural justice will always be more important than outcome favourability or perceived outcome fairness. Taken together they seem to have identified one situation where procedural justice will be dominant (citizens have little knowledge of outcomes other than their own) and two situations where perceptions of outcome might well be more important (high stakes; routine delivery of unfavourable outcomes). Empirical studies on this topic are still limited in quantity, but it ought to be possible for researchers to develop a fuller understanding of how procedures and outcomes seem to vary in their significance to citizens in different sets of social circumstances.

Section 4.3.1, above, focused among other things on citizens' 'deeply embedded core normative values'; by contrast, this section has considered the specifics of social situations. Clearly, any full 'substantivist' study of PJ and legitimacy will need to take account of both matters, and to assess how they might be interrelated. To close this section, we therefore draw attention to one recent study that carefully addresses this interaction.

Monica Bell (2016) became interested in the concept of 'legal cynicism', defined as a strong distrust of and cynicism about all legal authorities, especially the police; this worldview incorporates a moral rule that 'you don't snitch to the police'. She noted the extensive evidence that legal cynicism is pervasive among residents of poor, black neighbourhoods in the US; but she was also struck by some less frequently cited data, which show that residents of such areas have, even when one controls for crime rates, a higher rate of calls to police than residents of white, middle-class areas. To explore this apparent paradox, Bell conducted 50 lengthy qualitative interviews with poor African American mothers living in Washington, DC. She found plenty of evidence of legal cynicism in her sample, yet two-thirds of her respondents said that they had called the police at least once (p. 325). Why? Broadly, there were two main kinds of reason. One was 


\section{2}

what Bell calls 'officer exceptionalism'; that is, some women were willing to trust certain individual officers whom they had come to know personally, while still not placing any 'legitimacy or trust in the broader system' of policing (p. 329). Second, there were various circumstances in which the mothers might turn to the police because police seemed likely to offer better solutions than anyone else in specific situations. ${ }^{24}$ For example, one woman, while saying that she agreed with the 'street code' against calling the police, also reported that she had several times called police to help friends facing domestic violence, and to help control her teenage children (pp. 332-333). This example illustrates a further finding of Bell's study, namely that calls to the police were usually made about issues within or physically near to the women's homes, or those of their families or close friends, in an effort to regain or retain control of situations that were literally close to home. For more distant issues, such as drug trafficking and violent crime in the streets, the community norm against snitching held powerful sway, and the police were not called. Subtle findings such as these are important in reminding us of the value of qualitative as well as quantitative research methods; many surveys would simply record Bell's respondents as having negative perceptions of the police.

Monica Bell's research was not longitudinal, so she necessarily could not address the important question of how 'deeply embedded core normative values' might change in response to particular encounters or incidents. That is a further topic that requires research, although for some valuable 'informed speculation' on this issue, see Waddington et al. (2017, pp. 164-165).

\subsubsection{Moral contexts: 'good' versus 'right' relationships}

In an important paper on prisons, Alison Liebling (2011) differentiates between two kinds of relationships between prison officers and prisoners, described as 'good' and 'right' relationships. When talking about a particular prison, observers frequently ask whether that institution has good staff-prisoner relationships, but Liebling insists that this is not, ultimately, the correct question. She points out that having 'good' relations simply means that people are getting on with each other; however, a relationship between an officer and a prisoner may be 'good' but not 'right'. This can happen if, for example, the officer is turning a blind eye to the undercover importation of drugs into the prison, and/or if he or she is afraid to assert authority over some powerful prisoners. The problem is, essentially, that such relationships are 'too close or too informal, lacking boundaries and professional distance' (Liebling 2011, p. 491). ${ }^{25}$ By contrast, 'right' relationships are professional and ethical: the officer maintains humaneness, approachability, politeness, and so on, but is always aware of his or her professional obligations, including the need both to enforce and to abide by relevant laws and regulations.

It is important to note a theoretical point arising from this distinction. Following Hinsch (2010), many social scientists now distinguish between 
'empirical legitimacy' and 'normative legitimacy'. The 'good' versus 'right' distinction suggests that, as we have previously argued (Bottoms \& Tankebe 2012, pp. 156-158; Bottoms \& Tankebe 2017, pp. 48-51), while a predominantly empirical approach to the study of legitimacy is the appropriate starting point for social-scientific researchers, an exclusively empirical account is ultimately inadequate. However, rather than enter into this theoretical territory here, we will illustrate its implications from a recent empirical study.

Tankebe et al. (2019) conducted research with samples of drivers of commercial vehicles in two cities in Ghana. One of their regression analyses focused on self-reported traffic violations as the dependent variable. An initial analysis found that the variable 'personal experiences of police corruption' was associated with more traffic violations, but 'police fairness' (a standard set of PJ questions) was not significant. Further analyses explored possible interaction effects between 'personal experiences of police corruption' and 'police fairness', to determine whether the effects of the latter depended on the former. The results were significant, if disturbing. They suggested that the influence of police fairness on traffic violations depended on the moral context: where there was greater experience of corruption, 'police fairness' (better PJ) was associated with more, not fewer traffic violations. ${ }^{26}$ The research data did not allow further exploration of this fascinating finding, but - as the authors suggest - it is possible that underlying the data are 'good' rather than 'right' relationships: that is, the officers might have been willing to 'listen to what drivers have to say, explain decisions, show care for drivers' well-being, and avoid discriminatory stops of drivers, yet choose not to enforce the law on account of extra-legal considerations' (p. 11). Overall, therefore, the results of this study suggest that different moral contexts can generate different behavioural reactions to procedural justice; and in policy terms, we might wish to modify our advocacy of PJ by insisting that some (corrupt) versions of PJ are not to be encouraged.

\subsubsection{Comment}

In this section, we have traversed a great deal of ground rather quickly, but it is clear from the discussion that social and situational contexts can very significantly influence perceptions of PJ and legitimacy. Among the relevant issues in this respect are: citizens' deeply held political and moral views; neighbourhood norms; experiences of systematic distributive injustice; the nature of the current encounter with legal authorities (e.g. for police, calls for service versus arrests and searches); citizens drawing inferences about authorities' actions beyond what is actually observed; whether an encounter involves high stakes; experiences of underenforcement; setting aside one's normal perception of authorities in particular situations; and the distinction between 'good' and 'right' relationships. Many of these topics have yet to be explored in depth by scholars, so there remains a significant and challenging agenda for research. 


\subsection{Concluding discussion}

The importance of procedural justice for criminological analysis was first proposed by social psychologists. Social psychologists are, of course, concerned with social issues, but within that framework they focus especially on questions of individual psychology.

We are sociologists, not social psychologists, and in our first joint paper on legitimacy in criminology (which we titled 'Beyond Procedural Justice'), we summarised our position as one of 'going beyond - but emphatically not jettisoning the procedural justice framework' (Bottoms \& Tankebe 2012, p. 169). This stance has been interpreted by some as a rejection of procedural justice as a contributor to legitimacy, but this is incorrect. By 'going beyond' we meant simply that in our view other matters, of a more sociological character, had to be considered in order to explain empirical legitimacy adequately; but when we said we were 'not jettisoning' PJ, we meant just that. Accordingly, in our 2017 paper, we wrote that 'there is no doubt about its [PJ's] empirical importance in relation to police legitimacy' (Bottoms \& Tankebe 2017, p. 75). We remain of the same view today.

In that 2017 paper, we drew for the first time on Bernard Williams' conceptualisation of legitimacy. Within Williams' theoretical framework, we have no doubt that the exercise of procedural justice by state criminal justice agents is a 'basic legitimation expectation' (BLE) that citizens will justifiably express, bearing in mind the evidence that PJ touches crucially on citizens' 'social standing' and their 'feelings of security' within society (Tyler 1990/2006, p. 175). However, it is also pertinent to ask whether PJ will be the only such legitimation expectation that citizens will express to the state and its agents. Our answer is that it will not, and that some other matters (including distributive justice, lawfulness, and effectiveness) will also often constitute reasonable BLEs.

Even if that is so, however, perhaps these other matters will, empirically speaking, be regarded by citizens as much less important legitimation expectations than procedural justice? This seems to be the claim made by Tyler and Meares (2019) when they wrote in a recent paper that 'research points to evaluations of the justice or injustice of the procedures through which the police exercise their authority (i.e. procedural justice) as the key antecedents of legitimacy' (p. 71, emphasis added). However, if these authors are making such a claim, we would have to say that, in some circumstances, it is empirically doubtful, as various examples discussed in this chapter have shown (see for example Epp et al. 2014; Jay 2014; Tankebe et al. 2019). In our judgement, the available empirical evidence does not support the view that any one factor is in all circumstances the key basic legitimation expectation that citizens have of criminal justice systems. Instead, the evidence suggests that in different social contexts different legitimation expectations can be the most important. Accordingly, although in some social circumstances the exercise of PJ might be no more than 'palliative' (see note 19 below), in other circumstances it could be of vital importance. For example, if in a given social area there is a problem of heightened crime and insecurity, improved police effectiveness might be the main route to better legitimacy; but once that problem is resolved, issues of 
procedural justice-such as the respectful treatment of suspects and victims, and greater transparency in decisions-might well replace effectiveness as the most important factor within the structure of legitimacy. ${ }^{27}$ This contextual variability means, in our view, that PJ scholarship should in future pay greater attention to the social and situational circumstances in which PJ is delivered; ${ }^{28}$ and, as our discussion in Section 4.3 of this chapter has hopefully demonstrated, understanding these circumstances fully will be a complex undertaking. Meeting this research agenda will accordingly require the development of a stronger qualitative research literature than currently exists (Tankebe 2014, p. 254), to set alongside the survey work that has so far been dominant in this field of scholarship.

\section{Notes}

l It is important to distinguish these two meanings of the word 'normative' because-as described for example by Meyerson and Mackenzie (2018) - it is possible to formulate instrumental theories of PJ (such as utilitarianism) that are normative in the first but not the second sense. By contrast, social scientists studying PJ usually say that their work is descriptive and explanatory, and therefore not concerned with 'normative ethics' in the first sense. However, within this descriptive/explanatory framework, they draw a distinction between normative and instrumental explanations of human behaviour. Tom Tyler (1990/2006, p. 3) succinctly described this distinction as a contrast between 'the influence of what people regard as just and moral' [normative] and the influence of 'what is in [people's] self-interest' [instrumental].

2 Arising from this definition, we should note an important distinction between 'legitimacy' and what has been called 'dull compulsion' or 'fatalism'. Fatalism exists where there is a marked power imbalance between power-holders and their subjects, and people obey simply because they fatalistically accept that the structures of power, wealth and/or status are inexorably stacked against them (Lockwood 1992, p. 43). This is very different from an uncoerced acknowledgment that power is held rightfully.

3 There can however be a problem with this 'realist' theoretical approach where the content of a citizen-approved BLE is regarded as morally wrong by the governing authority. For a full discussion of this issue see Bottoms and Tankebe (2017).

4 This quotation is taken from a paper on PJ in the specific context of policing. In four places (indicated by square brackets) we have substituted 'authorities' for the original of 'the police'.

5 There has been some lively recent controversy concerning whether the causal links in this proposed sequence have been adequately demonstrated empirically (see Nagin \& Telep 2017; Tyler 2017). This debate is, however, of limited importance for the purposes of this chapter, because the issue of compliance with law (the final stage in the projected sequence, and the one of particular interest to critics) is outside the scope of our discussion.

6 The insights of the Group Value Model (GVM) were subsequently developed in the 'Group Engagement Model' (Tyler \& Blader 2003). This added to the GVM an explanation for why PJ shapes co-operation in groups and societies (p. 352) - a topic that (see note 5 above) is not our focus in this chapter.

7 In a previous paper (Bottoms \& Tankebe 2017, p. 76) we have also tentatively suggested that there may be conceptual links between the group value model of PJ and Axel Honneth's philosophical work on the recognition of individuals (see Honneth 1995; Zurn 2015). 
8 Although the reference here is to a single 'audience', elsewhere in the same paper we make clear that there can be several different audiences for a claim to legitimate authority. For example, when introducing a new operational policy, the Director of Prisons for a given state will certainly have to consider how prisoners will evaluate the justice of the policy; but she will also need to take into account the views of her political masters, and those of the prison staff who will have to implement the policy.

9 Note also that the nature of legitimacy dialogues can change significantly over time. For example, in 2019 Hong Kong experienced a series of conflicts on the streets between protestors and authorities, extending over several weeks. Initially, the demonstrators focused on grievances concerning an extradition law, but later their complaints became more general. Police behaviour was not at first a cause of complaint by protestors, but it later became so as they claimed that police had behaved inappropriately when dealing with some of their demonstrations.

10 See, however, the recent critique of PJ by David Thacher (2019), a central claim of which is that 'procedural justice leaves out lawfulness' (p. 99).

11 See also the comments by David Beetham (1991/2013, p. 137) in the context of the legitimacy of state government more generally: 'the performance of government makes a significant difference to, and forms a necessary component of, its legitimacy...After all, how can the enormous powers of the state be at all justified, or people obliged to obey it, unless it fulfil requirements necessary to the society and their own well being, and that it fulfil them effectively?'

12 An example is the situation in County Donegal, Republic of Ireland, described by Conway (2014) and summarised in Bottoms and Tankebe (2017, p. 86). Documented findings of serious police lawlessness and corruption had little effect on public confidence in the police in that county, for reasons connected with wider features of Irish history and politics.

13 The study included three ethnic groups of roughly equal size: blacks, Hispanics and whites. The only statistically significant differences between groups were that, as compared with black respondents, Hispanics were more likely to mention 'honesty' and less likely to mention 'fairness'.

14 To create the categories used in the research, the research team deliberately hired a research assistant who was not familiar with the academic literatures on legitimacy and trust. From the responses, this assistant created the category 'fairness', which included both procedural and distributive fairness.

15 On the first point, see Dunbar (2014) on the importance of group living within the complex story of human evolution. On the second point, see the classic analysis by the legal theorist Karl Llewellyn (1940) of the need for all social groups to develop ways of handling certain 'law-jobs', if the group is to function well. Among these law-jobs is 'The Say', which covers questions of who is given authority to make different kinds of decisions within the group.

16 On the theoretical importance of macro-social issues wihin democratic legitimacy dialogues, see Loader and Sparks (2013). For a vivid example of the relevance of such issues within a high-profile debate about the legitimacy of various practices in the Illinois prison system in the 1960s, see Jacobs (1977), summarised in Bottoms and Tankebe (2012, pp. 167-168).

17 The 'religious-traditional' factor was not related to legitimacy, possibly because many of the relevant questionnaire items 'measure religious practice instead of directly measuring religious-traditional core normative values' (p. 171). The results for the ethno-national factor bear some similarity to Tyler's (2000) findings that, within the U.S., citizens who identify more strongly with a particular ethnic group (rather than with American society as a whole) are less influenced by considerations of procedural justice and more influenced by whether policies are favourable to their ethnic group. This is because 'they identify more strongly with subgroups than with society, and/or view the authorities as representatives of a group to which they do not belong' (p. 983). 
18 As an exception to this generalisation, the authors cite the work of Anthony Bottoms on compliance; see now Bottoms (2019). See also Sato (2018, pp. 108, 121) on habit as a possible mechanism for co-operation with the police in Japan.

19 This point was recognised by Tom Tyler in a back-cover endorsement of the study by Epp and colleagues on police stops. Tyler wrote that 'polite and respectful police demeanor, while to some extent palliative, cannot assuage the damaging effects of the widespread and systematic use of this policing technique on the minority community'

20 An important exception to the dissensus was a 'remarkable agreement' that at the time of the stop on the motorway, the first officer to approach the stopped vehicle should have politely asked the driver to alight from the car. Instead, he reached into the car and began tussling with the driver, saying 'Get out before I drag you out' (Waddington et al. 2017, pp. 98-99). Note that here the focus groups are strongly endorsing a PJ approach.

21 By contrast, in citizen-initiated contacts, a rapid police response time was positively associated with subjective procedural justice (Model IV).

22 Waddington et al. (2017, p. 126) found that, in assessing police use of non-lethal force, members of the public in their focus groups 'relied, as the law does, on whether [it] is "reasonable"'. However, there was often marked dissensus as to whether the force used in a particular incident was in fact reasonable.

23 A well-known example of this is the case of Stephen Lawrence, a young black man who was murdered in the streets of south London in 1993. A commission of inquiry eventually concluded that the police's failure to take the case seriously had been occasioned by what the commission called 'institutional racism' defined as 'the collective failure of an organisation to provide an appropriate and professional service to people because of their colour, culture or ethnic origin ... [exemplified by] unwitting prejudice, ignorance, thoughtlessness and racist stereotyping which disadvantage minority ethnic people' (Macpherson Inquiry 1999, para. 6.34).

24 In more detail, Bell distinguished cases where (i) women thought that police would be the most effective agency to handle a particular problem ('domain specificity'); or (ii) they foresaw some beneficial outcome in a given situation ('therapeutic consequences'); or (iii) they turned to the police in a quest for protection or to secure leverage with other power-holders ('institutional navigation').

25 There are, of course, parallels to this within policing: see for example Muir's discussion of officers who adopt a 'reciprocator' role, aiming for a reputation as a 'Joe Good Guy' and with a tendency to 'bestow upon the citizen the reciprocal of [their] authority, [their] leniency, the power not to hurt' in exchange for personal profit (Muir 1977, p. 293).

26 Interestingly, the results were the same when the authors substituted 'vicarious experiences of police corruption' for 'personal experiences of police corruption'

27 See, for example, Chen (1997) who argues that legitimacy crises sometimes arise for authoritarian governments even when they are effective in producing economic prosperity. The reason is the emergence of new demands-such as pressure for voice and participation in governance-to which such governments might be ill-prepared to respond.

28 For a congruent message, see Roché and Oberwittler (2018).

\section{References}

Akinlabi, OM 2018, 'Why do Nigerians cooperate with the police?: legitimacy, procedural justice and other contextual factors in Nigeria', in D Oberwittler \& S Roché (eds.), Police-citizen relations across the world: comparing sources and contexts of trust and legitimacy, Routledge, London. 
Beetham, D 1991/2013, The legitimation of power, first edition 1991 Macmillan, London; second edition with new introduction and new Part III 2013, Palgrave Macmillan, Basingstoke.

Beetham, D 2013, 'Revisiting legitimacy, twenty years on', in J Tankebe \& A Liebling (eds.), Legitimacy and criminal justice: an international exploration, Oxford University Press, Oxford.

Bell, MC 2016, 'Situational trust: how disadvantaged mothers reconceive legal cynicism', Law \& Society Review, vol. 50, no. 2, pp. 314-47.

Bottoms, AE 2019, 'Understanding compliance with laws and regulations: a mechanism-based approach', in M. Krambia-Kapardis (ed.) Financial compliance: issues, concerns and future directions, Palgrave Macmillan, Basingstoke.

Bottoms, AE \& Tankebe, J 2012, 'Beyond procedural justice: a dialogic approach to legitimacy in criminal justice', Journal of Criminal Law and Criminology, vol. 102, no. 1, pp. 119-70.

Bottoms, AE \& Tankebe, J 2017, 'Police legitimacy and the authority of the state', in A du Bois-Pedain, M Ulväng \& P Asp (eds.), Criminal law and the authority of the state, Hart Publishing, Oxford.

Bradford, B, Huq, A, Jackson, J \& Roberts, B 2014, 'What price fairness when security is at stake?: police legitimacy in South Africa', Regulation \& Governance, vol. 8, no. 2, pp. 246-68.

Bradford, B, Jackson J \& Hough M 2018, 'Ethnicity, group position and police legitimacy: early findings from the European social survey', in D Oberwittler \& $S$ Roché (eds.), Police-citizen relations across the world: comparing sources and contexts of trust and legitimacy, Routledge, London

Chen, F 1997, 'The dilemma of eudaemonic legitimacy in post-Mao China', Polity, vol. 29 , no. 3, pp. 421-39.

Coicaud, JM 2002, Legitimacy and politics: a contribution to the study of political right and political responsibility, Cambridge University Press, Cambridge.

Conway, V 2014, Policing twentieth century Ireland: a history of An Garda Siochana, Routledge, London.

Dunbar, R 2014, Human evolution, Penguin, London.

Dunn, J 2013, 'Legitimacy and democracy in the world today', in J Tankebe \& A Liebling (eds.), Legitimacy and criminal justice: an international exploration, Oxford University Press, Oxford.

Epp, CR, Maynard-Moody, S \& Haider-Markel, D 2014, Pulled over: how police stops define race and citizenship, University of Chicago Press, Chicago.

Granovetter, M 1985, 'Economic action and social structure: the problem of embeddedness', American Journal of Sociology, vol. 91, no. 3, pp. 481-510.

Hawthorn, G 2005, 'Introduction', in B Williams, In the beginning was the deed: realism and moralism in political argument, Princeton University Press, Princeton.

Hinsch, W 2010, 'Justice, legitimacy, and constitutional rights', Critical Review of International Social and Political Philosophy, vol. 13, no. 1, pp. 39-54.

Honneth, A 1995, The struggle for recognition: the moral grammar of social conflicts, Polity Press, Cambridge.

Jacobs, JB 1977, Stateville: the penitentiary in mass society. Chicago University Press, Chicago.

Jacobson, J, Hunter, G \& Kirby, A 2015, Inside Crown Court: personal experiences and questions of legitimacy, Policy Press, Bristol. 
Jay, A 2014, Independent inquiry into child sexual exploitation in Rotherham. Available at https://www.rotherham.gov.uk/downloads/file/279/independent-inqui ry-into-child-sexual-exploitation-in-rotherham [Accessed December 2019]

Jenness, V \& Calavita, K 2018, “'It depends on the outcome”: prisoners, grievances, and perceptions of justice', Law \& Society Review, vol. 52, no. 1, pp. 41-72.

Jonathan-Zamir, T, Mastrofski, SD \& Moyal, S 2015, 'Measuring procedural justice in police-citizen encounters', Justice Quarterly, vol. 32, no. 5, pp. 845-71.

Kearns, EM, Ashooh, E \& Lowrey-Kinberg, B 2019, 'Racial differences in conceptualizing legitimacy and trust in police', American Journal of Criminal Justice, vol. 45, no. 2, pp. 190-214.

Liebling, A 2011, 'Distinctions and distinctiveness in the work of prison officers: legitimacy and authority revisited', European Journal of Criminology, vol. 8, no. 6, pp. 484-99.

Lind, EA \& Tyler, TR 1988, The social psychology of procedural justice, Plenum Press, New York.

Llewellyn, KN 1940, 'The normative, the legal, and the law-jobs: the problem of juristic method', Yale Law Journal, vol. 49, no. 8, pp. 1355-1400.

Loader, I \& Sparks, R 2013, 'Unfinished business: legitimacy, crime control and democratic politics', in J Tankebe \& A Liebling (eds.), Legitimacy and criminal justice: an international exploration, Oxford University Press, Oxford.

Lockwood, D 1992, Solidarity and schism: the problem of disorder in Durkbeim and Marxist sociology, Clarendon Press, Oxford.

MacCormick, N 2007, Institutions of law, Oxford University Press, Oxford.

Macpherson Inquiry, 1999, The Stephen Lawrence Inquiry: report of an inquiry by Sir William Macpherson of Cluny, Cm 4262, The Stationery Office, London.

McCluskey, JD, Uchida, CD, Solomon, SE, Wooditch, A, Connor, C \& Revier, L 2019, 'Assessing the effects of body-worn cameras on procedural justice in the Los Angeles Police Department', Criminology, vol. 57, no. 2, pp. 208-236.

Mehozay, Y \& Factor, R 2017, 'Deeply embedded core normative values and legitimacy of law enforcement authorities', Journal of Research in Crime and Delinquency, vol. 54, no. 2, pp. 151-180.

Meyerson, D \& Mackenzie, C 2018, 'Procedural justice and the law', Philosophy Compass vol. 13, no. 12, pp. 1-11.

Muir, WK 1977, Police: streetcorner politicians, University of Chicago Press, Chicago.

Nagin, D \& Telep, C 2017, 'Procedural justice and legal compliance', Annual Review of Law and Social Science, vol. 13, pp. 5-28.

Natapoff, A 2006, 'Underenforcement', Fordham Law Review, vol. 75, no. 3, pp. $1715-76$.

Nawaz, A \& Tankebe, J 2018, 'Tracking procedural justice in stop and search encounters: coding evidence from body-worn video cameras', Cambridge Journal of Evidence-Based Policing, vol. 2, pp. 139-163.

Peffley, M \& Hurwitz, J 2010, Justice in America: the separate realities of blacks and whites, Cambridge University Press, Cambridge.

Peyton, K, Sierra-Arévalo, M \& Rand, DG 2019, 'A field experiment on community policing and police legitimacy', Proceedings of the National Academy of Sciences, vol. 116, no. 40, pp. 19894-19898.

Roché, S \& Oberwittler, D 2018, 'Towards a broader view of police-citizen relations: how societal cleavages and political contexts shape trust and distrust, legitimacy and 
illegitimacy', in D Oberwittler \& S Roché (eds.), Police-citizen relations across the world: comparing sources and contexts of trust and legitimacy, Routledge, London.

Roché, S \& Roux, G 2017, 'The "silver bullet" to good policing-a mirage: an analysis of the effects of political ideology and ethnic identity on procedural justice', Policing: An International Journal of Police Strategies and Management, vol. 40, no. 3, pp. 514-28.

Sato, M 2018, 'Police legitimacy and public cooperation: is Japan an outlier in the procedural justice model?', in D Oberwittler \& S Roché (eds.), Police-citizen relations across the world: comparing sources and contexts of trust and legitimacy, Routledge, London.

Skogan, WG 2006, 'Asymmetry in the impact of encounters with police', Policing \& Society, vol. 16, no. 2, pp. 99-126.

Sparks, R, Bottoms, A \& Hay, W 1996, Prisons and the problem of order, Clarendon Press, Oxford.

Sunshine, J \& Tyler, TR 2003, 'The role of procedural justice and legitimacy in shaping public support for policing', Law \& Society Review, vol. 37, no. 3, pp. 513-48.

Tankebe, J 2009, 'Public cooperation with the police in Ghana: does procedural fairness matter?', Criminology, vol. 47, no. 3, pp. 1265-1293.

Tankebe, J 2013, 'Viewing things differently: the dimensions of public perceptions of police legitimacy', Criminology, vol. 51, no. 1, pp. 103-135.

Tankebe, J 2014, 'Police legitimacy', in MD Reisig \& R Kane (eds.), Oxford handbook of policing, Oxford University Press, New York.

Tankebe, J, Boakye, KE \& Amagnya, MA 2019, 'Traffic violations and cooperative intentions among drivers: the role of corruption and fairness', Policing and Society. doi:10.1080/10439463.2019.1636795

Thacher, D 2019, 'The limits of procedural justice', in D Weisburd \& A Braga (eds.), Police innovation: contrasting perspectives, Oxford University Press, Oxford.

Tyler, TR 1990/2006, Why people obey the law, first edition 1990 Yale University Press, New Haven; second edition 2006 (with afterword) Princeton University Press, Princeton.

Tyler, TR 2000, 'Multiculturalism and the willingness of citizens to defer to law and to legal authorities', Law \& Social Inquiry, vol. 25, no. 4, pp. 983-1019.

Tyler, TR 2017, 'Procedural justice and policing: a rush to judgment?', Annual Review of Law and Social Science, vol. 13, no. 1, pp. 29-53.

Tyler, TR \& Blader SL 2003, 'The Group Engagement Model: procedural justice, social identity and co-operative behavior', Personality and Social Psychology Review, vol. 7 , no. 4 , pp. 349-361.

Tyler, TR \& Meares TL 2019, 'Procedural justice in policing', in D Weisburd \& A Braga (eds.), Police innovation: contrasting perspectives, Cambridge University Press, Cambridge.

Waddington, PAJ, Williams, K, Wright, M \& Newburn, T 2015, 'Dissension in public evaluations of the police', Policing and Society, vol. 25, no. 2, pp. 212-235.

Waddington, PAJ, Williams, K, Wright, M \& Newburn, T 2017, How people judge policing, Oxford University Press, Oxford.

Williams, B 2005, In the beginning was the deed: realism and moralism in political argument, Princeton University Press, Princeton.

Worden, RE \& McLean, SJ 2017, Mirage of police reform: procedural justice and police legitimacy. University of California Press, Oakland.

Zurn, C 2015, Axel Honneth, Polity Press, Cambridge. 


\title{
5 Procedure-content interaction in attitudes to law and in the value of the rule of law
}

\author{
An empirical and philosophical \\ collaboration
}

\author{
Noam Gur and Jonathan Jackson
}

\subsection{Introduction ${ }^{1}$}

Analytical jurisprudence tends to operate with clean and sharp conceptual distinctions: content-dependence versus content-independence, substance versus form, legitimate versus illegitimate (merely de facto) authority, and so on. This impulse for sharp delineation has important benefits, such as the promotion of precision and clarity, but it also has at least one, less fortunate, side effect: it can, and sometimes does, blind one to certain nuances and complexities of the studied human phenomenon that do not readily fall on one side of the dividing line between alternative conceptual categories.

The empirical input of the social sciences can help the philosopher avoid, or correct for, such oversights. The point made here is not merely that an empirical perspective can serve to remind the philosopher that psychological realities-such as the realities of our attitudes, motivations, and deliberation vis-à-vis the laware not nearly as 'tidy' as the conceptual systems prevailing in analytical jurisprudence. Our point goes further: empirical findings can draw the philosopher's attention to what are, even from the perspective of his or her own discipline, interesting interrelations between the sharply delineated conceptual categories predominating in his or her field of inquiry. It is in this way that empirical inquiry informs philosophical analysis in the present chapter. ${ }^{2}$

Before outlining our argument, an additional comment is worth making regarding the link between empirical and philosophical inquiries. Empirical research can inform a philosophical discussion in various ways, some of which are straightforward (e.g. the verification of factual assumptions, such as assumptions about the human condition or about what people are like, which form part of a chain of moral reasoning), ${ }^{3}$ whereas others are more contested or might even be accused of making an unwarranted leap from descriptive arguments to evaluative conclusions. But one should take care not to invoke the latter accusation too readily; it would often be unjustified, since theorists working at the interface between empirical and philosophical inquiries normally do not suggest 'that we read morality directly off survey results' (to use the words of Alfano, Loeb, \& Plakias 2018, Section 5.2, in a rejoinder to a similar objection). Rather, work 


\section{Noam Gur and Jonathan Jackson}

done in this vein normally draws on empirical resources in more subtle and qualified ways.

At any rate, our own way of proceeding here is not susceptible to the above charge, because we do not treat empirical findings as the proof of a morally evaluative conclusion, but rather as a source of information that, by highlighting certain features of the attitudinal landscape, which may (but need not) have moral-philosophical parallels, draws the philosopher's attention to certain moral possibilities - possibilities that, in turn, ought to be borne out independently by recourse to morally evaluative arguments. To employ once more the words of Alfano, Loeb, \& Plakias (2018, Section 5.2), '[i]magination needs material to work with'. And, insofar as the material, or some aspect of it, is not readily visible from the philosopher's armchair, it is hard to see why he or she should resist the aid of empirical research, so long as it is used in the qualified manner just described.

A brief overview of our arguments is in order before plunging into substantive discussion. We begin, in Section 5.2, with an empirical discussion focused on survey data from the US about law-related attitudes and predictors of legal compliance. The survey, and the completion of this study, preceded the recent anti-police brutality widespread protests sparked by the killing of George Floyd, a development with likely reverberations in terms of public perceptions of police. But our empirical observations, and the principled inferences drawn from them, can be extrapolated to-and, indeed, can be utilised for analysing - these current changes in the landscape of police legitimacy. Consistent with a series of previous studies, we observe that a fair amount of variation in people's ascriptions of legitimacy to the legal system is explained by perceptions of procedural justice in, and lawfulness of, the operation of police and court officials. In addition, we identify two factors as significant predictors of legal compliance (as inferred from self-report): (i) people's belief that they have a (content-independent, moral) duty to obey the law (one index of legitimacy, as defined here); and (ii) people's moral assessments of the content of specific legal requirements (which is often labelled in the literature as 'personal morality', but which we prefer referring to as 'perceived moral content of laws'). Crucially for present purposes, we observe an interactive relationship between these two factors: higher levels of perceived moral content of laws make the felt duty to obey a better predictor of compliance than it otherwise is, and, similarly, perceived moral content of laws is a better predictor of compliance when the felt duty to obey is relatively strong.

Thus, at the empirical level we find that (perceived) procedural justice in, and lawfulness of, police and courts' actions operates as a legitimating factor and predicts compliance; however, the extent to which it predicts compliance is sensitive, at least partly, to people's substantive assessments of the law's content. This empirical picture prompts us, in Section 5.3, to ask the following question, with a particular focus on the moral significance of the rule of law: Might something like the above interactive modality hold good in a parallel, philosophical context, in the sense that procedure-content interaction is not only a feature of people's attitudes towards the law, but also a feature of the moral significance of the rule of law? 
We propose an affirmative answer, locating the value of the rule of law in a hybrid procedural-substantive source. We advance this claim as an alternative to two rival positions in the jurisprudential discourse: the first ('the procedural morality view', as we refer to it) claims that Lon Fuller's eight precepts of legality embody moral qualities not contingent on the law's content; while the second ('the instrumental view', as we call it) claims that Fuller's precepts are merely principles for the efficient execution of the law's substantive goals (whether morally good or bad), and thus have no independent moral value. In contrast, on the view we propound here, Fuller's principles possess (inter alia) an expressive moral quality, but their expressive effect does not materialise in isolation from other, contextual factors - and, in particular, the extent to which it materialises is partly sensitive to the moral quality of the law's content.

It is worth clarifying that we do not present our philosophical and empirical claims as counterparts of one another. Indeed, apart from their distinct characters qua empirical and philosophical claims, there are certain other differences of focus between them (alongside certain parallels) - for example, the notion of 'procedure' is used by each of them with a different emphasis, with one tending to focus on legal process while the other tending to focus on legal form. But such differences do not pose an obstacle for our line of analysis, since we never suggest that our philosophical claim derives, or can be deduced, from the empirical claim. Instead, as was noted above, we merely regard our empirical findings as a source of information or inspiration that leads us to examine a certain philosophical possibility; and we merely point out what we view as an interesting parallel (rather than sameness or equivalence) between our observations in these two contexts.

Having provided a preliminary sketch of our arguments, we now turn to the empirical part of this chapter.

\subsection{An empirical perspective on law-related attitudes: legitimation, legitimacy, and legal compliance}

We begin this section with a brief overview of our two empirical research questions: (1) What legitimates the police and the law generally? (2) Which normative factors predict compliance with the law? Further to this, we comment more specifically on the two corresponding parts of our analysis, and we then detail our method, measures, and results.

\subsubsection{Brief overview}

Our focus here is on people's ascriptions of legitimacy to the legal system (labelled here 'legitimacy'). We follow an approach in the social sciences that measures legitimacy by reference to two connected judgements (Jackson et al. 2012, 2013; Bradford et al. 2014a, 2014c; Hamm et al. 2017; Huq et al. 2017; Gerber \& Jackson 2017; Bradford \& Jackson 2018; Gerber et al. 2018; for a review of the international literature, see Jackson 2018). The first is the perceived 


\section{Noam Gur and Jonathan Jackson}

normative appropriateness of a legal institution: the institution gains legitimacy from a belief that it wields its power in normatively appropriate ways (for discussion of the appropriateness part of the legitimacy construct, see Jackson \& Gau 2015; Jackson \& Bradford 2019). Normative appropriateness is gauged through survey items referring to the extent of alignment between the institution's general operation and people's sense of right and wrong, such as 'Your own feelings about what is right and wrong usually agree with the laws that are enforced by the police and the courts' (we subsume such items under the heading 'normative alignment'). ${ }^{4}$ Positive answers to such questions suggest that the institution is perceived as having a valid claim to exercise power. The second index of legitimacy refers more directly to the perceived authority to govern (which we assume flows from perceived normative appropriateness), and is commonly measured by asking people questions such as whether they are under a duty to obey the requirements of legal institutions, whether they should obey the law even if they disagree with its content, and so on (for discussion of the obligation-to-obey part of the legitimacy construct, see Bottoms \& Tankebe 2012; Tyler \& Jackson 2013; Trinkner 2019; Pósch et al. 2020). As Tyler and Trinkner (2018, p. 3) state:

Perceptions of legitimacy ... lead individuals to feel that it is their obligation to obey rules irrespective of their content. Hence people authorize legal authorities to decide what is correct and then people feel an obligation to adhere to the law. ${ }^{5}$

Drawing on data from a nationally representative US-based survey, we examine the extent to which legal legitimacy is predicted by people's perceptions of how police and court officials behave. ${ }^{6}$ We consider public perceptions of procedural justice (e.g. impartial and accountable decision-making and the quality of interpersonal treatment in dealings with citizens) and lawfulness. We examine the extent to which these perceived attributes explain variation in police legitimacy and, more generally, legal legitimacy (Figure 5.1). Positive associations are taken to mean that procedural justice and lawfulness are two ways in which the police and other legal institutions legitimate themselves in the eyes of the public.

We also assess the predictors of legal compliance (Figure 5.1). In this regard, of particular interest to us is the extent to which the following two factors interact to explain variation in people's compliance with the law: (i) people's belief that they have a (content-independent) duty to obey the law (the second index of legal legitimacy); and (ii) people's moral assessments of the content of specific legal requirements. Testing an interactive relationship between these two factors, we assess whether a felt content-independent duty to obey the law has what might be termed an 'amplifier effect' on the motivational force of the contentdependent belief that specific laws are morally justifiable, and vice versa. In assessing the above two predictors, we adjust for other factors, such as the perceived risk of sanction and expected social disapproval. 


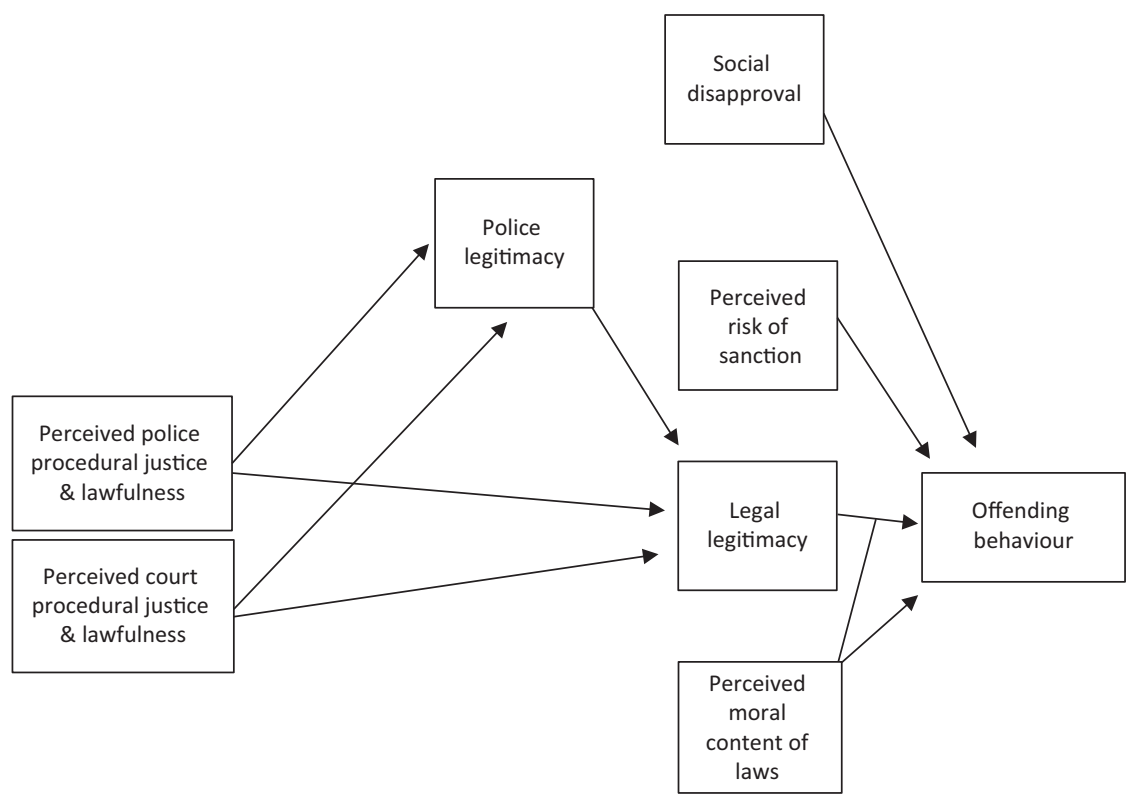

Figure 5.1 Overview of the theoretical model.

\subsubsection{Legitimation: examining the sources of police and legal legitimacy}

Our analysis builds on Trinkner et al.'s (2018) analysis of the same dataset, ${ }^{7}$ which found that police legitimacy was positively predicted by a formative construct based on people's beliefs about officers' actions in terms of interpersonal treatment (e.g. do officers treat citizens with dignity and respect?), decisionmaking (e.g. do officers make unbiased decisions?), and what they call 'bounded authority' (i.e. whether officers respect the limits of their rightful authority). In Trinkner et al.'s analysis, perceptions of appropriate police behaviour predicted police legitimacy, and police legitimacy predicted legal legitimacy more generally. They concluded from this that the police are tangible representations of the law and that interactions with the police provide information not only about police authority, but also about the law and government more generally (Meares 2009; Tyler \& Jackson 2014). On this account, the law's legitimacy is not a given power; rather, it is shaped partly through day-to-day encounters with its agents that serve an educative function in that they facilitate the internalisation of values from which the law gains its legitimacy (Justice \& Meares 2014; Trinkner \& Tyler 2016).

We expand this line of research to include people's perceptions not only of police behaviour but also of how court officials operate, and, as mentioned, we consider in particular perceptions of several primarily procedurally oriented 


\section{Noam Gur and Jonathan Jackson}

qualities as well as lawfulness. Thus, research participants were asked questions such as whether they thought that police and court officials generally make fair and impartial decisions, give people a chance to tell their side of the story, treat people with dignity and respect, make decisions based on the law, and do not arrest people or put them in jail for no reason. We test whether people who believe that officials act in such ways also tend to feel normatively aligned with the police and the law generally and feel a content-independent duty to obey the police and the law generally.

\subsubsection{A mutually amplifying interaction between content-dependent and content-independent factors?}

One method of empirically isolating the law-abiding-and content-independent-motivational force of legal legitimacy involves measuring offending behaviour, estimating its predictors, and focusing on the partial association between offending behaviour and the perceived-authority-to-govern index of legal legitimacy. The statistical modelling used for this purpose controls for the perceived (content-based) moral significance of the acts, the fear of sanction, and the appropriateness index of legal legitimacy. We follow this method here. We build specifically on Trinkner et al.'s (2018) study, which found that duty to obey the law was a significant negative predictor of offending behaviour (e.g. buying goods that might be stolen, shoplifting, and littering illegally), adjusting for normative alignment with the law, the perceived risk of sanction, and the perceived moral significance of the rule's content. ${ }^{8}$ Adjusting for normative alignment with the law in their statistical modelling allowed Trinkner et al. to have greater confidence that the isolated partial association between duty to obey (or, what we referred to as the perceived-authority-to-govern index of legal legitimacy) and legal compliance represents a content-independent motivation to comply.

Now, let us say that:

A is the normative motivation to act/not act in a particular illegal way,

$\mathrm{B}$ is the moral quality one attaches to the particular act (i.e. perceived moral content),

$\mathrm{C}$ is the moral quality one attaches (generically) to abiding by/breaking the law, $\mathrm{B}^{\prime}$ is the amount of motivational force generated by $\mathrm{B}$ alone, and

$\mathrm{C}^{\prime}$ is the amount of motivational force generated by $\mathrm{C}$ alone.

Trinkner et al. (2018) found an additive relationship of $A=B^{\prime}+C^{\prime}$. Thus, for example, the overall normative motivation not to steal (A) equals the sum of the motivational force generated by the (content-dependent) perceived moral wrongness of stealing $\left(\mathrm{B}^{\prime}\right)$ and the motivational force generated by the (contentindependent) felt duty to obey the law $\left(\mathrm{C}^{\prime}\right)$.

Building on Trinkner et al.'s (2018) analysis of their US dataset, we test a novel hypothesis that (content-independent) felt duty to obey the law and perceived moral content of specific laws are not merely additive predictors of compliance, 
but are also interactive predictors of compliance, in the sense that they strengthen each other's link to compliance. Put in the abbreviated form used above, the hypothesis is that $\mathrm{B}$ and $\mathrm{C}$ amplify each other's effect on A. That is, B enhances the motivational force of $\mathrm{C}$, and $\mathrm{C}$ enhances the motivational force of $\mathrm{B}$. For simplified illustration, if we assign the following numerical values, $\mathrm{B}^{\prime}=3$ and $\mathrm{C}^{\prime}=3$, A would be greater than 6 .

\subsubsection{Method}

\section{Sample}

A total of 2,561 respondents were initially drawn from KnowledgePanel, a nationally representative online panel operated by GfK (for more details see Tyler \& Jackson 2014; Tyler et al. 2015; Tyler \& Sevier 2013). The study was described to each individual, an offer of compensation extended, and a reminder email was sent to all people on the list who had not responded after three days. A total of 1,603 individuals completed the survey, representing a response rate of $62.5 \%$. The survey, which was in English or Spanish, was fielded in August and September of 2012 .

\section{Measures}

Because we mostly follow Trinkner et al.'s (2018) approach to conceptualisation and measurement, we direct the reader to that paper for details, while noting below certain differences in the current analysis. Most of the attitudinal measures used a five-point response scale, with higher scores indicating a more positive response to the measured construct.

\section{i) Offending behaviour:}

To assess offending behaviour, respondents were asked how often they had engaged in four different illegal behaviours in the previous five years. The vast majority of respondents reported engaging in no illegal behaviour. We should acknowledge that there is a clear potential for bias with self-report data. Having said that, some comparisons between self-report and other methods have indicated that self-report provides a viable way of establishing frequency of offending action (Hindelang, Hirschi, \& Weis 1981; Thornberry \& Krohn 2000). The four measures of offending behaviour were:

- 'How often in the last five years have you made an exaggerated or false insurance claim?'

- 'How often in the last five years have you bought something you think might be stolen?'

- 'How often in the last five years have you illegally disposed of rubbish or litter?’ 


\section{Noam Gur and Jonathan Jackson}

- 'How often in the last five years have you taken something from a store without paying for it?'

The response categories were 'never' (0), 'once' (1), 'twice' (2), ‘3-4 times' (3), and ' 5 times or more' (4). We took a total count for each research participant. A total of $1,265(82.0 \%)$ had a score of $0,136(8.8 \%)$ had a score of $1,48(3.1 \%)$ had a score of $2,25(1.6 \%)$ had a score of 3 , and $37(2.4 \%)$ had a score of 4 , with a skewed tail due to one person with a score of 16 .

ii) Perceived moral content of laws (aka 'personal morality'):

To measure people's perceptions of the moral quality of each illegal act, we used the following items:

- 'How wrong is it to make an exaggerated or false insurance claim?'

- 'How wrong is it to buy something you think might be stolen?'

- 'How wrong is it to illegally dispose of rubbish or litter?'

- 'How wrong is it to take something from a store without paying for it?'.

The response categories were 'not wrong at all' (1), 'only a little wrong' (2), 'wrong' (3), and 'seriously wrong' (4). We created an index by counting up each research participant's scores. Because of severe skewness of the graph in the range of scores between 6 and 9, and the small number of people in that range, we combined scores from 6 to 9 and created an index from 0 to 6 .

iii) Duty to obey the law:

Responses to the following statements were used to assess the extent to which people consider themselves to be under a duty to obey the law:

- 'People should do what the law says'.

- 'All laws should be strictly obeyed'.

- 'A person who disobeys laws is a danger to others in the community'. ${ }^{10}$

iv) Normative alignment with the law:

Normative alignment with the law was measured using the following indicators:

- 'Your own feelings about what is right and wrong usually agree with the laws that are enforced by the police and the courts'.

- $\quad$ 'The laws in your community are consistent with your own intuitions about what is right and just'.

- 'The laws of our criminal justice system are generally consistent with the views of the people in our community about what is right and wrong'. 
v) Police and courts procedural justice:

Following Trinkner et al. (2018), perceived procedural justice in the operation of the police and courts was measured here through, on the one hand, questions focused on the quality of interpersonal treatment, and, on the other hand, questions focused on the fairness of decision-making. The indicators used regarding police interpersonal treatment were:

- 'How often do the police treat people with dignity and respect?'

- 'How often do the police try to do what is best for the people they are dealing with?’

Similar survey items were used, mutatis mutandis, regarding the interpersonal treatment exhibited by courts (cf. Tyler \& Sevier 2013).

The measures of police fair decision-making were:

- 'How often do the police make fair and impartial decisions in the cases they deal with?'

- 'How often do the police give people a chance to tell their side of the story before they decide what to do?'

- 'How often do the police make decisions based upon the law and not their personal opinions or biases?'

- 'How often do the police explain their decisions and actions in ways that people can understand?'

Similar survey items were used, mutatis mutandis, regarding courts' fair decision-making.

vi) Lawfulness in the operation of police and courts ('police lawfulness' and 'court lawfulness'):

The measures of perceived lawfulness in police behaviour were:

- 'When the police deal with people they almost always behave according to the law'.

- 'The police often arrest people for no good reason' [reverse coded].

The measures of perceived lawfulness in the operation of courts were:

- 'When judges make decisions they almost always behave according to the law'.

- 'How often do courts in your community put people in jail for no good reason?' [reverse coded]. 


\subsubsection{Results}

Relationships among the primary variables of interest are presented in Figure 5.2. ${ }^{11}$ The model should be read as a series of regression paths, representing associations and partial associations between constructs. For example, on the left-hand side there are pathways from four constructs (police lawfulness, police procedural justice, court procedural justice, and court lawfulness) to normative alignment with the police. Here, normative alignment with the police is the response variable (the 'thing being explained') and police lawfulness, police procedural justice, court procedural justice, and court lawfulness are the four potential explanations. As noted below, police lawfulness and police procedural justice emerge as the most significant among the factors explaining variation in normative alignment

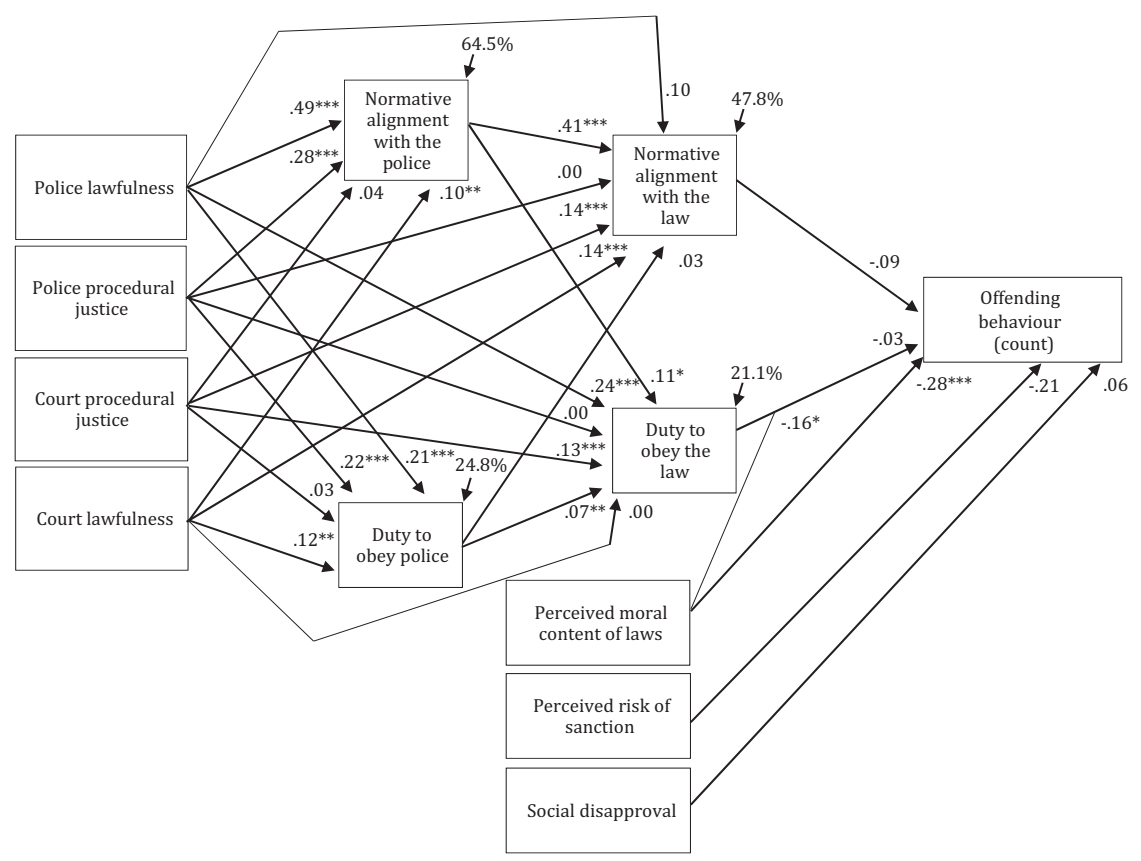

Figure 5.2 A model of procedural justice, police legitimacy, legal legitimacy, and legal compliance, with the interaction between felt duty to obey the law and perceived moral content. Structural equation modelling, predicting, inter alia, a count of offending behaviour (inferred from self-report) using negative binomial regression. Standardised coefficients (STDYX) are given for all but the fitted negative binomial regression part of the analysis (those are unstandardised coefficients). Note: pairs of variables without directed arrows were allowed to correlate. For instance: $r=.13^{* * *}$ normative alignment with the law and duty to obey the law; $r=.29 * * *$ normative alignment with the police and duty to obey the police; $r=.32^{* * *}$ perceived moral content and duty to obey the law; and $r=.08^{*}$ perceived moral content and normative alignment with the law. 
with the police, namely they are the strongest predictors of this response variable. Another thing to note when surveying Figure 5.2 is that standardised coefficients are given for all but the predictors of offending behaviour (unstandardised coefficients are given for offending behaviour because it is a count variable, and a negative binominal regression model is fitted as appropriate to the type of distribution under consideration). So, for instance, the .49 partial regression coefficient for police lawfulness predicting normative alignment with the police should be read as 'a one standard deviation unit increase in police lawfulness is associated with an increase in the expected level of normative alignment with the police of .49 standard deviation units'.

Starting with police legitimacy: just under two-thirds (64.5\%) of the variance in normative alignment with the police is explained, with police lawfulness being the strongest predictor $(B=.49, p<.001)$ and police procedural justice being the second strongest predictor $(B=.28, p<.001)$. When US citizens positively perceive police behaviour as involving lawful action, fair interpersonal interactions with citizens, and fair decision-making, they are more likely to ascribe legitimacy to the institution that officers embody. Additionally, just under one-quarter $(24.8 \%)$ of the variance of duty to obey the police is explained, with police procedural justice being the strongest predictor $(B=.22, p<.001)$ and police lawfulness being the second strongest predictor $(B=.21, p<.001)$.

As regards legal legitimacy, normative alignment with the law $(47.8 \%$ of explained variance) was predicted by normative alignment with the police $(B=$ $.41, p<.001)$, perceived court procedural justice $(B=.14, p<.001)$, and perceived court lawfulness $(B=.14, p<.001)$. Thus, the more US citizens believed that police officers generally act in normatively appropriate ways, the more likely they were to think that the law generally is normatively appropriate. Equally, the more US citizens believed that court officials act in procedurally just and lawful ways, the more likely they were to think that the law is normatively appropriate. Of the variance in felt duty to obey the law, $21.1 \%$ was explained. The main predictor was police lawfulness $(B=.24, p<.001)$, although both aspects of police legitimacy were significant factors (normative alignment, $B=.11, p<.05$; duty to obey, $B=.07, p<.01)$.

Offending behaviour was negatively associated with the interaction between the perceived moral content of laws and the felt duty to obey the law. The partial regression coefficient for the main effect of perceived moral content was $b=$ $-.28, p<.001$, and the partial regression coefficient for the main effect of felt duty to obey the law was $b=-.03, p>.05$. Importantly, the partial regression coefficient for the interaction term between these two factors was $b=-16, p<$ .05 . The parameter estimates indicate that the stronger the felt duty to obey, the stronger the negative statistical association between perceived moral content and compliance with the law. Interactions are symmetrical, so the higher the scores of perceived moral content, the stronger the negative statistical association between the felt duty to obey and compliance with the law.

The range of the perceived moral content index was from 0 to 6 . The range of the duty to obey the law was placed (using principal components analysis) on an index 
1.4

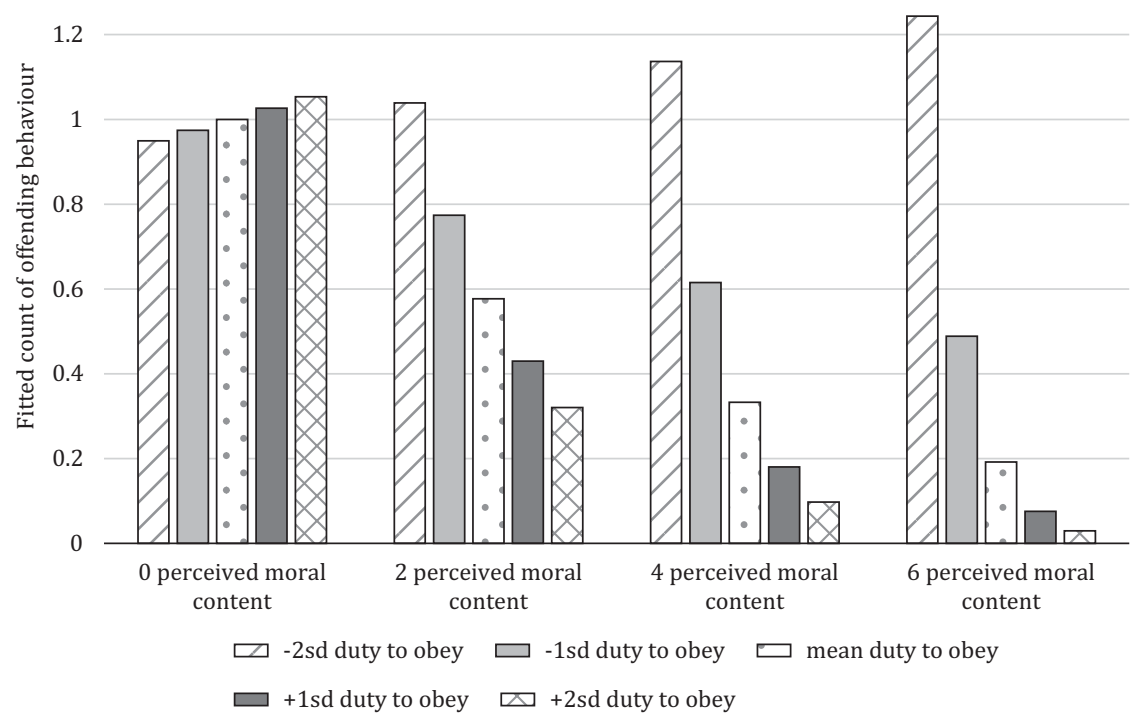

Figure 5.3 Visualising the interactive statistical effects of duty to obey the law and perceived moral content on offending behaviour.

from -3.6 to 1.6 , although hardly anybody had a score below -2 . Figure 5.3 provides fitted counts along the $\mathrm{Y}$-axis and clustered bar charts for scores of perceived moral content of $0,2,4$, and 6 . The five bars in each set represent scores of $-2 \mathrm{sd}$, $-1 s d$, mean $(0),+1 s d$, and $+2 s d$ on the duty to obey index. Note that when the perceived moral content is 0 , there is little difference in the expected counts across the different levels of duty to obey the law. As the perceived moral content increases from 0 to 2,2 to 4 , and 4 to 6 , the negative association between duty to obey and offending behaviour becomes stronger. For instance, if perceived moral content is fixed at the top of the score range (6): when duty to obey is $-2 \mathrm{sd}$, the expected count is just above 1.2; when duty to obey is $-1 \mathrm{sd}$, the expected count is around 0.5 ; when duty to obey is mean $(0)$, the expected count is just below 0.2 ; and so on.

\subsubsection{Empirical conclusions}

Before turning to the philosophical part of this chapter, it is worth summing up our main empirical findings. First, our analysis supports the idea that police legitimacy and, more generally, legal legitimacy are to a significant degree grounded in public perceptions of procedural justice and lawfulness in the operation of police and courts in the US. While our own analysis did not rule out the possibility 
that the arrow of causality goes in the other direction (cf. Nagin \& Telep 2017; Jackson \& Pósch 2019), Trinkner et al. (2019) found in an experimental study that prior perceptions of police legitimacy did not predict judgements of perceived procedural justice.

Second, in prior work (e.g. Tyler 2006a; Jackson et al. 2012; Bradford et al. 2014 b; Trinkner et al. 2018) the perceived moral content of laws was typically found to be the strongest predictor of compliance, while legitimacy was generally also found to be a significant (albeit less strong) positive predictor of compliance, adjusting for perceived moral content. That work has found additive effects of perceived moral content and legitimacy on legal compliance. In comparison, we found a positive statistical interaction between content-dependent values (perceived moral content of laws) and content-independent duty to obey, which means that content-dependent values attached to the required act strengthen (rather than merely add to) the motivational force that a general content-independent duty to obey the law has on people's behaviour (and vice versa). Taking again the example of stealing, people's content-dependent belief that stealing is wrong may form part of their motivation to refrain from stealing, but it may also amplify (rather than just add to) another part of their motivation not to steal, namely that which is generated by their sense that it is wrong to break the law.

\subsection{A philosophical perspective: procedure-content interaction in the value of the rule of law}

In this section, we identify a certain philosophical parallel to the above-observed interactive modality between content and procedure, with a particular focus on the value of the rule of law. Before propounding our ideas, some comments are required on the conception of the rule of law adopted here, its relation to the themes discussed in Section 5.2 above, and the principal controversy surrounding the rule of law's moral significance.

What conception of the rule of law are we assuming for purposes of this analysis? In particular, are we assuming a formal (or procedural) conception of the rule of law, such as Fuller's (1969) and Raz's (2009, pp. 210-218), ${ }^{12}$ according to which rule-of-law requirements pertain only to formal or procedural features of law (e.g. generality, clarity, and prospectivity of legal norms, a hearing by an independent and impartial tribunal, or the like)? Or are we assuming a conception such as Bingham's (2010, p. 67) $)^{13}$ and Dworkin's (1985, pp. 11-12), ${ }^{14}$ which includes also a substantive component in the rule of law, requiring that the content of legal norms conforms to certain standards or values (fundamental human rights, social justice, or the like)?

The conception assumed by our analysis is the formal (or procedural) conception of the rule of law. We adopt such a conception for the following reasons. First, we find merit in some of the objections voiced in the literature against the inclusion of substantive elements in the rule of law-for example, the concern that so doing would render the notion's meaning too open to controversies between differing ideological and political persuasions, thereby eroding the 


\section{Noam Gur and Jonathan Jackson}

notion's distinctive and useful function in theoretical and practical discourse (see expressions of a similar concern in Raz 2009, p. 211; Waldron 2016, Section 5.3). Second, a framework of analysis that lumps form and substance together in one conceptual category, in the way substantive conceptions of the rule of law do, is not likely to best facilitate our primary purpose here, which is to draw attention to a certain relation between form and substance; such a framework of analysis might, even if inadvertently, obscure the distinction between form and substance, and, hence, it might also make it difficult to gain a precise view of their interrelations. Thus, proceeding on a formal conception of the rule of law is likely to be more auspicious for our theoretical purpose. Third, past jurisprudential debate on the moral status of the rule of law, as shaped by dominant contributors such as Lon Fuller (1969), HLA Hart (1965), Nigel Simmonds (2007, 2010), Matthew Kramer (1999, pp. 37-77, 2004), and Kristen Rundle (2012, 2014), among others, has tended to revolve around a formal conception of the rule of law, ${ }^{15}$ and, by way of engaging with past discourse, it would be sensible for us to do the same.

As for the relation between this conception of the rule of law and the themes discussed in Section 5.2 above, it should be noted that there is an overlap between the two, but also that the overlap is merely partial. A clear example of the overlap comes into view when one notes the resemblance between, on the one hand, what Fuller called congruence between officials' actions and declared rules (his eighth principle of legality) and, on the other hand, survey items such as: 'How often do the police make decisions based upon the law and not their personal opinions or biases?'; 'When the police deal with people they almost always behave according to the law'; and '[Do courts] put people in jail for no good reason?'. However, what limits the extent of the overlap and renders it no more than partial is, mainly, the fact that the conception of rule of law assumed here tends to focus on legal form (as defined by Fuller's eight principles of legality), whereas the notions of 'procedural justice' featuring in Section 5.2 tend to focus on legal process. ${ }^{16}$ But, as was indicated earlier, we do not think that such differences undermine our overall line of analysis. This is so not only because the area of overlap noted above is important, albeit limited, but also (and, in fact, primarily) because we do not claim that our philosophical conclusions strictly follow from our empirical conclusions, or that the former are counterparts of the latter. Instead, once more, we merely point out a certain parallel between our observations in these two contexts - that is, a parallel in the modality of interaction between content and procedure/form. This modest claim does not depend for its viability on there being an especially high level of similarity, let alone identity, between the respective contexts of our empirical and philosophical observations.

Reverting to the rule of law, the central contested question among jurisprudential writers in this area can be couched as follows: Do rule-of-law preceptsfor example, generality, clarity, publicity, and prospectivity of legal norms, and congruence between the norms as announced and their actual administrationembody or serve any moral value (or, moral virtue, moral ideal, or the like)? ${ }^{17}$ The literature on this question contains a diverse range of approaches, but for 
present purposes it will be useful to consider two principal positions that have dominated the debate.

\subsubsection{Two conflicting positions on the moral status of the rule of law}

According to the first position, the rule-of-law principles embody a moral virtue not contingent on the law's content. The second position is an antithesis that views the rule-of-law precepts merely as principles for the efficient execution of the law's substantive goals (whether morally good or bad), principles that hold no independent moral value.

The first view is most notably associated with Lon Fuller (1969). To begin with, Fuller approaches his inquiry about law through what can be characterised as a 'purposive' framework of analysis. On this approach, law can be best understood by reflection on its purpose, and, in particular, on the ways it can fail to achieve its purpose and the conditions it must meet in order to achieve it. Famously highlighted by his imaginary tale of the monarch Rex are eight types of failure to craft law in a form fit for its purpose (pp. 33-38). From these eight failures, he derives his eight requirements of legal form: generality; promulgation; non-retroactivity; clarity; non-contradiction; not requiring the impossible; constancy through time; and congruence between official action and declared rules. High level of compliance with these eight precepts represents a form of excellence in legal craftsmanship (pp. 41-42), ${ }^{18}$ whereas, at the lower end of this scale of attainment, these precepts manifest themselves as constitutive elements of law, for a total failure to comply with any one of them results in something that is not a legal system properly so called (p. 39). Most crucially for our purpose, Fuller maintains that these eight formal requirements embody and promote certain moral values. They represent, in his signature terminology, 'the inner' or 'the internal' morality of law- 'inner' or 'internal' because they are integral to the nature of law. This formal or procedural moral aspect is distinguished by Fuller from what he calls 'the external morality' of law (pp. 47 and 96), namely substantive standards of moral behaviour that the law may (or may not) adopt into the content of its rules of conduct. And, in a similar vein, he sometimes describes his eight formal requirements as a 'procedural version of natural law' (pp. 96-97). Drawing on this terminology, we will refer to Fuller's approach as 'the procedural morality view'.

Now, exactly what moral values does Fuller associate with the eight rule-oflaw principles? We can conveniently divide his comments on this into those about direct and those about indirect relations to value. To start with direct relations, he notes, for example, that the last of the eight precepts (i.e. congruence) represents an aspect of reciprocity in the relation between government and citizens regarding the observance of rules, whereby government can be taken to say to the citizen something like: These are the rules we expect you to follow, and if you follow them you have our assurance that we will not sanction you (p. 40). This aspect of reciprocity ties in with a notion of fairness: a government that would sanction a 
citizen without there being any breach of rules on his or her part would be treating that citizen unfairly. In another key remark, Fuller links the eight requirements to respect for human agency and dignity. He notes that 'the view of man implicit in' these eight requirements is that of 'a responsible agent capable of understanding and following rules, and answerable for his defaults' (p. 162), and that every departure from these requirements 'is an affront to man's dignity as a responsible agent' (p. 162). As mentioned above, Fuller draws attention to some further, indirect moral significance of his eight requirements. He notes, for example, that acting by known rules is a precondition for any meaningful appraisal of the justice of the law, both by the public (because minimum consistency, promulgation, clarity, etc., expose actions to public scrutiny (p. 158)) and by the lawmaker herself (because people tend to be more answerable to their own conscience when they have to articulate what they are doing (p. 159)). Thus, in Fuller's view, although the eight requirements are about procedure rather than content, they create conditions conducive to the moral quality of the law's content.

The second, contrasting stance is most prominently reflected in the views of HLA Hart (1965) and Joseph Raz (2009). ${ }^{19}$ Hart accuses Fuller of conflating two different notions: morality and purposive activity (Hart 1965, pp. 1285-1286). Fuller's eight requirements of legal form, claims Hart, are principles for the efficient execution of a purposive activity - and a purposive activity can be morally good or morally bad, depending on the specific purpose pursued. Hart's illustrative example is the activity of poisoning-a purposive activity, whose purpose is to kill another being (p. 1286). Poisoning, Hart points out, also has 'internal' or 'inner' principles: for example, 'Avoid using poisons which cause the victim to vomit' or 'Avoid using poisons if their shape, color, or size is likely to attract notice and alert the intended victim' (p. 1286). But we would not, of course, call these principles of the poisoner's art 'the morality of poisoning'. And this point, Hart maintains, extends to the context of law: since, for him, law can be a vehicle for either morally worthy or morally depraved ends, we should avoid the slip from talking about its inner principles of operation as a purposive practice to talking about its inner morality.

Raz also put forward a number of notable objections to the idea that the rule of law embodies a moral quality. One of his objections builds on, and partly echoes, Hart's argument described in the previous paragraph. Conformity with ruleof-law principles (e.g. promulgation, clarity, prospectivity, and consistency), Raz points out, is essential to law's ability to guide conduct. It has, in other words, an instrumental significance, in that it enables the law to effectively achieve the direct goals it adopts (Raz 2009, pp. 225-226; hence, we will refer to this approach as 'the instrumental view'). But, like many other instruments, it can be utilised for good or ill purposes-namely, the substantive purposes that law is able to secure by effectively guiding conduct can be either morally good or morally bad (depending on the content of the law in question). That is why, according to Raz, the rule of law should not be conceived of as a moral virtue, though it is, in his view, a virtue of law. This last distinction-and, more generally, the notion 
that we can speak of some property as virtuous, but not as morally virtuousseems to comprise Raz's primary supplement to the initial argument of Hart. Raz fleshes out this distinction through a non-legal example: the property of sharpness as it relates to knives. Sharpness is part of what makes a knife effective, but the knife can be used for either morally good purposes (say, to prepare food for a person in need) or for morally ill purposes (say, to murder a person). So, sharpness is not a moral virtue, but we can nonetheless say that a sharp knife is a good knife-which is to say that sharpness is a good-making characteristic of knives. It is a virtue of knives, but not a moral virtue. And, according to Raz, something analogous holds in our context: namely, the rule of law is to law what the sharpness is to a knife-which is to say that the rule of law is a virtue of law, but not a moral virtue ( Raz 2009, p. 226). We should add that, in light of a recent revision by Raz of his view on the rule of law (Raz 2019), we are unsure as to whether he still maintains the above objection; but, since our purpose is not exegetical, this doubt is immaterial to our argument.

\subsubsection{Critical assessment and an alternative proposal: the hybrid view}

We will comment on the two foregoing positions and put forward our own approach. The instrumental view, as explained above, declines to attach moral value to the procedure embodied in the rule of law; the rule of law can at most serve morally valuable substantive goals reflected in the content of certain laws (insofar as this is the case). This, we will argue, is an erroneous position. The procedural morality view, on the other hand, ascribes to rule-of-law procedures moral value, which it views as entirely independent of the content of law. This, too, is erroneous in our view, as will be explained below. How can both these positions be mistaken at once? And if they are, what is the correct position? There is, we suggest, a middle path between these two positions, which better captures the moral significance of the rule of law. This middle path emerges into view with the following, twofold recognition: a given procedural feature of law can have a genuine moral-value-endowing quality (i.e. a genuine capacity to contribute, in itself, to the moral value of law); and yet, at the same time, the materialisation of that moral value - namely, the degree to which, or even whether at all, it materialises-may be partly sensitive to the law's content and substantive ends.

The twofold recognition just stated (which will assume a more concrete form below) reflects a type of hybridity between procedural and substantive moral qualities-hence, we term our proposed view 'the hybrid view'. The possibility of a hybrid modality involving content and procedure initially surfaced (if in a somewhat different form) in the course of our empirical analysis in Section 5.2. It was observed there that, empirically speaking, each of the following factors makes a significant contribution to compliance: (i) content-specific assessments of individual laws, and (ii) ascriptions of legitimacy to the legal system, which are themselves predicted significantly by perceived procedural justice and lawfulness. But 
the analysis also revealed an interactive, and synergetic, dynamic between these two factors, one aspect of this interaction being that higher levels of contentspecific moral approval make legitimacy - and, by implication, make perceived procedural justice and lawfulness - a better predictor of compliance than it otherwise is. ${ }^{20}$ When it comes to people's attitudes towards the law, then, procedural qualities perceived in the application of law operate as a legitimating factor and have a genuine influence on people's actions, but the extent of their influence is sensitive, at least partly, to people's substantive assessments of the law's content. This empirical picture prompts us to ask: Could it be the case that this (or some comparable) type of content-procedure hybridity not only is a feature of people's common attitudes towards law, but also characterises the actual moral significance of some attributes of law? We consider this possibility here with a focus on rule-of-law attributes. So the question can be couched as follows: Is there a philosophical explanation whereby the moral significance of the rule of law is shown to consist, wholly or partly, in content-procedure hybridity? We believe there is such an explanation, and will outline it in the following paragraphs.

The explanation starts with the moral value (or, at any rate, potentiality for moral value) attributable to procedural (or formal) rule-of-law features. In this regard, we believe that, whatever might be said of its deficiencies, Fuller's view contains some true insights. Thus, for example, it seems cogent to say that adherence to the rule of law contributes to the moral quality of the relation between government and citizens by securing a type of reciprocity between them with regard to the observance of rules. ${ }^{21}$ And there seems to be sound (if insufficiently qualified) intuitive sense to the claim that rule-of-law observance expresses-at least at a certain procedural level—respect for human dignity, and that it implicitly envisions the subject as a responsible agent in terms of her engagement with rules and ability to plan her actions in response to them. ${ }^{22}$ So, too, we find a good deal to agree with in subsequent elaborations or restatements of Fuller's position by some of his proponents, such as Simmonds' arguments about the rule of law's contribution to liberty (in the specific sense of independence of the will of another; Simmonds 2007, pp. 99-103 $)^{23}$ and Rundle's elucidation of the relation between legal form and human agency (Rundle 2012, pp. 8-11,97-101). ${ }^{24}$ It is, perhaps, easy to lose sight of the kernel of truth in these positions when dealing with the topic with purely theoretical tools at a relative distance from its practical settings. But even a brief consideration of the practical experience of those at the receiving end of violations of the rule of law should elicit appreciation of the good sense contained in the foregoing views. Consider, for example, the position of a participant in a legally permissible demonstration who is nonetheless detained by the police and held in custody without having violated any previously declared rule (some 'reason' is invoked-say, that he engaged in 'disorderly behaviour' but it is not traceable to any rule). Or, take the case of a shopkeeper who is ordered by the authorities to close her business on account of a failure to comply with regulations that were worded in a language too ambiguous to understand what they actually require. Would these individuals not be correct in thinking 
that the conditions enabling their agency have been prejudiced, and that their liberty (in the sense mentioned above) has been compromised? And, as far as expressive value is concerned, would individuals subjected to such treatment not be right to consider it an expression of disrespect for their agency and autonomy, and to feel an affront to their dignity? An affirmative answer to these questions seems to hold a compelling level of intuitive appeal.

So, why not view the value of the rule of law as dependent purely on procedural (or formal) attributes? What sort of content-procedure interaction do we recognise that leads us, instead, to adopt a hybrid understanding of that value? One principal type of content-procedure interaction revolves around the expressive significance of the rule of law. While adherence to rule-of-law standards is capable and apt to bear the expressive significance highlighted in the previous paragraph, its expressive effect partly depends for its materialisation (or, at least, its full materialisation) on contextual factors; and, as part of this, the degree to which it materialises is sensitive to the moral quality of the law's content. ${ }^{25}$ This claim rests on a recognition that is hardly unique to the specific context of the rule of law. What we observe here, in other words, is a particular case of the general way in which actions derive their expressive significance: they acquire their expressive significance partly by virtue of their own attributes, and from social conventions about their meaning, but their meaning and the message they convey are also sensitive to contextual factors (contextual factors which include, inter alia, other actions originating from the same source). We say more on this in the following section.

\subsubsection{Expressive value, contextual factors, and the rule of law}

To substantiate the above claim, some general comments on the expressive force of actions are required. To start with, it is a conspicuous fact and a salient feature of everyday life that many of our actions, including non-verbal actions, carry expressive significance - that is, they convey meanings (Sunstein 1996, pp. 2021-2022). ${ }^{26}$ Moreover, it seems difficult to adequately capture the richness of our normative and moral lives without accepting that the expressive meaning of an action, in at least some instances, morally matters, and (on the flipside) that whether the action is morally desirable, right, virtuous, or not, may depend (at least in part) on its expressive meaning (in this vein, see, e.g., Pildes \& Anderson 1990; Nozick 1993, pp. 28-32; Anderson \& Pildes 2000; Khaitan 2012, p. 4). It falls outside the scope of this chapter to provide a comprehensive account of the expressive significance of actions. We will thus largely operate within the framework of existing theories and mostly confine our explanatory comments to what is directly material to our claim.

One distinction worth noting at this point is between actions whose entire point is expressive (e.g. gestures such as salutation, tipping one's hat, bowing, shaking someone's hand, or kissing the picture of a loved one) and actions that have other, non-expressive purposes (consisting, e.g., in their physical or 
economic effect) but which also carry expressive meanings (e.g. physically assaulting another with the aim of causing them bodily harm normally also expresses disrespect for their dignity). ${ }^{27}$ In the interest of clarity, it seems warranted to reserve the label 'expressive action' for the former type, and to use a somewhat more inclusive language (e.g. 'expressively significant action') when referring to the latter type or to both types. Now, typically, where actions hold expressive moral significance, what those actions manifest is an attitude-for example, an attitude towards some person or persons, be it contempt, care, compassion, forgiveness, courtesy, or some other kind. But this is not to say that expressive meaning is reducible simply to the actor's (or indeed to any other person's) subjective state of mind (Anderson \& Pildes 2000, pp. 1512-1513, 1574). To give one example, an action can be offensive even when the actor is oblivious to its offensive meaning or positively believes that it conveys some other inoffensive meaning (p. 1524). Although the actor's subjective state of mind is morally relevant, regard must be had to other factors, whether for pragmatic or substantive reasons. Determinations of expressive meaning, as emphasised by several writers, are exercises of interpretation or construction that are at least partly guided or constrained by objective standards (Anderson \& Pildes 2000, pp. 1512, 1525; Khaitan 2012, pp. 9, 11-13). In some instances, such determinations will involve a relatively high measure of changeability according to local conventions and cultural codes - by way of example, subtly acting as if you have not noticed an acquaintance in the street in order not to be held up in a conversation might be socially acceptable in some cultures, but might come across as aloof and unsociable in other cultures. ${ }^{28}$ In other instances, however, it may be warranted for the attribution of expressive meaning to transcend, or break away from, specific social convention in response to less (or non-) contingent considerations. To borrow an example from Anderson and Pildes (2000), even when it was socially acceptable for 'men in business settings to routinely compliment their female colleagues and subordinates on the way they looked', there was nonetheless something insulting in that behaviour, in that it 'amounted to treating women as if they were not serious workers, but merely sexual or aesthetic adornments in a business scene' (pp. 1524-1525).

Especially pertinent to our argument is the following point. As is normally the case with exercises of interpretation, the attribution of expressive meaning to an action is sensitive to the context, and the context may include, inter alia, other actions originating from the same source. Context-sensitivity is a familiar and widely accepted feature of interpretation, certainly when it comes to the interpretation of verbal utterances, and there is no reason, it seems to us, to make an exception in this regard for the interpretation of non-verbal actions. ${ }^{29}$ Moreover, as a concomitant to the preceding point, contextual factors may bear on the attribution of moral significance to both verbal utterances and non-verbal expressive actions. Suppose, for example, a speaker (Jessica) begins a statement with the words 'With all due respect to X ...', but the rest of the statement is, in content and/or style, disrespectful to X. Should this not reflect on the expressive meaning 
and significance we are ready to assign Jessica's words 'With all due respect', perhaps inclining us to construe them as words of irony rather than an actual expression of respect? And should we not say something similar when the case involves, instead of an utterance, an expressive gesture-as, for example, when James shakes hands with George or smiles at him, but all the other actions he performs before and after that gesture are invariably unfriendly to George? It seems highly cogent to think that the full view of James' behaviour towards George detracts from, or undermines, the expressive significance his gesture could otherwise have, or even imbues it with the negative quality of a formal device used to disguise an improper attitude. Or, further consider Mark's actions of holding the door open for his companion or placing a hand on the companion's shoulder during their conversation. Are his actions courteous and friendly, or are they patronising? The answer may be sensitive, inter alia, to whether the general context of their relationship involves actions of domination and superiority, or instead respect between equals. Further examples in this vein, involving expressive or expressively significant actions, can be constructed. ${ }^{30}$

Actions by a legal authority, which are the type of action of interest here, are no exception to the above point: the expressive significance of such actions, or of any given aspect thereof (e.g. their procedure or substance), is also sensitive to context. As Hellman puts it in an article discussing the expressive meaning of government actions through the prism of the Equal Protection Clause, 'understanding their meaning [is] an inherently contextual task' (Hellman 2000, p. 29). And the context, it should be stressed, may include not only its (non-legal) factual backdrop, but also related actions of the same institution or related aspects of its operation. Consider, first, an example illustrating the context-sensitivity of expressive meaning within the law. In the case of County of Allegheny v. ACLU, 492 US 573, 601 (1989), the US Supreme Court considered whether two displays of religious symbols on public property in Pittsburgh amounted to endorsements of religious beliefs in violation of the First Amendment's Establishment Clause. ${ }^{31}$ Justice Blackmun for the court made the following remark on how the test should be applied:

the government's use of religious symbolism is unconstitutional if it has the effect of endorsing religious beliefs, and the effect of the government's use of religious symbolism depends upon its context.

Applying this test, Blackmun ruled that in one of the displays, which set a Hanukkah menorah next to a Christmas tree and a sign saluting liberty, the settings neutralised any message of endorsement of Judaism that might otherwise be conveyed by a menorah, whereas in the second display, where a crèche was displayed alone, the crèche retained its religious meaning.

Contextual factors do not cease to be relevant when the law's expressive significance is analysed from a moral standpoint. Thus, when we consider the 


\section{Noam Gur and Jonathan Jackson}

expressive moral significance of the law's procedural or formal mode of operation, the relevant context may encompass, inter alia, the law's substance or content. Suppose, for example, that your legal system limits its impositions on you to the confines of previously declared rules - a procedural mode of operation that can normally be regarded as an expression of respect for your dignity-but the content of its rules expresses the opposite attitude, disrespect for your dignity, in that it oppresses you or wrongly discriminates against you. ${ }^{32}$ The content of its rules, on our approach, detracts from the message of respect its procedures could otherwise convey - it takes away from its credibility as an expression of a genuine attitude of respect. Indeed, it is not unreasonable to suspect that a government of this sort conforms to the rule of law not out of respect for its citizens, but in order to mask its iniquitous agenda with a mantle of legitimacy, and in this way to lower people's moral guard and avoid civil resistance-a strategy involving a form of manipulation that actually signifies an attitude of disrespect for citizens' autonomy, agency, and dignity. And, in a similar vein, such content-procedure hybridity can manifest itself in positive terms too: namely, when the rule of law is adhered to in a context where government also shows respect for citizens by adopting morally appropriate substantive policies into its laws, the expressive value of rule-of-law adherence, and the relational quality attached to it, are likely to materialise and flourish to their fullest potential.

To forestall possible misunderstanding, note that the hybridity we identify here concerns the value of the rule of law (and the conditions for the materialisation of that value), not the question of what the rule of law is (i.e. which requirements it includes). The latter question was commented on at the outset of Section 5.3, where we adopted for the purpose of this analysis a formal or procedural conception of the rule of law; our proposal does not depart from this presupposed conception.

Finally, how do we perceive the relationship between our argument and relational theory of procedural justice? As we see it, our argument dovetails well with relational theory of procedural justice, even if it is not strictly dependent on it or exclusively bound up with it. A few words of explanation are required. Relational theory of procedural justice (in its normative variety propounded by Meyerson \& Mackenzie 2018) locates the value of procedural justice in 'the message of social inclusion and equality sent by satisfactory interpersonal interactions with authorities' (p. 7), and its positive contribution to individuals' sense of self-respect and self-worth. The evaluative frame of reference used by this approach is focused neither on the community per se nor on a socially atomistic notion of the individual, but rather on the individual as a social creature whose identity is constituted through interpersonal relationships and in the context of the broader social and political environments' in which he or she lives (p. 6).

Now, by way of relating this outlook to our own argument, two aspects of their compatibility should be highlighted. First, like our own argument, the relational conception of procedural justice contains reference to, and (at least implicit) recognition of, the expressive significance of actions. Thus, for instance, the relational conception of procedural justice adverts to the 'message of social 
inclusion and equality sent by satisfactory interpersonal interactions with authorities', noting that satisfactory treatment by group authorities 'symbolically communicates the information that we possess value or status in the eyes of our community' (p. 7, emphases added). Such expressive attributes possibly suggest that the relational conception of procedural justice should even be subsumed as a specific variety of expressive theories of value. Second, a relational outlook seems particularly auspicious for our argument, or at any rate to one crucial element of our line of reasoning - namely, our emphasis on context-sensitivity in the attribution of expressive significance to actions. This is so for the following reason. The very idea of a social or interpersonal relationship implies an enduring connection and association between the relevant parties that extends beyond a mere one-off interaction, and it is plausible that this sort of relational backdrop would also reflect on the expressive significance attached to actions done in a relationship. Thus, especially in the context of a relationship-be it a relationship of friends, spouses, employer-employee, or government-citizen-it seems appropriate to attach expressive significance to various actions not by seeing them in complete isolation from one another, but by taking a more holistic view of the relationship and of certain other actions performed in it. This notion is highly consonant with our claim that the expressive significance of legal procedure or form is sensitive to its context, and to the law's content as part of that context. To couch an example borrowing the terminology of relational theory, 'the message of social inclusion and equality' sent by adherence to due procedures will be, ceteris paribus, considerably attenuated (if not completely obliterated) where the associated laws have, say, racially segregating or gender discriminatory content, rather than just and equitable content. In sum, then, although our line of reasoning has not been developed in terms confined to relational theory, a relational outlook, we believe, strikes a particularly harmonious tone with our argument.

\subsection{Conclusion}

This collaborative work initially put forward a number of empirical claims regarding law-related attitudes and predictors of compliance, which, in turn, inspired a fresh engagement with the legal-philosophical question of the moral status of the rule of law.

Our empirical observations were summarised at the end of Section 5.2. At this point, it suffices to reiterate one key empirical finding regarding the interactive effect between procedural attributes and lawfulness on the one hand and moral content on the other. While we observed that procedural justice and lawfulness perceived in police and courts' operation predict people's compliance (as inferred from self-report), we also found that the strength of their predictive quality is sensitive to people's substantive assessments of the law's content. In particular, higher levels of moral approval of a given rule's content render the (more generic) ascription of legal legitimacy — and, by implication, render perceived procedural justice and lawfulness-a better predictor of compliance than it otherwise is. 


\section{Noam Gur and Jonathan Jackson}

In Section 5.3, we put forward a jurisprudential argument with a certain parallel to the above interactive phenomenon. The specific context of this argument was the debate over the moral value of Fuller's rule-of-law precepts. Fuller's procedural (or formal) precepts, we recognised, have a genuine capacity to carry expressive moral value, but we argued that the realisation of their expressive potential involves (and depends upon) a type of hybridity of procedure (or form) and content. In other words, the expressive effect of these procedural (or formal) requirements does not materialise in isolation from other, contextual factors; and, in particular, the extent to which it materialises is partly sensitive to the moral quality of the law's content. This, we suggested, is a specific case of the general way in which actions derive their expressive significance: they acquire their expressive significance partly by virtue of their own attributes, and from social conventions about their meaning, but their meaning and conveyed message are also sensitive to contextual factors (including other actions originating from the same source). Thus, if certain aspects of government's operation are such that they normally express respect for your dignity (e.g. limiting its impositions on you to a set of previously declared rules), but other related aspects of its operation are such that they clearly express the opposite attitude, namely disrespect for your dignity (e.g. subjecting you to rules whose content oppresses you or wrongly discriminates against you), then the latter contaminate the message of the former, detract from it, or take away from their credibility as expressions of a genuine attitude of respect. And the same idea has a positive facet: when the rule of law is adhered to in a context where government also shows respect for citizens by adopting morally appropriate substantive policies into its laws, the expressive value of ruleof-law adherence is then likely to materialise and flourish to its fullest potential.

\section{Notes}

1 We are grateful to the editors for their valuable comments and suggestions. We also thank Charis Kleio Bagioki and Zinat Jimada for their diligent work as research assistants in connection with this chapter.

2 That jurisprudence can benefit from-or, even, that it is essential for it to draw on-social scientific empirical inquiry is a notion endorsed by a sizable number of theorists (in various distinct versions not necessarily fully identical to our own). See, for example, Roger Cotterrell (2018, Chapter 4); Nicola Lacey (2010); Brian Leiter (2007, 2009); Brian Tamanaha (2000, esp. p. 288); William Twining (2009); Kevin Walton (2015). Regarding Leiter's position, see also the discussion in Dickson (2011).

3 As can be seen, e.g., in Gur (2018, pp. 110-131, 181-192).

4 Wording the measures of perceived normative appropriateness in a general way (as done, e.g., in the above cited survey item) avoids the imposition of specific criteria, thus leaving which specific criteria people use for judging appropriateness an open empirical question (Tyler \& Fagan 2008; European Social Survey 2011; Jackson et al. 2013; Tyler \& Jackson 2014). We follow the same approach here.

5 See Trinkner (2019) for discussion of whether Tyler (2006a, 2006b) specifies duty to obey as downstream to legitimacy or a constituent of legitimacy.

6 For discussion of the distinction between possible sources of legitimacy and constituent components of legitimacy, see Huq et al. (2017); Jackson (2018); Jackson \& Bradford (2019); Trinkner (2019). 
7 With some limited modifications, namely a few survey items from their dataset that are not used, or that are used differently, in our analysis.

8 See also evidence on tax compliance from Murphy et al.'s (2016) Australianbased study.

9 In theory, a negative response to this item might be compatible with a belief in an overridable (or 'prima facie') duty to obey the law. But we still consider that respondents' choice on a five-point scale are, by and large, indicative of the strength of their felt duty to obey (an assumption reinforced by the fact that we found the above three items to be strongly correlated); and, at any rate, positive responses to this item indicate a felt duty to obey.

10 It is worth noting that this item is framed generically (referring to 'laws', not, e.g., to 'some' or 'certain' laws) and unconditionally ('is', not, e.g., 'can be' or 'can be, depending on which law ...'), which means it is indicative of a duty not contingent on the content of any specific given rule. This is also reinforced by the fact that we found the above three items to be strongly correlated.

11 Like Trinkner et al. (2018) we use MPlus to fit a path analysis model (using full information maximum likelihood to deal with missing values). We also treat the constructs as formative, in the sense that the measures constitute the construct. Components scores from principal components analysis for the separate indices (with the exception of police lawfulness and court lawfulness, since they had only two indicators each) were saved using Stata and imported to MPlus.

12 A less univocal example in this regard is Dicey's (1885) notion of the rule of law: his notion seems largely procedural, though certain aspects thereof are interpretable as substantive. See relevant analysis in Craig (1997, pp. 470-474).

13 Other notable former judges who endorsed this conception include Aharon Barak (Barak 2006, p. 55) and Arthur Chaskalson (quoted in Agrast, Botero \& Ponce 2011, p. 9).

14 Cf. Allan (1993, ch. 2, 2001, esp. chs. 2-3). See also the discussion in Craig (1997, pp. 477-479, 481-483).

15 Indeed, a substantive conception might be thought to obviate the question of whether the rule of law embodies or serves any moral value.

16 There are conceptions of the rule of law (e.g. Raz 2009, pp. 214-218; Waldron 2008, pp. 6-9) that include both formal Fullerian attributes and process-related attributes. While there are good reasons to view such conceptions as more complete than Fuller's, as said above contemporary debate over the moral significance of the rule of law has frequently centered on Fuller's legality precepts, and, in the limited context of the present discussion, our focus will be similar.

17 This question, it is worth noting, closely bears on the debate over the so-called separability thesis (i.e. over whether there is a necessary conceptual connection between law and morality, and, if so, what it is); and it also bears on issues such as law's capacity to morally bind and to give reasons for action. Regarding the separability thesis, see: Gardner (2012, pp. 27, 48, 193-194, 221-237); Simmonds (2007, pp. 70-73, 2010, pp. 281-283); Green (2008).

18 Though Fuller also explains that prefect realisation of all of these eight principles is 'not actually a useful target for guiding the impulse toward legality' (Fuller 1969, pp. 4l-46).

19 A similar stance is notably adopted and defended by Matthew Kramer (e.g. Kramer 2004). Also note that, while our reading of Hart and Raz is consistent with the standard interpretation of their position, other interpretations have been put forward. Cf., for example, the interpretation offered by Mark Bennett (2011).

20 An interaction in the opposite direction was also observed: namely, content-specific moral approval is a stronger predictor when legal legitimacy is higher.

21 A claim endorsed by Finnis too (2011, p. 274). See also Murphy's (2005) advocacy of this claim. 
22 See also, in this vein, Waldron (2008, esp. pp. 27-28).

23 To wit, Simmonds (2007, p. 101 ) explains that he refers to 'liberty' not in the sense of how wide one's range of optional actions is, for he acknowledges that rules may restrict that range. Instead, he means 'liberty' in the sense that the limits of that range of actions are, at any given point in time, independent of the present will of another person. The rule of law prohibits the ruler from exercising force outside the scope of rules laid down in advance; thus, what we are allowed or not allowed to do at any given point in time is determined by those rules, and not by the present will, or whim, of the rulers. In this connection, see also Hayek (1943, Chapter VI).

24 See also Gur's (2014) discussion of the above work and Rundle's reply (2014, pp. 139-142, 144-147). On effective agency in Fuller's work, see also Winston (1994).

25 In a valuable article on the rule of law, Coleen Murphy briefly makes at one point a statement that can be understood as consistent with our hybrid view (Murphy 2005 , p. 252).

26 Or, as Taylor (1979) puts it, they manifest something in an embodiment.

27 Cf. Wittgenstein's (1993) distinction between instrumental or effective action on the one hand and ritualistic or expressive action on the other.

28 For another example to a similar effect, see Sunstein (1996, p. 2022). See also related point in Taylor (1979, pp. 79-80).

29 Indeed, it is arguable that the role of context in the interpretation of non-verbal expression is often greater than it is with regard to verbal expression, because non-verbal means of expression are often more ambiguous than verbal ones.

30 In some instances, contextual factors that bear on the expressive significance of an action can be cited either separately from the action or as part of the action, depending on which action description is adopted. Consider, for example, Martin's act of supplying food for the sustenance of a certain group of people. Does the action express care and compassion, and, if so, to what extent? This may depend on further factors, such as whether that group consists of destitute homeless people whom Martin came upon or is, in fact, a group of hostages held by Martin. But such factors can plausibly be included in the action description itself (e.g. 'Martin supplies food for the sustenance of destitute homeless people whom he came upon/hostages held by him'). However, our point in the accompanying body-text paragraph is a general one that holds irrespective of this type of example, not least because (expressively relevant) contextual factors cannot always be incorporated in what is a reasonably intuitive (as opposed to, e.g., an oddly contrived or strained) description of an action. Moreover, the essential point of our position on the expressive value of the rule of law-i.e. how that value is sensitive to both the form and the content of the law-could be defended even if formal and content-related features of the operation of legal authority were to be brought together under one action description. For a general discussion of action individuation, see, e.g., Anscombe (1957, $\$ \$ \$$ 6, 23-26); Davidson (1971); Goldman (1971); Thomson (1971); Gallagher (2020, ch. 1).

31 See relevant discussion in Hellman (2000, esp. pp. 25-26); Anderson \& Pildes (2000, pp. 1545-1551).

32 For some relevant examples in the context of law's expressive function, see van der Burg (2001, Section IV).

\section{References}

Agrast, MD, Botero, JC \& Ponce A 2011, 'The world justice project rule of law index 2011', in The world justice project, Washington, available at: https://worldjustice project.org/sites/default/files/documents/WJP_Rule_of_Law:Index_2011_ Report.pdf 
Alfano, M, Loeb, D \& Plakias, A 2018, 'Experimental moral philosophy', in EN Zalta (ed.), The Stanford encyclopaedia of philosophy, available at: https://plato.stanfo rd.edu/archives/win2018/entries/experimental-moral/

Allan, TRS 1993, Law, liberty and justice: the legal foundations of British constitutionalism, Clarendon Press, Oxford.

Allan, TRS 2001, Constitutional justice: a liberal theory of the rule of law, Oxford University Press, Oxford.

Anderson, ES \& Pildes, RH 2000, 'Expressive theories of law: general restatement', University of Pennsylvania Law Review, vol. 148, no. 5, pp. 1503-1576.

Anscombe, GEM 1957, Intention, Basil Blackwell, Oxford.

Barak, A 2006, The judge in a democracy, Princeton University Press, Princeton.

Bennett, MJ 2011, 'Hart and Raz on the non-instrumental moral value of the rule of law: a reconsideration', Law and Philosophy, vol. 30, no. 5, pp. 603-635.

Bingham, T 2010, The rule of law, Allen Lane, London.

Bottoms, A \& Tankebe, B 2012, 'Beyond procedural justice: a dialogic approach to legitimacy in criminal justice', Journal of Criminal Law and Criminology, vol. 102, no. 1, pp. 119-170.

Bradford, B, Huq, A, Jackson, J \& Roberts, B 2014a, 'What price fairness when security is at stake? Police legitimacy in South Africa', Regulation and Governance, vol. 8, no. 2, pp. 246-268.

Bradford, B, Jackson, J \& Hough, M 2014b, 'Police legitimacy in action: lessons for theory and practice', in M Reisig \& R Kane (eds.), The Oxford handbook of police and policing, Oxford University Press, Oxford, pp. 551-570.

Bradford, B, Murphy, K \& Jackson, J 2014c, 'Officers as mirrors: policing, procedural justice, and the (re)production of social identity', British Journal of Criminology, vol. 54, no. 4, pp. 527-550.

Bradford, B \& Jackson, J 2018, 'Police legitimacy among immigrants in Europe: institutional frames and group position', European Journal of Criminology, vol. 15 , no. 5 , pp. $567-588$.

Cotterrell, R 2018, Sociological jurisprudence: juristic thought and social inquiry, Routledge, Abingdon.

Craig, P 1997, 'Formal and substantive conceptions of the rule of law: an analytical framework', Public Law, vol. 21, pp. 467-487.

Davidson, D 1971, 'Agency', in RW Binkley, RN Bronaugh \& A Marras (eds.), Agent, action and reason, Toronto University Press, Toronto, pp. 3-25. Reprinted in Davidson, D 1980, Essays on actions and events, Oxford University Press, Oxford, pp. 43-61.

Dicey, AV 1885, Introduction to the study of the law of the constitution (1982 edn.), McMillan \& Co, London.

Dickson, J 2011, 'On naturalizing jurisprudence: some comments on Brian Leiter's view of what jurisprudence should become', Law and Philosophy, vol. 30, no. 4, pp. 477-497.

Dworkin, R 1985, A matter of principle, Harvard University Press, Cambridge.

European Social Survey 2011, 'Trust in justice: topline findings from Round 5 of the European Social Survey', ESS Topline Results Series, Issue 1, by Jackson, J, Hough, M, Bradford, B, Pooler, TM, Hohl, K, \& Kuha, J, available at: http://www.euro peansocialsurvey.org/docs/findings/ESS5_toplines_issue_1_trust_in_justice.pdf Finnis, JM 2011, Natural law and natural rights, 2nd edn, Clarendon Press, Oxford. Fuller, LL 1969, The morality of law, 2nd edn, Yale University Press, New Haven. Gallagher, S 2020, Action and interaction, Oxford University Press, Oxford. 
Gardner, J 2012, Law as a leap of Faith, Oxford University Press, Oxford.

Gerber, MM, Gonzalez, R, Carvacho, H, Jimenez-Moya, G, Moray, C \& Jackson, $\mathrm{J} 2018$, 'On the justification of intergroup violence: the roles of procedural justice, police legitimacy and group identity in attitudes towards violence among indigenous people', Psychology of Violence, vol. 8, no. 3, pp. 379-389.

Gerber, MM \& Jackson, J 2017, 'Justifying violence: legitimacy, ideology, and public support for police use of force', Psychology, Crime and Law, vol. 23, no. 1, pp. 79-95.

Goldman, A. 1971, 'Individuation of actions', The Journal of Philosophy, vol. 68, no. 21, pp. 761-774.

Green, L 2008, 'Positivism and the inseparability of law and morals', New York University Law Review, vol. 83, no. 4, pp. 1035-1058.

Gur, N 2014, 'Form and value in law', Jurisprudence, vol. 5, no. 1, pp. 85-95.

Gur, N 2018, Legal directives and practical reasons, Oxford University Press, Oxford.

Hamm, JA, Trinkner, R \& Carr, JD 2017, 'Fair process, trust, and cooperation: moving toward an integrated framework of police legitimacy', Criminal Justice and Behavior, vol. 44, no. 9, pp. 1183-1212.

Hart, HLA 1965, 'Book review: "Fuller, The morality of law"', Harvard Law Review, vol. 78 , no. 6, pp. 1281-1296.

Hayek, FA 1943, The road to serfdom, Routledge, London.

Hellman, D 2000, 'The expressive dimension of equal protection', Minnesota Law Review, vol. 85, no. 1, pp. 1-70.

Hindelang, MJ, Hirschi, T \& Weis, JG 1981, Measuring delinquency, Sage Publications, Beverly Hills.

Huq, A, Jackson, J \& Trinkner, R 2017, 'Legitimating practices: revisiting the predicates of police legitimacy', British Journal of Criminology, vol. 57, no. 5, pp. $1101-1122$.

Jackson, J 2018, 'Norms, normativity and the legitimacy of legal authorities: international perspectives', Annual Review of Law and Social Science, vol. 14, pp. $145-165$.

Jackson, J \& Bradford, B 2019, 'Blurring the distinction between empirical and normative legitimacy? A methodological commentary on "Police legitimacy and citizen cooperation in China"', Asian Journal of Criminology, vol. 14, no. 4, pp. 265-289.

Jackson, J, Bradford, B, Hough, M, Myhill, A, Quinton, P \& Tyler, TR 2012, 'Why do people comply with the law? Legitimacy and the influence of legal institutions', British Journal of Criminology, vol. 52, no. 6, pp. 1051-1071.

Jackson, J, Bradford, B, Stanko, EA \& Hohl, K 2013, Just authority? trust in the police in England and Wales, Routledge, Abingdon.

Jackson, J \& Gau, JM 2015, 'Carving up concepts?: differentiating between trust and legitimacy in public attitudes towards legal authority', in E Shockley et al. (eds.), Interdisciplinary perspectives on trust: towards theoretical and methodological integration, Springer, Cham, Switzerland, pp. 49-69.

Jackson, J \& Pósch, K 2019, 'New directions for research into fairness and legal authority: a focus on causal mechanisms', in EA Lind (ed.), Social psychology and justice (Frontiers of Social Psychology Series), Routledge, New York, pp. 181-212.

Justice, B \& Meares, TL 2014, 'How the criminal justice system educates citizens', Annals of the American Academy of Political and Social Science, vol. 651, no. 1, pp. 159-177, available at: https://doi.org/10.1177/0002716213502929

Khaitan, T 2012, 'Dignity as an expressive norm: neither vacuous nor a panacea', Oxford Journal of Legal Studies, vol. 32, no. 1, pp. 1-19. 
Kramer, MH 1999, In defence of legal positivism: law without trimmings, Oxford University Press, Oxford.

Kramer, MH 2004, 'On the moral status of the rule of law', Cambridge Law Journal, vol. 63 , no. 1, pp. 65-97.

Lacey, N 2010, 'Out of the "witches' cauldron"? Reinterpreting the context and reassessing the significance of the Hart-Fuller debate', in P Cane (ed.), The HartFuller debate in the twenty-first century, Hart Publishing, Oxford, pp. 1-42.

Leiter, B 2007, Naturalizing jurisprudence: essays on American legal realism and naturalism in legal philosophy, Oxford University Press, Oxford.

Leiter, B 2009, 'Naturalizing jurisprudence: three approaches', in J Shook \& P Kurtz (eds.), The future of naturalism, Prometheus Books, Amherst, pp. 197-207.

Meares, TL 2009, 'The legitimacy of police among young African-American men', Marquette Law Review, vol. 92, no. 4, pp. 651-666.

Meyerson, D \& Mackenzie, C 2018, 'Procedural justice and the law', Philosophy Compass, vol. 13, no. 12, el2548, available at: https://doi.org/10.1111/phc3. 12548

Murphy, C 2005, 'Lon Fuller and the moral value of the rule of law', Law and Philosophy, vol. 24, no. 3, pp. 239-262.

Murphy, T, Bradford, B, \& Jackson, J 2016, 'Motivating compliance behavior among offenders: procedural justice or deterrence?', Criminal Justice and Behavior, vol. 43 , no. 1, pp. 102-118.

Nagin, DS \& Telep, CW 2017, 'Procedural justice and legal compliance', Annual Review of Law and Social Science, vol. 13, no. 1, pp. 5-28.

Nozick, R 1993, The nature of rationality, Princeton University Press, Princeton.

Pildes, RH \& Anderson, ES 1990, 'Slinging arrows at democracy: social choice theory, value pluralism, and democratic politics, Columbia Law Review, vol. 90, no. 8, pp. 2121-2214.

Pósch, K, Jackson, J, Bradford, B, \& MacQueen, S 2020, 'Truly free consent? Clarifying the nature of police legitimacy using causal mediation analysis', Journal of Experimental Criminology, available online: https://ssrn.com/abstract=2620274

Raz, J 2009, The authority of law, 2nd edn, Oxford University Press, Oxford.

Raz, J 2019, 'The law's own virtue', Oxford Journal of Legal Studies, vol. 39, no. 1, pp. 1-15.

Rundle, K 2012, Forms liberate: reclaiming the jurisprudence of Lon L Fuller, Hart Publishing, Oxford.

Rundle, K 2014, 'Reply', Jurisprudence, vol. 5, no. 1, pp. 133-160.

Simmonds, NE 2007, Law as a moral idea, Oxford, Oxford University Press.

Simmonds, NE 2010, 'Reply: the nature and virtue of law', Jurisprudence, vol. 1, no. 2, pp. 277-293.

Sunstein, CR 1996, 'On the expressive function of law', University of Pennsylvania Law Review, vol. 144, no. 5, pp. 2021-2054.

Tamanaha, BZ 2000, 'Conceptual analysis, continental social theory, and CLS: a response to Bix, Rubin, and Livingston', Rutgers Law Journal, vol. 32, pp. 281-306.

Taylor, C 1979, 'Action as expression', in C Diamond \& J Teichman (eds.), Intention and intentionality: essays in honour of G.E.M. Anscombe, Harvester Press, Brighton, pp. 73-89.

Thomson, JJ 1971, 'Individuating actions', Journal of Philosophy, vol. 68, no. 21, pp. 774-781. 
Thornberry, TP \& Krohn, MD 2000, 'The self-report method for measuring delinquency and crime', Criminal Justice, vol. 4, no. 1, pp. 33-83.

Trinkner, R 2019, 'Clarifying the contours of the police legitimacy measurement debate: a response to Cao and Graham', Asian Journal of Criminology, vol. 14, pp. 309-335, available at: https://doi.org/10.1007/s11417-019-09300-4

Trinkner, R, Jackson, J \& Tyler, TR 2018, 'Bounded authority: expanding "appropriate" police behavior beyond procedural justice', Law and Human Behavior, vol. 42, no. 3, pp. 280-293.

Trinkner, R, Mays, RD, Cohn, ES, Van Gundy, KT \& Rebellon, CJ 2019, 'Turning the corner on procedural justice theory: exploring reverse causality with an experimental vignette in a longitudinal survey', Journal of Experimental Criminology, vol. 15, no. 4, pp. 661-671.

Trinkner, R \& Tyler, TR 2016, 'Legal socialization: coercion vs. consent in an era of mistrust', Annual Review of Law and Social Science, vol. 12, pp. 417-439.

Twining, T 2009, General jurisprudence: understanding law from a global perspective, Cambridge, Cambridge University Press.

Tyler, TR 2006a, Why people obey the law, 2nd edn, Yale University Press, New Haven.

Tyler, TR 2006b, 'Psychological perspectives on legitimacy and legitimation', Annual Review of Psychology, vol. 57, pp. 375-400.

Tyler, TR \& Fagan, J 2008, 'Legitimacy and cooperation: why do people help the police fight crime in their communities?', Ohio State Journal of Criminal Law, vol. 6, pp. 231-275.

Tyler, TR \& Jackson, J 2013, 'Future challenges in the study of legitimacy and criminal justice', in J Tankebe \& A Liebling (eds.), Legitimacy and criminal justice: an international exploration, Oxford University Press, Oxford, pp. 83-104.

Tyler, TR \& Jackson, J 2014, 'Popular legitimacy and the exercise of legal authority: motivating compliance, cooperation and engagement, Psychology, Public Policy and Law, vol. 20, no. 1, pp. 78-95.

Tyler, TR, Jackson, J \& Mentovich, A 2015, 'On the consequences of being a target of suspicion: potential pitfalls of proactive police contact', Journal of Empirical Legal Studies, vol. 12, no. 4, pp. 602-636.

Tyler, TR \& Sevier, J 2013, 'How do the courts create popular legitimacy?: the role of establishing the truth, punishing justly, and/or acting through lust procedures', Albany Law Review, vol. 77, pp. 1095-1137.

Tyler, TR \& Trinkner, R 2018, Why children follow rules: legal socialization and the development of legitimacy, Oxford University Press, New York.

Waldron, J 2008, 'The concept and the rule of law', Georgia Law Review, vol. 43, pp. 1-61.

van der Burg, W. 2001, 'The expressive and communicative functions of law, especially with regard to moral issues', Law and Philosophy, vol. 20, pp. 31-59.

Waldron, J 2016, 'The rule of law', in EN Zalta (ed.), The Stanford encyclopedia of philosophy, available at: https://plato.stanford.edu/archives/fall2016/entries/ru le-of-law/

Walton, K 2015, 'Legal philosophy and the social sciences: the potential for complementarity', Jurisprudence, vol. 6, no. 2, pp. 231-251.

Winston, KI 1994, 'Legislators and liberty', Law and Philosophy, vol. 13, no. 3, pp. $389-418$.

Wittgenstein, L 1993, 'Remarks on Frazer's Golden Bough', in J Klagge \& A Nordmann (eds.), Philosophical occasions: 1912-1951, Hackett, Indianapolis, pp. 119-155. 


\title{
6 Legal legitimacy and the relevance of participatory procedures
}

\author{
Sarah Sorial
}

\subsection{Introduction}

The relevance of certain forms of participation for legitimacy is well documented in the extensive social sciences literature. ${ }^{1}$ This empirical research demonstrates the importance of having a 'voice' in legal proceedings, or an opportunity to present one's case, and the importance of being treated with respect by legal officials. This research adds substantive weight to the theoretical arguments that procedural justice is intrinsically valuable because of the way it respects individual dignity and autonomy, ${ }^{2}$ and increases people's willingness to comply and cooperate with authorities (Meyerson 2015a, p. 26; 2015b, p. 76).

In this chapter, I draw on procedural theories of law and democracy ${ }^{3}$ to develop a normative account of why participation matters for legitimacy and compliance with the law. I suggest that this normative account can help explain the issues of authority and compliance in ways that are sensitive to the nature of law in democracies, and with laypersons' intuitions about why participation matters. ${ }^{4}$ In particular, I demonstrate the ways in which the relationship between the citizen and the state is more complex and less linear than it is characterised and described in some of the psychological literature. In this respect, this chapter builds on the 'relational' aspect of legitimacy identified by Meyerson (2015a, 2015 b), and on the idea of 'legitimacy as dialogue' developed by Bottoms and Tankebe (2012, p. 159).

In Section 6.2, I give an account of the empirical evidence, which is concerned with people's perceptions of legitimacy. I suggest that these descriptive claims about why people accept the authority of law and comply with it represent the relationship between the citizen and the state as a 'top down' relationship, rather than a complex dialogical and relational one. In Section 6.3 I give an account of procedural theories of legitimation, to demonstrate two things: first, the ways in which participation shifts the locus of authority and law-making from the state to the citizenry. Second, the ways in which this shift from government to citizens enables us to give a different account of legitimacy: namely, that people should accept the authority of law issuing and law applying institutions and should comply with legal norms if these procedural processes are in place. I refer again to some of the empirical evidence to substantiate this claim, and to suggest

DOI: $10.4324 / 9780429317248-9$ 


\section{Sarah Sorial}

a different theoretical model for interpreting this evidence. ${ }^{5}$ In Section 6.4, I use this theoretical model to explain the relationship between procedural fairness and legitimacy in the context of the criminal trial, focusing on the opportunity to be heard in one's own defence. Finally, I discuss some policy implications and respond to potential objections in Section 6.5.

\subsection{Participation and legitimacy: the empirical evidence}

In his ground-breaking book, Why People Obey the Law, Tom Tyler distinguishes between instrumental and normative reasons for obedience to law (Tyler 1990, p. 3). He further breaks down normative reasons into two categories: personal morality (consisting of people's beliefs about how they should act) and legitimacy (referring to people's perceptions as to whether law enforcement officials rightly have authority over them, i.e. descriptive legitimacy). In a series of surveys asking people questions about their recent contacts with the police or the courts, their reactions to those contacts, and their subsequent behaviour, Tyler concludes that people comply with the law when they perceive that legal authorities are legitimate and that their actions are generally fair (Tyler 1990, p. 6). These findings lead Tyler to prioritise normative compliance over instrumental compliance, and within normative compliance, to prioritise legitimacy. Interestingly, it was the perceived procedural fairness of law enforcement authorities, rather than the perceived fairness of the outcome, that was most significant for subsequent compliance.

There has been a significant amount of further research, which confirms these initial findings. Legal institutions and authorities are deemed legitimate when people have trust and confidence that legal authorities are honest (Tyler \& Jackson 2014 , p. 78). This causes people to 'authorise' the legal authority to dictate appropriate behaviour because they trust and have confidence that legal authorities are honest and act in ways that have citizens' best interests at heart (Tyler \& Jackson 2013, pp. 87-88; 2014, p. 78). The connection between legitimacy and compliance with the law is based on the theoretical consideration that people are able to transcend their short-term self-interest, including getting the outcome they want, to take actions that are consistent with their conceptions of what is right and appropriate (Tyler \& Jackson 2014, p. 81).

Procedural justice emerges as the key criterion for conferring legitimacy and securing compliance in the descriptive sense. It refers to whether people perceive that authoritative officials - police and court officers - use their power in fair, just, and neutral ways. In these descriptive accounts, procedural justice is understood in four main ways. First, people want an opportunity to explain their situation or tell their side of the story in a conflict (Jackson \& Tyler 2014, p. 81). Second, people value neutrality, which means they expect that the decisions that are made are based on consistently applied legal principles and the facts of the case, and not on personal opinion or biases. Related to this, people expect processes to be transparent and for officials to be open about how decisions are being made. This facilitates the belief that decision-making procedures are neutral and made in 
an objective way (p. 82). Third, people are sensitive to whether they are treated with dignity and politeness, and whether their rights as citizens are respected: 'people believe that they are entitled to treatment with respect and react very negatively to dismissive or demeaning interpersonal treatment' (Tyler \& Jackson 2013 , p. 82). Finally, people focus on cues that communicate the intentions and characters of the authorities with whom they are dealing:

authorities communicate this type of concern when they listen to people's accounts and explain or justify their actions in ways that show an awareness of and sensitivity to people's needs and concerns.

Tyler and Jackson conclude:

The key point about procedural justice is that being treated fairly communicates value and respect within a group, which fosters compliance with group rules, promotes cooperation, and leads to identification and engagement with the group. Hence procedural justice promotes legitimacy and advances each of the three goals outlined: compliance, cooperation, and engagement.

While there is generally broad agreement about the importance of legal legitimacy in the social sciences literature, there is no accepted definition of legitimacy more generally (Jackson \& Gau 2015, p. 49). Moreover, given the important role played by the concept in the empirical literature, a number of researchers have highlighted the need to re-examine and expand the ways in which legitimacy is conceived (Tyler \& Jackson 2013, p. 87; Bottoms \& Tankebe 2012, p. 119). Jackson and Tyler, for example, have argued that it is important to ask why legitimacy influences behaviour, in the sense that it achieves compliance with legal norms (Tyler \& Jackson 2013, p. 87 supra note 39). They offer three reasons that potentially explain why legitimacy influences behaviour: psychological reasons associated with perceived duties to obey institutions, the trust and confidence people have in authorities, and the extent to which legal norms 'morally align' with peoples' values.

According to Tyler and Jackson, legitimacy is a motivation to act based on positive and intentional beliefs about the right to power and influence (Tyler \& Jackson 2013, p. 87). When one recognises the legitimacy of an institution, one believes that the institution has the right to proscribe and enforce appropriate behaviour, and that one has a corresponding duty to obey those proscriptions. Kelman and Hamilton call this 'authorisation' to reflect the idea that the person has authorised the authority to determine the appropriate behaviour in some contexts, and then feels obligated to follow those directives or norms (Kelman \& Hamilton 1989, p. 16). This is referred to as 'internalisation' where the norms become part of an individual's motive system, guiding behaviour in the appropriate way, even when no authority exists (Hoffman 1977, pp. 55-57). 


\section{Sarah Sorial}

The second reason legitimacy influences behaviour is the trust and confidence that people have in authorities and legal officers. Jackson and Gau define trust as the subjective judgement that a person (the trustor) makes about the likelihood of another person (the trustee) following through with an expected action. This requires the trustor to draw on a variety of sources, such as past experience with the trustee, personal relationships, and intuitive or 'gut' responses when deciding on the level of trust to place in the person (Jackson \& Gau 2015, p. 52). For example, with respect to law enforcement officials such as the police, this definition of trust refers to people's expectations regarding future behaviour from police officers under conditions of uncertainty (Jackson \& Gau 2015, p. 53). A person can never be sure that the police will respond promptly if called, that she will be treated with respect, and that she will be heard. However, the person may have formed a judgement about the intentions and the capacity of the police officers to respond appropriately with respect to their social role, based on prior contact with law enforcement officials, and these judgements will shape the individual's willingness to accept uncertainty and vulnerability, by perhaps coming to the police with information about a crime (Jackson \& Gau 2015, p. 53).

The third reason why legitimacy influences behaviour is because of identification and a sense of shared values or 'moral alignment'. According to Tyler and Jackson:

Pride and status encourages identification with the group, and identity judgments then shape attitudes, values and cooperative behaviour. Pride, respect, and group identification-activated by the use of fair procedures-may consequently encourage not just a felt obligation to obey the rules of the group, but also a (connected) sense of shared moral values and purpose.

(Tyler \& Jackson 2013, p. 92, supra note 39)

Moral alignment is considered a constitutive element of legitimacy because it justifies the power and authority of legal officials in the eyes of the community (Tyler \& Jackson 2013 p. 92, supra note 39). Finally, these features shape law-abiding behaviour because people tend to cooperate, comply, and accept the authority of the state and its use of force when they believe that the state has rightful authority, when they trust the state and its officials, and when they identify with its goals and moral values. If these conditions of legitimacy are met, then it is likely that people will accept that they have a duty to obey the law.

While I do not contest the importance of identification, trust, and fair treatment for the purposes of achieving compliance with legal norms, I suggest that this account of legitimacy fails to fully appreciate why participation might contribute to legitimacy for reasons aside from trust and why it matters for the purposes of identification. These reasons may have more to do with the nature of legitimacy in democratic societies, where participatory procedures confer objective legitimacy on governments. As such, the empirical research continues to adopt a 'top down' approach regarding the relationship between citizens and 
the state, rather than a 'bottom up' or dialogical relationship. For example, Tyler and Jackson rely on a traditional model of social regulation, where legal authority is centralised in elites, who issue legal norms and make legal decisions. They explain,

Legal elites expect the public to accept their authority and comply with the law; legitimacy as authorisation and perceived obligation means that people allow legal authorities to prescribe their behaviour when enforcing rules. People obey the law because they believe that legal authorities have the right to dictate appropriate behaviour.

(Tyler \& Jackson 2014, p. 78)

But why do legal elites expect this level of compliance and why and how do people authorise them to make legal norms? While it is the case that people obey the law because they accept the law's authority, they do not blindly follow it or simply do what authorities command because the authority says so. The language of lawmakers having 'authority' over 'subordinates' assumes a disconnect between those who govern, issue directives, and make decisions, and those who are governed and obey those directives. It assumes that citizens come to identify with the law for reasons that have more to do with trust in legal authorities, than because of the existence of participatory procedures. The more benevolent and trustworthy the officials are, the more their power is recognised, and their orders complied with. There is very little to suggest that citizens also have significant power and protections in legal processes (although this is implied by the evidence), and that they might accept the legitimacy of the law because they had some involvement in how that law or legal decision was made, by virtue of the existence of participatory procedures. The nature and extent of this involvement will vary depending on the kind of issue under consideration and a person's level of interest, ability, and engagement, to name a few. What matters, however, is that in various fora appropriate participatory procedures are in place, to enable appropriate levels of participation in legal decision-making.

In the following section, I draw on procedural models of law and democracy to offer a normative account of legitimacy. I suggest that legitimacy is conferred in the normative sense by virtue of an ongoing relationship and dialogue between citizens and the state, where citizens participate in various ways in issuing authority or in devising the norms that will bind them. This participation occurs in a number of different contexts, including in elections, in law-making, and in the context of a trial or other kind of hearing (such as a tribunal or a commission inquiry). Of course, the level and kind of participation in these different fora will vary, but my claim is that the existence of participatory procedures, no matter their form, confers legitimacy in a normative sense, and brings about compliance with the law. This procedural model is better able to respond to the unique features of legitimacy in democratic societies, a feature that is somewhat absent from the social sciences and traditional jurisprudential literature. 


\section{Sarah Sorial}

\subsection{Procedural theories of democracy and law}

The ideal of democracy views government action as a collective action. It is the actions of the community, achieved through various procedures that determine the preferences or views of its members. Procedural theories of legitimacy focus on how the directives of an authority are arrived at and how an individual might contribute to the outcome. For example, a procedural theory might judge whether the process was deliberative, fair, or public (Hershovitz 2003, p. 212). Lon Fuller, perhaps one of the few legal theorists to take seriously this connection between democracy and law, and between participation and legitimacy, argued that adjudication, contract, and elections are three ways of reaching decisions, settling disputes, and regulating relations between people. The characteristic feature of these different kinds of social ordering 'lies in the manner in which the affected party participates in the decision reached' (Fuller 1978, p. 363). Ideally, each of these arrangements requires that certain background conditions be met, or the existence of certain procedures. In the case of elections, it requires an intelligent and fully informed electorate, an active interest in the issues being discussed, candid discussion of the issues in public debate, and widespread participation, conditions that Fuller thought were 'scarcely ever realised in practice' (p. 364).

Adjudication also depends on various procedures that provide the affected parties with an opportunity to participate in the decision, by way of presenting evidence and reasoned arguments. However, it differs from participation in democratic politics because it demands a higher standard of reasoning, both in terms of the arguments being presented by the parties, and the judgement that is reached by the impartial adjudicator:

adjudication is ... a device which gives formal and institutional expression to the influence of reasoned argument in human affairs. As such it assumes a burden of rationality not borne by any other form of social ordering.

(Fuller 1978, p. 367)

The process of adjudication becomes a farce should the decision that is reached make no pretence to rationality.

Elections, by contrast, are often decided by the preferences of voters who are 'emotional, inarticulate, and not subject to rational defense ... the will of the majority controls, not because it is right, but-well, because it is the will of the majority' (Fuller 1978, p. 367). Despite his scepticism about the reasoning ability of the electorate, Fuller nevertheless offered an account of law as a cooperative venture between rulers and ruled, requiring reciprocal obligations of mutual respect. Fuller's account of law and legitimacy is capable of application to liberal democracies in general and is consistent with the moral and political assumptions underpinning them.

As Allan argues, Fuller's 'internal morality' can be interpreted as a demanding ideal of due process of law that, when fully elaborated, imposes an obligation 
on the government to defend every coercive act on the grounds that it in the interests of all. The rule of law is essentially a procedural ideal, because the common good or the interests of all is left open for public debate, and any decision reached by the government needs to be rationally defended with reference to the needs and interests of the community as a whole (Allan 2001, p. 75). When the state's demands are understood as making an appeal to the general good, 'the citizen's moral judgment is inextricably engaged in the identification of law. He is enjoined by the constitution itself' (p. 76). Closely connected with this relationship between the citizen and the state, and the rule of law, is a distinctive view of procedural fairness that reflects the sense in which the government, under the rule of law, is required to enter into a dialogue with citizens. The rule of law demands an opportunity for consultation with relevant officials.

Fuller's theory does not, however, elaborate on this relationship or dialogue between the citizen and the state. ${ }^{6}$ More recent procedural theories of democracy and law give a richer, and less cynical account of public reason and of the specific procedures, which enable such a dialogue. For example, Habermas' procedural model of legal legitimacy shifts the locus of legislative and decision-making power from the formal institutions of the state and locates it in the communications of an unsubverted public sphere. The public sphere is, in turn, tied to the 'associational network of a liberal civil society and gains support from the core private spheres of the lifeworlds' (Habermas 1998, p. 18). This model also shifts the normative expectations from the level of the actors' qualities and competences to the forms or procedures of communication in which opinion-formation can develop and interact with the formal organs of the state (p. 18).

For Habermas, legal legitimacy is achieved by way of various participatory procedures or in the communicative networks of public spheres, which can include anything from a town-hall meeting, online discussion fora, media discussions, and so on. Participation is essentially a discursive activity, requiring people to present reasons and arguments for particular policies, ones that are based not only on their own self-interest, but also in the interests of their community more broadly. This participation takes place in a variety of different fora, including public opinion-formation, institutionalised elections, and legislative decisions. These fora are categorised in terms of informal and formal processes of deliberation, and together form Habermas' two-track model of deliberative democracy so that,

deliberative politics thus lives off the interplay between democratically institutionalised will-formation and informal opinion-formation. It cannot rely solely on the channels of procedurally regulated deliberation and decision-making.

(Habermas 1998, p. 308)

The two tracks of deliberation perform two different functions.

Informal communication in the public sphere is disorganised, anarchic, and uncoordinated. It provides an unregulated space for detecting new problems, 
bringing them to public awareness without the use of specialised language, and suggesting ways to address them,

because the general public sphere is 'unconstrained' in the sense that its channels of communication are not regulated by procedures, it is better suited for the 'struggle over needs' and their interpretation.

(Habermas 1998, p. 314)

In this way, 'the communicative structures of the public sphere constitute a farflung network of sensors that react to the pressure of society-wide problems and stimulate influential opinions' (Habermas 1998, p. 300). The public space is founded on a network of associations that 'specialise ... in discovering issues relevant for all society, contributing possible solutions to problems, interpreting values, producing good reasons, and invalidating others (p. 485). Only after such a public struggle for recognition of issues as political can the responsible political authorities take up the proposals, put them on a parliamentary agenda and then legislate and make binding decisions in relation to them. This is referred to as the formal track of the legislative process.

The formal track of deliberative decision-making is how informal deliberation is made into positive law by conventional political institutions and the organs of the state. Formal political processes also include elections and legislatures, and the formal organs of the state include courts. The function of these institutions is to assess ideas, solutions, and make authoritative decisions that will be accepted by those affected. Habermas (1998) explains that these formal political processes rely on the informal public sphere when devising policies and laws:

The operative meaning of these regulations consists less in discovering and identifying problems than in dealing with them; it has less to do with becoming sensitive to new ways of looking at problems than with justifying the selection of a problem and the choice among competing proposals for solving it. The publics of parliamentary bodies are structured predominantly as a context of justification. These bodies rely not only on the administration's preparatory work and further processing but also on the context of discovery provided by a procedurally unregulated public sphere that is borne by the general public of citizens.

(Habermas 1998, p. 307)

This two-track system displaces the principal locus of participation from formal political institutions to the informal public sphere and is intended to explain how legal legitimacy ought to be achieved, with respect to both the issues of authority and compliance. It describes the kinds of communication necessary between the citizen and the state, and the various procedures that mediate this dialogue.

Why do these participatory procedures produce legitimacy (or why can they give us a more adequate answer to the issues of authority and compliance?). First, 
participatory procedures ensure that all those affected by an issue have some input into how that issue is addressed. They can ensure that all aspects of the issue have been identified and that all available evidence is presented. The resulting law issued by the legislature is thus considered legitimate because citizens have had the opportunity to participate in and formulate the law that will ultimately bind them. The law has the authority it does because it was achieved using a 'bottom up' process, rather than a 'top down' one.

Of course, it will not be the case that everyone who participated in the discussion will agree with the decision that is eventually reached. Nevertheless, they are still bound to comply with the law because the procedures were democratic, transparent, and based on good reasons, even though the final decision is contested. As Waldron puts it,

When something is enacted as law or as a source of law, I believe it makes on us a demand not to immediately disparage it, or think of ways of nullifying it or getting around it ... it is a demand for a certain sort of recognition and ... respect-that this, for the time being, is what the community has come up with and that it should not be ignored or disparaged because some of us propose, when we can, to repeal it.

(Waldron 2001, p. 100)

Second, participatory procedures ensure that all citizens are treated with equal concern and respect. They presuppose that citizens are autonomous, selfdetermining agents, capable of organising their own affairs, and pursuing their own interests and conceptions of the good. As such, participatory procedures assume that citizens not only have the ability to participate in political debate but that they would want some say in how decisions that affect them are made. As Hershovitz explains,

since governments play a pervasive role in organising our lives, denying people the opportunity to participate in the process of government closes off opportunities to organise one's life autonomously. Democratic procedures afford people opportunities to participate in life-defining decisions.

(Hershovitz 2003, p. 214)

So, while features like identification and trust in legal officials are important for people's perceptions of legitimacy, as the psychological literature describes, it is participatory procedures that confer legitimacy and bring about compliance with the law. Moreover, identification with one's community and the establishment of shared values presupposes participation, insofar as it is the community itself that comes together to deliberate about what those shared values are and how they can be actualised in law. While elites might be responsible for shaping the actual law, this is not something that they impose from the 'top', onto 'subordinates' who then obey. As I have suggested, in a democracy, it is the people who ought to decide what is best for themselves and their communities, who ought 
to identify various issues that need to be addressed, and who ought to propose various ways of solving them. It is the citizens who should give reasons to one another to support one course of action over another, and it is the people who are affected by a particular issue who are best placed to make recommendations about how that issue should be addressed.

Again, the empirical evidence bears out these normative claims. Tyler and Jackson note that studies of long-term approaches to creating social order indicate the importance of creating viable communities, ones where people have a shared attitude, which in turn motivates engagement. If people are encouraged to engage in their communities socially and economically, they build social capital. They come to know others and how to work with them when problems arise in the community; they build trust in others and develop the belief that others can and will act collectively when issues arise (Tyler \& Jackson 2014, p. 80).

Tyler and Jackson seek to explore whether such engagement can be enabled and facilitated by legal authorities: whether 'the legal system can develop policies and practices that generate supportive attitudes and values that enhance communities' $(2014$, p. 80 ). They find that the exercise of authority by way of fair processes and decision-making strengthens the social bonds between individuals and communities. People come to identify with the group that the authority represents and internalise the belief that they should follow the rules of the group and the laws that are issued by it. They find that legal institutions and authorities play a crucial role in fostering the identity needed to establish legitimacy, and in forging the social and collective bonds of a community (p. 80).

Using a proceduralist model of democracy and law, it is possible to interpret these findings using a 'bottom up' approach to legitimacy: it is the people themselves who come together to identify and help solve various social coordination problems, thereby fostering identification and solidarity with a group, a sense of shared values and respect for one another. Social elites and legal officers might then play a role in actualising a particular decision, perhaps by creating legislation and enforcing it. The relationship between legal authorities and communities in democratic societies is thus more complicated and less linear than Tyler and Jackson suggest. People do not accept the legitimacy of law because of the benevolence of legal institutions and authorities, but they ought to by virtue of the existence of various participatory procedures. This is a dialogical and discursive process, involving deliberation between citizens themselves, and between citizens and their elected representatives. Citizens thus should accept the law as legitimate and should consider themselves bound to obey it (even if they do not agree with it) because they played some part in shaping it. In the following section, I use this procedural account of legitimacy to explain the importance of procedural fairness in the context of a criminal trial, focusing on the opportunity to be heard in one's own defence. 


\subsection{The opportunity to be heard in one's own defence and legitimacy}

There are three significant relations between participation and legitimacy in the context of a criminal trial. First, giving the accused the opportunity to be heard in his or her defence may lead the accused to accept the decision, even if it does not go in his or her favour. Second, publicly presenting reasons for a decision means a political order is recognised as right and just, and thus as deserving of legitimacy. Third, participation extends to other actors in the criminal trial, such as members of a jury, and the participation of these various actors contributes to legitimacy in different ways.

Of course, there are vast differences between the kind of participation that occurs in the informal deliberative spheres and in a formal trial. In the public sphere, participation can take the form of deliberating over a public policy issue at a town-hall meeting, protesting, writing to elected representatives or to newspapers, making submissions to parliamentary inquiries, and so on. These kinds of participation are, to greater or lesser degrees, unconstrained by various rules of order, and they are governed by various and differing procedures. For example, a town-hall meeting is likely to have more formal procedures that require participants to take turns speaking, and are regulated by a chairperson, whereas a protest march may have multiple deliberative sites and be largely unregulated, in terms of what people say and how they say it. These forms of participation are also open to all persons who are interested or who have a stake.

Participation in an adjudicative process differs in some fundamental ways. It is not open to anyone to participate in a trial (although the public nature of trials means that anyone can attend one). Only the parties affected are represented and allowed to present their cases; how they present evidence is subject to strict rules of procedure. Moreover, the kind of reason-giving in a trial is typically subject to higher standards than one would expect to find in the public sphere. A further distinctive feature of the procedural aspects of the rule of law is the requirement that individuals facing the imposition of some kind of penalty by the government must have a right to make legal arguments about the bearing of evidence and the legal norms relevant to the case. In doing so, participants are given an opportunity to affect a legal outcome, and this contributes to making a legal decision legitimate (Solum 2004, p. 274).

Despite these differences in the kinds of participation in different contexts, some key features of participation remain relevant across all deliberative contexts. First, the person whose interests are at issue is entitled to be heard, should be able to give evidence and make arguments for his or her position or case. Second, in each context, these arguments should be given due consideration and incorporated in the final decision. Third, all decisions reached need to be supported with good reasons that all participants can accept, even if the person does not get the outcome she was hoping for. And finally, this participation is crucial for legitimacy across these different deliberative spheres. ${ }^{7}$ 


\section{Sarah Sorial}

Another causal factor to achieving legitimacy in the context of a trial is reasongiving by legal officials. Adjudication is thus not merely a process of reaching the correct result, consistent with appropriate legal standards, but more importantly, an attempt to justify that result to both parties (Allan 2001, p. 79). Lucas further argues that a principal purpose of the rules of natural justice, which define a 'fair hearing', is to enable a person to identify with the decision-making process and 'make it manifest to anyone disappointed at the outcome that we were solicitous of his interests and did not reach an adverse decision lightly or wantonly, but only for good reason and with evident reluctance' (Lucas 1980, p. 97).

Participation in one's own trial, in the form of being given an opportunity to be heard, may lead the accused to accept the decision and comply with the law. However, the public nature of a trial and the close scrutiny and argumentation about the legal norms at issue can achieve legitimacy more generally through widespread recognition of the courts as just institutions. Decisionmaking is, as Galligan puts it, an 'unruly process', one that requires judges and lawyers to try to make sense of the law as a whole, including not only the law and the evidence, but also in relation to the norms and standards, values, and beliefs operating in a complex social world (Galligan 1997, p. 65). It is, then, much more than the simple application of relevant laws to the facts of particular cases; because decision-making occurs in this space between legal norms, the facts of the case, and complex social circumstances, the procedures that are best suited for this purpose are ones that encourage inquiry, argument, and deliberation. They should reflect the fact that different ways of interpreting an issue are available, and that interpreting evidence and evaluating facts are open processes.

Subjecting legal norms to such intense and public scrutiny achieves widespread recognition of the authority of the courts. As Ho puts it, the trial is itself a process of public justification. Publicity is understood primarily in two ways: first, the grounds the executive has for a conviction must be presented in a forum in which the citizenry have right of access-justice must be seen to be done; and second, the reasons given for a guilty verdict must aim at public acceptability, meaning that reasonable citizens must be able to accept the reasons as sound and sufficient grounds for a conviction (Ho 2010, p. 53). The kind of debate that occurs in a courtroom and the accessibility of these arguments by the citizenry ought to achieve widespread legitimacy, insofar as people should come to recognise the authority of the courts and respect their decisions.

Participation in this context is not direct participation, because those who are not part of the proceedings do not have a right to make submissions or arguments. However, they indirectly participate in having access to the court proceedings (any person can, for example, attend court) or they can access the arguments that are made, and the courts' reasoning for its decisions, and can participate in an ongoing public dialogue about those issues, where appropriate. In this respect, the courtroom forms part of a broader political and legal dialogue, in some cases, promoting public debate about various legal issues, which may lead to law reform in other spheres. 
Finally, participation in criminal trials also extends to the role of juries and promotes and achieves legitimacy in various ways. Notwithstanding some of the problems with juries, as an ideal, trial by jury has deep democratic roots- to be tried by a jury is to be tried by one's own peers, and hence to be judged by the norms and standards of one's community. Jury deliberation, the process of discussion, argumentation, and reasoning by a representative group of citizens in search of a collective judgement of a fellow citizen, has been described as the 'crucible of democracy' and it has been said that 'the democratic theory of law would favour the retention of trial by jury as the means whereby the people play a direct, contributory part in the application of the law' (Ho 2010, p. 253). The jury is one occasion where citizens participate in legal decision-making, and there have been occasions where a jury has refused to apply a norm that it deems oppressive, and hence, illegitimate. ${ }^{8}$

\subsection{Objections and policy implications}

There are at least two potential objections to this normative account that bear mentioning. First, actual participation in public deliberation falls significantly short of the ideal as represented here. A great deal of law is made by political elites without adequate participation by those affected, so in the absence of genuine participation, it is necessary that people come to trust legal officials to achieve legal legitimacy. Second, participation in one's own trial is also overstated. The increasing frequency of plea bargaining may mean the right to be heard in one's own defence is forfeited in some criminal trials, and this does not appear to affect the legitimacy of decisions or affect whether people ought to comply with the law.

With respect to the first claim, while it is the case that actual law-making is made by legal elites, this is often in response to issues that have been identified in the public sphere as requiring legal responses, at least more often than not. For example, law reform in areas such as domestic violence, sexual assault and sexual harassment have occurred because women have identified these as serious social and political issues (first in the informal public sphere), and put these issues on the legislative agenda. Participation at the informal levels thus can and does influence the legislative agenda. Provided these participatory mechanisms are in place, it should lead to legitimacy and compliance with the law.

At a practical level, I concede that not every person affected by an issue will participate in law-making. It might be sufficient for the purposes of legitimacy that a wide range of views are represented in deliberation and are reflected in the final decision reached. This weakens the requirement that every person affected by an issue should participate in dialogue for the law or decision to be deemed legitimate (for this would be impractical, and time and resource intensive), but it does not affect that normative claim that so long as various participatory procedures are in place, legitimacy and compliance with the law ought to be achieved.

There are also persistent issues of equality of access, especially for people who are socially marginalised or less well-educated, and so may not be able to genuinely participate in dialogue. This is a more intractable and complex problem, and 


\section{Sarah Sorial}

a full examination of these issues is outside the scope of this chapter. Suffice it to say that large-scale inequalities in a society will distort deliberative exchanges, and may over time, undermine or weaken the legitimacy of authorities (such as governments or law enforcement officials) and compliance with the law.

The second concern is that participation in the context of legal trials is also overstated. Arlie Loughnan, for example, has argued that the rise of institutional practices such as plea bargaining or charge negotiation suggest that the criminal trial plays a 'symbolic role that far outstrips its practical significance' (Loughnan 2010 , p. 536). Dubber goes further, arguing that the prevalence of plea bargaining, especially in the American criminal justice system is symptomatic of a crisis in the modern criminal process, where informal and non-public arrangements are increasingly replacing public trials in the imposition of punishment (1996-1997, p. 547).

At a descriptive level, there is an increased tendency to forfeit one's right to be heard and forgo criminal trials in favour of plea bargaining. There are also good practical reasons for this, including increased efficiency, caseload management, and to spare victims the trauma of a trial. However, given the normative account I have defended, the increased use of practices such as plea bargaining should be of concern. If participation matters for legitimacy, perhaps over time, these institutional practices will erode the legitimacy of authorities, or undermine legal decisions.

Finally, this account of the relevance of participation has some important policy implications for both the criminal trial and for policing. It suggests that despite the costs and time resources associated with trials, the right to a fair hearing and an opportunity to defend oneself during a trial are important, and ought not be eroded or replaced by plea bargaining and charge negotiation. The trial provides an important opportunity for participation, which is not only important for legitimacy of outcomes in particular cases, but also for legitimacy of law more broadly. The account of participation presented here also indicates the importance of involving and consulting with communities in the context of policing. It is likely that communities are best placed to understand their needs and will be more likely to accept police decisions and cooperate with police if they have the opportunity to participate in developing the policies that are to govern them.

I have argued that participatory procedures are relevant to answering the complex questions posed by the issue of legitimacy — what gives institutions and legal officials the authority they have to make and issue legal norms and why should we comply with these norms? I have focussed on the relational and dialogical features of participation, in order to demonstrate that the relationship between the citizen and the state is more complex and less linear than conceived in traditional jurisprudential debates and in the empirical literature; that the dialogue is an ongoing one; and that it occurs across multiple deliberative spaces, including in courtrooms. If this account of the relevance of participatory procedures to achieving legitimacy is convincing, it might help explain the damage that can be done to our legal institutions when the principle of participation is undermined, through practices such as the increasing use of non-public plea bargaining. It can 
also explain why some communities do not cooperate or trust police and other law enforcement bodies, and it can also provide ways of fostering this trust and identification through dialogical means.

\section{Notes}

1 See for example, Tyler $(1990,2006)$, Sunshine and Tyler (2003), Tyler and Fagan (2008), Tyler and Jackson (2014), Jackson et.al. (2012), and Murphy Bradford, and Jackson (2016).

2 See for example, Waldron (2011), Duff, Farmer, Marshall, and Tadros (2007).

3 In particular, I draw on the work of Lon Fuller (1978) and Habermas (1996).

4 See for example, Jeremy Waldron's comments that the 'dirty little secret' of modern jurisprudence is that it is uncomfortable with democracy (Waldron $2001 \mathrm{pp}$. 8-9), and his comments that when lay persons talk of the 'rule of law', they are not referring to the form of law, but to procedures. (Supra note 2, p. 5 ).

5 For example, I use this account to offer a different interpretation of Tyler and Jackson's (2014) findings.

6 See for example, Allan's comments that Fuller's account of law is too spartan and 'his commitment to the values of liberal democracy overly self-restrained.' (Allan 2001, p. 73). See also Waldron's criticisms in 'The Rule of Law and the Importance of Procedure.' (Waldron 2011, pp. 10-11).

7 See also Galligan (1997, pp. 130-132).

8 Consider, for example, some instances of 'jury nullification' where juries have ignored the law to acquit defendants who are otherwise guilty at law because they perceive the application of the law in the circumstances to be unjust. In the case of $R \vee R 28$ SASR 321 (1981), a woman was initially convicted of murder for killing her violent and abusive husband because the trial judge refused to direct the jury on the issue of provocation (traditionally a defence used by men who kill their partners for reasons of separation or suspected infidelity). On appeal, a second jury acquitted the woman. Or consider the more recent US trial of William Lynch, charged with felony assault for attacking an elderly priest who had abused him as a child. He was also acquitted by a jury despite being guilty at law. See https://nswcourts.com.au/articles/juries-dont-always-follow-the-law/

\section{References}

Allan, TRS 2001, Constitutional justice, Oxford University Press, Clarendon.

Bottoms, A \& Tankebe, J 2012, 'Beyond procedural justice: a dialogic approach to legitimacy in criminal justice', Journal of Criminal Law and Criminology, vol. 102, no. 1, pp. 119-170.

Dubber, M 1996-7, 'American plea bargains, German law judges and the crisis of criminal procedure', Stanford Law Review, vol. 49, no. 3, pp. 547-605.

Duff, A, Farmer, L, Marshall, S \& Tadros, V 2007, The trial on trial, vol. 3, Hart Publishing, Oxford.

Fuller, L 1978, 'The forms and limits of adjudication', Harvard Law Review, vol. 92, no. 2, pp. 353-409.

Galligan, DJ 1997, Due process and fair procedures: a study of administrative procedures, Published to Oxford Scholarship Online, viewed 18/11/2019, https://www.oxf ordscholarship.com/view/10.1093/acprof:oso/9780198256762.001.0001/ac prof-9780198256762

Habermas, J 1996, Between facts and norms, MIT Press, Cambridge, MA. 
Habermas, J 1998, 'Paradigms of law', in M Rosenfeld and A Arato (eds), Habermas on law and democracy: critical exchanges, University of California Press, Berkeley, CA.

Hershovitz, S 2003, 'Legitimacy, democracy, and Razian authority', Legal Theory, vol. 9 , no. 3 , pp. 201-220.

Ho, HL 2010, 'Liberalism and the criminal trial', Sydney Law Review, vol. 32, no. 2, pp. 269-287.

Hoffman, M 1977, Empathy and moral development, Cambridge University Press, New York.

Jackson, J, Bradford, B, Hough, M, Myhill, A, Quinton, P \& Tyler, TR 2012, 'Why do people comply with the law? Legitimacy and the influence of legal institutions', British Journal of Criminology, vol. 52, no. 6, pp. 1051-1071.

Jackson, J \& Gau, JM 2015, 'Carving up concepts? Differentiating between trust and legitimacy in public attitudes towards legal authority', in E Shockley, T M S Neal, L Pytlik Zillig \& B Bornstein (eds), Interdisciplinary perspectives on trust: towards theoretical and methodological integration, Springer, New York.

Kelman, HC \& Hamilton, VL 1989, Crimes of obedience, Yale, New Haven.

Loughnan, A 2010, 'Understanding the criminal trial: a response to H L Ho', Sydney Law Review, vol. 32, no. 3, p. 536.

Lucas, JR 1980, On justice, Oxford University Press, Clarendon.

Meyerson, D 2015a, 'The moral justification for the right to make full answer and defence', Oxford Journal of Legal Studies, vol. 35, no. 2, pp. 237-265.

Meyerson, D 2015b, 'Why should justice be seen to be done?', Criminal Justice Ethics, vol. 34, no. 1, pp. 64-86.

Murphy, K, Bradford, B \& Jackson, J 2016, 'Motivating compliance behaviour among offenders: procedural justice or deterrence?', Criminal Justice and Behaviour, vol. 43 , no. 1, pp. 102-118.

Nedim, U 2015, 'Juries don't always follow the law', NSW Courts, Sydney Criminal Lawyers, posted 15th March 2015, viewed 17th January 2020, Available at https:/ nswcourts.com.au/articles/juries-dont-always-follow-the-law/

Solum, LB 2004, 'Procedural justice', Southern California Law Review, vol. 78, no. 1 pp. 181-321.

Sunshine, J \& Tyler, TR 2003, 'The role of procedural justice and legitimacy in shaping public support for policing', Law and Society Review, vol. 37, no. 3, pp. 513-48.

Tyler, TR 1990, Why people obey the law, Princeton University Press, Princeton, NJ.

Tyler, TR 2003, 'The role of procedural justice and legitimacy in shaping public support for policing', Law and Society Review, vol. 37, no. 3, pp. 513-48.

Tyler, TR 2006, 'Psychological perspectives on legitimacy and legitimation', Annual Review of Psychology, vol. 57, no. 1, pp. 375-400.

Tyler, TR \& Fagan, J 2008, 'Legitimacy and cooperation: why do people help the police fight crime in their communities?', Ohio State Journal of Criminal Law, vol. 6 , no. 1, pp. 231-75.

Tyler, TR \& Jackson, J 2013, 'Future challenges in the study of legitimacy and criminal justice', in J Tankebe and A Liebling (eds), Legitimacy and criminal justice, Oxford University Press, Clarendon.

Tyler, TR \& Jackson, J 2014, 'Popular legitimacy and the exercise of legal authority: motivating compliance, cooperation, and engagement', Psychology, Public Policy, and Law, vol. 20, no. 1, pp. 78-95.

Waldron, J 2001, Law and disagreement, Oxford University Press, Clarendon.

Waldron, J 2011, 'The rule of law and the importance of procedure', Nomos, vol. 50, no. 1, pp. 3-31. 


\section{Part III}

The concept of procedural justice

Philosophical perspectives 


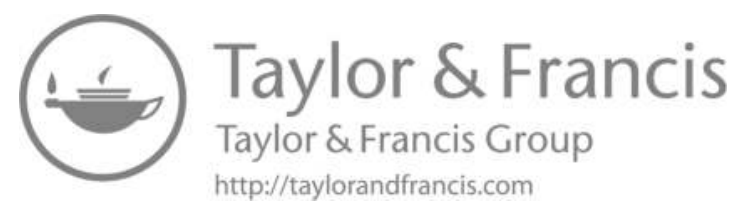




\title{
7 The inadequacy of instrumentalist theories of procedural justice
}

\author{
Denise Meyerson
}

\subsection{Introduction ${ }^{1}$}

The requirements of procedural justice may vary depending on a range of matters. These include the nature and importance of the substantive interests at stake; whether the decision concerns the treatment of particular individuals or is a general policy decision affecting many people; whether decision-makers are required to decide by applying rules or standards which have been laid down in advance or free to decide as they think best in the exercise of their discretion; and whether decision-makers are private individuals or are exercising public power as governmental officials.

This chapter will be concerned exclusively with governmental decision-making that concerns the treatment of particular individuals, using 'government' in the broad sense in which it includes the judicial branch. By way of further narrowing the issues, it will focus on the procedures that should be used when decisions of this kind are made by applying pre-existing legal rules and standards, since, as DJ Galligan says, decision by the application of rules and standards is 'the characteristically legal mode' (1996, p. 24), involving, as it does, determining the content of the law, finding the facts, and applying the law to the facts. ${ }^{2}$ I will describe this activity as 'adjudicative', while noting that it is undertaken not only by judges, but also by administrative tribunals and administrative officials. ${ }^{3}$ This chapter asks how we should evaluate the justice of the procedures used for this task.

It is important to emphasise at the outset that when I talk about 'procedural justice', I am using the term 'justice' in a broad sense, rather than in the more traditional, narrow sense, according to which principles of justice are contrasted with consequentialist moral principles. Consequentialism holds that what makes an act right are its consequences, whereas principles of justice as traditionally conceived hold that individuals are entitled to be treated in certain ways even if the consequences are not overall beneficial. For instance, justice is frequently taken to require respect for rights as something to which individuals are morally entitled by virtue of their dignity and equality, even if this frustrates important social objectives. This is not necessarily to say that rights are absolute and should always prevail, no matter what the consequences, but rather to say that they enjoy great weight and cannot be straightforwardly balanced against consequentialist

DOI: $10.4324 / 9780429317248-11$ 
considerations. It follows that in the traditional sense of the word 'justice', a consequentialist theory using cost-benefit analysis as the basis for recommending particular procedural rules and practices will not count as a theory of procedural 'justice'. However, since I want to provide a sufficiently rich description of the theories on offer, I prefer not to exclude consequentialist theories by definition. Instead, I will follow Michael Bayles in describing as a theory of 'procedural justice' any theory that offers an account of the procedures that morality requires (1990, p. 9). Thus, when I talk about theories of procedural justice, I mean any normative theory directed towards justifying procedural requirements.

In particular, I count theories that evaluate procedures from the economic point of view as theories of procedural justice. As will be explained later, economic theories evaluate procedures by reference to the extent to which they allocate resources efficiently, which makes them consequentialist theories, rather than theories of justice in the narrow sense. Economic theories are nevertheless normative theories, since they maintain that it is morally desirable to design procedural rules so as to promote economic efficiency. ${ }^{4}$ Indeed, from their point of view, economic efficiency is synonymous with justice. Since it would impoverish the discussion to rule out economic theories on the ground that they are not strictly speaking theories of 'justice', and because it would be unfamiliar and inconvenient to describe economic theories as theories of 'procedural morality' (as opposed to theories of procedural justice), I have chosen to use the term 'theory of procedural justice' as shorthand for any theory that aims to specify which procedures are required by morality.

It is also important to emphasise that the procedures required by morality may diverge from the procedural requirements imposed by the law. This point may be obscured by the fact that the law helps itself to the language of morality when it describes the procedural obligations it imposes as requirements of 'natural justice', 'procedural fairness', and 'procedural due process'. Still, there is no guarantee that legal notions of what procedures are just, fair, and due will be morally sound. Since the law's understanding of procedural justice might not reflect a satisfactory understanding of the concept, the legal approach to these matters will not be dealt with here.

My main purpose in this chapter is to argue against the instrumentalist view that the only purpose of procedures in the adjudicative context is to lead to accurate outcomes. ${ }^{5}$ In Section 7.2, I explain that there are two kinds of instrumentalist account. What distinguishes them is their different attitude to conflicts between the achievement of accuracy and other social goals. The first account is willing to weigh the value of accuracy against its cost to society, while the second takes the view that accuracy-enhancing procedures are necessary to treat individuals fairly, even at some cost to society. Section 7.3 explores the difficulties with the first idea, and Sections 7.4 and 7.5 explore the difficulties with the second. The arguments made in these sections suggest that procedures must matter intrinsically as well as instrumentally. As to how we should understand the intrinsic value of procedures, Section 7.6 concludes with some brief remarks suggesting that procedural justice requires the use of procedures that promote 
relations of social equality between individuals and authority figures, especially governmental authorities.

\subsection{Instrumentalism introduced}

In the adjudicative context that is the subject of this chapter, there will frequently be a legally correct outcome to which the affected persons have a legal right (such as a right to social security benefits if they meet the relevant legal conditions or to acquittal if they are not guilty of a crime with which they have been charged). This makes procedures important because the procedures chosen to ascertain the facts and relate the law to the facts may be more or less suited to vindicate these substantive legal rights. To give an obvious example, judges are more likely to discover whether someone has committed a crime if they give defendants the opportunity to present evidence and arguments on their own behalf than if they toss a coin. In general, appropriate procedures can facilitate the discovery of relevant facts and make it easier to test the accuracy of factual and legal propositions (Bone 2017, p. 143). Since everyone will agree that giving effect to substantive legal rights has some moral value, it follows that the instrumental capacity of procedures to enforce the substantive law is one obvious way in which they can be judged for their justice.

But is contributing to the accuracy of legal outcomes the sole benefit to be derived from procedures, in which case it would follow that the value of procedures is entirely instrumental, being tied exclusively to the role they play in arriving at the right legal result? Empirical research into the psychology of procedural justice has shown that people do not see it this way. For instance, people value for its own sake the opportunity to present evidence and arguments on their own behalf, regarding this as fair in itself, and a requirement of justice, even when the correct outcome is obvious and there is no likelihood that the substantive rules will be incorrectly applied if they do not participate (Lind et al. 1983, p. 347; Tyler 1987, pp. 342-343; Tyler et al. 1985, pp. 79-80). In this chapter, I will give reasons for thinking that people's procedural justice judgements, as revealed by the empirical studies, are philosophically supportable: procedures matter for reasons other than the outcomes to which they lead. To this end, I will argue against two kinds of instrumentalist theory: economic theories and outcomebased theories. Both regard the avoidance of legal error as the only purpose of procedures. They differ, however, in their willingness to balance the benefits of accuracy-promoting procedures against their costs.

In order to understand this, it is necessary to note that procedures designed to avoid legal error are generally expensive. Economic theories take this into account by applying routine cost-benefit analysis, fixing on the optimal level of procedural accuracy by reference to considerations of cost-effectiveness. In Section 7.3, I criticise the economic approach. I argue that it fails to take our substantive legal entitlements seriously, since it makes no sense for the state to create legal rights with one hand but take them back with the other by allowing the procedures for enforcing these rights to be entirely dictated by economic considerations. If 
there are no principled limits on the extent to which procedural protections can be withheld in the public interest, it is difficult to see the point of recognising substantive rights in the first place.

Outcome-based theories agree with economic theories that the justice of procedures is solely a matter of the correctness of the outcomes to which they lead. However, they differ from economic theories in taking the view that '[i]t is a matter of injustice when judges make mistakes about legal rights' (Dworkin 1977, p. 130). Since they believe that adjudication engages issues of fairness to individuals, this leads outcome-based theorists to rule out routine trade-offs between the benefits of accuracy-promoting procedures and their costs. Unlike economic theories, outcome-based theories are therefore theories of procedural justice in the narrow sense of 'justice' explained in Section 7.1.

In Sections 7.4 and 7.5, I criticise outcome-based versions of instrumentalism. I begin by pointing out that there are practical limits on the instrumental value of procedures, since perfectly accurate procedures are unattainable and procedures that reduce error to the lowest possible level are too expensive. I argue that this fact creates a difficulty for outcome-based theories. Either they are forced to insist that procedural justice requires perfectly accurate procedures notwithstanding the fact that society cannot afford to provide them, or they are obliged to concede that procedural justice is compatible with substantively unjust (that is, legally incorrect) results. I argue that the first response implies, implausibly, that no real-world legal system can be procedurally just, and that the second response, although correct, pulls the rug out from under instrumentalism. In particular, once it is acknowledged that there is a disconnect between just procedures and just outcomes, it becomes difficult to see why providing concededly imperfect instrumental protection should exhaust the content of procedural justice. On the contrary, it is more plausible to infer that procedures must serve intrinsic values in addition to their capacity to enforce the substantive law. In light of this, I conclude by briefly considering the intrinsic values that procedures might serve.

\subsection{Economic theories of procedural justice}

Economic theories of procedural justice, as defended by theorists such as Richard Posner (1973, 2011) and Louis Kaplow (1994), analyse legal procedures from the perspective of the 'law and economics' school. Like utilitarianism, the law and economics approach takes the consequentialist view that legal rules should aim to maximise or produce the largest amount of the good (Weinrib 1980, p. 310). The economic approach differs from utilitarianism, however, in its view of what is good, being concerned to maximise wealth, not utility. ${ }^{6}$

In discussing the optimal design of procedural rules, Posner distinguishes between two types of costs: error costs and direct costs. Posner defines error costs as the economic costs caused when legal officials make erroneous determinations - for instance, when judges mistakenly impose legal liability or mistakenly fail to impose legal liability (1973, pp. 400-401). These errors are costly because they affect the extent to which people are deterred from violating the substantive 
law. For example, if people who have caused accidents are mistakenly found not to be negligent, then this will detrimentally affect the extent to which people will be deterred from engaging in negligent activities, and the cost of accidents to society will increase. Accuracy-promoting procedures (such as providing hearings and subsidising the cost of lawyers for defendants) help to minimise error costs and therefore promote compliance with the law, which is socially beneficial (Bone 2017 , p. 145; Kaplow 1994, p. 310).

Direct costs (or decision costs) are the costs associated with running a decisionmaking system - for instance, the time spent by legal officials and lawyers and the resources required to operate the system (Posner 1973, p. 400). Although procedural safeguards reduce error costs by producing information that increases the accuracy of the outcome, they are also expensive and therefore generate direct costs. Generally speaking, the more reliable a procedure is, in terms of the additional information it allows to be presented, the more it is likely to cost in time and money.

Posner argues that since the direct costs are just as real as the error costs, it would be irrational to provide procedural protections that reduce the error costs by 50 cents or even 99 cents but increase the direct costs by 1 dollar. In these kinds of cases, greater accuracy is, according to him, not worth the cost (Posner 1973, p. 401; see also Kaplow 1994, p. 308). Posner concludes that the objective of a procedural system is to minimise the total social costs (the sum of the error costs and the direct costs) $(2011$, p. 757). Or, as Kaplow puts the point, procedures should be 'efficient producers of information': the degree of accuracy they should afford is whatever degree is cost-effective (1994, p. 338, fn. 86). Since the only procedural entitlements recognised by the economic approach are to procedures that are economically efficient, it follows that we do not enjoy genuine procedural rights, viz. entitlements that should be respected even if this is not on balance beneficial for society.

The well-known United States case of Mathews $v$ Eldridge (424 US 319 (1976)) approaches procedural justice along these lines, as a matter of finding an optimal balance between the benefits of procedures and their costs, at any rate in the administrative law context. In justifying its finding that a procedure based on written submissions (as opposed to oral testimony) before terminating social security benefits provided sufficient due process, the United States Supreme Court stated:

identification of the specific dictates of due process generally requires consideration of three distinct factors: First, the private interest that will be affected by the official action; second, the risk of an erroneous deprivation of such interest through the procedures used, and the probable value, if any, of additional or substitute procedural safeguards; and finally, the Government's interest, including the function involved and the fiscal and administrative burdens that the additional or substitute procedural requirement would entail.

(pp. 334-335) 
The primary objection to the economic approach to procedural justice is that it is difficult to square with the fact that when society creates legal rights it undertakes to protect them, even if disregarding these rights would have better social and economic consequences. As Ronald Dworkin observes, 'someone is entitled to win a lawsuit if the law is on his side, even if the society overall loses thereby' (1985, p. 94). How can this entitlement be reconciled with the economic view that the only procedures that should be provided for the enforcement of substantive legal rights are those that are in the public interest? Although the decision to create a particular right may initially have been based on public interest considerations, the right thus created cannot be ignored just because it does not suit society to give effect to it. To quote Dworkin again, the 'boast' that society honours people's rights under the law even at the expense of the public interest is no more than an 'idle gesture' if the procedures necessary to enforce these rights can be denied 'for no better reason than that same public interest' (1985, p. 77). Along the same lines, Robert G Bone observes:

[t]he existence of substantive rights implies procedural rights. Because effective enforcement is critical to respecting a substantive right, limiting procedure for reasons of utility would be tantamount to limiting the substantive right on utilitarian grounds. Put differently, without the constraint of procedural rights, courts could undermine substantive rights in order to serve utilitarian goals by denying the costly procedures necessary for their enforcement.

(1999, pp. 993-994)

\subsection{Outcome-based theories of procedural justice}

Although both economic theories and outcome-based theories defend the instrumental view that the moral value of procedures depends solely on their ability to prevent legal error, there is a key difference between them. From the economic point of view, the value of accurate procedures lies in the contribution they make to maximising the good. By contrast, outcome-based theories are concerned with the just treatment of individuals. Outcome-based theories maintain that people suffer an injustice when they are deprived of their legal rights and they value accurate procedures for their ability to guard against this form of substantive injustice. Outcome-based theories are therefore fairness-based or rights-based theories, not consequentialist theories (Bone 2003, pp. 487-488, 495-496).

Outcome-based theorists make a distinction between two kinds of error costs: those that impose costs on society and those that impose costs on individuals. Posner is concerned only with the former-the social costs that arise when legal error prevents the purpose of the law from being achieved. For outcome-based theorists, by contrast, error can have a 'moral cost' as well as a social cost. This will be the case when individuals are mistakenly denied their substantive legal rights. Although legal errors do not always consist in a denial of legal rights, since some errors may be in the interest of individuals (e.g. the acquittal of someone 
who is guilty), outcome-based theorists maintain that when people are mistakenly denied their legal rights, this is unfair and a form of injustice (Bayles 1990, pp. 120-121).

Dworkin defends something like this view, ${ }^{7}$ arguing that we suffer a special kind of injury whenever our legal rights are not upheld. Using the example of a criminal trial, he says that someone who is mistakenly convicted and sent to prison does not experience only 'bare harm', such as the unpleasantness and frustration of being deprived of one's liberty (something that the guilty also suffer). In addition to this subjective form of harm, the innocent also suffer a further, objective injury, which consists simply in the fact that their punishment is unjust. Dworkin calls this kind of injury the 'injustice factor' in someone's punishment, or their 'moral harm', and says that it is a distinct kind of harm against which people should be specially protected. This requires procedures that make it possible for them to test their substantive rights (1985, pp. 80-81). Galligan makes the similar claim that "where the individual person is treated unfairly by being deprived of a right to which he is entitled, injustice results and the integrity of the process is called into question' (1996, p. 113). The injustice may be extreme, as in the case of wrongful convictions or 'miscarriages of justice' (Galligan 1996, p. 112), as we call them, but outcome-based theorists do not confine their claim to factually inaccurate determinations of guilt. In their view, any failure to uphold a legal right is the source of injustice. For instance, administrative decisions that deny benefits to individuals when they are entitled to them are unjust (Dworkin 1985, pp. 100-101; Galligan 1996, p. 112). ${ }^{8}$

In my view, outcome-based theories are correct to think that legal justice (upholding legal rights) is an aspect of substantive justice. Dworkin defends this position because he thinks that it is impossible to identify the law without recourse to moral reasoning. This means that there is, in his view, no clear distinction between legal rights and moral rights (1986, Chapter 7). It is not, however, necessary to endorse Dworkin's controversial view to understand why it is prima facie desirable to give effect to people's legal rights. As Galligan observes, legal standards give rise to normative expectations, including the expectation that one will be treated in accordance with the law. This expectation arises out of an implicit undertaking society gives to its members that their legal rights will be upheld. This does not mean that the commitment to treating people according to law can never be overridden-for instance, if a law is gravely unjust according to more fundamental standards of justice, this could be a reason to disregard it. It does, however, mean that treating people according to law is to treat them justly in one important sense of that term (Galligan 1996, pp. 58-62).

Since outcome-based theorists believe that the denial of legal rights is unfair and a form of injustice, and since avoiding injustice has some degree of priority over the public interest, it follows that outcome-based theorists reject the consequentialist idea that the benefits of accurate procedures should be routinely or straightforwardly balanced against their costs. They maintain, in other words, that procedures that increase the risk of mistakenly denying someone their legal rights cannot be justified by simply appealing to the benefits to society of saving 
money (Bone 1993, p. 598). A higher standard of justification must be met. Thus, in a discussion of the choice of criminal procedures, Dworkin expressly rejects a 'cost-efficient' approach, saying that questions of criminal procedure and evidence should not be decided 'entirely on the basis of cost-benefit calculations about the interests of society as a whole, balancing the interests of the accused against the interests of those who would gain from public savings' (1985, p. 73). According to Dworkin, the use of a utilitarian calculus for fixing criminal procedures denies the importance of moral harm (1985, p. 81), and implies that people accused of a crime are 'entitled to no particular level of accuracy at all' (p. 73).

It will be clear from the discussion so far that although outcome-based theorists emphasise the 'utility' of procedures in leading to accurate outcomes, they do not take a utilitarian approach to procedure, ${ }^{9}$ since they are not willing straightforwardly to balance the importance of achieving accurate outcomes against the cost of doing so. At first glance, then, it might seem that, unlike economic theories, outcome-based theories cannot be criticised for not taking our legal entitlements seriously. Matters are, however, more complex than this, as will shortly become apparent.

\subsection{Tolerating outcome error: Galligan, Dworkin, and Rawls}

If the purpose of procedures is to protect against the injustice that consists in denying legal rights, how robust must the protection be, according to outcomebased theorists? Any answer to this question must begin by acknowledging that procedural perfection is unattainable. There are no procedures available to us that are guaranteed to produce correct results (Solum 2004, p. 185). All procedures in the adjudicative context are attended by some risk of error, given what Bone describes as 'the cognitive and other natural human constraints on accurate decision-making' (2003, p. 514). It is not even feasible for the state to provide maximally accurate procedures, i.e. procedures that reduce unjust mistakes to the lowest possible level, since this would be so expensive as to severely limit the state's ability to provide for other important needs. In a context of limited resources, no one would prioritise accuracy over all other competing interests (Dworkin 1985, p. 84).

Since inaccurate procedures and the substantive injustice to which they lead are inevitable, whether because of human fallibility or limited resources, this leaves outcome-based theorists with two possibilities. They can insist that procedural justice requires perfectly accurate procedures, which carries the implication that procedural justice is unobtainable in the real world. Alternatively, they can narrow the concept of procedural justice, so as to adjust its demands to the constraints imposed by the real world.

Galligan takes the first approach. He argues that substantive rights justify a claim to whatever procedures are necessary to protect and uphold these rights (1996, p. 102). He writes: 
[o]nce it is recognized that to have a right is to have an undertaking from the community that a certain interest will be protected in a certain way, it is a short step to the conclusion that the undertaking ought to include the procedures and institutions necessary for the purpose. Procedures are part of what is necessary to take rights seriously and so to prevent unfair treatment.

(1996, p. 101)

Galligan concedes that society cannot afford to provide fully adequate procedures, and he also believes that if a society does its best to provide adequate procedures within the resources available, any inadequacy in the procedures provided is excusable. He insists, however, that to excuse is not to justify. In his view, there is no denying the fact that some of the resulting legal mistakes will violate rights and that these individuals will have been treated unjustly (1996, p. 116).

Dworkin takes the second approach. Although, as noted above, he appears to defend an outcome-based approach, he narrows the notion of procedural justice by reference to what is affordable, arguing that identifying procedural justice with maximum accuracy is too 'severe' a requirement $(1985$, p. 82), and that it is not unjust to provide less than maximally accurate procedures with a view to spending money on other worthwhile social programmes (1985, p. 72). It is not, however, clear that Dworkin's position is stable. How can one recognise the 'injustice factor' in certain kinds of mistaken decisions while simultaneously affirming that it is not unjust to tailor procedural protections to what is affordable? If certain kinds of mistaken decisions are unjust, it would seem to follow that people are entitled to robust procedures that protect their underlying legal entitlements, even if the expense involved cannot be justified from the economic perspective. On the other hand, if providing less than maximally accurate procedures in order to save money is not unjust, this would seem to be the equivalent of the costefficient approach defended by Posner. ${ }^{10}$

In an attempt to explain why affordability considerations can legitimately be taken into account within a rights-based framework, Dworkin argues that 'we do not lead our lives to achieve the minimum of moral harm at any cost' (1985, p. 86). Instead, we accept substantial risks of suffering injustice in order to achieve 'even quite marginal gains in the general course of our lives' (1985, p. 86). This shows, according to Dworkin, that we reject a 'grand right to supreme accuracy' (1985, p. 90). Does this mean that the economic approach is correct and that we have no procedural rights at all? Dworkin thinks not. He argues that it is possible to carve out a middle ground between the idea that we have a right to maximally accurate procedures and the idea that the choice of procedures should depend entirely on what is economically efficient (1985, pp. 72-73). This supposed via media can be found in procedural rules that are appropriately sensitive to the fact that denying people their legal rights is a form of injustice, while not regarding this kind of injustice as something to be avoided at any cost. Dworkin argues, in particular, for two procedural rights that are weaker than the grand right to supreme accuracy, but still genuine rights, according to Dworkin, because they trump ordinary utilitarian calculations (1985, p. 89). 
Dworkin derives these two procedural rights from the principle that political decisions must treat everyone with equal concern and respect. He argues, first, that when the legislature enacts procedural rules, it must show concern for moral harm by making an assessment of the magnitude of the moral harm caused when people are unjustly convicted or otherwise denied their legal rights. Thus a legislature would violate the first procedural right if, for instance, it refused to enact a procedural rule which would increase the accuracy of a trial at no additional cost to society, since that would indicate no concern at all with the risk of moral harm $(1985$, p. 89). At the same time, Dworkin rejects the idea that there is what Bone calls a 'normatively acceptable level of error risk' (2010, p. 1016). Provided that the legislature has attached importance to the risk of moral harm, it is free to decide how much to spend on procedures to guard against the risk, taking into account policy considerations and other competing social goals. This is because the first procedural right is

the right that a particular importance be attached to the risk of moral harm, not a right to a particular, independently describable, overall level of accuracy in adjudication ... [I]f a rule would improve accuracy by a great deal but cost the community heavily, then a failure to adopt the rule would be consistent with valuing the risk of injustice very high indeed.

(Dworkin 1985, pp. 95-96)

Dworkin thinks that it is fair to leave the decision as to how important moral harm is to the legislature because this is a moral issue about which people reasonably disagree. Furthermore, provided a legislative decision to sacrifice accuracy subjects everyone to the same risk, it will be fair to everyone $(1985$, p. 87$)$. The procedural rules chosen by different legislatures may therefore justifiably differ in the degree of protection they afford, since there is no one set of rules of evidence and procedure which is uniquely permissible when a legislature considers whether the social gains achieved by choosing less expensive and therefore less accurate procedures outweigh the moral harm that these procedures risk (Plaxton 2008, p. 364). This approach should not, however, be confused with a cost-benefit approach, according to Dworkin, because the decision is not a 'pure' matter of policy. On the approach prescribed by Dworkin, a legislature would not balance the 'bare' harm caused by mistaken decisions against the savings made by providing reduced procedural protections. It would weigh the interests of those who stand to be deprived of their legal rights much higher than that, because it would see them as interests in avoiding moral harm. A legislature following this approach could therefore not be accused of utilitarianism, according to Dworkin, even though it might ultimately take the view that scarce resources should be spent on social goals other than accuracy (Dworkin 1985, pp. 77, 94, 97-98).

The second procedural right for which Dworkin argues is the right to consistency in procedure. He maintains that once procedures have been established, they should be consistently applied (1985, pp. 89-90). If, for example, the number of jurors in a criminal case has historically been fixed at 12 , it would be a 
violation of the rights of accused persons if this number were to be substantially decreased. Even though there is no reason why a different number should not have been chosen initially, substantially winding back the protection would be unjustifiable, because it would diminish 'the level of safety provided at the center of the criminal process for so long' (1985, p. 91).

Dworkin (2002) expands on this idea in a more recent article considering United States anti-terrorism measures that dilute the rights of those accused of serious crimes. Dworkin concedes that the traditional rights of accused persons have evolved over time, that their details can be explained only historically, and that some of the procedural rights taken to be indispensable in the United States are not necessary features of all fair criminal justice systems. He maintains, however, that fairness requires, as a matter of equal concern for anyone who might be innocent, that the rights that have evolved historically are owed to anyone who is now accused of a serious crime and tried within the United States criminal justice system. It follows that it is unfair to persons suspected of terrorism to try them under special conditions that run an increased risk of convicting the innocent - for instance, before special military tribunals in which they have fewer rights than in ordinary criminal courts. Dworkin adds that if we believe that the danger from terrorism is so serious that we are justified in denying persons suspected of terrorism the traditional rights extended to other accused persons, then at least we should have 'the candor to admit that what we do to them is unjust' (Dworkin 2002).

In effect, Dworkin turns his back on the idea of outcome accuracy. Since his two procedural rights are not rights to the enforcement of one's substantive legal entitlements, but rather rights that guarantee that the risk of injustice created by inadequate procedures is fairly distributed across individuals, he turns procedural justice into a form of distributive justice (Bone 2010, pp. 1018, 1020; Galligan 1996, p. 119). This means that Dworkin does not carve out the desired via media between the purist view that we have a right to maximally accurate procedures and the economic view that we are entitled to no particular level of accuracy at all. Instead, he gives us an account of how to distribute scarce process resources fairly. As Bone observes, Dworkin tries to deal with the problem of limited resources by conceiving of procedural rights

as rights to fair treatment, not to accurate outcomes ... [E]rror does not violate procedural rights so long as the error is not due to skimpy procedures justified on utilitarian grounds and so long as the procedural system as a whole treats litigants fairly.

(Bone 1999, p. 934, emphasis in original)

However, even procedures that carry a very high risk of injustice may distribute the risk fairly. It therefore seems that we can ask the same question of Dworkin as he asks of the economic approach. It is central to Dworkin's rights-based theory of adjudication that society should honour people's substantive rights under the law even if this comes at a social cost. How is this to be reconciled with the idea 
that the only procedural rights we have are to a just distribution of the risk of error? Does the resulting mismatch between procedure and substance not entail that people's rights under the law are not rights in the strict sense, contrary to everything else Dworkin tells us about legal rights?

Galligan's approach is more coherent than Dworkin's. Dworkin attempts to have it both ways: insisting that society should honour people's legal rights while also maintaining that there is no specific or pre-defined level of accuracy which the procedures for enforcing these rights need to meet. Galligan, by contrast, connects substance and procedure as tightly as possible, since he holds that substantive rights justify a claim to whatever procedures are necessary to protect and uphold these rights. Procedural rights are therefore rights to procedures that always produce the right results (1996, pp. 113-114). In theory, this is an attractive position, because the idea that we are entitled to procedures that guarantee correct outcomes takes our legal rights with utmost seriousness. However, as previously noted, Galligan is forced to concede that inadequate procedures are unavoidable for practical reasons, such as resource limitations, which turns his conception of procedural justice into a utopian ideal. Galligan's purist approach implies that no procedural system in the real world can be just and that all legal systems violate people's procedural rights on a daily basis - a conclusion that is counter-intuitive. ${ }^{11}$

If Dworkin's procedural rights do not deliver on the promise of the outcomebased approach - that the purpose of procedures is to protect against the injustice that consists in the deprivation of substantive legal rights - and if Galligan's approach puts procedural justice out of reach, is there any other way of retaining the idea that people are entitled to procedures that are designed to vindicate their legal rights, while simultaneously narrowing the scope of procedural justice in response to considerations of affordability and efficiency?

The remaining possibility is that procedural justice requires giving substantial, although not absolute, priority to the value of accuracy over the public interest. If accuracy were to be prioritised in this way, procedures would be chosen that generate the right conclusion in the majority of cases, even if the expense could not be justified on utilitarian grounds. The risk of erroneous decisions would then be low, even if efficiency would justify running a higher risk. Moral harm would be avoided to a significant extent, and trade-offs between accuracy and cost would be permissible only once a morally acceptable threshold level of accuracy has been guaranteed. An approach of this kind would occupy a true mid-way position between the purist view and the economic view, since it would fix a morally acceptable level of risk of moral harm and identify just procedures with procedures that do not impose more than that level of risk.

Arguably, this is what Rawls had in mind when he said that the pursuit of correct outcomes in criminal trials competes with 'other ends of the law' (i.e. considerations of cost), and that 'imperfect' procedural justice is therefore the most the legal system can offer us. Rawls wrote:

[t]he desired outcome is that the defendant should be declared guilty if and only if he has committed the offense with which he is charged. The trial 
procedure is framed to search for and to establish the truth in this regard. But it seems impossible to design the legal rules so that they always lead to the correct result. The theory of trials examines which procedures and rules of evidence, and the like, are best calculated to achieve this purpose consistent with other ends of the law. Different arrangements for hearing cases may reasonably be expected in different circumstances to yield the right results, not always but at least most of the time.

(1971, pp. 85-86)

Along similar lines, Rawls describes due process as 'a process reasonably designed to ascertain the truth, in ways consistent with the other ends of the legal system' (1971, p. 239). This version of an outcome-based approach is superior to both Galligan's and Dworkin's approaches. It does not turn procedural justice into an unattainable ideal, à la Galligan. On the other hand, it takes the underlying substantive rights more seriously than Dworkin's approach, which rejects the idea of even a qualified right to accuracy and replaces it with a different kind of right altogether-one to the fair distribution of the risk of error. Yet imperfect procedural justice can still lead to substantive injustice, since procedures that satisfy Rawls's test (of yielding the right results most of the time) can lead to unjust results some of the time.

\subsection{Rejecting instrumentalism}

My discussion has shown that the relationship between procedures and legally correct outcomes in the real world is imperfect. Infallible decision procedures do not exist and maximally accurate procedures are too costly. If an outcomebased theorist responds by saying that people nevertheless have a right to perfectly accurate procedures, albeit one that cannot be met in practice, this means that procedural justice is not an ideal for the real world. On the other hand, if an outcome-based theorist concedes that considerations of cost reduce the scope of our procedural entitlements, and that procedures that are likely but not guaranteed to produce substantively just outcomes are sufficient to satisfy the demands of procedural justice (Rawls's view), this implies that procedural justice is compatible with substantive injustice. The risk of injustice is even greater on Dworkin's even weaker view that procedural justice merely requires a fair distribution of the risk of error. Dworkin's view approaches very close to economic theories of procedures.

Furthermore, once it is conceded that procedural justice is compatible with the violation of people's substantive legal rights, it becomes difficult to sustain the instrumentalist view that the only way to evaluate the justice of procedures is by evaluating the accuracy of the results to which they lead. Instrumentalism is at home within the economic framework of a cost-benefit approach to procedures, since a cost-benefit approach is, by definition, concerned only with the consequences of following different procedural rules. However, if one sees procedural justice as a matter of entitlements based in fairness to procedures that protect our 
substantive rights, and if one also concedes that the ability of just procedures to play this role is limited, the insistence that the only point of just procedures is to avoid violations of substantive rights becomes puzzling. Outcome-based theorists have not grappled with this question. Instead, they seem to regard the truth of instrumentalism as obvious.

Dworkin, for instance, quickly dismisses the view that there are 'process values', or that process can matter apart from outcomes. According to the process values view, certain procedures can be morally required even if they are not necessary to reach accurate outcomes (Summers 1974). For instance, participation in legal decision-making processes is thought by some theorists to be valuable independently of its instrumental value. Thus, it is argued that it is intrinsically unjust not to allow affected parties to participate by telling their side of the story, even if their participation will have no effect on the outcome, the case being cut and dried and the outcome obvious (Mashaw 1981, pp. 902-903). ${ }^{12}$ Dworkin responds to this claim by saying that he finds it difficult to understand how there could be any moral harm other than the harm of a mistaken decision and therefore how there could be any basis for finding procedures unjust other than the fact that they create a risk of substantive injustice (1985, pp. 102-103). Bone also gives the process values view short shrift. He says that the reason why we have an adjudication system is to produce quality outcomes, and defenders of the process values view therefore need to explain why people should be given participation rights without regard to whether this is needed to ensure outcome quality (2008, pp. 338-339).

The problem lies, however, in attempting to combine the claim that procedural justice is exclusively a matter of procedures that avoid injustice to individuals with the concession that just procedures are compatible with a substantial risk of outcome error. The effect is to turn procedural justice into an implausibly anaemic ideal—one that implies that there is very little that people are entitled to expect as a matter of fairness from the processes officials use to determine their legal situation. Procedures merely need to have some capacity to protect substantive rights or should distribute the risk of error fairly.

In my view, the solution is to reject instrumentalism. I agree with the outcome-based claim that procedural justice involves treating individuals fairly, not maximising benefits for society, and I also think that theorists like Dworkin and Rawls are correct to concede that even just procedures will not always be capable of protecting people's substantive legal rights. However, I draw the conclusion that there must therefore be more to procedural justice than being the servant of substantive justice. In particular, procedures should be assessed not only for their capacity to reduce legal error, but also for their intrinsic justice. Following intrinsically just procedures could then assist in offsetting the substantive injustice of the mistaken decisions whose possibility has to be accommodated within any real-world conception of procedural justice.

This raises the question as to what might make procedures intrinsically just. I will end by briefly explaining what kind of account I would offer in answer to this question. Some defenders of the process values view appeal to the value of 
dignity, understood as the capacity for rational agency. Thus, Jeremy Waldron argues that procedures should respect human dignity by treating people as active subjects, not passive objects - as people who can reason and explain themselves before decisions are made affecting them (2011, p. 19). Similarly, Laurence Tribe argues that it is unjust to deny persons the 'right to be heard from' and 'the right to be told why', because 'to be a person, rather than a thing, is at least to be consulted about what is done with one' (1988, p. 666, emphasis in original). For Tribe and Waldron, decision-makers are under an obligation to treat people in a way that respects them as rational agents, even if this is not necessary to achieve accurate results. ${ }^{13}$

Dignitarianism is not, however, the only way to understand the intrinsic value of procedures. The understanding of procedural justice in the empirical literature alerts us to another possibility-one that is not focussed on respect for rational agency. I mentioned in Section 7.2 that empirical research in psychology shows that people's understanding of procedural justice is not entirely instrumental or outcome-based. I did not, however, explain the non-instrumental concerns that dominate people's procedural justice judgements. The empirical studies show that these concerns are primarily focussed on the nature of people's social relationships with authorities - whether authorities are trying to be fair towards them, are treating them even-handedly and with respect, and are considering their views properly (Tyler \& Lind 2001, pp. 75-77). According to Tom Tyler and Allan Lind, it is 'striking how much issues concerning relationships to authority color the perception of [procedural] justice. Relational concerns seem to overwhelm concerns about the specific problem or dispute involved' (1992, p. 160). It seems that the reason why interpersonally satisfying interactions with group authorities are such a powerful influence on people's perceptions of fair treatment is because positive interactions send the symbolic message that one has equal status in one's group, which in turn promotes feelings of self-worth and self-respect (Tyler \& Blader 2000, pp. 90-92).

In my view, there are sound normative arguments supporting this alternative understanding of procedural justice, with relational theory in ethics providing the requisite normative underpinnings. Very briefly, relational theory emphasises the role of egalitarian social relations in an equal society. It defends the attractive idea that equality is an ideal that consists in people relating to each other as equals and enjoying equal standing (Anderson 2010; Scheffler 2003). As Catriona Mackenzie emphasises in her contribution to this volume, relations of equality are particularly susceptible to being undermined by attitudes of expressive disrespect on the part of state institutions and state officials. ${ }^{14}$ Relational theory therefore implies that officials are under a moral duty to interact with citizens in ways that communicate a message of equal status. As to what this might involve, the psychology research shows that it requires officials to treat people with respect, listen attentively, behave impartially, and demonstrate goodwill. In this way we arrive at a satisfying account of procedural justice that both dovetails with and justifies people's expectations about how officials should treat them. 


\subsection{Conclusion}

Although the value of accurate procedures must form part of any adequate conception of procedural justice, I have argued that instrumentalist theories of procedural justice are unsatisfactory. Economic theories do not take people's legal rights seriously, since the procedures they provide for the enforcement of these rights are fixed by reference to a cost-benefit calculation, which could lead to large-scale under-enforcement of the rights. It makes no sense to grant legal entitlements without recognising procedural rights that are to some extent insensitive to considerations of cost or social welfare more generally.

At the other end of the spectrum from economic theories, Galligan takes legal rights as seriously as it is possible to take them, since he insists that right-holders have a right to the perfectly accurate procedures needed to uphold their rights. I have argued, however, that his conception of procedural justice is unachievable, and that attempting even to approximate it would make it impossible to satisfy other important social needs.

Dworkin and Rawls recognise that maximal accuracy is too demanding a conception of procedural justice in a world of limited resources. This leads them to regard procedures as unjust only when the risk of error is not distributed fairly (Dworkin) or when the risk is too high (Rawls). Although I agree with them that just procedures are not capable of fully protecting legal rights, and that procedural justice is compatible with some degree of substantive injustice, I have argued that the difficulty is in combining this relatively insipid form of protection for legal rights with the instrumental view that procedural justice is nothing more than the servant of substantive justice. How can protecting substantive legal entitlements be the only purpose of procedure if it is such a flawed means to this end? I have claimed that it is more plausible to infer that there must be more to procedural justice than 'a process reasonably designed to ascertain the truth', to use Rawls's phrase. Procedures serve values other than reducing error and the moral assessment of legal procedures should not be limited to the outcomes they generate. Finally, I have suggested that relational theory in ethics enables us to grasp the aspects of procedural justice overlooked by instrumental accounts.

\section{Notes}

1 I would like to thank Catriona Mackenzie and Therese MacDermott for their very helpful comments. I am also grateful to participants who commented on aspects of this chapter when earlier versions were presented at the Law and Society Association Meeting held in Toronto in 2018, a workshop on procedural justice held at Macquarie University in 2018, and a seminar in the Philosophy Department at the University of the Witwatersrand in 2019. Wendy Carlton provided excellent editorial and research assistance. Some of the discussion in this chapter draws on material in Meyerson and Mackenzie (2018). Research for this chapter was funded by the Australian Government through the Australian Research Council's Discovery Project funding scheme (DP1701009600: ‘A Relational Theory of Procedural Justice'). 
2 For a discussion of procedural justice in the context of discretionary decisions, see Kristen Rundle's contribution to this volume (Chapter 11).

3 Compare Galligan (1996, p. 241): '[i]n a broad sense, all standard-application decisions are adjudicative, in that they require judgment in applying standards to facts'.

4 In Posner's view, 'morality is derived from the economic principle itself' (1979, p. 139).

5 In her contribution to this volume, Emanuela Ceva also provides reasons to reject what she calls the 'epistemic interpretation of the value of due process' (Chapter 8).

6 Posner defines wealth as 'the value in dollars or dollar equivalents ... of everything in society. It is measured by what people are willing to pay for something, or, if they already own it, what they demand in money to give it up' $(1979$, p.119).

7 Bone describes Dworkin's view as 'an outcome-oriented theory based on a right to treatment as an equal' $(2003$, p. 489 , fn. 10$)$.

8 Mistaken decisions in civil trials likewise cause injustice. For discussion, see Dworkin (1985, pp. 92-98).

9 Contra James Edelman, who maintains that tying the justice of procedures to their 'utility' in promoting accurate outcomes is equivalent to providing a 'utilitarian rationale for procedural fairness' (2016, p. 148).

10 See also Bone's observation that procedural rights present a puzzle in that '[b]ecause they are rights, they must resist arguments for limiting procedure based on the high social costs of litigation, but to fit prevailing intuitions of procedural fairness, they must also yield to social cost arguments at least to some significant degree' (2010, p. 1013).

11 Compare Bone (2010, p. 1016): if people have a right to perfect accuracy, 'every case would involve a rights violation, which hardly fits common intuitions of procedural fairness'.

12 For a defence of the non-negotiable value of participation in tribunal proceedings, see Therese MacDermott's contribution to this volume (Chapter 12).

13 In her contribution to this volume, Emanuela Ceva also defends a version of dignitarianism, arguing that due process has a 'constitutive value', which consists in the way in which it confers the normative status of being an agent or active subject on the parties to legal proceedings (see Chapter 8).

14 See Mackenzie's contribution to this volume (Chapter 9).

\section{References}

Anderson, E 2010, 'The fundamental disagreement between luck egalitarians and relational egalitarians', Canadian Journal of Philosophy, vol. 40, sup 1, pp. 1-23.

Bayles, MD 1990, Procedural justice: allocating to individuals, Kluwer Academic Publishers, Dordrecht.

Bone, RG 1993, 'Statistical adjudication: rights, justice and utility in a world of process scarcity', Vanderbilt Law Review, vol. 46, no. 3, pp. 561-651.

Bone, RG 1999, 'The process of making process: court rulemaking, democratic legitimacy, and procedural efficacy' Georgetown Law Journal, vol. 87, no. 4, pp. 887-955.

Bone, RG 2003, 'Agreeing to fair process: the problem with contractarian theories of procedural fairness', Boston University Law Review, vol. 83, no. 3, pp. 485-552.

Bone, RG 2008, 'Making effective rules: the need for procedure theory', Oklahoma Law Review, vol. 61, no. 2, pp. 319-340.

Bone, RG 2010, 'Procedure, participation, rights', Boston University Law Review, vol. 90, no. 2, pp. 1011-1028. 
Bone, RG 2017, 'Economics of civil procedure', in F Parisi (ed.), The Oxford handbook of law and economics volume 3: public law and legal institutions, Oxford University Press, Oxford.

Dworkin, R 1977, Taking rights seriously, Duckworth, London.

Dworkin, R 1985, 'Principle, policy, procedure', in A matter of principle, Harvard University Press, Cambridge.

Dworkin, R 1986, Law's empire, Belknap Press of Harvard University Press, Cambridge.

Dworkin, R 2002, 'The threat to patriotism', New York Review of Books, 28 February, vol. 44, no. 49, viewed 11 November 2019. Available at https://www.nybooks. com/articles/2002/02/28/the-threat-to-patriotism

Edelman, J 2016, 'Why do we have rules of procedural fairness?', Australian Journal of Administrative Law, vol. 23, no. 31, pp. 144-154.

Galligan, DJ 1996, Due process and fair procedures: a study of administrative procedures, Clarendon Press, Oxford.

Kaplow, L 1994, 'The value of accuracy in adjudication: an economic analysis', Journal of Legal Studies, vol. 23, no. 1, pp. 307-401.

Lind, EA, Lissak, RI \& Conlon DE 1983, 'Decision control and process control effects on procedural fairness judgments', Journal of Applied Social Psychology, vol. 13, no. 4, pp. 338-350.

Mashaw, JL 1981, 'Administrative due process: the quest for a dignitary theory', Boston University Law Review, vol. 61, no. 4, pp. 885-931.

Meyerson, D \& Mackenzie, C 2018, 'Procedural justice and the law', Philosophy Compass, vol. 2018, p. el2548. Available at https://doi.org/10.1111/ phc3. 12548

Plaxton, M 2008, 'Arguments of virtue and constitutional criminal procedure', University of Toronto Law Journal, vol. 58, no. 3, pp. 355-376.

Posner, RA 1973, 'An economic approach to legal procedure and judicial administration', Journal of Legal Studies, vol. 2, no. 2, pp. 399-458.

Posner, RA 1979, 'Utilitarianism, economics and legal theory', Journal of Legal Studies, vol. 8, no. 1, pp. 103-140.

Posner, RA 2011, Economic analysis of law, 8th edn, Aspen Publishers, New York.

Rawls, J 1971, A theory of justice, Oxford University Press, Oxford.

Scheffler, S 2003, 'What is egalitarianism?', Philosophy and Public Affairs, vol. 31, no. 1, pp. 5-39.

Solum, LB 2004, 'Procedural justice', Southern California Law Review, vol. 78, no. 1, pp. 181-321.

Summers, RS 1974, 'Evaluating and improving legal processes-a plea for "process values", Cornell Law Review, vol. 60, no. 1, pp. 1-52.

Tribe, L 1988, American constitutional law, 2nd edn, Foundation Press, Mineola.

Tyler, TR 1987, 'Conditions leading to value-expressive effects in judgments of procedural justice: a test of four models', Journal of Personality and Social Psychology, vol. 52, no. 2, pp. 333-344.

Tyler, TR \& Blader, SL 2000, Cooperation in groups: procedural justice, social identity and behavioral engagement, Psychology Press, Philadelphia.

Tyler, TR \& Lind, EA 1992, 'A relational model of authority in groups', Advances in Experimental Social Psychology, vol. 25, pp. 115-191. 
Tyler, TR \& Lind, EA 2001, 'Procedural justice', in J Sanders \& VL Hamilton (eds.), Handbook of justice research in law, Kluwer Academic/Plenum Publishers, New York.

Tyler, TR, Rasinski, K \& Spodick, N 1985, 'The influence of voice on satisfaction with leaders: exploring the meaning of process control', Journal of Personality and Social Psychology, vol. 48, no. 1, pp. 72-81.

Waldron, J 2011, 'The rule of law and the importance of procedure', in JE Fleming (ed.), Getting to the rule of law, New York University Press, New York/London.

Weinrib, EJ 1980, 'Utilitarianism, economics, and legal theory', University of Toronto Law Journal, vol. 30, no. 3, pp. 307-332. 


\title{
8 The many facets of procedural justice in legal proceedings
}

\author{
Emanuela Ceva
}

\subsection{Introduction}

After spending a night drinking in a bar, a young woman named Sarah is gangraped by three men. Although the rape occurs in front of a cheering crowd, no one besides the victim is willing to testify. Therefore, before the case goes to court, the prosecuting attorney and the defence lawyers bargain, and the three rapists plead guilty to the assault. The sentence imposed for an assault charge is similar to that standardly imposed for rape. However, given the guilty plea, the victim is prevented from presenting her own story before a jury. This course of action leaves Sarah distraught and enraged. ${ }^{1}$

What went wrong in the criminal proceedings that can account for Sarah's reaction? To be sure, we can start from the conjecture that, by her reaction, Sarah claims that justice was denied to her. The formality of this initial conjecture calls for an analysis of what it means to do justice to the victim of a crime in legal proceedings. It requires, in other words, that we disentangle the many facets of procedural justice in this context.

To move forward, consider due process as an epitomic instantiation of procedural justice in legal proceedings. I devote this chapter to the presentation and discussion of three possible ways in which we can make a normative assessment of legal proceedings in the context of criminal trials. Two interpretations are quite customary in the philosophical debate and they both locate the value of due process in some external good to which criminal proceedings relate. The first account is instrumental and offers an 'epistemic interpretation' of due process as valuable because (and to the extent that) it allows for the truth of the matter to be revealed through the criminal trial. The criminal proceeding is thus valuable because it is causally related to reaching a 'just' verdict, one that declares the defendants guilty of the crime they have actually committed. Because there is no guarantee that this outcome will be reached on all occasions, the criminal proceedings, informed by due process, are an instance of what John Rawls (1971) dubbed 'imperfect procedural justice' (pp. 85-86). The second view comes from the 'expressivist interpretation' of the value of due process. In this interpretation, due process is a means to convey to the parties a certain message. On this view, criminal proceedings that instantiate the principle of due process are valuable because they contribute to the

DOI: $10.4324 / 9780429317248-12$ 
display of an appropriate consideration of the alleged victims and perpetrators. Under the 'expressivist view', justice thus resides in there being a vehicle for the public acknowledgement of persons' status - an ideal function that the proceedings may or may not be capable of achieving in practice.

Alongside these received interpretations, I want to suggest a third way of valuing due process. Besides their role in securing some kind of external good (establishing the facts or conveying a certain institutional consideration of the parties), the procedures according to which the different parties interact in legal proceedings can be considered inherently valuable and an object of normative assessment in their own right. In this 'interactive interpretation', due process has a specific 'constitutive value', which is realised ipso facto by the establishment of proceedings that instantiate it. This value consists in its capacity to change the parties' normative status by establishing them as the holders of rights and the bearers of duties that they would not otherwise have. ${ }^{2}$ Because criminal proceedings thus create, by their very establishment, deontic relations, they can be more or less just in themselves depending on their structural features but independently of their results. My final claim will be that to bring this third way of valuing due process to the fore is essential to rendering a complete picture of how procedural justice can be realised through and in legal proceedings (thus offering a full account of what goes wrong when a party is denied a procedural right, as was the case with Sarah's right to be heard in court).

\subsection{The instrumental value of due process}

\subsubsection{The epistemic interpretation}

According to a well-established instrumental approach to the normative assessment of legal proceedings, the importance attributed to the principle of due process derives from an epistemic interpretation of its value: ${ }^{3}$ When we look at criminal trials from this point of view, the proceedings are just to the extent that they are structured in a way that facilitates the revelation of the truth. Criminal proceedings are just, in this epistemic sense, only because and when they work as effective instruments in making sure the defendant is declared guilty only if he has actually committed the crime of which he is accused.

However, the eventuality that legal proceedings may fail to deliver an epistemically accurate result makes them an instance of what Rawls (1971, pp. 85-86) has famously characterised as 'imperfect procedural justice'. ${ }^{4}$ For Rawls, procedural justice is perfect, when we have a process capable of leading to the just outcome with certainty. Crucially, what constitutes a just outcome is known even before we engage in the process, and the process is in fact devised in entirely instrumental terms towards said outcome. ${ }^{5}$ In the case of criminal proceedings, we have seen that a just outcome is one that meets the epistemic standard of declaring the defendants guilty only of the offence they have actually committed. But it is apparent that there is no guarantee that a specific procedure can be devised that constantly delivers such an outcome (Rawls 1971, p. 85). ${ }^{6}$ 
The imperfect nature of the kind of procedural justice that the epistemic interpretation of the value of due process instantiates can be usefully employed to make sense of one facet of the distressed and enraged reaction of the victim of rape in our example. From this epistemic point of view, it seems inevitable that Sarah was enraged and distraught by the negotiated outcome of the proceeding. While the prison sentence for assault is similar to that usually imposed for a rape, the fact that Sarah was raped was not at all established, and therefore the proceeding by which the sentence was reached cannot be considered just on the grounds that it failed to deliver an epistemically accurate outcome. The victim was not offered reparation for the actual offence she had suffered.

This instrumental interpretation can thus make sense of one important dimension of the normative assessment of criminal proceedings. In the epistemic interpretation, criminal proceedings are unjust if they fail to lead to a legal decision that is appropriately responsive to the facts in question, as was the case with Sarah's rape. Notice that the normative source of the value of the criminal trial is external. This means assessing the proceedings in view of their being causally related to reaching a decision whose value (being respondent to the truth of the matter) pre-exists the proceedings and their development. We can thus see how the proceedings are valued to the extent that they are subservient to the achievement of that decision.

While this epistemic aspect is important in the normative assessment of legal proceedings, I want to show that it is not sufficient. It cannot give a full account of how those proceedings may be more or less just, nor can it offer a solid defence of the value of due process. This is because in the epistemic interpretation, due process is entirely fungible. Consider the critical discussion Richard Arneson has offered of the legal procedural rights enjoyed by defendants and implied by the principle of due process. These procedural rights include 'the right to confront one's accusers, the right to a speedy trial, the right against self-incrimination, the right to counsel, the right to a jury of one's peers, and so on'. Arneson (1993) argues that,

this panoply of rights would dissolve if it were discovered that abrogating them wholesale would produce trial verdicts that are fairer (and generate no morally undesirable outcomes of such magnitude as to outweigh the increased fairness of trial verdicts).

So, Arneson concludes, given the imperfect nature of criminal proceedings informed by the principle of due process in delivering justice, were we to find more effective instruments to establish the truth of the matter about a crime, we should abandon due process without any regrets. In response to Arneson's challenge, we could easily point out an implausible implication of his argument. If we claimed that procedures are inherently irrelevant from a moral point of view (because they are mere fungible instruments to deliver justice), we should be prepared to accept that any procedure enhancing the accuracy of criminal trials 
should be preferred to a criminal trial guided by the principle of due process, even if that implied torturing the defendant to establish the truth of the matter. But who can possibly be willing to bite this bullet? Arneson is not and, in fact, he has a response to such a rejoinder:

The idea that procedures should be chosen in order to attain morally best results does not mean that the immediate consequences of operating the procedures themselves should be excluded from calculation ... My position is that there are no special procedural rights determinable by examining our intuitions about inherently fair procedures (supposed to be independent of our convictions about the substantively fair outcomes that procedures work to reach) ${ }^{7}$

(Arneson 1993, p. 121)

Arneson's line of argument is successful in showing that when we engage in the normative assessment of a criminal proceeding (just like any other process) we must also consider the impact the operation of such proceeding has on those who participate in it. This point is, in fact, empirically corroborated by a vast body of literature on the social psychology of procedural justice (see Tyler 1988, pp. 103-135; Thibaut \& Walker 1975; Napier \& Tyler 2008, pp. 509-510). This literature shows that the participants in any given process are psychologically more inclined to recognise the outcomes of that process as fair when they feel they have been treated fairly in the process itself even if the outcomes are not in their favour. This inclination is likely due to the positive effects that the participation in a fair process has on the parties. For example, the feeling of being respected when participating in a process where one has the opportunity to speak up and be heard, may enhance self-respect and encourage participants towards a more positive assessment of the fairness of the outcome. ${ }^{8}$ I shall expound this thought in the next subsection.

It bears highlighting now that these psychological findings lend empirical support to the twofold limitations of the epistemic interpretation I have mentioned above. First, the epistemic value of due process - while weighty and importantis not exhaustive of the considerations that matter for a complete normative assessment of legal proceedings. We should also, at least, consider the effects that the participation in a process has on the parties in it. Second, in order to offer a solid account of the value of due process, we should pinpoint the features of the process that make it inherently worthwhile, beyond its extrinsic appreciation as a fungible instrument of epistemic justice.

\subsubsection{The expressivist interpretation}

To address the limitations of the epistemic interpretation of the value of due process in legal proceedings, I want to present a second received interpretation. This further interpretation also points to an external good as the source of the value of due process, but it also assesses legal proceedings in virtue of their capacity to 


\section{Emanuela Ceva}

convey to the parties a certain message with respect to that good. Notably, in this interpretation, the good in question is the appropriate consideration of the status of the alleged victims and perpetrators, which must be publicly displayed. The justice of the criminal trial thus resides in its contributing to the acknowledgement of persons' status in a specific legal context. This acknowledgement is often deemed important because of the impact it is expected to have on the parties' self-perception, particularly their self-esteem.

To see the rationale of this expressivist interpretation of the value of due process, I proceed by analogy with what Charles Beitz (1989) termed the idea of 'fairness as equal respect'. ${ }^{9}$ Beitz's idea is straightforward: The way citizens are treated by the procedures through which they interact in society reveals the consideration institutions have of them. Take the case of democratic egalitarian decision-making procedures. The democratic way of making collectively binding decisions bears an expressive value because it is the way in which institutions display their public recognition of the status of citizens as equal political agents. ${ }^{10}$ On this basis, Beitz (1989, p. 23) argues that just democratic decision-making must be perfectly egalitarian. This feature is necessary to ensure that all citizens' interests are taken into due consideration, which, in turn, is expected to have a positive impact on their self-esteem.

Taking the cue from this expressivist assessment of the democratic decisionmaking process, we can translate the same line of reasoning into an expressivist interpretation of the value of due process in criminal proceedings. In this interpretation, the value of due process is irreducible in full to its instrumental capacity to produce just outcomes, that is legal decisions that establish the facts. Legal proceedings informed by the principle of due process retain their value even when judicial errors taint their outcomes insofar as their operation conveys to people important institutional messages whose public expression might also have a positive impact on the parties' self-perception. This expressivist interpretation seems to pinpoint an important normative dimension of criminal proceedings that was clamorously frustrated in the case of Sarah's rape. By pleading guilty to assault, the rapists were not publicly recognised as such (that is, as the perpetrators of the brutal offence Sarah had actually suffered). Correspondingly, by that sentence, Sarah was not recognised in her status as a victim of rape, thus diminishing her status as the sufferer of a horrendous crime with a negative impact on her sense of self-worth. But most significantly, by not being offered the opportunity to tell the story in her own voice before a jury in court, we can see that she was denied the procedural status as the bearer of a reliable testimony of her own story. This denial is a source of injustice because it expresses a diminished consideration of Sarah's standing in the legal proceeding, which is likely to have a negative impact on Sarah's sense of self-worth and hence her reaction of distress and rage.

Including the expressivist value of due process in our normative assessment of legal proceedings is an important step towards offering a fuller account of the relevant considerations necessary to perform a well-rounded and nuanced evaluative exercise. It is, therefore, a significant improvement over the use of only the 
instrumental kinds of assessments that the epistemic view enabled us initially to do. However, I wish to suggest that the capacity to appreciate the complexity of the normative worth of legal proceedings can be further enhanced. This enhancement, in line with the thread of the argument followed in the previous subsection, should be capable of offering a solid account of the value of due process-more solid than one consisting in its appreciation as a fungible instrument of justice.

When the expressivist interpretation refers to the positive impact that the participation in a certain process may plausibly have on people's self-perception, it is exposed to erratic empirical considerations. The expressivist interpretation establishes a relation between the operation of certain criminal proceedings and the realisation of some moral values such as self-respect and self-worth. It is important to notice that this relation is mediated, extrinsic and contextual. The relation is mediated by the psychological effects that the participation in a certain process can be expected to have on the parties in that process. It is extrinsic because it draws substantially on certain mental states and attitudes that are external to the structural features of the process itself (although it is crucial to acknowledge that personal mental states and attitudes and the process's structural features are causally related). Finally, the relation between due process and justice is contextual because it is clearly conditional on the empirical verification of the abovementioned psychological effects and the realisation of the related mental states and attitudes, which may or may not occur. Quite plainly, different people can plausibly be expected to react differently to the same events, given their own inclinations and states of minds. ${ }^{11}$ It is little more than a truism to notice that what is deeply humiliating for one sensitive human being, may be just a mild offence for another.

Further, people may develop complex sets of adaptive preferences that make it impossible to predict how they are going to react to contextual stimuli and institutional treatment. ${ }^{12}$ To complicate the picture further, these variations are personal as well as cultural, and they may be subject to influence by historical developments too. How can we say that Sarah is just not overreacting to a perfectly acceptable bargained solution? Had she not been incensed, out of timidity or indifference, would that be a reliable basis not to question the justice of the legal proceeding denying her a fair hearing at all?

I think these are important questions to address to advance the refinement of our normative assessment of legal proceedings and understanding of the value of due process within that context. My claim, which I elaborate in the remainder of the chapter, is that to run a complete normative appraisal of the properties of criminal proceedings and offer a solid account of the value of due process, we should pinpoint the procedural features that make processes inherently worthwhile. To appreciate the normative powers the mere participation in a process constitutively confers upon the parties, it is essential to engage in a structural analysis of the inherent properties of that process. This analysis, I will submit, is also crucial to see the normative statuses, which the parties acquire just by virtue of their participation in the process. 


\subsection{The inherent value of due process: the 'interactive interpretation'}

\subsubsection{The different sites of the justice of a process: outcomes and procedures}

The idea I want to present in this second part of the chapter is that the procedures according to which the different parties interact make a third important contribution to any normative assessment of a criminal trial. Besides their instrumental role in leading to an epistemically accurate final verdict, and besides their contribution to expressing certain positive institutional attitudes, procedures informed by the principle of due process can be considered inberently valuable by virtue of their structural properties. ${ }^{13}$

To articulate this idea, a good place to start-ad absurdum-is Martha Nussbaum's (2006) critical discussion of procedural justice. With some irony, Nussbaum, argues that the idea that substantive value may lie in the structural properties of a process (rather than entirely in its outcome) should be rejected because it sounds

as if a cook has a fancy, sophisticated pasta-maker, and assures her guests that the pasta made in this machine will be by definition good, since it is the best machine on the market. But surely ... the guests want to taste the pasta and see for themselves.

(Nussbaum 2006, p. 83)

Surely enough, Nussbaum's critique exposes a weak spot of a certain mainstream view of procedural justice that conceives it, in Rawls's terms, as a pure exercise of formality, by virtue of which having a just process is both necessary and sufficient to securing a just outcome. ${ }^{14}$

Central to Rawls's idea of pure procedural justice is the claim that procedures are capable of transferring the justice of their properties to their outcomes (Rawls 1971, p. 86). ${ }^{15}$ So, it is sufficient to have a just procedure and apply it correctly for the justice of its outcome to be secured. This idea, which Rawls had formally illustrated with reference to a procedure of fair bets, has become very popular in the characterisation of the authority of the democratic decision-making process (see Christiano 2008; Waldron 1999). The idea is that because there is disagreement over what a good or just collective decision is on many politically relevant issues, we must ensure that whatever decision is taken that decision is at least legitimate, that is, recognised as binding by all citizens (including, of course, those who disagree with its content). To this end, the resort to pure proceduralism is based on the conviction that if we get citizens to agree on the legitimacy of the decision-making process, they would ipso facto recognise the legitimacy of the outcomes of that process (even if they could question them as inherently bad or unjust).

As argued extensively in previous work (Ceva 2016, pp. 71-73), pure procedural justice is in fact the formal property of the outcomes of a process. We need 
just procedures not because having them (or making them operative) realises any distinctive dimension of value per se. We need just (or legitimate) procedures only to identify acceptable outcomes in circumstances of moral disagreement. Whatever outcome has the formal property of being produced by a just (or a legitimate) procedure is, in this view, itself just (or legitimate) or, at least, not unjust (or not illegitimate). Nussbaum's example suggests the inconsistency of this interpretation of proceduralism by questioning the inference from the qualities of procedures to those of their outcomes. Of course, to question this inference does not mean to undermine the practical possibility that people may decide to agree between themselves to abide by the outcome of a process, whatever this outcome will happen to be. Not only are we familiar with this commitment within democracies, but also anytime we toss a coin to make a decision or participate in a lottery we engage in an exercise of pure proceduralism. However, the familiarity with these practical occurrences does not justify, nor does it entail, the philosophical claim that the normative properties of an outcome may be inferred from the normative properties of the procedure that produced it. As Nussbaum's example suggests, the claim that we can identify the justice of an outcome with its formal correctness is fallacious. Processes and outcomes are distinct social objects, and recognising the justice of one tells us nothing about the justice of the other (see Ceva 2016, p. 74).

But there is an important 'but'. In my previous work in the domain of justice (Ceva 2016, Chapters 3 and 4), I introduced a claim about the normative assessment of the structural properties inherent to processes, which lies beyond Nussbaum's critical target. This is the claim that procedures and outcomes are distinct sites of justice; therefore, they can and should be assessed in the light of distinct normative standards. The way in which I see this claim is actually quite crude: in assessing the normative force of processes of human interaction (in the domain of justice), what matters is not only what people get, but also how they get it. While the former kind of assessment concerns the normatively relevant properties of the outcomes of a process, the latter concerns the structural properties inherent to the process itself. When we assess a process from this latter perspective, we focus on its inherent structural properties and the form of interaction they establish among the participants in the process. In this sense, processes (and the normative principles that inform them) may also have an 'interactive value'.

To see what the interactive value of a process is, start from the simple notion of a process as a rule-based embodied practice. ${ }^{16}$ From this point of view, to offer a full characterisation of a process and a complete assessment of its properties, we must consider the formal rules that articulate the process but also what happens when people enter the process and have their dealings regulated by the rules of that process. Differently put, to characterise and assess a process, we must look at what changes occur to the status of the participants in the process and their reciprocal relations by virtue of the process's rules. Notably, the rules on which a process is based establish the participants in the process in a new normative capacity that does not exist prior to or outside the process. The participation in a process confers-ipso facto-special normative powers to the participants in the process. 
That is to say, the rules of the process establish what people who participate in the process can claim against and owe to each other when they interact within the boundaries of those rules. In this sense, processes can be usefully understood as practices based on 'constitutive rules'.

John Searle $(1969,1995)^{17}$ has offered the best-known account of the idea of a constitutive rule. Constitutive rules establish new practices and make them possible. These practices instantiate forms of action and relations that could not occur, nor could they be conceived, prior to or outside those rules. Rawls outlines the same view in the parlance of a 'practice conception' of rules (1955). According to this conception, rules define practices. To make people engage in a practice, the rules that define the practice (and on which the process in which the practice consists is based) must be taught to them. This understanding of a practice makes rules logically prior to particular activities because an activity may be described in a certain way only if it takes place against a certain practice, in accordance with a process articulated through the rules that define that practice. A typical illustration of this practice-based understanding of a process and its constitutive rules comes from games (Searle 1969, p. 33). A group of people can kick a ball around a field and aim at throwing it in a net; but they cannot score a goal or commit a fault unless they engage in the practice of playing soccer. However, they cannot engage in the practice of playing soccer unless a process that articulates the rules of soccer is established. When someone plays a game, they must abide by its defining rules; otherwise, they are just not playing that game but engage in an altogether different kind of practice.

Interestingly for the purposes of my discussion, those who engage in a process, thus understood as a practice, start acting and interacting with others in a special capacity with which special normative powers are associated. To continue with the game-based illustration, someone's participation in a game of soccer as a player establishes and gives a special normative sense to what the partipants in the game do. By entering into the practice of playing soccer, players acquire special normative powers that derive from their status in the process. For example, any random person blowing in a whistle does not normally have the power to stop anyone else from running unless the relevant interaction happens within the process of playing soccer and the protagonists are the referee of the game and a player.

We can thus see how the constitutive rules of a process have two main normative functions. First, they establish people in certain statuses, and second they confer on them the powers linked to those statuses (see Hindriks 2009, pp. 254, 262). These normative powers establish deontic relations between their holders, as they constitute a form of interaction between right-holders and duty-bearers, which has an inherent value-what I have called an interactive value. To see this value, consider the way Joel Feinberg (1970, pp. 243-257) has brought this feature to light with admirable clarity. Feinberg invites us to imagine the society of Nowhereville, where rights do not exist. We can assume that even in such a society people might act according to justice and give each other their due, either by benevolence, because they all adopt some teleological principle of desert, or 
because some law or authority makes them do so. However, if rights were not in place, something important would be different from the rights-populated world we are used to: People would receive justice, but could not make claims as the final authorities to which justice is due.

The status of a claim-maker that the conferral of rights implies is importantly different, Feinberg (1970, pp. 244-245, 249-250) explains, from that of the beneficiary of some good because it entails the attribution and recognition of agency. Right-holders can claim against others that certain actions be performed (or omitted), and they are those to whom the others need to account for their behaviour toward them. The conferral of rights is thus importantly related to persons' moral standing or, to put it in Feinberg's words, 'having rights enables us to stand up like men ... to look others in the eye' (Feinberg 1970, p. 252). The establishment of rights is thus constitutive of an inherently worthwhile form of human interaction that could not occur outside the procedures in which those rights are exercised. We can thus start to see how the value of this form of interaction is inherent to the structural properties of the process through which this interaction occurs, and may not be reduced either to the value of its final results or the effects it may cause as it develops. To gain a better view, let us finally bring this general discussion to bear on the normative assessment of criminal proceedings.

\subsubsection{The inberent interactive justice of criminal proceedings}

The claim that the inherent structural properties of a process may have a value of their own-what I have called an 'interactive value'-does not hold true for any organised set of procedures. There are of course some procedures that are designed and made operative only as instruments to produce certain independently valuable outcomes. Think of the procedures of traffic regulation or, in fact, the instructions to operate a pasta-maker, to revisit Nussbaum's burlesque example. This apparent qualification granted, it is equally apparent that any one set of procedures in society can have more than an instrumental value (e.g. of the kind we have seen with reference to the epistemic view of due process in the first part of the chapter).

A conspicuous instance of a process that can have inherent interactive (as well as, as seen, instrumental) value, I want to suggest, emerges in consideration of the principle of due process in criminal proceedings. To engage in a normative assessment of criminal proceedings by bringing out the interactive value of due process means and requires concentrating on the inherent structural properties of the process and the moral values these structural properties realise in themselves. This kind of assessment is worthwhile, I believe, because it enhances our capacity for appraising the many facets of justice in criminal proceedings and presenting a theoretically solid account of the value of due process. This enhanced assessment may help us to ponder the extent to which we have reasons to value due process irrespective of whether the criminal trial informed by it leads to epistemically inaccurate verdicts or fails to express a message capable of eliciting the right kind of attitudes in those who participate in it. 
To see where the interactive value of due process lies, reconsider the case of the legal proceeding by which Sarah's rapists plead guilty to a charge of assault before the case could go to court. We have seen that Sarah was distraught and enraged at the end of this story, and we have already pointed out why that could be the case from an instrumental perspective. I want to suggest that besides the disappointment over an epistemically inaccurate verdict, and the sense of frustration derived from the lesser consideration of the offence she had suffered, Sarah's reaction can be seen as a manifestation of an interactive injustice she has suffered by not being heard telling her story in her own voice before a jury in court. Sarah's negative reaction speaks to the inherent moral importance of the structural properties of legal proceedings informed by the principle of due process, access to which was denied to Sarah by virtue of the agreement that was bargained before the case could be brought to court.

The right to a fair hearing that due process confers upon the participants in criminal proceedings changes the normative status of the victim and, thereby, the nature of what goes on between her and the perpetrators of the offence she had suffered. This change is important because it opens up new possibilities of action and interaction that would be impossible outside the process in virtue of the constitutive rules that define it. By being prevented from giving her own account of the facts, Sarah was denied the normative status of an agent speaking out in her own voice, as the holder of rights and as the potential maker of a valid claim. She was relegated to the role of a mere patient who passively receives both the offence and the sentence negotiated by others. This denial is not only problematic because it was an impediment to establishing the truth of the matter in court; nor was it wrong only because it is likely to have resulted in a loss of self-appraisal on the part of the accuser (thus misrecognised in her status as a victim). The frustration of due process was wrong in itself because it constituted a mistreatment of Sarah, a failure to do justice to her moral status as an agent capable of engaging in peer-interaction with her offenders. This enabling capacity is a typical feature of rights and the normative status their conferral bestows on their holders-the status of a claim-maker (or, an agent). As seen above, following Feinberg's characterisation, the conferral of rights by virtue of someone's participation in a rule-based process is importantly related to a person's standing. More precisely, the conferral of rights is constitutive of an inherently worthwhile form of human interaction that could not occur outside the procedures in which those rights are exercised.

The time has come to emphasise how this general feature of rights is realised in due process and how it gives inherent value to fair hearing as a structural feature of criminal proceedings modelled on that principle. I think that this idea can make sense of those views of due process that insist on its relation to the conferral of a certain kind of 'dignity' on the parties in criminal proceedings. So, for example, Jeremy Waldron (2013) seems to point at this feature when he argues that 'deciding what to do about a suspected offender is not like deciding what to do about a rabid dog or a dilapidated house' (p. 12). The parties' status must be reckoned with and adequate procedural provisions must be designed, whether 
these also contribute to truth-finding and boosting the parties' self-perception or not.

Within this context, Waldron (2013, p. 201) presents dignity as a status-concept, as it has to do with 'the standing (perhaps the formal legal standing or perhaps, more informally, the moral presence) that a person has in society and in her dealings with others'. ${ }^{18}$ So conceived, a person's dignity supervenes on her agential capacities to be the author of her own actions on the basis of her own account of herself and of 'the norms and reasons that apply to her' (Waldron 2012a, p. 202). In line with the Kantian tradition, possession of such capacities is the mark of moral personality; it is what makes people agents rather than mere patients, and what makes them act as subjects rather than merely undergo others' actions as an object. In this sense, this status as agents is a precondition for people to be considered as the bearers of rights, that is, of valid claims that each of them may stake against each other. When rights are established in certain processes, people can interact by participating in those processes in a way that gives them due consideration in their capacity as potential makers of valid claims.

Criminal proceedings informed by the principle of due process may rightfully be considered an instantiation of this form of interaction and have, therefore, also an inherent interactive value. The very idea that a person has a right to have her say on her own behalf before a public tribunal is a constitutive component of the treatment of a person in accordance with her status of claim-maker. But due process is not the only instantiation of this kind of value in legal proceedings. Waldron, for example, discusses in a similar vein Lon Fuller's account of 'selfapplication' in law. This is the idea that people comply with official legal provisions prior to the coercive intervention of law (see Fuller 1969).

An example is unsuccessful defendants in civil litigation, who are expected to pay by themselves what is ordered by the court or, in criminal justice, convicted offenders who are expected to report to prison on a given date. Clearly, should defendants fail to do what they are expected to do, the authorities would intervene (to seize the former's property or to escort the latter to jail); but-Waldron (2012a, p. 206) argues that the presence of provisions of self-application is to be viewed as an instantiation of a person's capacity for agency. This is the case, I add, irrespective of the possibly suboptimal implications such provisions may have for the effective and time-efficient application of the judicial decision.

The attribution of this moral status of an agent to the parties in legal proceedings, in general, and in a criminal trial, in particular, is not a mere side constraint on what can be done in courts while justice is pursued, while juries try to establish the truth and reach the right verdicts. This attribution and the forms of interaction thereby inaugurated between the parties are a structural feature of criminal proceedings that make them an object of normative assessment in their own right and in accordance with standards internal to their own functioning. Note also that the presence of procedural provisions treating persons in ways that protect them from humiliation and degradation is not only a symbolic matter, expressing the consideration in which institutions hold those who take part in them. The recognition of the moral status of an agent is not just expressed through 
procedural provisions, ${ }^{19}$ it is participation in the proceedings regulated by such provisions, which bestows this status upon the parties and enables them to entertain dignifying forms of interaction.

Finally, it is important to notice that the normative assessment that the adoption of this interactive perspective makes possible is not an alternative to, but an integration of the instrumental kinds of assessment I have reviewed earlier in this chapter. As my current discussion of legal proceedings shows, the normative evaluation of processes is a complex and composite exercise that requires the cooperation of many different evaluative criteria. All of these criteria should work in tandem to render an all things considered normative evaluation of a process that makes discrete assessments valid only pro tanto. The realisation of interactive justice in procedures is a necessary, but not sufficient, condition for the realisation of justice in politics, in society, and in legal courts (see Resnick 1977, p. 213). This normative approach to processes of human interaction introduces nuances that may complicate their assessment, but such complications are worthwhile because they make the evaluation of those processes more philosophically accurate.

\subsection{Conclusion}

In conclusion, one important result of the discussion in this chapter has been that, when we engage in the normative assessment of criminal trials (like any other process), no loss in one dimension of justice may be fully compensated by a gain in the other. The demand for interactive justice would remain valid even if we had omniscient and infallible juries capable of getting to the just outcome in all possible cases. The demand for interactive justice is a demand for being reckoned with as active subjects and not merely treated as the objects of others' actions. The attribution of this status bears an inherent value whose frustration makes a process inherently unjust, no matter how it could serve any other function.

\section{Notes}

1 Sarah is the leading role played by Jodie Foster in the 1988 film The Accused. (https://www.imdb.com/title/tt0094608/). I borrow the example from Miller (1999, pp. 97-98).

2 I have tentatively presented this idea in Ceva (2016), Chapter 3. This chapter revisits and expounds the thoughts therein introduced.

3 For a seminal account of the epistemic approach in political theory, see Estlund (2008); I have discussed this approach at length in Ceva (2012, pp. 192-194).

4 For a discussion of the plausibility of Rawls's typology of procedural justice see Nelson (1980, pp. 502-511).

5 To illustrate this kind of procedural justice, Rawls (1971, p. 85) provides this example: 'A number of men are to divide a cake: assuming that the fair division is an equal one, which procedure, if any, will give this outcome? Technicalities aside, the obvious solution is to have one man divide the cake and get the last piece, the others being allowed their pick before him. He will divide the cake equally, since in this way he assures himself the largest share possible'. For a critique of 
the tenability of the distinction between perfect and imperfect proceduralism, see Gustafsson (2004, pp. 300-305); the claim that Rawls's im/perfect account of procedural justice is indeed a form of 'proceduralism' is disputed by Rosenfeld (1998).

6 These versions of proceduralism are distinguished from what Rawls (1971, p. 86) calls 'pure procedural justice'. In this last idea, the qualities of a just outcome cannot be known before a just procedure is actually operated, and in fact the justice of outcomes depends entirely on the justice of the procedures leading to them. Once we operate a just procedure correctly, its outcome will be just whatever its inherent features. I will not engage with this interpretation here (but will revisit it below) because it is not relevant to the assessment of legal proceedings, which cannot of course be open-ended in the way Rawls thinks pure procedural justice should be. For an extensive discussion, see Ceva (2016, pp. 67-69).

7 For an in-depth discussion of Arneson's argument see Ceva (2012, pp. 196-197).

8 The centrality of the value of self-respect for procedural justice is at the core of the argument in Meyerson (2015).

9 Of course, this is one interpretation of the expressivist value of due process. A different way of framing the view would insist that the process is not just a mere means to convey a certain message but embodies or enacts the message. Two possible readings are available of this version of the expressivist view. One, as suggested above, would look at due process as enacting a message whose content is, nevertheless, valuable independently of the process. In this reading, for example, we could think that just criminal trials are those positively responsive to the moral dignity the parties have outside the proceedings (as persons) and that must be preserved in the process too. In this sense, the parties' status acknowledged in the process would be a reflection of a more general moral status that people have (as the external source of the value of due process). I view this version as exposed to the same limitations that I attribute to the view I discuss in what follows. On an alternative interpretation, the process would embody a message, which would confer (not just acknowledge) a certain normative status on the parties in the process. This further reading would be a game changer, as it were, akin to the position that I am going to defend in the second part of the chapter to which I refer for any further comment. I am grateful to the editors of this volume for pressing me on this point.

10 Recent statements of this position may be found in Christiano (2008) and Griffin (2003). For a general discussion of the position, see Elster (1999).

11 For a classic set of critiques of utilitarianism along these lines, see Sen and Williams (1982).

12 Jon Elster (1982, p. 237) has seminally characterised these preferences and preferences of the 'sour grapes' kind.

13 I have introduced this idea in the debate concerning just conflict management under the label of 'intrinsic proceduralism' (see Ceva 2016, pp. 74-79; 84-86; 99-107).

14 Formal accounts of procedural justice are presented, for example, in Hart 1961, pp. 155-157; Kramer 1997; May \& Morrow 2012. For a discussion, see Lyons (1973).

15 The steps towards the formulation of this idea of procedural justice can be traced back to Hobbes (1985, p. 14), and they have been developed after Rawls in, e.g. Hampshire (1999).

16 I take this conception to be well received in the philosophical debate on institutional theory-see, e.g., Emmet (1966); Rawls (1955). For a practice-dependent approach to justice, see Sangiovanni (2008).

17 For a discussion, see Hindriks (2009, pp. 253-275). 


\section{Emanuela Ceva}

18 For a more extensive discussion, see Waldron (2012b).

19 This reading is suggested by Michael Rosen (2012, pp. 94-97) in his commentary Waldron's discussion of dignity.

\section{References}

Arneson, RJ 1993, 'Democratic rights at national and workplace levels', in D Copp, J Hampton \& JE Roemer (eds.), The idea of democracy, Cambridge University Press, Cambridge.

Beitz, C 1989, Political equality, Princeton University Press, Princeton.

Ceva, E 2012, 'Beyond legitimacy: can proceduralism say anything relevant about justice?', Critical Review of International Social and Political Philosophy, vol. 15, no. 2 , pp. 186-89.

Ceva, E 2016, Interactive justice. a proceduralist approach to value conflict in politics, Routledge, New York.

Christiano, T 2008, The constitution of equality, Oxford University Press, Oxford.

Elster, J 1982, 'Sour grapes', in A Sen \& B Williams (eds.), Utilitarianism and beyond, Cambridge University Press, Cambridge.

Elster, J 1999, 'The market and the forum: three varieties of political theory', in J Bohman \& W Rehg (eds.), Deliberative democracy: essays on reason and politics, MIT Press, Cambridge.

Emmet, D 1966, Rules, roles and relations, MacMillan, London.

Estlund, DM 2008, Democratic authority. a philosophical framework, Princeton University Press, Princeton.

Feinberg, J 1970, 'The nature and value of rights', Journal of Value Inquiry, vol. 4, no. 4 , pp. $243-57$.

Fuller, LL 1969, The morality of law, revised ed., Yale University Press, New Haven.

Griffin, C 2003, 'Democracy as a non-instrumentally just procedure', Journal of Political Philosophy, vol. 11, no. 1, pp. 111-21.

Gustafsson, M. 2004, 'On Rawls's distinction between perfect and imperfect procedural justice', Philosophy of the Social Sciences, vol. 34, no. 1, pp. 300-5.

Hampshire, S 1999, Justice is conflict, Duckworth, London.

Hart, HLA 1961, The concept of law, Clarendon Press, Oxford.

Hindriks, F 2009, 'Constitutive rules, language, and ontology', Erkenntnis, vol. 71, no. 2 , pp. $253-75$.

Hobbes, T 1985, Leviathan, Penguin Books, London.

Kramer, MH 1997, 'Justice as constancy', Law and Philosophy, vol. 16, no. 3, pp. 561-80.

Lyons, D 1973, 'On formal justice', Cornell Law Review, vol. 58, no. 5, pp. 833-61.

May, L \& Morrow, P (eds.) 2012, Procedural justice, Ashgate, Burlington.

Meyerson, D 2015, 'The moral justification for the right to make full answer and defence', Oxford Journal of Legal Studies, vol. 35, no. 2, pp. 237-65.

Miller, D 1999, Principles of social justice, Harvard University Press, Cambridge.

Napier, JL \& Tyler, TR 2008, 'Does moral conviction really override concerns about procedural justice? A re-examination of the value protection model', Social Justice Research, vol. 21, no. 4, pp. 509-10.

Nelson, W 1980, 'The very idea of pure procedural justice', Ethics, vol. 90, no. 4, pp. 502-11. 
Nussbaum, M 2006, Frontiers of justice: disability, nationality, species membership, Harvard University Press, Cambridge.

Rawls, J 1955, 'Two concepts of rules', Philosophical Review, vol. 64, no. 1, pp. 3-32. Rawls, J 1971, A theory of justice, Oxford University Press, Oxford.

Resnick, D 1977, 'Due process and procedural justice', in JR Pennock \& JW Chapman (eds.), Due process, vol. 18 of Nomos, New York University Press, New York.

Rosen, M 2012, 'Dignity past and present', in J Waldron (ed.), Dignity, rank, and rights, Oxford University Press, Oxford.

Rosenfeld, M 1998, 'A pluralist critique of contractarian proceduralism', Ratio Juris, vol. 11, no. 4, pp. 291-319.

Sangiovanni, A 2008, 'Justice and the priority of politics to morality', Journal of Political Philosophy, vol. 16, no. 2, pp. 137-64.

Searle, JR 1969, Speech acts: an essay in the philosophy of language, Cambridge University Press, Cambridge.

Searle, JR 1995, The construction of social reality, Penguin, London.

Sen, A \& Williams, B (eds.) 1982, Utilitarianism and beyond, Cambridge University Press, Cambridge.

Thibaut, J \& Walker L 1975, Procedural justice: a psychological analysis, Erlbaum, Hillsdale.

Tyler, TR 1988, 'What is procedural justice?: criteria used by citizens to assess the fairness of legal procedures', Law \& Society Review, vol. 22, no. 3, pp. 103-35.

Waldron, J 1999, Law and disagreement, Oxford University Press, Oxford.

Waldron, J 2012a, 'How law protects dignity', Cambridge Law Journal, vol. 71, no. 1, pp. 200-22.

Waldron, J 2012b, Dignity, rank, and rights, Oxford University Press, Oxford.

Waldron, J 2013, 'Political theory: an inaugural lecture', Journal of Political Philosophy, vol. 21, no. 1, pp. 1-23. 


\title{
9 Procedural justice, relational equality, and self-respect
}

\author{
Catriona Mackenzie
}

\subsection{Introduction ${ }^{1}$}

The literature on procedural justice (hereafter PJ) in social psychology has amassed a significant body of empirical evidence showing the importance of relational considerations, both to citizens' views about what makes the use of power and authority in legal and organisational contexts legitimate and to citizens' willingness to comply with the law and to cooperate with police, administrative, and legal authorities. ${ }^{2}$ This literature has shown that people care as much, if not more, about how authorities exercise power and make decisions as they do about the actual decisions that are made. ${ }^{3}$ Specifically, people care about whether administrative and legal processes are fair, and they care about the attitudes expressed by police, administrative and legal authorities in their interactions with the public. What emerges from the empirical findings is that four factors really matter to people in their dealings with authorities: that authorities 'treat citizens in a fair and respectful way, make neutral and unbiased decisions, display trustworthy motives, and allow the citizen a voice in their interactions' (Jackson 2018, p. 4). These four factors influence the extent to which people view police, legal and administrative authorities as legitimate, the extent to which people are likely to obey the law, and the extent to which they are motivated to cooperate with these authorities.

Insofar as the social psychology literature is concerned with people's perceptions of legitimacy it operates with a descriptive or sociological conception of legitimacy, according to which a set of institutions 'is legitimate ... if those subject to its directives widely believe it to enjoy the moral right to rule' (Levitov 2016, p. 1, emphasis in original). This sociological conception of legitimacy should be distinguished from a prescriptive or normative conception of legitimacy, according to which a set of institutions is legitimate 'if it in fact enjoys the moral right to rule over those it claims the authority to govern' (Levitov 2016, p. 1, emphasis in original). Social psychologists do not explicitly address the question of whether the four elements of PJ (respect, neutrality, trustworthiness, and voice) provide criteria for assessing the normative legitimacy of police, legal, or administrative authorities, although this claim does seem to be implicit in some of the literature on PJ. At the very least, however, an implication of the empirical research is that

DOI: $10.4324 / 9780429317248-13$ 
citizens are more likely to confer legitimacy on police and legal authorities (and hence to consent to their use of power) if they judge that those authorities are behaving in line with citizens' normative expectations. Hence, if authorities want to be perceived as legitimate (i.e. to be legitimate in the descriptive sense), they should take steps to ensure that the four elements of PJ are embedded in legal and administrative processes and that they guide officials in their interactions with citizens.

Several different kinds of justification for the view that authorities should try to satisfy citizens' procedural expectations by attending to the four elements of PJ are suggested, but not clearly distinguished, in the empirical literature. One kind of justification appeals to people's psychological motivations for voluntarily complying and cooperating with authorities, explicitly linking these motivations to the four elements of PJ. Tyler and Lind (1992), for example, claim:

The belief that the authority views one as a full member of society, trust in the authority's ethicality and benevolence, and belief in the authority's neutrality-these appear to be the crucial factors that lead to voluntary compliance with the directives of authority.

Tyler and Lind explain the link between PJ and psychological motivations to cooperate and comply via group-value theory. Group-value theory contends that relational concerns are central to people's judgements about procedural justice. According to the theory, people's sense of self-identity is based on their membership in valued groups, and they are very attuned to their perceived standing or status in such groups. For this reason, people are highly sensitive to the messages about their status conveyed by group processes and by how they are treated by persons in positions of authority:

To the extent that a procedure is seen as indicating a positive, full status relationship, it is judged to be fair, and to the extent that a procedure appears to imply that one's relationship with the authority or institution is negative or that one occupies a low-status position, the procedure is viewed as unfair.

The empirical research provides strong evidence that procedures embodying the four elements of PJ are more likely to be perceived as fair. Hence, if authorities want to be perceived as legitimate and if they want to secure cooperation and compliance, they should ensure their processes are responsive to people's relational concerns.

This justification for why authorities should be concerned about PJ admits of both an instrumental and a normative interpretation. The instrumental interpretation is that authorities, such as police, should be responsive to people's relational concerns and hence should embed PJ in their interactions with citizens 
because approaches based on PJ are more effective than other methods of law enforcement, such as deterrence based strategies that rely on coercion or reward mechanisms. While deterrence based strategies rely on motivations such as fear of punishment or self-interest, PJ is more effective, it is claimed, because it is more likely to encourage belief in the legitimacy of authorities, and to promote the internalisation of legal norms and voluntary compliance with the law (see, e.g., Tyler 2009). ${ }^{4}$ The normative interpretation is that authorities should be responsive to people's relational concerns and hence should embed PJ in their interactions with citizens because it is morally right that citizens are treated in a procedurally just manner. Both the instrumental and the normative interpretation are invoked by social psychologists. However, to the extent that they do invoke the normative interpretation, social psychologists tend to assume, rather than argue for the normative correctness of PJ.

My aim in this chapter is to develop an argument in support of the normative interpretation. I argue that there are good normative reasons why people care about their standing in social groups and why citizens are more likely to perceive authorities as legitimate and to cooperate with them if these authorities treat them fairly and respectfully, are neutral and trustworthy, and allow them a voice in their interactions. I also argue that authorities should be responsive to people's relational concerns and hence should embed PJ in their interactions with citizens because it is morally right that citizens are treated in a procedurally just manner by social institutions and their representatives. The moral correctness of PJ, I claim, is connected with its role in expressing attitudes of respect and supporting ideals of social equality among citizens. If this argument is persuasive, it also suggests that legitimacy in the descriptive or sociological sense provides the basis for legitimacy in the normative sense.

In developing this argument in the following sections, I draw on the resources of recent work in normative political philosophy. In Section 9.2, I discuss recent philosophical theories of relational equality and outline their relevance for articulating a normative argument for a relational approach to PJ, as it is understood in the empirical literature. In Section 9.3, I discuss Emanuela Ceva's (2016) recent 'interactive theory' of PJ, which articulates a normative conception of procedural equality and presents an argument for why states have obligations to ensure that interactions between authorities and citizens, and among citizens, are procedurally just. In Section 9.4, I briefly outline two influential views in moral philosophy that link the normative requirement of respect for others to the normative and psychological importance of self-respect. I conclude by explaining why the view defended in this chapter lends support to the idea that legitimacy in the descriptive sense may provide the basis for legitimacy in the normative sense.

\subsection{Relational equality and procedural justice}

Reviewing the empirical literature on procedural justice in tandem with recent debates in normative political philosophy reveals an interesting parallel shift in both literatures towards more relational conceptions of justice. To start with a 
very broad outline, philosophical theories of relational ethics and justice uphold the normative importance of individual rights, welfare, dignity, and autonomy (Anderson 2009, p. 132). However, these theories reject social atomism. They hold that we are social beings whose individual identities are constituted through interpersonal relationships and in the context of the broader social and political environments in which we live. Our self-identities and sense of self-respect are therefore necessarily shaped by and vulnerable to the quality of our interpersonal relationships and our interactions with social institutions. Relational theories of ethics and justice draw specific attention to the moral significance of social oppression, marginalisation, and inequalities of social power and standing, and their effects on individuals' self-identities, autonomy, and sense of self-respect.

Theories of relational equality are relational in this broad sense. More specifically, relational egalitarian theorists, such as Elizabeth Anderson (1999, 2008), Jonathon Wolff $(1998,2015)$, and Samuel Scheffler $(2003,2015)$, among others, have argued that the preoccupation among post-Rawlsian liberal political philosophers with distributive justice fails to appreciate the real point of liberalism's concern with equality. For these philosophers, concerns about equality are not only, or not primarily about minimising gross inequalities in the distribution of social goods and resources, but more importantly about relational or social equality. Liberal political philosophers take one of the foundational principles of liberalism to be that people should be treated as moral equals. Theories of distributive justice assume that the best interpretation of this principle of moral equality is that people should be equally entitled to fair shares of the currency of justice. Debates in the post-Rawlsian literature have focused almost exclusively on the question of how best to conceptualise this currency or metric-e.g. welfare, resources, opportunity, or capabilities. These debates have done much to clarify the differences between equality of welfare, equality of resources, equality of opportunity, and equality of capabilities. Yet, the exclusive focus in these debates on questions concerning what distributive shares people are entitled to has overlooked other important dimensions of justice.

Relational egalitarian theories do not dismiss distributive considerations as unimportant for justice. However, they claim that justice is about more than patterns of distribution. It is more fundamentally about social equality. Relational egalitarianism can be expressed both as a positive ideal of social equality and as a critique of social inequality. In articulating a positive ideal of social equality, Samuel Scheffler, for example, characterises social equality as a broad and complex ideal, bound up with other values such as respect and reciprocity. At its core is the ideal of a society of equals: 'justice requires the establishment of a society of equals, a society whose members relate to one another on a footing of equality' $(2015$, p. 21$)$. The ideal of a society of equals directs the focus of concerns about justice from purely distributive concerns to concerns about the structure and character of social relationships. In a just society, Scheffler argues, the idea of social equality should shape the attitudes and dispositions of both institutions and individuals in their interpersonal relationships, so that commitment to equality becomes a social practice. Central to this practice is a reciprocal commitment to 
respect others, a commitment to a common social framework, and commitment to participatory decision-making procedures where no person's interests (values, needs, preferences) are discounted without due consideration.

Similarly, Elizabeth Anderson articulates a positive ideal of social equality that she refers to as 'democratic equality'. Anderson claims that the fundamental obligation of citizens in a democratic state towards one another is to secure the social conditions for everyone's freedom. This requires, in her view, 'a social order in which persons stand in relations of equality' and respect (1999, p. 313), because 'the counterpart to an individual's inalienable right to the social conditions of her freedom is the unconditional obligation of others to respect her dignity or moral equality' (p. 319). A social order based on this kind of reciprocal respect is one in which all citizens have equal access to the capabilities required to participate in a democratic state, not only in the political sphere, but also in civil society. It is a social order that expresses respect for citizens, and in which state institutions and citizens feel an obligation 'to justify their actions by principles acceptable to the other' and in which 'mutual consultation, reciprocation, and recognition' are taken for granted (p. 314). In other words, such a social order is a democratic community of collective self-determination and cooperation. ${ }^{5}$

Perhaps of more fundamental concern to relational egalitarians than the articulation of a positive ideal of social equality is the importance of exposing and criticising social inequality and the harms it causes. Jonathan Wolff (2015) argues, for example, that the primary theoretical and epistemological task of political philosophy should not be to formulate ideals of justice but to identify and criticise manifest injustices. He suggests that the main contribution of relational egalitarian theory is not the articulation of an ideal of social equality but rather the way it draws attention to social inequality as one of the primary causes of injustice. For relational egalitarians, social inequality is characterised by social hierarchies of rank and esteem, and by social institutions, norms and relationships that entrench social relations of oppression, exploitation, domination and subordination. These kinds of inequalities of status and standing are inherently unjust, according to relational egalitarians, because, as Anderson (2008) puts it, they are 'degrading, humiliating and assaultive of individuals' status as beings entitled to moral standing before others' (p. 142).

Further, status inequalities undermine the mutual respect and recognition that should characterise social relationships in democratic communities. Entrenched social inequalities cause a range of harms to those who are on the receiving end of attitudes of social disrespect and disregard. These harms include being subject to social stigma and exclusion, being distrusted, being silenced, ignored, or regarded as not credible in discursive and testimonial contexts, being required to act towards one's social superiors in ways that one finds demeaning, servile and shameful, and being vulnerable to violence.

Two key concerns of relational egalitarianism are particularly important to note at this point. First, relational egalitarians hold that a central commitment of liberalism should be to ensure equality of access to the social bases of self-respect. Entrenched social inequality, they maintain, undermines this commitment 
because social disrespect and the harms that it causes also damage self-respect (Garrau \& Laborde, 2015 pp. 49, 57). I will return to this issue in Section 9.4. Second, relational egalitarians are particularly concerned with the expressive role of state institutions. They hold that state institutions have special responsibilities to ensure that their processes express respect for citizens, and that, in their interactions with citizens, office holders treat individuals in ways that convey attitudes of equal respect. Christian Schemmel (2011) notes that the expressive demand is not just a matter of what the institution or its agents meant to express by their actions, but also a matter of 'how those subject to the action may reasonably understand it' (p. 138). Wolff is especially critical, for example, of the way the social welfare system in the UK routinely subjects welfare recipients to demeaning and intrusive forms of expressive disrespect. ${ }^{6}$ However, expressive respect is not just a matter of the attitudes conveyed by legal or bureaucratic processes and office holders; it is also a matter of what structural protections institutions put in place to mitigate social inequality and the vulnerabilities and harms it causes. As Schemmel puts the point,

institutions treat individuals with the proper attitude when they offer them adequate and equal structural protection against unjust treatment by other individuals, against ending up on the wrong side of inegalitarian relationships.

Relational egalitarians maintain that to be just, social institutions must ensure that individuals are not dominated by others, that others cannot interfere with their choices in an arbitrary manner' (p. 142).

Given this critique of social inequality, one of the questions that relational egalitarian theory needs to address is what it has to say about the inescapable hierarchies of authority and command in complex modern societies. For it is these kinds of social hierarchies that, in democratic societies, often threaten people's status as social equals, and expose them to relations of domination, social stigma and disrespect. In addressing this question, Anderson (2008) makes a useful distinction between three kinds of unequal social hierarchies (pp. 144-145): i) hierarchies of standing, which deny rights and privileges, or grant inferior rights and privileges, to those at the bottom of the social hierarchy; ii) hierarchies of esteem, where those at the top 'command honour and admiration, while those below are stigmatized and held in contempt, as objects of ridicule, loathing, or disgust'; and hierarchies of command, 'of domination and subordination, whereby those at the top issue orders to those below, who must defer and obey' (p. 145). 'Egalitarians aim', she says, 'to the extent possible, to abolish such hierarchies and replace them with relations of equality'.

While state-sanctioned hierarchies of standing, such as those based on class, caste, gender, race or ethnicity can be abolished through constitutional and legislative measures, it is more challenging to abolish the hierarchies of esteem that are typically associated with unofficial hierarchies of standing in civil society. Nevertheless, these must be the focus of sustained egalitarian critique. The same 
applies to hierarchies of command when these are not required for coordinating social functions. But what should relational egalitarians say about the hierarchies of command that are required for coordinating complex social functions, such as command hierarchies in bureaucracies, courts and legal systems, the police, the military, corporations, and other large workplaces? These kinds of hierarchies may be rationally required to ensure social order and cooperation, but are they normatively justifiable? Relational egalitarians hold that such hierarchies can be normatively justified if they meet the requirements of legitimacy. To count as legitimate, institutions and command hierarchies must first abide by principles of non-domination. What this entails is that state institutions have obligations to ensure that the differential power, authority and status attached to office holders in these kinds of command hierarchies do not enable them to wield arbitrary power and dominate those who are subject to their commands. As Schemmel puts the point:

in successful social cooperation, power must, most of the time, not be exercised in the form of naked coercion but in the form of commands and directives on the part of holders of offices and occupants of privileged social positions whose legitimacy is generally recognized by those subject to their power.

A further requirement of legitimacy, as this quote from Schemmel suggests, is that differences in the exercise of power and authority arising from command hierarchies can only be normatively justified if institutions and the authorities who represent them are recognised as legitimate by those who are subject to them; that is, if they are legitimate in the descriptive or sociological sense. This requires that institutions put in place mechanisms or processes by which those who exercise power can be held publicly accountable for their actions and decisions, and those who are subject to that power are able to voice and defend their interests.

This brief summary of relational egalitarian theory provides a starting point for explaining how relational egalitarian theories of justice might be used to provide normative support for relational approaches to PJ. Relational egalitarianism, as outlined above, shifts the focus of claims about justice to the structure and character of social institutions and relationships. It claims that justice is normatively grounded in an ideal of social equality and that social inequality and domination are major sources of injustice. Social institutions therefore have normative obligations to ensure that their processes and office holders express respect for the moral and social equality of all persons; that the exercise of power and authority by office holders in command hierarchies is regarded as legitimate by the persons who are subject to it; and that mechanisms are in place both for holding institutions and office holders publicly accountable and for enabling persons who are subject to power and authority to voice their concerns and interests. 
These claims, I suggest, give normative substance to the concerns about social standing and fair treatment by authorities that emerge as strong themes in the empirical research on procedural justice. Tyler and Lind (1992) say:

Information about standing-i.e. status recognition-is often communicated to people by the interpersonal quality of their treatment by those in a position of authority. In particular, when one is treated politely and with dignity and when respect is shown for one's rights and opinions, feelings of positive social standing are enhanced ... On the other hand, undignified, disrespectful or impolite treatment by the authority carries the implication that one is not a full member of the group, and this is very threatening indeed.

(p. 141)

Tyler and Lind explain people's concerns about standing in terms of group-value theory, which focuses on people's psychological motivations. Relational egalitarianism suggests, however, that people's concerns about how they are treated by authorities, about the attitudes expressed towards them, and the messages these interactions convey about a person's social standing are not just matters of psychological motivation. These concerns are grounded in an expectation of normative entitlement to be treated as a moral and social equal, an entitlement that is violated by interactions with authorities that express disrespect. ${ }^{7}$

The four elements of PJ identified in the empirical research, I suggest, embody citizens' expectations of normative entitlement to be treated as social and moral equals. Institutions and authorities that treat people fairly and with respect, ensure that people have opportunities to participate in processes that affect them, make decisions neutrally, and act from trustworthy motives, are responsive to those expectations. The empirical research shows that institutions and authorities that are responsive in these ways are more likely to be regarded as legitimate in the descriptive sense. Relational egalitarianism helps to explain why this kind of responsiveness is normatively required, and hence why institutions and authorities that act in procedurally just ways, are normatively legitimate; namely, because procedurally just processes and interactions express respect for citizens as moral and social equals.

Given the potentially fruitful conceptual connections between relational egalitarian theories of justice and the empirical research on procedural justice, it is surprising that relational egalitarians have paid little attention to procedural justice. Nor have they said much about how institutional processes should be designed so that they both act as constraints on the arbitrary exercise of power in command hierarchies, and more positively help to foster genuine cooperation between authorities and the individuals and communities with whom they interact. In order to flesh out these conceptual connections more fully, in the following section I discuss Emanuela Ceva's recent 'interactive theory' of justice (2016). ${ }^{8}$ Like relational egalitarianism, Ceva identifies social relationships and interactions as a locus of claims of justice. However, her specific focus on procedural justice makes a distinctive contribution to the literature on justice in contemporary normative 
political philosophy, and one that is highly relevant to the argument of this chapter. I begin by providing a brief outline of Ceva's conception of procedural justice and then assess its merits and relevance, relative to relational egalitarianism, with respect to providing normative support for the findings of the empirical research on PJ.

\subsection{Ceva's 'interactive' theory of procedural justice}

Like relational egalitarian theories, Ceva (2016) argues that debates about justice in normative political philosophy have been overly focused on 'end-state justice', that is questions concerning justice in distributive shares and outcomes. However, little attention has been paid to questions of 'interactive' or procedural justice. Interactive justice is concerned with the justice or injustice of processes and procedures of social and political interaction. Ceva's specific concern in the book is with debates about intractable, antagonistic value conflicts in politics-for example, debates over abortion, or gay marriage. The problem with these kinds of conflict, she argues, is that they often expose people, especially vulnerable minorities, to inherently morally unacceptable forms of treatment, such as silencing, marginalisation, and public stigmatisation, or 'interactive injustice' (p. 15). The question that Ceva seeks to answer is how these kinds of value conflict can be shifted from antagonistic and disrespectful exchanges towards what Rawls calls 'reasonable disagreement' (Rawls 1993) - that is, forms of disagreement in which the parties do not feel disrespected or marginalised but engage with each other in a mutually respectful and trusting manner, and are open and willing to try to understand the other party's viewpoint (Ceva 2016, pp. 13-31). I will not engage in any detail with this aspect of Ceva's argument. The main focus of my discussion will be on her more general normative arguments for the importance of procedural justice. I want to highlight four main claims that are of particular relevance to my concerns in this chapter.

First, Ceva argues that outcomes and procedures are distinct social objects and raise distinct questions of justice. What matters is not only what people get but also how they get it. End-state or outcome-focused justice and interactive or procedural justice, although complementary, are therefore conceptually and normatively distinct (pp. 78-79). She says, 'procedures ... may be a locus of justice for quite distinct reasons and in accordance with quite distinct standards from those employed to evaluate the qualities of outcomes' (p. 74). While outcomebased theories might accept that procedures are instrumentally important, insofar as procedures are a means of achieving just outcomes, outcome-based theories do not regard procedures as inherently or intrinsically important for justice. ${ }^{9}$ In contrast, Ceva (2016) argues for intrinsic proceduralism. Intrinsic proceduralism claims that,

certain procedures are inherently valuable insofar as they are constitutive of inherently valuable forms of human interaction in politics and society; these are interactions in which people are treated in an inherently morally 
acceptable manner because they are given appropriate consideration-they are reckoned with in terms that are fittingly responsive to their status as potential makers of valid claims.

Second, Ceva (2016) grounds moral acceptability in the principles of procedural equality and human dignity. The principle of procedural equality is the principle that all parties to a conflict are equal in a fundamental but minimal sense-that is, they are 'entitled to an equal chance to have their say' (p. 115). The test for whether a procedure or form of social and political interaction is morally acceptable and hence meets the requirements of procedural equality is whether the parties are treated in a manner consistent with the demands of human dignity. Ceva understands dignity, following Jeremy Waldron (and Kant), as a status concept that is grounded in recognition of our human capacities for rational agency, and hence recognition of our rights as rational agents to make claims against others (pp. 76-77). The demands of human dignity require that no individual is regarded or treated by public institutions and office holders as morally inferior to others, that each person is regarded as having the status of a potential maker of valid claims, and that each person is entitled to a chance to voice their claims that is not inferior to the chance granted to others (p. 125). Having an equal chance does not mean 'that the outcome is equally influenced or shaped by all views in an equal manner'; rather, it means that all claims are voiced on an equal footing (p. 132). She cites the principle of due process in legal contexts as an instantiation of this form of dignity and procedural equality:

The very idea that a person has a right to have her say on her own behalf before a public tribunal is a constitutive component of the treatment of a person in accordance with her dignity as it implies that she is recognized as the source of a potentially valid claim that should be aired. From this perspective due process is not only-and perhaps not primarily-valuable as an instrument to reach an accurate verdict (a just outcome) but as it realizes in itself the fundamental normative commitment to treating persons with dignity (with just procedures being constitutive of such a treatment). ${ }^{10}$

Third, Ceva (2016, pp. 115-117) argues that states have a moral duty to design institutions and processes that meet the requirements of procedural equality and interactive justice. Exactly how to meet these requirements will vary depending on the context, because factors that may hinder the realisation of procedural equality need to be taken into account and mitigated. These factors include the effects of material and relational inequalities on individuals' abilities to voice their claims, including the effects of lack of education, being a member of an unpopular minority, being disenfranchised, socially marginalised, and so on.

Finally, Ceva argues that intrinsic proceduralism provides a stronger argument for the value of procedures than expressive forms of proceduralism. ${ }^{11}$ Many 
relational egalitarian theories, as discussed above, are expressivist in maintaining that state institutions have special responsibilities to ensure that their processes express respect for citizens, and that, in their interactions with citizens, office holders treat individuals in ways that convey attitudes of equal respect. On the expressivist view, respect (or disrespect) are not only conveyed but also embodied in the processes and procedures by which citizens interact with social institutions and authorities. In other words, procedures matter because of the messages they embody about a person's social standing in the eyes of authorities. Procedures that express respect publicly acknowledge a person's standing as a moral and social equal. Ceva argues, however, that procedural equality does not simply express or promote normative commitments to human dignity, it actually realises those commitments and bestows dignity. This is because just procedures, such as due process, confer a normative status on participants in those procedures, a normative status they would not otherwise have and that is constituted by the procedures themselves. I think Ceva is correct that procedurally just processes can confer or bestow, as well as express, dignitary standing. However, I think that one way in which they confer this standing is by virtue of embodying a message about citizens' social and moral equality. For this reason, I am not sure that as much hangs on the distinction between expressive and intrinsic proceduralism as Ceva claims.

Ceva's understanding of dignity as grounded in rational agency is, however, quite Kantian, and so I think the notion of respect for dignity that is central to her account of procedural justice differs in important ways from the understanding of respect that is at stake in both relational egalitarianism and relational models of procedural justice in the empirical literature. Although relational egalitarianism is grounded in the idea of moral equality, it claims that social equality is a central requirement of justice, while inequalities of social standing that undermine the social conditions required for individual freedom, autonomy and self-respect are inherently unjust. So for relational egalitarians, respect for others' dignity is not just a matter of respecting their status as rational agents. Respecting others' dignity is also a matter of respecting their rights to be included as equal participants in a social community, conceived of as 'a system of cooperation and affiliation among equals' (Anderson 2008, p. 143). Further, inclusion in a social community, as an equal participant is a condition for self-respect.

For this reason, I think the relational egalitarian view may be closer than Ceva's view to Tyler's relational notions of respect and dignity, which are based on group-value models of identity. However, as outlined above, Tyler's groupvalue account is psychological-he says, 'people are concerned about their status in groups because high status within a group validates their own self-identity' (Tyler \& Lind 1992, p. 141) and their sense of self-worth. Relational egalitarianism, I have argued, is both psychological and normative. Certainly, there are psychological reasons why, as social beings, we value others' recognition of our status as equal participants in a social community. But relational egalitarians also 
claim that we are normatively entitled to the conditions for that recognition and hence to the social bases of self-respect. That is why social processes that deny those conditions to individuals or social groups are unjust.

To sum up the argument presented in this section, I have suggested that Ceva presents an important argument for procedural justice as a distinct locus of justice. She also develops a normative argument for why state institutions have an obligation to design and enact procedurally just processes - that is, processes that express and bestow dignity and respect on those who are subject to these processes. However, I have suggested that her account of respect is more dignitarian than relational. In the next section, I will briefly outline two philosophical analyses that will help to further clarify the differences between dignitarian and relational conceptions of respect and self-respect. ${ }^{12}$

\subsection{Respect, self-respect, and procedural justice}

The conception of respect for dignity that underpins Ceva's account of procedural justice resonates with Stephen Darwall's (1977) influential analysis of recognition respect. Darwall distinguishes two kinds of respect: appraisal and recognition respect. Appraisal respect for someone as a person is respect or esteem for that person's character as a moral agent. Appraisal respect for a person is therefore responsive to merit or excellences of character $(1977$, p. 39). Because it is responsive to persons' moral qualities, there is no moral obligation to regard all persons with appraisal respect; such respect is only due when it is warranted. Recognition respect for persons, by contrast, is categorical and is the kind of respect that is owed to all persons in virtue of their status and dignity as persons. It involves giving due weight to the recognition that someone is a person, that is, a free and rational agent, in the way one treats and acts towards her. In later work $(2004,2006)$, Darwall adds to this the idea that recognition respect involves recognition and acknowledgement of another person's second-personal authority to demand that she be respected as a person. It thus involves 'addressing the other in a way that presupposes and reciprocally recognizes the equal dignity, hence mutual accountability, of addresser and addressee' (2004, p. 55). Relational egalitarians would argue that the expectation that one is due this kind of recognition respect is normatively grounded in the requirement to respect others as moral and social equals. The expectation that one is due recognition respect, I suggest, also underpins the expectation of respect that emerges as a strong theme in the empirical research on PJ.

However, while Darwall's analysis of respect is relational to the extent that it places second-personal interactions at its heart, it overlooks the social and political context of these interactions and the way they are shaped by dynamics of social power and inequality. ${ }^{13}$ Hence, it overlooks the ways in which these dynamics can shape both individuals' second-personal authority to demand respect and their sense of self-respect-that is, their sense of themselves as respect-worthy persons 
whose lives have value. Robin Dillon's (1997) analysis of self-respect is more attuned to these relational dynamics. She argues that,

the nature and meaning of self-respect and how it is constituted and expressed, both at the level of individual experience and at the level of concept, is a function of social relationships and the structure and functioning of the social institutions among which we live.

Dillon draws on Darwall to distinguish two kinds of self-respect: appraisal and recognition self-respect. Appraisal self-respect is 'confidence in one's merit as a person' (p. 231), or the evaluative appraisal of oneself as living up to the standards of one's normative self-conception. Recognition self-respect involves respecting oneself as a moral agent, and regarding oneself as having equal moral worth and standing, or to use Darwall's later terminology, as having the secondpersonal authority to demand that others respect one as a person. Dillon argues, however, that the ground for both appraisal and recognition self-respect is a more fundamental kind of self-respect, basal self-respect, which is a basic emotional and experiential attitude toward oneself and one's life as having intrinsic value or worth. This basic value orientation to oneself 'is relational, interactional and institutionally structured and enacted' (1997, p. 245) and can be damaged by dysfunctional interpersonal relationships, and by experiences of social marginalisation and exclusion.

Dillon's claim about basal self-respect being relational, interactional, and institutionally structured and enacted resonates with group-value theory. It provides a complementary explanation of why people are so sensitive to the messages about their status conveyed by group processes and by how they are treated by persons in positions of authority. Dillon's emphasis on the impact of social dynamics of power and inequality on people's sense of self-respect is also borne out in the empirical research literature on PJ. Tyler and Blader (2003, p. 358), for example, argue that for members of minority social groups who are subject to stereotyping and stigmatisation, the quality of both the decision-making and interpersonal treatment they receive at the hands of authorities has direct impacts on their sense of identity, especially their sense of self-worth and self-esteem. Fair and neutral decision-making by authorities communicates to members of minority groups that they will not be subject to prejudice and stereotyping. Being treated politely and with respect communicates the message that they are valued members of society. By contrast, practices such as racial profiling can 'communicate marginality and exclusion from important protections' that are extended to members of other social groups, such as freedom from arbitrary arrest and detention (2003, p. 359), thereby undermining what Dillon refers to as basal self-respect, as well as prompting reactions of anger and alienation. ${ }^{14}$

Critics of expressivist views, such as Ceva argue that the expressivist appeal to the negative effects of unfair and disrespectful treatment on citizens' sense of self-respect and self-worth is vulnerable to empirical contingencies. ${ }^{15}$ Different 
people may react in different ways to such treatment, and these different reactions may also be connected to contextual, cultural or historical factors. Tyler's work suggests, however, that people's reactions may be less variable than Ceva thinks. Furthermore, to the extent that such differences exist, Dillon's relational analyses of recognition self-respect (as respect for one's equal moral worth and standing), and of basal self-respect (as a basic emotional and experiential attitude toward oneself and one's life as having intrinsic value or worth) show that the existence of any such differences does not undermine the normative force of the obligation to treat others in ways that promote self-respect.

The relational analysis of self-respect thus provides further support for the normative claim that authorities should embed PJ in their interactions with citizens because it is morally right that citizens are treated in a procedurally just manner. Governmental officials, such as police, members of the judiciary, and administrative officers in areas such as social welfare, are representatives of institutions that exercise considerable coercive power over people's lives. Many citizens who are subject to the determinations of such officials may be socially disadvantaged or marginalised and predisposed to be mistrustful of government institutions. Moreover, they may not regard themselves as having the second-personal authority to demand respectful treatment from officials. Even citizens who are not disadvantaged in terms of their social standing may feel similarly powerless in the context of judicial or administrative decision-making processes that affect their rights and welfare. The empirical research on PJ shows that this sense of powerlessness can damage not only people's sense of self-respect but also their confidence in the neutrality and trustworthiness of governmental officials and institutions. A commitment to procedural justice entails a commitment to processes that support and promote self-respect by expressing respect for individual citizens as moral and social equals. Enacting this commitment requires taking seriously the institutional power wielded by officials, and developing processes that keep this power in check, and that aim to convey the sense that officials and the citizens who are subject to their determinations are mutually accountable. This requires processes that demonstrate officials' neutrality, trustworthiness, willingness to listen, commitment to justice, and concern for the welfare of those who appear before them.

\subsection{Conclusion}

The empirical research on procedural justice provides strong evidence that the four factors of respect, neutrality, trustworthiness and voice are central to citizens' judgements about whether institutions and authorities are legitimate in the descriptive or sociological sense. Social psychologists do not presume that their findings provide criteria for legitimacy in the normative philosophical sense. Nevertheless, in this chapter I have argued that recent work in normative political philosophy lends support to the idea that legitimacy in the descriptive sense may converge with legitimacy in the normative sense. Relational egalitarian theory provides normative support for citizens' expectations that they should be treated fairly and 
with respect. It grounds these expectations in the idea that a central requirement of justice is that citizens should be treated as moral and social equals. Ceva's work provides support for the view that procedural justice is a distinct domain of justice, as well as for the claim that procedures are inherently normatively important. Darwall's analysis of recognition respect explicates what respect for a person as a moral equal entails, while Dillon's relational analysis of self-respect underscores the normative connection between social equality and self-respect. If the argument developed in this chapter is persuasive it shows that, to the extent that the four factors of PJ satisfy citizens' expectations for fair and respectful treatment, institutions and authorities that embed PJ in their processes and interpersonal interactions with citizens will count as both descriptively and normatively legitimate.

\section{Notes}

1 Thanks to Denise Meyerson and Therese MacDermott for their very helpful comments on earlier versions of this chapter. Thanks also to participants at a workshop on procedural justice held at Macquarie University in 2018. Research for this chapter was funded by the Australian Research Council's Discovery Project funding scheme (DP1701009600: 'A Relational Theory of Procedural Justice').

2 While the empirical research on procedural justice is voluminous, my discussion in this chapter has been most influenced by the work of Tom Tyler and Alan Lind. See especially Tyler and Lind (1992).

3 However, see Bottoms and Tankebe's contribution to this volume (Chapter 4) for a more qualified endorsement of this claim.

4 In referring to an 'instrumental' justification here I mean to contrast it with a normative justification in the philosophical sense, as explained in the text that follows. However, it is important to clarify that the term 'instrumental' is often used in the social psychology literature to refer to approaches to authority and legitimacy which assume that people are motivated to obey the law primarily from selfinterested concerns. In this context, 'instrumental' approaches to authority and legitimacy are typically contrasted with 'relational' and 'normative' approaches to procedural justice, which claim that relying on people's instrumental (i.e. self-interested) motives to obey the law is not an effective way to govern, and that encouraging belief in the legitimacy of the law via PJ is more effective. Tina Murphy's contribution to this volume (Chapter 1) understands the term 'instrumental' in this way. For a more detailed analysis, see, e.g., Tyler and Lind (1992, 119-121), who refer to 'social exchange' theories of legitimacy as instrumental in this sense. According to Tyler and Lind, social exchange theories hold that people are primarily motivated by self-interested concerns and hence people evaluate social relationships and interactions in terms of their costs and benefits. Thus, people's perceptions of the legitimacy or otherwise of procedures and authorities are tied 'to the extent to which the authority's decisions and the procedures used to generate those decisions are personally favourable', as well as the transaction costs and benefits of those procedures (1992, p. 120). In their chapter in this volume (Chapter 4), Bottoms and Tankebe provide a useful and related analysis of the way social psychologists understand the terms 'instrumental' and 'normative'.

5 There are parallels between Anderson's argument and Habermas' analysis of the importance of democratic participatory procedures for political and legal legitimacy. For discussion of the relevance of democratic or 'bottom up' participatory procedures for procedural justice, see Sarah Sorial's contribution to this volume (Chapter 6). 
6 In her contribution to this volume (Chapter 10), Natalie Stoljar argues that the feeling by members of racially profiled groups that the justice system is unfair and disrespectful is justified, because racial profiling both expresses and constitutes disrespectful treatment. This is another powerful example of how the processes and procedures by which authorities interact with citizens can embody messages of disrespect.

7 This expectation of normative entitlement to be treated as a moral and social equal might be a form of what Bottoms and Tankebe, in their contribution to this volume, refer to as a 'basic legitimation expectation'. (See Chapter 4).

$8 \mathrm{My}$ discussion focuses primarily on the account of interactive justice developed in Ceva (2016). However, see also Ceva's contribution to this volume (Chapter 8).

9 In her contribution to this volume (Chapter 7), Denise Meyerson also provides a detailed argument against instrumentalist, outcome-based accounts of the value of procedures.

10 In her contribution to this volume (Chapter 8), Ceva provides a more detailed analysis of due process in legal contexts as an instantiation of interactive justice.

11 For Ceva's critique of expressivism, see Ceva (2016, pp. 82-84). Her argument for intrinsic proceduralism is developed in detail in Ceva (2016, esp. pp. 92-107). See also her contribution to this volume (Chapter 8).

12 Some of the discussion in the following section draws on material in Meyerson and Mackenzie (2018).

13 Drawing on Darwall's work, in her contribution to this volume (Chapter 10), Natalie Stoljar argues that racial profiling constitutes a form of both recognition and appraisal disrespect. Racial profiling provides a salient example of why relational theories of justice should attend not just to second-personal interactions but the way these interactions are shaped by dynamics of social power.

14 See also the findings of empirical studies reported in Tyler (2001 and 2009), which indicate that perceived quality of treatment is directly linked to the extent to which members of minority groups are supportive of law and legal authorities.

15 See Ceva's contribution to this volume (Chapter 8).

\section{References}

Anderson, E 1999, 'What is the point of equality?', Ethics, vol. 109, no. 2, pp. 287-337.

Anderson, E 2008, 'Expanding the egalitarian toolbox: equality and bureaucracy', Proceedings of the Aristotelian Society, Supplementary Volumes, vol. 82, pp. 139-160.

Anderson, E 2009, 'Towards a non-ideal, relational methodology for political philosophy', Hypatia, vol. 24, no. 4, pp. 130-145.

Ceva, E 2016, Interactive justice: a proceduralist approach to value conflict in politics, Routledge, New York/London.

Darwall, SL 1977, 'Two kinds of respect.' Ethics, vol. 88, no. 1, pp. 36-49.

Darwall, SL 2004, 'Respect and the second-person standpoint', Proceedings and Addresses of the American Philosophical Association, vol. 78, no. 2, pp. 43-59.

Darwall, SL 2006, The second-person standpoint: morality, respect, and accountability, Harvard University Press, Cambridge.

Dillon, RS 1997, 'Self-respect: moral, emotional, political', Ethics, vol. 107, no. 2, pp. 226-249.

Garrau, M \& Laborde C 2015, 'Relational equality, non-domination, and vulnerability', in C Fourie, F Schuppert \& I Wallimann-Helmer (eds.), Social equality: on what it means to be equals, Oxford University Press, New York. 
Jackson, J 2018, 'Norms, normativity, and the legitimacy of justice institutions: international perspectives', Annual Review of Law and Social Science, vol. 14, no. 1, pp. 17.1-17.21. doi: 10.1146/annurev-lawsocsci-110316-113734

Levitov, A 2016, 'Normative legitimacy and the state', retrieved from Oxford Handbooks Online, online publication date October 2016. doi: 10.1093/oxfor dhb/9780199935307.013.131.

Meyerson, D \& Mackenzie, C 2018, 'Procedural justice and the law', Philosophy Compass, vol. 13, no. 12, e12548, pp. 1-11. doi: 10.1111/phc3.12548

Rawls, J 1993, Political liberalism, Columbia University Press, New York.

Scheffler, S 2003, 'What is egalitarianism?' Philosophy and Public Affairs, vol. 31, no. 1, pp. 5-39.

Schemmel, C 2011, 'Distributive and relational equality', Philosophy, Politics \& Economics, vol. 11, no. 2, pp. 123-148.

Schemmel, C. 2015, 'Social equality—or just justice?', in C Fourie, F Schuppert \& I Wallimann-Helmer (eds.), Social equality: on what it means to be equals, Oxford University Press, New York.

Sheffler, S 2015, 'The practice of equality', in C Fourie, F Schuppert \& I WallimannHelmer (eds.), Social equality: on what it means to be equals, Oxford University Press, New York.

Tyler, T 2001, 'Public trust and confidence in legal authorities: what do majority and minority group members want from the law and legal institutions?', Behavioral Sciences and the Law, vol. 19, no. 2, pp. 215-235.

Tyler, T 2009, 'Majority and minority perspectives on justice and trust: Is there a consensus on goals?', in S Demoulin, JP Leyens \& JF Dovidio (eds.), Intergroup misunderstandings: impact of divergent social realities, Psychology Press, New York/London, pp. 233-249.

Tyler, T \& Lind, A 1992, 'A relational model of authority in groups', in MP Zanna (ed.), Advances in experimental social psychology, vol. 25, Academic Press, San Diego, pp. 115-191.

Tyler, TR \& Blader, SL 2003, 'The group engagement model: procedural justice, social identity, and cooperative behavior'. Personality and Social Psychology Review, vol. 7, no. 4, pp. 349-361.

Wolff, J 1998, 'Fairness, respect and the egalitarian ethos', Philosophy and Public Affairs, vol. 27, no. 2, pp. 97-122.

Wolff, J 2015, 'Social equality and social inequality', in C Fourie, F Schuppert \&I Wallimann-Helmer (eds.), Social equality: on what it means to be equals, Oxford University Press, New York. 


\section{Part IV}

Implications and applications

Legal institutions and the exercise of legal authority 


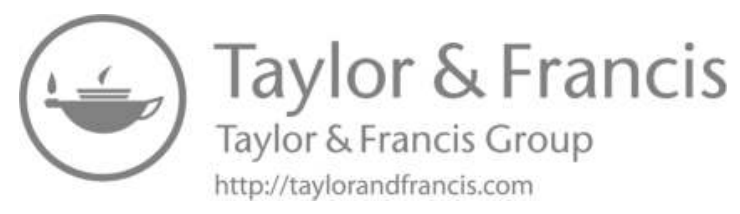




\title{
10 Racial profiling as pejorative discrimination $^{1}$
}

\author{
Natalie Stoljar
}

\subsection{Introduction}

It seems intuitive to many people that racial profiling is morally repugnant. A 2017 report of the Ontario Human Rights Commission, Under Suspicion, calls racial profiling an 'insidious and particularly damaging type of racial discrimination that relates to notions of safety and security' (p. 9). The report details the daily reality of racial profiling for members of Indigenous communities, Muslims, Arabs, West Asians, and Canadians of African descent. It includes a wide range of phenomena under 'racial profiling', such as surveillance in retail or airport security that disproportionately affects members of minority groups, suspicion and prejudice directed towards Indigenous people by child protection services, and the criminalisation of racialised youth in policing. The focus of the philosophical literature is often narrower and limited to racial profiling in law enforcement. Following this literature, I adopt the definition that 'racial profiling' is 'any police-initiated action that relies on the race, ethnicity, or national origin, and not merely on the behaviour of an individual' (Risse \& Zeckhauser 2004, p. 136). ${ }^{2}$

David Harris (2017) describes three waves of racial and ethnic profiling in criminal contexts (in the United States in particular). The first refers to policies developed in the 1980s and 1990s targeting drug crimes that concentrated on highway traffic stops of Black and Hispanic men; the second is the profiling of Arabs and people of Middle Eastern appearance after the terrorist attacks of 11 September 2001; and the third is the more recent targeting in the United States of people of Hispanic descent who appear to be undocumented or 'illegal' immigrants (Harris 2017, pp. 120-124). It is important to note that profiling need not be de jure, namely sanctioned by an explicit law or policy. It can also occur de facto without authorisation of the state, due to racist implementation of policies, implicit racial biases or even unintentional microaggressions (cf. Hosein 2018, p. e3). ${ }^{3}$

Philosophers classify racial profiling as discrimination because it constitutes disadvantageous differential treatment of people who are profiled relative to people who are not profiled (Lippert-Rasmussen 2013, Chapter 12; Eidelson 2015, Chapter 7). It also counts as group discrimination because it is disadvantageous differential treatment on the basis of perceived group identity (Lippert-Rasmussen 2013 , p. 273). Discrimination can be direct or indirect; it can be the result of an 


\section{Natalie Stoljar}

explicitly discriminatory policy, or of a facially neutral policy that has a differential impact on minority groups (Khaitan 2018). Stop-and-frisk, or the 'Terry stop', is an ostensibly neutral policy allowing police to stop and search people whom they reasonably suspect have committed, are committing, or will commit a crime (Torres 2015, p. 932). However, empirical evidence about racial disparities in the implementation of the Terry stop shows that it is indirectly discriminatory. From 2004 to 2012 in New York, 83\% of those stopped under stop-and-frisk were Black and Hispanic (Torres 2015, pp. 933-934).

On most philosophical analyses, neither racial discrimination nor racial profiling is immoral by definition. There is also no consensus in the philosophical literature that racial profiling is morally wrong. On the contrary, profiling has seemed to be warranted on the basis of statistical correlations between criminality and people of certain racial or ethnic backgrounds. As Mathias Risse and Richard J. Zeckhauser put it, 'racial profiling assumes certain crimes are committed disproportionately by certain racial groups. Hence special efforts at crime reduction directed at members of such groups are justified, if not required' (2004, p. 144). Racial profiling is 'rational' if it increases the number of criminals caught by the police, reduces overall criminal activity, and therefore promotes the important public good of security. ${ }^{4}$ However, this does not settle the question of whether profiling is morally permissible. Despite being beneficial for crime reduction, there may be significant costs that outweigh the benefits. In addition, or alternatively, profiling may be impermissible for non-consequentialist reasons: it may violate rights or be inconsistent with the obligation of the state to treat all citizens with equal respect.

The first goal of this chapter is to employ procedural justice theory to examine consequentialist arguments for and against the morality of racial profiling. Procedural justice focuses on the interpersonal or process-related aspects of laws and policies that obtain independently of and in addition to the outcome-related aspects (Tyler 1990, p. 7). Tom R. Tyler calls this:

the normative perspective on procedural justice, [which] views people as being concerned with aspects of their experience not linked only to outcomes. Normative aspects of experience include neutrality, lack of bias, honesty, efforts to be fair, politeness, and respect for citizens' rights.

(Tyler 1990, p. 7)

For instance, groups that are targeted by profiling experience both the policy itself, and the specific police-citizen interactions that occur when it is implemented, as biased, unfair, and disrespectful. Tyler and his colleagues argue that such experiences lead to loss of trust in the police and a perception that the criminal justice system is illegitimate, which in turn reduces compliance (e.g. Tyler 2006, p. 379). Reducing compliance with law will inhibit overall security and hence undermine the very goals that profiling aims to achieve. Therefore, considerations from procedural justice call arguments for racial profiling (that putatively establish its rationality) into question. They also reinforce consequentialist arguments against profiling. Consequentialist arguments focus on weighing 
outcomes: the benefits of reducing crime are weighed against the costs of contributing to racism. One prominent argument claims that, in an already-racist society, the small additional contribution of racial profiling to racism will be outweighed by the benefit of promoting security (Risse \& Zeckhauser 2004, p. 147). But once we recognise the magnitude of the process-related harms experienced by members of profiled groups, this argument is no longer plausible. ${ }^{5}$

The second goal is to develop a new, non-consequentialist objection to racial profiling. I argue that profiling constitutes disrespectful treatment and therefore violates the state's obligation to treat citizens with equal respect. The procedural justice literature is important for this argument as well. There is evidence that when people think that the procedures used to enforce laws or policies are unfair, this negatively affects their sense of self-worth and self-respect (e.g. Meyerson 2015, pp. 258-259). This raises the question of whether profiling constitutes disrespectful discriminatory treatment. Does the experience of profiled groups that they are being treated unfairly and disrespectfully track actual disrespectful treatment by police or by the state? If so, this would provide a non-consequentialist or deontological objection to racial profiling. Many philosophers nonetheless dismiss the deontological argument. ${ }^{6}$ In particular, despite arguing that the moral wrongness of core racial discrimination can be traced to disrespectful treatment, Benjamin Eidelson (2015) claims that racial profiling itself is not disrespectful in the relevant sense. My goal is to counter this argument and show that profiling constitutes disrespectful treatment.

Section 10.2 addresses the consequentialist arguments for and against racial profiling. I argue that the procedural justice notion of legitimacy undermines the rationality argument for profiling. I also identify the costs of racial profiling and suggest that process-related harms are an important component of these costs. I conclude that there is no convincing justification for profiling on consequentialist grounds. In Section 10.3, I explain Eidelson's argument that racial profiling does not constitute disrespectful treatment. The argument turns on a distinction between 'basic disrespect' and 'conventional disrespect'. The former corresponds to Stephen Darwall's notion of recognition disrespect, namely, failure to appropriately take account of a person's normative standing in moral deliberation (Darwall 1977). Eidelson claims that profiling perpetuates racist social meanings (generalisations that associate racialised groups with criminality), which are conventionally disrespectful to racialised groups. However, by hypothesis, racial profiling is based on true statistical correlations between these racialised groups and criminality, and hence does not convey an attitude of basic disrespect (Eidelson 2015, p. 86). Section 10.4 challenges this argument. I agree that racial profiling is conventionally disrespectful; it contributes to conventional meanings that are racist and hence is morally problematic on consequentialist grounds. However, this does not preclude the possibility that it also corresponds to basic disrespect. I propose that profiling functions as a particular form of generalisation called a 'striking-property generic' (Leslie 2007, 2008, 2017). On Sarah-Jane Leslie's analysis, striking property generics make claims about the natures of the members of the groups they describe. I argue that attributing criminality by nature to members of profiled 


\section{Natalie Stoljar}

groups is both a violation of recognition respect-it makes a moral mistake about the normative status of members of profiled groups - and an unjustified violation of a second form of respect, appraisal respect (Darwall 1977).

\subsection{Consequentialist arguments and procedural justice}

Some philosophers maintain that the adverse consequences of profiling are not significant enough to establish that it is unethical. Risse and Zeckhauser (2004) assume that profiling is rational and offer a 'qualified defence' of its moral permissibility; they claim that the costs to targeted groups are likely to be minimal and hence do not outweigh the beneficial consequences of reducing crime. David Boonin's (2011) 'reluctant defence' is more circumspect, arguing that profiling is sometimes rational and sometimes not (p. 326). However, for Boonin, the costs of profiling are all reducible to subjective responses on the part of members of profiled groups. These types of costs are neither weighty enough nor welljustified enough to override the presumed benefits. In this section, I revisit the rationality and morality arguments in the light of procedural justice theory.

\subsubsection{The rationality argument}

The claim that profiling is rational constitutes the first step in a broadly consequentialist defence of racial profiling. For the sake of argument, I accept the assumption that there are non-spurious, statistical correlations between certain racialised groups and rates of criminality. ${ }^{7}$ Does profiling these groups in fact reduce criminal activity and promote the public good of security? According to one prominent argument, the answer is no. Harris points to empirical evidence about 'hit rates', the 'rate at which officers' activity results in the recovery of contraband or guns, the detection of other offenses, the making of arrests, or the writing of summonses' (Harris 2017, pp. 138-139, Harris 2002, pp. 79-80). The evidence suggests that whereas people in minority groups are stopped by police at a higher rate than whites, the hit rate for these groups (e.g. for possession of contraband or weapons) is lower than it is for whites (Harris 2017, p. 138). This seems to establish that racial profiling is less successful at apprehending criminals than random searches.

It has been suggested, however, that the hit rates argument is inconclusive. ${ }^{8}$ I therefore propose an alternative reason to question the rationality of profiling. Consider the idea of legitimacy in procedural justice theory. Legitimacy corresponds to citizens' beliefs that an authority's power is legitimate and exercised in ways that are appropriate (Tyler 2006, p. 377). It includes the sense that one ought to obey the directives of the authority. According to scholars of procedural justice, when law and other authorities are perceived as legitimate, compliance will be achieved without coercion or incentives that are in citizens' self-interest. The contrary is also true: when authorities are perceived as unfair and illegitimate, compliance will be undermined. Since racial profiling is perceived by targeted groups as unfairly singling them out, compliance is therefore likely to be eroded. 
Indeed, this is recognised by the police themselves. In describing attempts of advocates of tighter immigration controls to involve local police in their efforts, Harris (2017) says,

Local police ... understood that becoming adjunct forces to federal deportation efforts would cause their own immigrant communities-both undocumented and documented people - to fear involvement with them. That fear would cause people to avoid calling police with reports of crime for fear of bringing immigration policing into any given situation. This would give predators in the community-robbers, killers, domestic-violence perpetrators, even child molesters-free rein.

(Harris 2017, p. 124)

Rick Trinkner, Jonathan Jackson, and Tom R. Tyler (2018) identify an additional concern: citizens' sense of the legitimacy of an authority is not limited to the 'how' of the exercise of the authority's power, but also extends to the 'when' and 'where' of its exercise-that is, to the citizen's perception of the appropriate boundaries of the power being exercised (2018, p. 282). For instance, in discussing the Terry stop, these authors note that:

some citizens are not only concerned about the manner in which the police conduct such stops, but also question whether the police have the right to enter individuals' personal space.

Thus, racial profiling is likely to undermine legitimacy due to the perception that it unfairly singles out profiled groups and its implementation exceeds the boundaries of the legitimate authority of the police.

Advocates of the rationality of profiling assume a simple proposition, namely, that profiling groups who disproportionately engage in criminal activity will reduce crime and promote security, including for the targeted groups themselves. Evidence about how profiling affects legitimacy within targeted communities calls this conclusion into question. If profiling generates fear, distrust, and the sense that law enforcement is illegitimate, this is likely to reduce compliance and hence make policing such communities much more difficult. Even if we assume for the sake of argument that profiling leads to the apprehension of more criminals, this is not the only dimension to be considered when assessing its rationality. Any small reduction in criminal activity is likely to be offset by a substantial increase in non-compliance within profiled communities. Thus, overall, it is unlikely that profiling will achieve its stated aims of promoting security.

\subsubsection{The morality argument}

Even if profiling turns out to be rational, this does not settle the question of whether it is morally permissible. I now turn to the arguments offered by Risse 


\section{Natalie Stoljar}

and Zeckhauser (2004) and Boonin (2011) claiming that the costs of profiling do not outweigh the benefit of promoting security. Risse and Zeckhauser classify racial profiling as an 'expressive' harm, which corresponds to either a 'reminder of other painful events or practice ... or a focal point for events or practices, a symbol of structural disadvantage or mistreatment' (2004, p. 147). A focal point becomes 'associated with harm [that] plausibly accounts for the lion's share of the harm associated with that practice' (2004, p. 147). Risse and Zeckhauser ask how much better off 'African Americans would be if we just got rid of profiling, keeping everything else fixed. We think that the answer is "only slightly so" (2004, p. 149). ${ }^{9}$ Thus, underlying racism is responsible for the harm suffered by minority groups and racial profiling is a mere focal point. Any additional harm due to profiling in an already-racist society is negligible and insufficient to outweigh the benefits to security.

Boonin argues that the costs of profiling are all reducible to the negative reactions of members of profiled groups. He claims that this type of cost, although not negligible, is insufficient to outweigh the benefits. ${ }^{10}$ The costs identified by Boonin include direct costs, such as feeling 'distressed, upset, degraded, angry, and outraged at being targeted by race for investigation, at least in part, because of the color of [one's] skin', and indirect costs, such as reluctance to move around freely in certain neighbourhoods and distrust of the police and criminal justice system (2011, p. 337). Boonin claims that all the costs arise from the negative reactions of members of profiled groups and that the negative reactions of people subject to a policy do not generate a moral reason against it: '[a] moral objection to racial profiling should give us a reason to be outraged by the policy, not a reason to think that people will be outraged by it' (Boonin 2011, p. 340).

These arguments misrepresent, respectively, the extent and the type of harm suffered by profiled groups. As others have pointed out (Lever 2005; Eidelson 2015; Hosein 2018), the harms of profiling are not always psychological. Even when they are, they are significant and not reducible to mere negative reactions. The profiling of minority groups leads to a wide variety of harms: it exacerbates the subordination and unequal status of minority groups, inflicts stigma and reputational harm, and contributes to psychological harms such as diminished selfworth and an insecure sense of social identity. For example, the Ontario Report points out that profiling leads to inequality, such as the overrepresentation of minority groups in prisons. ${ }^{11}$ The report explains that,

Racial profiling by law enforcement can have far-reaching impacts that go beyond the specific incident. For example, racial profiling may contribute to the overrepresentation of racialized and Indigenous peoples in the criminal justice system, beginning with racial differences in stop and search practices. Involvement with the criminal justice system can lead to loss of connections with families and communities, and loss of opportunities for employment, education and social mobility. This exacerbates existing systemic racial barriers for racialized and Indigenous peoples in society.

(OHRC 2017, p. 85) 
Profiling also contributes to racial inequalities by perpetuating conventional meanings that associate minority groups with criminality. As Annabelle Lever puts it, racial profiling reinforces 'odious claims about immorality and criminality' and 'white tendencies to draw invidious and complacent racial distinctions' $(2005$, p. 97). This will perpetuate the racism that affects all members of profiled groups even if they are never profiled themselves (Eidelson 2015, p. 207).

Further, racial profiling causes significant psychological harms, such as extreme anxiety, humiliation, and alienation. One member of a profiled group describes her reaction as follows:

I live in fear for my black son, I experience sickening levels of anxiety if I text him or call him and [he] does [not] respond within 30 minutes or so. I feel bad that I have put my black children under surveillance in order to protect them from the system that is supposed to protect them (Black female, age 35-44).

(OHRC 2017, p. 86)

Profiling is perceived to place a disproportionate burden on minority groups and hence to be unfair, which-as procedural justice theory has extensively documented will compound the psychological harm. The perception of fair treatment by authorities promotes positive attitudes of self-worth and self-respect, and a secure sense of one's own social identity (Meyerson 2015, pp. 258-259). As Denise Meyerson explains,

the empirical findings ... show that a key factor in developing and maintaining a favourable social identity is the perception that one has status within one's group and, furthermore, that when authorities treat people in ways that are interpersonally satisfactory, this sends the message that they have status within their group. ${ }^{12}$

(Meyerson 2015, p. 258)

Interpersonal treatment that is perceived to be biased, unfair, and disrespectful will have the opposite effect. Racial profiling is therefore likely to have extensive negative consequences including undermining self-worth and self-respect, destabilising social identity, and producing a sense of inferior social status. ${ }^{13}$

It is implausible therefore to construe the harms of profiling as either 'expressive' of underlying racism and thus minimal, or of a type that is insufficiently weighty to be included in moral argument. Boonin (2011) is correct that subjective outrage or offence in response to some policy is insufficient on its own to provide a moral argument against it (p. 340). But his position conflates an offence argument with a harm argument. The negative psychological effects inflicted on the targets of profiling should not be equated with a subjective sense of offence or even outrage that is felt in response to a policy with which one does not agree. In short, the combined costs of profiling are likely to outweigh any benefits. ${ }^{14}$ The remaining question is whether there is a plausible non-consequentialist objection 
to racial profiling in addition to the consequentialist ones. Does racial profiling, independently of its consequences, constitute disrespectful treatment of racialised minorities by the state?

\subsection{Eidelson's argument: profiling and disrespect}

Eidelson claims that profiling is not disrespectful in a 'basic' sense. Although the wrong-making feature of core cases of racial discrimination is disrespectful treatment, racial profiling is an exception because it is not a violation of what Darwall calls 'recognition respect' (Darwall 1977). Racial profiling is based on statistical correlations, not on a mistake about the personhood of the recipient. Eidelson (2015) observes that it 'seems foolish to deny that there are often genuine correlations between certain perceptual features, such as race or sex, and other relevant traits, including some forms of criminality' (p. 175). Hence, on Eidelson's account, racial profiling based on genuine statistical correlations does not display the attitude necessary for disrespectful treatment. This section outlines Eidelson's argument in detail. The argument turns on a distinction between profiling as an attitude of basic disrespect and profiling as contributing to conventionally disrespectful social meanings. Eidelson rejects the former and therefore the possibility of a nonconsequentialist argument based on recognition respect. He nevertheless adopts the latter to argue that profiling is impermissible for consequentialist reasons.

Eidelson considers racial profiling as a case study of racial discrimination. The conceptual analysis of discrimination should be distinguished from its wrongmaking features. He says, 'discrimination is best seen as a very general kind of act-one that is only sometimes wrong. Acts fitting within that type may be wrong in different cases for different reasons' (Eidelson 2015, p. 73). Eidelson claims, however, that 'core' cases of discrimination are wrong for non-consequentialist reasons. Suppose a person is denied a job purely on the basis of their race (or other arbitrary personal characteristic), but finds a better one immediately afterwards. Eidelson argues that the wrong is not just a 'contingent' matter, as it would be on a consequentialist analysis. Rather, our moral intuitions imply that such cases are 'intrinsically' wrong - that there is an objective basis of the wrongness independently of contingent effects. The objective basis in core cases of racial discrimination is a violation of recognition respect. Eidelson (2015) explains that,

the relevant sort of respect-recognition respect for someone's standing as a person-imposes an affirmative obligation that one take to heart the various normative upshots of ... being a person and regulate one's action accordingly. On this view, what matters is how an agent deliberates, rather than the social meaning of her act. But her deliberation is rendered morally defective not merely by the presence by some positive factor of animus or a discriminatory belief, but by the absence of appropriate recognition of someone's personhood whether that absence comes about willfully or by neglect.

(pp. 74-75) 
Thus, Eidelson (following Darwall) offers a 'deliberative' conception of respect. This should be distinguished from two other possible conceptions: (i) a 'mental state' conception on which a necessary condition of disrespectful treatment is contempt or animus for the targeted group; and (ii) an expressivist conception on which a sufficient condition for an agent to express disrespectful treatment is for that agent to express a disrespectful conventional meaning through actions or words. ${ }^{15}$ The expressivist conception takes exemplars of racial discrimination, for instance, the 1890 Louisiana law that prohibited people of different races from travelling together on trains, ${ }^{16}$ to be wrongful, not because they are the result of hostile racist intent, but because the meaning they express is morally unacceptable. ${ }^{17}$ Different expressivist views explain the wrong-making feature in different ways. For instance, such treatment may constitute an insult, 'an expression of the view that certain people are inferior or socially unacceptable' (Scanlon 1998, p. 72); or it may convey a demeaning message which is disrespectful 'in an especially strong way [because it is] an expression of a lack of respect for the equal humanity of the other' (Hellman 2008, p. 36).

Eidelson unpacks the relations between the different conceptions of respect as follows. Disrespect on the mental state conception is an example of basic disrespect on the deliberative conception because deliberation can be morally defective as a result of racist animus or a racist belief. On the other hand, expressive disrespect is not equivalent to basic disrespect on the deliberative conception. Engaging in action that corresponds to a demeaning conventional meaning is not sufficient on its own for the attitude of basic disrespect. This is because, on expressive views, the presence of certain social conventions is sufficient for disrespect to be displayed and hence expressivist views effectively render the moral wrongness of discrimination a contingent matter. For example, failing to shake someone's hand in a culture when this is required by norms of courtesy is taken to be disrespectful just because it expresses an insulting or disrespectful social meaning (Anderson \& Pildes 2000, pp. 1512-1513, quoted in Eidelson 2015, p. 86). Eidelson argues that although this might be conventionally disrespectful, it does not correspond to an attitude of basic disrespect. He explains that,

one can act disrespectfully by unwittingly failing to integrate someone's standing as a person in one's practical deliberation ... But one does not fail to satisfy the relevant criteria simply by acting in ways that are conventionally disrespectful, such as failing to shake someone's hand in a culture with which one may be unfamiliar. To disrespect someone is to fail to take account of the normative significance of some facet of her moral standing; and it is just not up to a culture to decide what constitutes such a failure.

(Eidelson 2015, p. 86)

The implication of Eidelson's analysis is that racial profiling is not disrespectful in an 'intrinsic' sense on any of the three conceptions of respect. Racial profiling is not disrespectful on the mental state conception because it need not and typically does not rely on racist animus or contempt. It is not disrespectful on the deliberative conception because the associations on which racial profiling is based, 


\section{Natalie Stoljar}

such as 'Blacks are more likely to be drug couriers', are non-spurious statistical correlations. There are 'genuine correlations between certain perceptual features, such as race or sex, and other relevant traits, including some forms of criminality' (Eidelson 2015, p. 175). Hence, racial profiling cannot be traced to a mistake in practical reasoning about the moral status of the profiled groups. Finally, racial profiling is not disrespectful in the basic sense on the expressive conception. Even if profiling were to convey an insulting or demeaning social meaning, this would be due to contingent circumstances only and would constitute at most 'conventional disrespect'. It would not correspond to the basic or intrinsic disrespect that is the wrong-making feature of core cases of racial discrimination.

Although Eidelson rejects the conclusion that racial profiling constitutes an attitude of basic disrespect, he argues that profiling is impermissible on consequentialist grounds. In particular, profiling contributes to racist social meanings that inflict 'broad' social harm on members of profiled groups even absent actual encounters with police (2015, p. 197). This 'Broad Harm Argument'18 first distinguishes profiling from 'suspect descriptions', individualised descriptions based on evidence about the actual perpetrator of a crime (2015, pp. $178 \mathrm{ff}$.). Unlike profiling, the use of suspect descriptions is often taken to be morally acceptable (2015, p. 178). For example, Harris says that,

The state-through its agents, the policetigate and prevent crime, but ... must meet legal standards that require some amount of evidence stemming from the personal conduct of the suspect, or because they match the appearance of a perpetrator (in a somewhat detailed, not general, way) witnessed by others.

(Harris 2017, p. 137)

For Eidelson the morally relevant distinction between uses of profiling and suspect descriptions is that the former 'derive all their force' $(2015, \mathrm{p}$. 182) from generalisations about the whole group, whereas the latter do not.

Consider Eidelson's examples. Suppose a redheaded person is observed fleeing the scene of a crime and the police stop all redheaded people in the vicinity. The justification for stopping redheaded people is that having red hair (matching the suspect description) increases the probability that the stopped person is the perpetrator. The suspect description ('being redheaded') does not rely on any generalisation that connects being redheaded to criminality. Indeed, redheads as a group may in fact commit fewer crimes than other groups $(2015$, p. 183). Now suppose the police stop people of Middle Eastern appearance because of the (putative) statistical correlation between being Middle Eastern and being a terrorist. Unlike the evidence on which suspect descriptions are based, the evidence for racial profiling is non-individualised because,

if nothing further is known about the [unidentified] terrorist, the criteria used to identify him in particular may derive all of their force from generalizations about the whole class of people who commit terrorist acts.

$(2015$, p. 182) 
Suspect descriptions and profiling are morally distinct because,

when we scrutinize someone because of a suspect description rather than a profile, we effectively dilute the inference from possessing a particular trait to criminality by introducing a mediating factor of personal identity. ${ }^{19}$

Eidelson therefore claims that the moral harm of profiling is its perpetuation of social meanings that are generalisations associating whole racialised groups with criminality. This is, however, a contingent effect of profiling not an example of 'intrinsic' or basic disrespectful treatment.

On Eidelson's argument, the problematic generalisations conveyed by profiling are at most conventionally disrespectful. There is no 'intrinsic' or objective basis for the wrongness of these generalisations that is independent of the contingent (and historically racist) association between racialised groups and criminality. In the next section, I develop an argument based on striking property generics to challenge this claim. For now, let me briefly mention two prima facie reasons to question Eidelson's conclusion. First, as noted by procedural justice theory, people have 'normative experiences' in response to the procedures used by the state to achieve its ends; they can be perceived as biased and disrespectful of citizens' rights (Tyler 1990, p. 7). Even if people endorse the goal of racial profiling (that is, to promote security), being stopped by police for no reason except skin colour (which often occurs for instance to Black drivers of expensive cars $)^{20}$ is experienced as disrespectful because,

it undermines and calls into question everything you've accomplished in your life, everything you've worked for. No matter how hard you've worked, no matter what you do ... you're treated like a common criminal.

(quoted in Eidelson 2015, p. 205)

The experience of citizens provides some evidence, albeit defeasible evidence, that the encounters with police that occur in profiling constitute actual disrespectful treatment. In addition, one may wonder whether Eidelson's insistence that there is an intrinsic wrong-making feature of core cases of racial discrimination could be applied to racial profiling itself. Subjecting innocent people to stop-and-frisk on the basis of arbitrary personal characteristics seems wrong even absent historically racist associations between the characteristic and criminality. For instance, suppose there are statistical correlations between certain types of criminality and being redheaded, being white, or being male. ${ }^{21}$ Since there are no problematic social meanings that associate these characteristics with criminality, would profiling on the basis of these characteristics be permissible?

\subsection{Profiling and generics}

Drawing on the lessons of procedural justice research, I return in this section to the attitudes inherent in the police-citizen encounter. Eidelson's argument that 


\section{Natalie Stoljar}

profiling contributes to conventionally disrespectful racist generalisations does not preclude the possibility that the encounter is also disrespectful in a basic sense. I propose three arguments for the claim that racial profiling constitutes an attitude of disrespect. First, in addition to the conventional generalisations identified by Eidelson and the statistical generalisations on which profiling is based, there is a third form of generalisation, a 'striking property generic', that is relevant to the morality of profiling. I argue that racial profiling conveys striking property generics that implicitly attribute a negative property by nature to members of profiled groups (Leslie 2017). ${ }^{22}$ Since this is a moral mistake about their personhood, it is inconsistent with recognition respect and therefore constitutes a kind of basic disrespect. Second, in permitting racial profiling policies, the police and the state disregard the perpetuation of the racist conventional meanings identified by Eidelson. The attitude of indifference towards the perpetuation of racist meanings that attribute criminality to minority groups also constitutes basic disrespect. Third, there is a second form of disrespect, 'appraisal disrespect', that often occurs as a result of racial profiling. Appraisal respect is an attitude of 'positive appraisal of a person or his qualities' (Darwall 1977, p. 39). Whereas recognition respect is a moral requirement and hence recognition disrespect is always morally wrong, negative appraisal may in some instances be justified, namely when a person's merits do not warrant an attitude of positive appraisal. However, since racial profiling mostly targets innocent people just on the basis of their group identity, racial profiling corresponds to unjustified negative appraisal, or disrespect.

Sarah-Jane Leslie's work provides an illuminating account of the psychology and the semantics of generalisations or 'generics' (Leslie 2007, 2008, 2017). Generics attribute a trait to a category in general without employing the quantifiers 'all', 'some', or 'many', such as 'Scots drink Iron Brew' or 'Sharks attack surfers' ${ }^{23}$ Leslie claims that the cognitive mechanism that forms generics is 'primitive' and is 'our most basic and immediate means of obtaining information about categories' (2007, pp. 383-384). The mechanism forms generalisations in three ways that correspond to different types of generics. First, the mechanism makes 'neutral' generalisations that rely on statistical information about the possession of the trait by members of the kind: 'Scots drink Iron Brew' or 'Cars have radios' are true only because a majority of members of the kind possess the trait. Second, generics can be formed in the absence of evidence that the majority of members of the kind have the property if the property is considered to be characteristic of the kind. For example, reproduction is a characteristic of animal kinds in general and egg-laying is a characteristic of the particular animal kind 'duck'. Speakers assent to 'ducks lay eggs' despite the fact that only female ducks lay eggs (Leslie 2008, pp. 32-33). ${ }^{24}$

For purposes of the argument here, I focus on the third category, 'striking property generics', such as 'Sharks attack surfers' or 'Blacks are violent'. These attribute 'harmful, dangerous, or appalling properties to the kind ... the sort of property of which one would be well served to be forewarned' (Leslie 2008, p. 15). Like characteristic generics, their truth does not require a majority of 
members of the kind to exemplify the property. Indeed, we often assent to striking property generics even when there are only a small number of instances of a kind that possess the property. Less than $1 \%$ of mosquitoes carry the West Nile virus yet we take the generic 'Mosquitoes carry the West Nile virus' to be true; only a small number of sharks have attacked surfers, yet we take 'Sharks attack surfers' to be true, and so forth. Leslie argues that the formation of these generics is due to an 'unreflective' and 'pervasive' cognitive tendency to make generalisations about both the natural and the social world (2017, pp. 398-403). She proposes that when we encounter harmful or appalling properties, 'we seek to generalize the property to a kind whose members are disposed to manifest it' and that this requires essentialising the kind-that is, tacitly positing 'that there is some hidden, nonobvious, and persistent property or underlying nature shared by members of that kind that causally grounds their common properties and dispositions' (2017, p. 405). Leslie's proposal about the truth conditions of striking property generics is that they are true if and only if there is at least one instance of the kind that has the property and the kind is an essentialised kind, i.e. members of the kind are disposed by nature to have the property (2017, p. 404). Therefore, the generic 'Sharks attack surfers' is true because some sharks have attacked surfers and all sharks have a tendency to attack surfers due to their underlying nature.

It is especially important to note that Leslie's psychological picture applies to the social world. There are numerous historical examples of the formation of striking property generics in social contexts (Leslie 2017, pp. 398-403). As Leslie notes, "the "introduction" conditions ... are very undemanding when it comes to how prevalent the property has to be in the general population' $(2017$, p. 397). People regularly assent to striking property generics about social kinds-'Blacks are criminals' or 'Muslims are terrorists'-because of a primitive cognitive tendency to form striking property generics when confronted by harmful, dangerous properties. The undemanding introduction conditions are easily satisfied in racist background conditions, which already include implicit biases and historical tropes that connect minorities with criminality. ${ }^{25}$ Even the presence of exceptions will not block the formation of these generics. Leslie argues that the cognitive mechanism of generalisation is unaffected by the simple fact of 'negative counterinstances' (there are many Muslims who are not terrorists) and will be undermined only when the members of the kind who are exceptions display a 'positive alternative property' $(2007$, p. 385$)$. It is plausible that in societies that are both racist and highly segregated (in which for instance members of the majority rarely encounter Muslims), there will be little evidence available to the majority that members of the minority have positive alternative properties. ${ }^{26}$ Hence, the lack of sufficient available evidence about the positive traits of minority groups will be an important additional factor in the formation of (false) striking property generics.

I now draw on both aspects of Leslie's account-the psychology and the semantics - to argue that racial profiling is inconsistent with recognition respect. Consider first the psychological picture. When a racial profiling policy is introduced, there will be little cognitive resistance to seeing it as anything other than 
tacitly conveying a striking property generic. Although it purports to be a neutral crime-reduction strategy based on statistics, both the police who implement profiling and the targeted person or group will be hard-pressed to differentiate the statistical rationale from a generic that attributes criminality. An especially important aspect of Leslie's psychological picture is her observation that the introduction conditions of striking property generics are undemanding. In racist social conditions, a racial profiling policy will itself contribute to the introduction conditions because it will reinforce the already-present association between the profiled group and the to-be-avoided property. As Adam Omar Hosein points out, a claim by the criminal justice system, that profiling is a neutral crime-reduction policy because it relies on statistical evidence about crime rates, could reasonably be treated as a sham $(2018$, p. ell) - especially because the state could have selected an alternative crime-reduction strategy, such as randomised screening, that genuinely is morally neutral. ${ }^{27}$

Suppose I am right that racial profiling tacitly conveys striking property generics due to the cognitive disposition to form these generics in precisely the circumstances in which racial profiling operates. Leslie's conception of the semantics of these generics helps to shows that they, and hence racial profiling, violate recognition respect. The crucial feature of striking-property generics is that they pick out essentialised kinds and attribute a disposition to have the negative property (i.e. criminality, being a terrorist) to the nature of each member of the kind. This is inconsistent with recognition respect because it is a moral mistake about the personhood of each profiled person (as well as about members of the whole group). Notice that, although social conditions might be required to trigger the formation of striking-property generics, once they are formed, they provide the objective basis of the wrongness of racial profiling. That is, the wrongness of profiling does not depend on the contingent effects of such generics. Notice, too, that the disrespect argument does not have to rely on Leslie's (perhaps controversial) analysis of the truth conditions of generics. Sally Haslanger develops a parallel account that relies on pragmatics rather than semantics. She claims that generics like 'Blacks are criminals' implicate, rather than assert, false claims about natures:

There is a set of problematic generics that introduce implicitly into the common ground a proposition about how ... blacks are by nature or intrinsically. These cases are problematic because the proposition introduced is false.

(Haslanger 2011, p. 193)

The advantage of employing Haslanger's approach is that it is compatible with saying that problematic striking-property generics are sometimes true. Suppose the criminal justice system insists that it is relying on true statistical generalisations about Muslims being more likely to engage in terrorism or Blacks being more likely to be drug dealers. The pragmatic implicature identified by Haslanger is compatible with the truth of these claims. Nevertheless, because the implicature that is introduced by a racial profiling policy makes false claims about the 
nature and personhood of Muslims or Black people, the policy is inconsistent with recognition respect. ${ }^{28}$

Let's now turn to a second argument that racial profiling is inconsistent with recognition respect. Recall Eidelson's conclusion that the wrongness of racial profiling is due to its contingent effects, namely its contribution to racist social meanings. He claims that therefore racial profiling is only conventionally disrespectful; it is not a mistake of practical deliberation but rather expresses a social meaning that is disrespectful in a racist cultural context. (In the same way, failing to shake someone's hand might express disrespect in a culture, yet not correspond to a failure of appropriate practical deliberation about a person's normative status.) Eidelson does acknowledge, however, that indifference to and disregard for people's normative standing will constitute recognition disrespect: 'one can act disrespectfully by unwittingly failing to integrate someone's standing as a person appropriately in one's practical deliberation' $(2015$, p. 86). I suggest that introducing de jure profiling or permitting de facto profiling corresponds precisely to this kind of disregard. Indifference on the part of the state towards the effect of policies in contributing to racist social meanings is itself equivalent to disregarding the moral standing of such minority groups. This is especially true when these racist social meanings are, as I have just argued, indistinguishable from problematic striking-property generics that attribute criminality by nature to members of the profiled group. This disregard on the part of the state in specific police-citizen encounters, or more generally, turns a violation of conventional disrespect into a violation of basic recognition disrespect. As Darwall puts it, 'One is not free, from a moral point of view, to act as one pleases in matters which concern something which is an appropriate object of moral recognition respect' (1977, p. 40).

Finally, there is another potential disrespect argument based on the second form of respect identified by Darwall, appraisal respect, which is an attitude of 'positive appraisal of a person or his qualities' (1977, p. 39). Unlike recognition disrespect, appraisal disrespect is morally wrong only when it is unjustified. If someone actually has an evil character, it will be justified to negatively appraise his character. However, most people who are profiled are innocent; they are subjected to policies such as stop-and-frisk purely on the basis of their group membership or social identity. This relies neither on evidence from their own behaviour that they have engaged in criminal activity, nor even on individualised evidence about the perpetrator of the crime being investigated (that is, on a suspect description).

Moreover, if I am right about the operation of striking-property generics in racial profiling, profiling conveys the generalisation that members of profiled groups are disposed to criminality by nature. It is obvious that this is a false and unjustified appraisal of their characters. In addition, a study by Leslie and her colleagues suggests that, once people assent to striking-property generics, they think that arbitrarily selected members of the kind are not only disposed by nature to have the relevant property but actually have it (Leslie 2017, pp. 397-398; Khemlani, Leslie, \& Glucksberg 2012). This finding is a plausible explanation of why innocent people who are profiled experience it as disrespectful. They rightly 
suspect that racial profiling conveys the unjustified assessment that they are actually a criminal. For these reasons, it is plausible to conclude that racial profiling conveys an attitude of unjustified appraisal disrespect in addition to constituting recognition disrespect.

\subsection{Conclusion}

This chapter has made a case for the moral impermissibility of racial profiling. I employed considerations about legitimacy from procedural justice theory to undermine arguments for the rationality of profiling. I also noted that processrelated harms, such as diminished self-respect, reinforce the consequentialist arguments against profiling. The main argument of the paper developed a nonconsequentialist objection to profiling. Being subjected to profiling, or being a member of a profiled group, generates the feeling that the criminal justice system is unfair and disrespectful. I argued that the feeling that it is disrespectful is justified; profiling actually does constitute disrespectful treatment. The argument does not imply, however, that racial profiling in all contexts is disrespectful, or that racial profiling that is disrespectful is always impermissible. For instance, racial profiling with the aim of promoting diversity in jury selection (Lever 2011), will not be based on false striking-property generics or negative appraisals of people's characters and hence may well be morally unobjectionable.

Further, although I have not spelled out the implications of my argument for the obligations of the state, this chapter has shown only that de jure and de facto racial profiling violates a prima facie state obligation to treat people with respect. I have not shown that this obligation is absolute or always overriding, so it is possible that in some rare and unusual situations, the obligation will not obtain all things considered. In all standard situations, however, racial profiling will be morally impermissible.

\section{Notes}

1 This chapter has benefited from very helpful comments from Catriona Mackenzie, Denise Meyerson, and Therese MacDermott, as well as from members of audiences at Macquarie University, the University of Glasgow, and Western University, especially Sarah Armstrong, Andrew Botterell, Carolyn McLeod, and Rob Stainton.

2 A note on the term 'race': although there is philosophical debate about the term 'race', I assume here what I take to be the consensus view that there no such thing as race as an intrinsic biological property of individuals. The term 'race' as I use it here is shorthand for perceived race or assumed race.

3 For a definition and discussion of microaggressions, see McTernan (2018).

4 Boonin clarifies the distinction between the rationality and morality arguments. Profiling can be 'an effective public policy, and so in that sense a rational one' (2011, p. 308). However, even if it is rational or 'instrumentally useful', [it] 'could be unethical nonetheless and would merit rejection for that reason' (2011, p. 308).

5 Eidelson makes a similar point under what he calls the 'Narrow Harm Argument'. For example, he says that opponents of racial profiling 'might do better to emphasize simply how badly it hurts innocent people relative to the benefits it yields' (2015, p. 206). 
6 Risse and Zeckhauser (2004) and Boonin (2011) both argue that profiling does not constitute a rights-violation, so there is no non-consequentialist objection to profiling. Lever (2005), Lippert-Rasmussen (2013) and Eidelson (2015) all argue against profiling on consequentialist grounds. As far as I know, Hosein's (2018) defence of the position that racial profiling is an injustice is the only example in the literature of a non-consequentialist critique.

7 Hosein points out that these statistical correlations can be challenged (Hosein 2018 , p. e4).

8 I cannot do justice here to Boonin's extensive discussion of Harris's hit rates argument (2011, pp. 314-323).

9 Risse and Zeckhauser's expressive argument is extensively critiqued by Eidelson (2015, pp. 203-206). I have benefited immensely from his careful discussion of their view.

10 Boonin offers a second objection based on knowledge, which I do not address here (2011, p. 338).

11 Some authors argue that these kinds of negative consequences are due to police abuses in executing racial profiling rather than racial profiling itself (e.g. Risse and Zeckhauser 2004 discuss the potential abuses that occur in the context of profiling). It is true that we should not conflate the negative consequences of police abuse with the negative consequences of profiling. However, it seems undeniable that profiling will lead to there being a greater number of encounters between police and minority groups than between police and whites. This in itself could lead to the consequences mentioned here, even if there is no police abuse in these encounters.

12 Meyerson is referring in particular to work by Tyler \& Blader (2000).

13 See also Hosein's recent argument that profiled minority groups have a 'reasonable sense of inferior political status' (Hosein 2018).

$14 \mathrm{My}$ discussion does not cover all the consequentialist arguments against profiling in the literature, e.g. Kasper Lippert-Rasmussen (2013, Chapter 7) proposes a critique of racial profiling drawing on G.A. Cohen's 'interpersonal test'.

15 For a more detailed discussion of the three approaches to characterising disrespectful treatment, see Beeghly (2018).

16 This law was challenged in the notorious United States Supreme Court case of Plessy o Ferguson 163 U.S. 537 (1896). Homer Plessy, who was seven-eighths white (only his great grandmother was Black), had sat in a white car on a train.

17 Note that this understanding of 'expressive' is different from that of Risse and Zeckhauser (2004), discussed above.

18 Eidelson also develops a 'Narrow Harm Argument' against racial profiling; see footnote 5 .

19 Although I cannot pursue this line of thought here, I do not wish to imply that the use of suspect descriptions is never morally problematic, even if it is less obviously problematic than racial profiling.

20 The Ontario Report points out that, in general, people risk being profiled when they are deemed to be doing something 'out of place' (OHRC 2017, p. 23).

21 Annabelle Lever considers this question using a hypothetical statistical correlation between being white and being a drunk driver $(2017$, p. 430).

22 There are alternative accounts of generics in the literature. See, e.g., the discussion in Haslanger (2011).

23 Most of the examples come from Leslie's work or are variations on her examples. I thank Fiona Macpherson for the 'Scots drink Iron Brew' example.

24 See Haslanger (2011, pp. 184-185) for further discussion. Haslanger suggests that there are some generics that do not fit neatly into Leslie's taxonomy. Stereotypes such as 'Women are submissive' seem at first to be social generics that are taken to be true because they attribute a characteristic or typical trait to 
the kind (i.e. they are analogous to 'Ducks lay eggs'). However, Leslie's analysis implies that speakers should not assent to 'Women are submissive' (as a characteristic generic) because there are numerous women who have alternative positive traits (see Leslie 2007, p. 385, for an explanation). Perhaps then these generics are making normative not descriptive claims, such as that good examples of the kind 'women' are submissive (Haslanger 2011, p. 200). As Haslanger points out 'Women are submissive' could also be a majority generic: if so, it would be true only if most women are in fact submissive.

25 I am grateful to members of the audience at Western University, especially Carolyn McLeod, for insisting on the role of implicit biases and other aspects of structural oppression in this argument.

26 Jennifer Saul points out that the generic 'Muslims are terrorists' is unlikely to be taken to be true in a majority Muslim society (Saul 2017).

27 Eidelson himself points to the difficulty of keeping the statistical rationale for profiling separate from an attribution of criminality by nature: '[T]he distinction between a trait's making one (epistemically) more likely to be a drug courier, and its actually making one more likely to be a drug courier, is predictably lost on many people ... adopting a profiling policy may encourage the familiar and hurtful biases that attribute differences in rates of crime to deep-seated differences internal to the people involved, rather than to their social context' (Eidelson 2015, p. 210).

28 In a recent paper, Saul critiques the arguments due to Leslie and Haslanger that generics are 'especially pernicious' (Saul 2017). She argues that the focus on generics is misguided, and that the real problem is statements (whether generic or not) that have implicatures of irrelevant associations, e.g. between Blackness and criminality. Unfortunately, I cannot do justice to Saul's argument in the space available here. I note, however, that it would be difficult to claim that the associations implicit in racial profiling policies between rates of criminality and certain social groups are irrelevant. It is precisely because these associations are (putatively) based on genuine statistical correlations and deemed relevant that profiling is thought to be a worthwhile crime-reduction policy.

\section{References}

Anderson, ES \& Pildes, RH 2000, 'Expressive theories of law: a general restatement', University of Pennsylvania Law Review, vol. 148, no. 5, pp. 1503-1575.

Beeghly, E 2018, 'Discrimination and disrespect', in K Lippert-Rasmussen (ed.), The Routledge handbook of the ethics of discrimination, Routledge, Abingdon-onThames, UK, pp. 83-96.

Boonin, D 2011, Should race matter?: unusual answers to the usual questions, Cambridge University Press, New York.

Darwall, SL 1977, 'Two kinds of respect', Ethics, vol. 88, no. 1, pp. 36-49.

Eidelson, B 2015, Discrimination and disrespect, Oxford University Press, Oxford.

Harris, DA 2002, Profiles in injustice. Why racial profiling cannot work, New Press, New York.

Harris, DA 2017, 'Racial profiling', in E Luna (ed.) Reforming criminal justice volume 2: policing (A Report by the Academy for Justice, Arizona State University), pp. 117-152.

Haslanger, S 2011, 'Ideology, generics, and common ground', in C Witt (ed.), Feminist metaphysics. Explorations in the ontology of sex, gender and the self, Springer, Netherlands, pp. 179-207. 
Hellman, D 2008, When is discrimination wrong?, Harvard University Press, Cambridge.

Hosein, AO 2018, 'Racial profiling and a reasonable sense of inferior political status', Journal of Political Philosophy, vol. 26, no. 3, pp. el-e20.

Khaitan, T 2018, 'Indirect discrimination', in K Lippert-Rasmussen (ed.), The Routledge handbook of the ethics of discrimination, Routledge, Abingdon-onThames, UK, pp. 30-41.

Khemlani, S, Leslie SJ \& Glucksberg, S 2012, 'Inferences about members of kinds: the generics hypothesis', Language and Cognitive Processes, vol. xxvii, pp. 887-900.

Leslie, SJ 2007, 'Generics and the structure of the mind', Philosophical Perspectives, vol. 21 , no. 1, pp. 375-403.

Leslie, SJ 2008, 'Generics: cognition and acquisition', Philosophical Review, vol. 117, no. 1, pp. 1-47.

Leslie, SJ 2017, 'The original sin of cognition: fear, prejudice and generalization', Journal of Philosophy, vol. 114, no. 8, pp. 1-29.

Lever, A 2005, 'Why racial profiling is hard to justify: a response to Risse and Zeckhauser', Philosophy and Public Affairs, vol. 33, no. 1, pp. 94-110.

Lever, A 2011, 'Treating people as equals: ethical objections to racial profiling and the composition of juries', The Journal of Ethics, vol. 15, no. 1/2, pp. 61-78.

Lever, A 2017, 'Racial profiling and the philosophy of race', in N Zack (ed), The Oxford handbook of philosophy and race, Oxford University Press, Oxford, pp. $425-435$.

Lippert-Rasmussen, K 2013, Born free and equal: philosophical inquiry into the nature of discrimination, Oxford University Press, Oxford.

McTernan, E 2018, 'Microaggressions, equality, and social practices', Journal of Political Philosophy, vol. 26, no. 3, pp. 261-281.

Meyerson, D 2015, 'The moral justification for the right to make full answer and defence', Oxford Journal of Legal Studies, vol. 35, no. 2 pp. 237-265.

Ontario Human Rights Commission (OHRC) 2017, Under suspicion: research and consultation report on racial profiling in Ontario, viewed 15 December 2019. Available at http://www.ohrc.on.ca/en/under-suspicion-research-and-consul tation-report-racial-profiling-ontario

Risse, M \& Zeckhauser, R 2004, 'Racial profiling', Philosophy and Public Affairs, vol. 32 , no. 2 , pp. 131-170.

Saul, JM 2017, 'Are generics especially pernicious?', Inquiry - An Interdisciplinary Journal of Philosophy, published online 13 February 2017. doi: 10.1080/0020174X. 2017.1285995

Scanlon, TM 1998, What we owe to each other, Harvard University Press, Cambridge.

Torres, J 2015, 'Race/ethnicity and stop-and-frisk: past, present, future', Sociology Compass vol. 9, no. 11, pp. 931-939.

Trinkner, R, Tyler, TR \& Jackson, J 2018, 'Bounded authority: expanding "appropriate" police behavior beyond procedural justice', Law and Human Behavior', vol. 42, no. 3, pp. 280-293.

Tyler, TR 1990, Why people obey the law, Princeton University Press, Princeton.

Tyler, TR 2006, 'Psychological perspectives on legitimacy and legitimation', Annual Review of Psychology, vol. 57, no. 1, pp. 375-400.

Tyler, TR \& Blader, S L 2000, Cooperation in groups: procedural justice, social identity, and behavioral engagement, Psychology Press, Philadelphia. 


\title{
11 Administrative discretion and governing relationships Situating procedural fairness
}

\author{
Kristen Rundle
}

\subsection{Introduction ${ }^{1}$}

When 'procedural fairness', 'procedural justice', or 'procedural due process' have been singled out as sites of theoretical inquiry, efforts have primarily been directed to identifying the value of observing this cardinal demand of fair treatment within decision-making processes. ${ }^{2}$ Among administrative law scholars, responses to this question have especially emphasised the intrinsic value of rules of procedural fairness to honouring human dignity, as well as the consequential value of such observance to the efficiency of government decision-making. ${ }^{3}$ These responses have largely tracked the more general effort of philosophers to illuminate the contribution of procedural fairness to 'dignitarian', 'utilitarian', or other 'outcome-based' values across different legal contexts, with particular emphasis on the instrumental value of fair procedures to the realisation of substantive legal rights. ${ }^{4}$

The recent turn towards 'relational' approaches to procedural justice signals a new philosophical perspective among these established accounts of the value of procedurally fair treatment within decision-making processes. Drawing upon research in social psychology, relational theories seek to explain and justify the intrinsic value of procedures in terms of how they enhance the quality of interpersonal interactions with individuals, groups and institutions (Meyerson \& Mackenzie 2018, p. 6). Yet while the perspective might be new, relational theories share with established accounts a common background assumption: namely, that the legal form within which procedural justice carries its relevant value is an order of rules. This default to rules and the adjudicative processes that enliven them is hardly misguided. Adjudication based on the application of rules is 'the characteristically legal mode' across criminal, civil and administrative decision-making processes (Galligan 1996, p. 24). Still, the virtually exclusive focus on rule-based orders within inquiry into the value of procedural fairness represents a significant limitation on the scope of analysis, and joins a wider tendency to assume the presence of rule-based orders as the focus of legal theoretical inquiry generally.

My aim in this chapter is to turn attention to a different legal formadministrative discretion - with a view to addressing its relative neglect by scholars of procedural justice. Though my approach is distinctly relational in orientation, 
my goal is not to offer a relational theory of procedural fairness with justificatory or explanatory aims. Rather, my aim is to illuminate the significance of the relational dynamics carried by procedural fairness to the possibility of situating administrative discretion within a condition of the rule of law. Building on other work in which I have illuminated the centrality of procedure to an understanding of the rule of law as a practice of framing governing relationships by the authority of law, the argument I develop can be summarised as follows.

An administrative discretion is a distinctive legal form in which its repository is 'free to make a choice between possible courses of action or inaction' (Davis 1969, p. 4). This core feature of administrative discretion carries important implications for the relationship between repository and subject that is convened and sustained through it. Above all, it causes the relational dynamics between repository and subject to be highly unpredictable. This unpredictability is in turn likely to be amplified in relation to those aspects of administrative discretion that address larger political or policy goals - such as considerations of the 'public interest' - as contrasted with those aspects which attend solely to the subject's individual circumstances.

Acknowledging these features of administrative discretion invites consideration of the special contribution that observance of procedural fairness might make to correcting this relational unpredictability, and by extension, to situating administrative discretion within the relational conditions necessary for the rule of law. Examined from this wider perspective, the relational dynamics sustained by procedural fairness carry a significance beyond their contribution to treating that person fairly or with dignity within a decision-making process, important though that might be. On the account I develop here, these relational dynamics bear directly upon the fundamental question of whether what is constituted by an exercise of administrative discretion is recognisable as a governing relationship framed by the authority of law.

I begin in Section 11.2 by setting out the resources of legal theory from which I have developed my account of the importance of procedure within an understanding of the rule of law as a practice of framing governing relationships by the authority of law. These are drawn from insights of Lon Fuller's jurisprudence of the 'internal morality of law' (Fuller 1969), and in particular from my interpretation of that jurisprudence as yielding a conception of the rule of law in which the quality of governing relationships between those who possess authority and those who are subject to it is central. Relevantly for present purposes, I argue that the demands Fuller places on these governing relationships hold irrespective of the characteristics of the legal form through which they are carried. It is this feature of my account that opens up consideration of governing relationships that are not framed by the model of an order of rules to which thinking about the rule of law typically attaches, and which therefore makes it ripe for application to the phenomenon of administrative discretion.

My task in Sections 11.3 and 11.4 is to lay the groundwork for extending these relational demands and the procedural conditions necessary to support them to 


\section{Kristen Rundle}

administrative discretion. This requires consideration of how procedural fairness (Section 11.3) and administrative discretion (Section 11.4) need to be theorised if the relational significance of their interplay is to be brought to the fore. As I emphasise in Section 11.4, of special importance to my analysis is that aspect of administrative discretion in which the governing relationship between repository and subject is shaped by political or policy considerations beyond the individual circumstances of the subject, and which invites its exercise to orient towards more unilateral than relational dynamics.

In Section 11.5 I make the case for why the interplay between procedural fairness and administrative discretion is so significant: namely, because of the relational correction that procedural fairness supplies to the stark asymmetry between repository and subject that is a defining feature of administrative discretion. In materially altering the experience of the subject within the particular governing relationship that is convened through the possession and exercise of administrative discretion, I argue that this correction goes some way towards locating that relationship within the relational conditions necessary for the rule of law. I then turn in Section 11.6 to situate my analysis within other efforts to illuminate the promise of relational approaches to administrative law, before offering some thoughts on its significance to practice by way of conclusion in Section 11.7.

\subsection{The demands of governing relationships framed by the authority of law: situating the importance of procedure}

Elsewhere (Rundle 2019a), I have developed an account of the demands of the rule of law in terms of prescriptions to be imposed on governing relationships framed by the authority of law. The place of procedure within this account is central. As the primary vehicle for relational contact between legal officials and legal subjects, procedures, processes, and institutional forms provide the channels through which the authority of law directly touches upon those subject to it. Accordingly, how a repository of legally constituted authority engages with the subject of his or her authority within those procedures, processes, and institutional forms is of foundational significance to what is required to convene and sustain a condition of lawful authority rather than one of mere power.

I have developed this argument from elements of Lon Fuller's jurisprudence of the 'internal morality of law' (1969, pp. 33-38). Fuller's point in introducing the idea that a condition of law implicates an 'internal morality' was to direct attention to how governing through law requires practices, conditions, and commitments conducive to that end. Fuller conveyed these lessons through his famous tale of a king, Rex, who failed in eight ways to make law. By exemplifying how not to create and administer a legal system, Fuller's account of Rex's eight failures was designed to invite reflection on the constitutive demands of the enterprise that he had undertaken but failed to achieve. The eight principles of Fuller's 'internal morality of law' are thus understood in terms of the need for law to be (1) general, (2) publicly promulgated, (3) non-retroactive, (4) sufficiently 
clear, (5) non-contradictory, (6) possible to comply with, (7) relatively constant through time, and (8) that there be congruence between official action and declared rule.

In my reading of Fuller I have emphasised the irretrievably relational commitments that he sought to convey through these eight principles. This is clear from his analysis of the 'reciprocity' between 'government and citizen' that is built into the structure of governing through enacted rules, and how this causes his principles of the 'internal morality of law' to entail 'a relationship with persons generally' (Fuller 1969, pp. 39-40). But I have equally emphasised the importance of grasping the context of these relational demands in Fuller's jurisprudence: namely, his concern to articulate the conditions necessary for the authority of law. Fuller speaks of these conditions in terms of the mutual 'fidelity to law' in the part of both legal officials and legal subjects that must be sustained if legal order is to be achieved. The subject's acceptance of the authority of the lawgiver or other legal official has a special place within this picture, for the reason that legal officials ultimately take their authority to govern from that acceptance. Thus, the lawgiver must enter into a relationship of 'reciprocity' with the subject to secure her fidelity to law, otherwise 'nothing will be left on which to ground the citizen's duty to observe the lawgiver's rules' (1969, p. 40). Fidelity to law on the part of (putative) legal subjects is to be earned through, and only through, relational conditions between legal officials and legal subjects that are capable of generating and sustaining that fidelity.

The burden that Fuller's jurisprudence places on legal officials if they are to be regarded as participating in a condition of lawful authority as opposed to one of mere power is clearly a demanding one. He described these burdens as belonging to the 'role morality' that attaches to being a legal official. ${ }^{5}$ Central to the fulfilment of this role morality is appropriate regard for and respect towards those with whom the legal official seeks to be in a relationship of authority. ${ }^{6}$ This is why Fuller also provided an account of what it means to be a subject of law as opposed to mere power in his reflections on 'the view of man implicit in the internal morality of law' (1969, p. 162). To embark on the enterprise of subjecting human conduct to the governance of rules, Fuller argued, involves of necessity 'a commitment to the view that man is, or can become, a responsible agent, capable of following rules and answerable for his defaults' (1969, p. 162).

On their face, these reflections on 'responsible agency' are directed to the capacities required of the legal subject in order to participate in an order of rules. The emphasis is on the kind of agency that is presupposed by legal rules. But Fuller also went on to explain the important difference between engaging with the subject through the medium of rules and merely acting upon him. To do the latter, he argued, was not just to convey indifference to the subject's 'powers of self-determination', but to negate the reciprocal dynamics upon which the achievement of legal order itself depends (see Rundle 2019a, pp. 24-25; 2014, pp. 220-225). The point of interest for present purposes is what this suggests about the kind of agency that is constituted by participation in a condition of law as opposed to one in which the putative subject is merely acted upon. I have 


\section{6}

called this species of agency 'legal agency': ${ }^{7}$ that which materialises and is made visible when a subject participates within a condition of law.

The significance of procedure to Fuller's jurisprudence enters here, and, I have argued, is much deeper and more profound than what has typically been indicated in the description (initially articulated, if cautiously, by Fuller himself) of the eight principles of the 'internal morality of law' as a kind of 'procedural natural law' (Fuller 1969, pp. 96-97). ${ }^{8}$ When Fuller's reflections on the conception of the person to which the demands of the internal morality of law attach are situated within his overarching concern for what is required to sustain a condition of lawful authority as opposed to one in which subjects are merely acted upon, the significance of procedures and institutional channels capable of supporting the possibility of legal agency becomes apparent. The dynamics between legal official and legal subject through which a relationship of lawful authority is given concrete expression must be not just respectful, but productive, of the kind of agency that supports participation in a governing relationship framed by the authority of law (see also Rundle 2012, p. 42). In Fuller's jurisprudence it cannot be otherwise. What it takes to bring a condition of lawful authority into existence is equally what it must take to keep that condition in existence.

This last point is critical to the analysis of the significance of procedural fairness in circumstances of administrative discretion that I develop in the pages to follow. Most crucially, the requirement that the relational conditions that attach to an instance of authority in its concrete expression must be continuous with the relational conditions that generate the authority of legal order in the first place is a general demand. As such, it need not and should not be limited to the rulebased orders with which Fuller's jurisprudence has been explicitly if not exclusively associated so far (see Rundle 2019a, pp. 32-36), and which occupy the primary focus of legal theory generally. Rather, on my reading the demands of Fuller's 'internal morality of law' attach to all governing relationships framed by the authority of law. Indeed, observance of these relational demands might ultimately be more critical in the context of modalities of contemporary government that are not modelled on an order of rules, as is the case for administrative discretion. ${ }^{9}$ I therefore turn now to consider how we might need to think about procedural fairness and administrative discretion, respectively, to develop this analysis.

\subsection{Procedural fairness: mapping the territory}

At their essence, the terms 'procedural fairness', 'procedural justice', and 'procedural due process' each speak to the idea that a person subject to the decision of another should be provided with a fair opportunity to advance their case before that decision-maker. While particular emphasis might historically have been given to the significance of this demand of fair treatment in the face of adverse allegations, in contemporary administrative law the obligation to afford procedural fairness is thought to apply to any exercise of power apt to affect an individual's interests, broadly understood. To establish a denial of procedural fairness as a matter of law, therefore, the issue for determination will be whether the 
aggrieved person has suffered some material encroachment on a fair opportunity to advance his or her case before the decision-maker. ${ }^{10}$

I explained in Section 11.1 that until the recent emergence of 'relational' approaches to procedural fairness, philosophers have gravitated towards two broad sites of analysis when seeking to identify the 'value' of the provision of procedural fairness in decision-making contexts: 'dignitarian' and 'utilitarian' or other 'instrumental' or outcome-based accounts. A wide range of arguments falls within these broad categories. ${ }^{11}$ The efforts of administrative law scholars to explain the value of procedural fairness have borrowed directly from these philosophical debates, giving primary emphasis to 'dignitarian' and 'utilitarian' justifications.

Those who favour the dignitarian view emphasise the enduring appeal of its evident concern for persons. ${ }^{12}$ For example, Jerry Mashaw, the leading American administrative law scholar and proponent of the dignitarian view, has argued that procedural 'due process' is important precisely because it respects 'values inherent in or intrinsic to our common humanity-values such as autonomy, self-respect, or equality' (1985, p. 171). ${ }^{13}$ By contrast, those who promote 'utilitarian' perspectives see the observance of the rules of procedural fairness as consequentially valuable for their contribution to more efficient decision-making processes and better decisional outcomes. The appeal of such perspectives thus lies in their apparently more concrete and measurable orientation to results. ${ }^{14}$ Though often pitted against each other, these two standard justifications for procedural fairness in administrative law need not always be in opposition. For instance, if the opportunity to advance one's case is led by utilitarian considerations, that opportunity might still secure the 'side-effect' of respecting the dignity of the subject, with all the benefits that proponents of the dignitarian view have emphasised so far. Be that as it may, in my own work I have insisted that something important is overlooked in these analyses.

This missing element is attention to the particular setting in which the demands of procedural fairness arise in administrative law: namely, in the context of one person possessing authority to exercise administrative power over another. When this context is brought into view, we can see that at stake in different ways of explaining the value, rationale, or justification for the rules of procedural fairness; are different ways of prioritising the perspective and experience of the repository and subject of that exercise of authority respectively and, crucially, the relationship between them (see Rundle 2016, pp. 164-167). Although there might be nothing intrinsic to the utilitarian view that necessarily excludes orientation to the perspective or experience of the subject within this relationship, there is equally nothing intrinsic to the utilitarian view that orients towards that perspective or experience. Fundamentally, utilitarian perspectives are directed to the position of the repository of authority and the wider institutional frame within which that repository operates. They are not, or not primarily, directed to the position and experience of the subject who ultimately has no power to direct the outcome of the repository's exercise of authority beyond the influence afforded to her in the processes leading to it. Only dignitarian accounts can support an understanding 


\section{8}

of the exercise of administrative authority as a relationship between those who possess government power and those who are subject to it. Dignitarian justifications for the demands of procedural fairness must therefore take priority over utilitarian justifications not merely for their own sake, but for how they lend support to the empowerment of the subject necessary for the relational conditions of authority itself. ${ }^{15}$

\subsection{Administrative discretion: mapping the territory}

Echoes of the wider legal theory commitments outlined in Section 11.2 will be discernible in the argument just outlined. In the work in which it was developed, my interest lay with the place of procedural fairness within circumstances of administrative power generally. I did not single out administrative discretion as potentially demanding separate treatment, as I propose to do here.

The reason why administrative discretion may demand such separate or additional treatment is because the form of legal relation constituted by its possession and exercise is materially different from that which is constituted under the model of an order of rules that ordinarily lies in the background of discussions of procedural fairness. Under an order of rules, the role of the lawgiver is to articulate the relevant rule(s), the role of the law-applier is to apply those rules to the circumstances of the legal subject, and the role of the legal subject is to 'obey' or otherwise to cooperate with their normative demands. Contestation around processes of rule-application typically concerns conflicting interpretations of the rules, or complaints about the fairness of their application in the individual case. But the important point for present purposes is that the legal relation itself is framed by an order of rules to which rule-applier and rule-subject alike are mutually subordinate. Asymmetries will undoubtedly still be present within this rule-governed relationship. These will moreover stand to be amplified by the fact that some discretion will typically be vested in the rule-applier to determine precisely how the rules will be applied. Still, even accounting for such asymmetries, it remains the case that the legal relationship itself will be framed by the rules, that these rules will be known in advance, and that any discretion as to their application will be subject to some degree of contestation.

The form of legal relation constituted by the possession and exercise of administrative discretion is different. As earlier noted, when a discretion is reposed in an administrative official, it leaves that official 'free to make a choice between possible courses of action or inaction' (Davis 1969, p. 4). This defining feature of freedom of choice on the part of the repository, whatever its degree, produces a different form of legal relation to that which arises when an exercise of power is framed by rules. This legal relation still has boundaries, in the sense that it is framed and therefore confined by the boundaries of the statutory provision through which a discretion is reposed. The discretion might also be structured through the statutory imposition of certain requirements for its exercise, such as mandating consideration of particular facts about the individual, or reference to specified public policy priorities or simply the 'public interest'. 
These ways in which administrative discretions are confined and structured are undoubtedly important to the character and quality of the governing relationships between repository and subject that come to be convened through them. Nonetheless, the point to highlight for the purpose of the present analysis is that neither of these ultimately contingent features of an administrative discretion alters the relational implications that necessarily follow from the feature of choice between possible courses of action that belongs to the repository of the discretion and the repository alone. In short, the element of mutual subordination characteristic of an order of rules is starkly absent in the case of administrative discretion.

This key difference in the form of legal relation constituted by rule-based and discretionary administrative orders, respectively, has received an-at mostimplicit treatment in the literature on procedural justice so far. Two key studies, however, have yielded arguments and insights that provide important support for those that I wish to develop and defend here. The first is the seminal effort of the mid-twentieth century American administrative law scholar Kenneth Culp Davis to situate administrative discretion at the centre of administrative law inquiry. The second is the socio-legal study of due process in the context of administrative procedures undertaken by Dennis Galligan (1996).

In Discretionary Justice: A Preliminary Inquiry (1969) Davis sought to address the problem of individual injustice that can result from either too much or insufficiently limited discretionary power. In pursuing this inquiry Davis highlighted some key theoretical commitments that had led to the marginalisation of administrative discretion as a site of legal inquiry to that point. In particular, Davis emphasised the extent to which this marginalisation had been encouraged by what he described as 'extravagant' versions of the rule of law according to which enacted rules are presented as the only legal form, and the courts the only supervisory institutions, through which a condition of the rule of law can be maintained (pp. 28-41). ${ }^{16}$ On this understanding administrative discretion essentially embodies and gives legal form to arbitrary power: the very antithesis of the rule of law. To Davis's eyes, this 'extravagant' version of the rule of law not only presented a descriptively inaccurate account of modern government and the centrality of the administrative state within it, but also operated to limit wider theoretical inquiry into conditions necessary for the rule of law (pp. 29-30).

It is important to emphasise that Davis was not a defender of discretion per se. Indeed, he thought that 'a good deal of discretion is illegal or of questionable legality' (p. 4). His point was simply that not all administrative discretion is necessarily at odds with a condition of the rule of law. Thus, while arbitrary power 'should be eliminated to whatever extent it can be eliminated without undue sacrifice of other values that may be deemed more important' (p. 30), so long as administrative discretions are appropriately confined and structured 'discretionary justice' in the individual case and compliance with the rule of law could both be achieved. For Davis, then, the key question is how administrators can 'regularise', 'organise', and 'produce order' in their exercise of discretionary power in order to avoid unjust arbitrariness (p. 98) or other miscarriages of justice in the 
individual case (p. 119). ${ }^{17}$ Among the 'instruments' he identified as potentially contributing to that aim was the provision of 'fair informal procedure', which he described in terms of the 'opportunity for the affected party to know what is considered and to respond to it before a decision is made' (p. 98).

A more extended treatment of the demands of procedure in the context of administrative discretion can be found in Galligan's study of due process in the context of administrative processes (1996). The taxonomical aim of Galligan's project was to differentiate common families of processes on the basis of their legal purpose (the particular mode of resolution each offers within the legal system itself) so as to consider the implications for procedural fairness reflected in each. Within this taxonomy he identified discretion as belonging to a family of processes characterised by the capacity of the official in whom it is reposed to decide as he or she 'thinks best', which was to be distinguished from the characteristic legal mode of the application of authoritative standards (pp. 26-27). Galligan recognised that a discretion will still generally be situated within a system of standards, even if only those to be implicitly taken from the wider purposes of the statute within which the discretion is reposed. But he argued that it would be a 'distortion' to overstate the role of authoritative standards within discretion given the substantial degree to which the exercise of discretion depends on the judgement of the official as to what standards should apply (p. 26).

Galligan's observations on 'policy-based discretion' are of particular interest to present concerns (pp. 264-267). 'Policy-based discretion' arises in circumstances where, in deciding how a person is to be treated, the authority is obligated to act as appears best in the public interest (p. 264). Examples include the discretion to decide whether to release a prisoner on parole, deport an alien, or grant a planning permission. What distinguishes this kind of administrative discretion is how it involves 'an uneasy combination of an individualised process on the one hand and a policy-based process on the other hand' (p. 264), inviting attention to the individual's circumstances at the same time as leaving space for considerations of politics.

Relevantly for present purposes, the tension between these two elements carries important implications for the demands of procedural fairness in relation to such discretions (p. 266). As Galligan explains it, the individualised aspect of a 'policy-based' discretion points towards the standard 'adjudicative' model of procedural fairness and its prescriptions for how facts are to be determined and issues of merit considered. Yet the absence of authoritative standards of the kind typical in rule-based orders complicates even these individualised aspects of 'policy-based' discretions, with the consequence

that the relationship between the official and the party ... is better characterised as one in which the official may decide as seems best while at the same time being responsive to the claims of the party.

(p. 265, emphasis added)

As for the policy-based component, here Galligan suggests that the notion of 'consultation' might better capture the procedural demands of the relationship 
between the official and the subject that is in play. This is because even if the subject might use her procedural rights to attempt to influence the application of the policy-based aspects of the discretion, the official ultimately 'may decide for reasons which go beyond those submissions' (p. 265). The dual features of a 'policy-based' discretion thus make it impossible to prescribe precisely what is needed to meet the demands of procedural fairness in such contexts, beyond well-settled general standards of fair treatment (p. 375). ${ }^{18}$ But in Galligan's view these demands of fair treatment should include an opportunity for the affected party to make a case specifically directed at influencing the policy aspects of the discretion, at least in relation to their application to the individual case. Galligan acknowledges that this controversial suggestion might be thought to invite into the administrative space a kind of participation in assessing the merits of policy that belongs foremost to the legislative domain (p. 378). ${ }^{19}$ But, as he puts it, 'in this shadowland between adjudication and policy, the very understandings governing the citizen-state relationship are unsettled' (p. 266).

The present analysis benefits from Davis's and Galligan's in several respects. The affinity with Davis lies above all in the latter's effort to bring administrative discretion to the fore, and to illuminate the rules-based assumptions and commitments of legal theory that have operated to marginalise its study as a distinctive form of legal relation or to associate it with arbitrariness for its non-alignment to that archetypal legal mode. Davis was also entirely alive to the asymmetries generated by discretion and the dangers this produces for those subject to its exercise. The affinity between Galligan's project and the present lies on another plane. Galligan's careful differentiation of the 'individualised' versus 'policy-based' components typical of many administrative discretions helps us to see that the very same person whose particular circumstances might be brought into focus within the 'individualised' aspect of this kind of discretion might in turn be at best tenuously situated within its 'policy-based' aspects. Thus, even if implicitly, he points to the relational problems that accompany the phenomenon of administrative discretion.

I turn now to make the case for why the interplay between procedural fairness and administrative discretion is so significant to managing and potentially correcting these tensions, and how this might in turn contribute to the possibility of situating administrative discretion within conditions necessary for the rule of law as Fuller understood them.

\subsection{The interplay of procedural fairness and administrative discretion: promoting the relational conditions for authority}

The feature of choice as to possible courses of action that is the hallmark of the possession and exercise of administrative discretion complicates its character as a form of legal relation into which practices of procedural fairness might enter. What we can take from Galligan is that this complexity is amplified in the face of the dual character of 'policy-based' discretions. Saliently, it is precisely this 


\section{Kristen Rundle}

kind of administrative discretion that tends to be in view when the location of discretion within a condition of the rule of law is disputed. What, then, is the significance of procedural fairness when a governing relationship is framed by administrative discretion?

Following Galligan's division, this question must be considered separately for the individualised versus policy-based aspects of administrative discretion. With respect to the former, it is not difficult to discern how procedural fairness in the context of the individualised aspect of an administrative discretion facilitates a recognisable relationship between its repository and subject. The obligation to observe procedural fairness is clearly most at home in the individualised aspect of administrative discretion, where the concern has been to ensure that the person subject to the discretion is given a fair opportunity to put a case for its exercise in her favour. This demand has been strenuously protected by courts in their supervisory jurisdiction over administrative action, in no small measure because courts have long recognised the alignment between their own procedural fairness obligations within judicial processes and what the law ought to demand within this aspect of administrative decision-making.

But what of the relational significance of procedural fairness in the context of those policy or political aspects of a 'policy-based' administrative discretion where, as just noted, the very same person whose particular circumstances might be brought into focus within the 'individualised' aspect of this kind of discretion might be at best tenuously within the repository's gaze? This tendency, inherent in the very form of administrative discretion, gains further traction from the trappings of unilateral power inherent in the idea of being 'authorised' to exercise such discretion. This invitation to unilateralism is even more extreme when the exercise of an administrative discretion is conditioned on the 'public interest', for the reason that such considerations necessarily operate to divert the perspective of the repository away from the subject. It is therefore precisely here, I want to suggest, that affording procedural fairness contributes a crucial relational correction to what could otherwise operate as mere power over the individual affected by it.

It is important to understand why the relational correction needed in this context can only be supplied by affording procedural fairness to the subject positioned within it. Other structural features of administrative discretions, such as their answerability to certain stated mandatory, relevant, or irrelevant considerations may well operate to direct attention to some or other aspect of the circumstances of the subject. But beyond the fact of how the presence of these features is contingent on how the boundaries of the discretion are formulated, these structural features ultimately go to the conditions of authorisation imposed by the vesting authority on the official in whom the discretion is reposed. Though they might provide important standards against which that repository can be called to account, it does not follow that these structural features of an administrative discretion are concerned with the agency of the person subject to that discretion, or the obligation of the repository to engage with it.

Procedural fairness, by contrast, makes precisely this agency-investing contribution. In doing so, it operates to render concrete a governing relationship 
between repository and subject that otherwise stands to be absent or radically attenuated as a consequence of the relational vulnerability that characterises administrative discretion generally. The statutory boundaries of an administrative discretion might provide the frame for a governing relationship, but it is the agency-investing character of procedural fairness that secures the relational quality of that relationship. It is therefore essential to grasp the relational contingency that characterises administrative discretion, and which is most acute in the case of 'policy-based' discretion, if we are to achieve a more sophisticated account of its place within overarching commitments to the rule of law. The extent to which observance of procedural fairness operates to provide a relational correction to that contingency will determine whether administrative discretion can be so situated.

In developing this view, it is important to consider what this relational correction serves in terms of situating administrative discretion within conditions of the rule of law. Here we meet a number of complications that attend the effort to theorise administrative law generally. ${ }^{20}$ In the context of the exercise of administrative power it might be difficult to argue that the relational dynamics at play in the provision of procedural fairness serve the acceptance of authority in the manner signalled in Fuller's arguments about the relational conditions that constitute the authority of legal order in the first instance. Administrative law belongs to a domain of practice concerned with the application or administration of legally authorised power, rather than the conditions for the constitution of that power. The descriptive or normative theoretical commitments we might associate with those constitutive conditions might therefore strain to be extended, without modification, into the administrative space: specifically, the notion that procedural fairness serves the subject's acceptance of the repository's power might be misplaced as either a description or a normative demand. Further, though procedural fairness might play an important role in supporting acceptance of the repository's decisions, it is unlikely that such acceptance will be carried by procedural fairness alone. The justificatory practice of reason-giving is arguably more likely to contribute to the acceptance of administrative decisions in this sense.

The claim I want to advance about what the relational correction supplied by procedural fairness serves, in terms of situating administrative discretion within conditions of the rule of law, addresses something beyond the conditions necessary for accepting the authority of administrative decisions. My argument is instead that the relationality supplied by procedural fairness is fundamental to the intelligibility and recognisability of the experience of authority itself within an order of law. To be experienced as an instance of lawful authority rather than mere power, the relational conditions that structure administrative action must be continuous with those which support conditions for the acceptance of authority in its constitutive aspect. This position can accept that the structure of authorisation underscoring administrative action will hardly collapse if a subject does not actively 'accept' an administrative decision: the person authorised to make that decision will still be authorised to make it regardless. But, and crucially, the legal status of being 'authorised' still comes with relational demands. 


\section{Kristen Rundle}

These demands necessarily follow from the theoretical commitments outlined earlier, in which the central idea was that what it takes to bring a condition of lawful authority into existence is equally what it must take to keep that condition in existence. Once we defend a normative conception of the rule of law in these terms, we must reject the idea that the concrete expression of authority, in its administrative aspect, can be characterised by unilateralism or other conditions in which relational dynamics are radically attenuated. This is precisely why procedural fairness is so important. The particular species of agency there generatedwhat I earlier termed legal agency-stands to effectively convert an instance of authorisation into a condition continuous with the foundational conditions of authority from which that authorisation is derived.

\subsection{Promoting relational approaches to administrative law}

In addition to marking out a new contribution to relational approaches to procedural justice, the arguments just offered might be situated among other recent works that have sought to promote 'relational' approaches to questions of administrative law, including with respect to procedural fairness and administrative discretion specifically. Jennifer Nedelsky's treatment of ideas of bureaucratic autonomy within American approaches to procedural 'due process' is a leading contribution to the former (Nedelsky 2011), while Genevieve Cartier's conception of 'discretion as dialogue' within Canadian administrative law offers an innovative account of the latter (Cartier 2005).

As part of her study in Law's Relations: A Relational Theory of Self, Autonomy, and Law, Nedelsky considers what kinds of practices and values might be needed 'to make autonomy viable in a bureaucratic state' (2011, p. 139). Questions of autonomy in this context are of special interest to Nedelsky, as a theorist of 'relational autonomy' more generally (1989), as those who are 'in the most dependent relation to the government' will invariably find themselves in bureaucratic relationships (2011, p. 140). In such settings, Nedelsky argues, affording procedural fairness is potentially status-transforming in regard to the components of autonomy with which she is concerned: dignity, competence, comprehension, and defence against arbitrariness. As she expresses the point, 'a hearing designates recipients as part of the process of collective decision-making rather than as passive, external objects of judgment', and may accordingly prevent the subjects of administrative decisions 'from becoming passive objects' of bureaucratic intervention (2011, p. 140).

Nedelsky takes her cue for the autonomy-promoting promise of procedural fairness from an (albeit limited) era of 1970s American 'due process' jurisprudence that indicated how autonomy can be fostered through bureaucratic relations between the individual and the state (2011, p. 140). Although Nedelsky describes this 'due process explosion' as growing out of 'the best of the American liberal tradition' in its emphasis on the protection of individuals from the power of the state (2011, p. 143), she observes many problems associated with it. Some are specific to the American constitutional context: for example, Nedelsky notes 
that the conceptual framework underlying the 'due process explosion'-conceiving of welfare payments as a form of 'new property' that required constitutional 'due process' protections before being taken away-does not of itself provide an adequate basis for articulating affirmative responsibilities of the state (2011, p. 143). Other problems are more general: for instance, she identifies how the objective of fostering autonomy will be rendered vulnerable if procedural fairness protections are tied to the specificities of a particular agency's powers or particular substantive rights $(2011, \mathrm{pp} .140,144)$. The objective must instead be 'to protect the autonomy of all in their interactions with government', in all circumstances (2011, p. 144).

Resonating with Nedelsky, the normative aim of Cartier's project (2005) is to promote a relational view of what is demanded in the exercise of administrative discretion specifically. Cartier's conception of 'discretion as dialogue' as opposed to 'discretion as power'21 accordingly seeks to foster 'a reciprocal relationship between the decision-maker and the individual affected by the decision' (p. 644). According to this conception, the process of communication triggered within the idea of 'discretion as dialogue' prevents a repository from imposing its decision 'unilaterally' on the subject, and supplies an opportunity for the subject to participate in the creation of the norms that will govern the exercise of the discretion (p. 644). At an interpretive level, Cartier claims that her conception best accounts for the progressive trend reflected in a line of key Canadian cases commencing in the late 1970s that saw the courts impose procedural obligations on repositories of discretionary powers, and which departed from a previous reluctance to supervise the exercise of discretionary powers so as to avoid overstepping into questions of policy (pp. 640, 642). ${ }^{22}$ But most relevantly for present purposes, Cartier insists that her conception of 'discretion as dialogue' brings discretion 'down to the individual, instead of maintaining it in the high spheres of the government machinery' (pp. 630-631), and gives concrete expression to the principle 'that the administrative state is there first and foremost to serve the individuals submitted to the authority of the state' (p. 648).

Situating my account alongside Nedelsky and Cartier's reveals some key points of common emphasis. First, and foundationally, we are each preoccupied with questions of agency in the face of administrative power, and specifically with ameliorating or removing the possibility that the repository of such power will unilaterally 'act upon' the person subject to it. We are each equally concerned to highlight the importance of procedural fairness in providing a channel not just for participation in administrative decision-making, including in processes of normcreation, but for situating the relational contact between repository and subject within the larger project of government. The agentic and relational demands of the bureaucratic space are thus, in each analysis, viewed as continuous with the agentic and relational demands of democratic constitutionalism and the institutions through which it is given concrete expression. Moreover, in each analysis the normative prescriptions advanced in association with these shared preoccupations are inseparable from a relational conception of administrative authority itself, whether implicitly or explicitly. 
In the present instance, however, the foundation for insisting on a relational conception of administrative authority, and for drawing out the unique relationship between administrative discretion and procedural fairness that it yields, is an extension of a particular set of theoretical commitments: namely, my concern to develop and defend an understanding of the rule of law itself as a practice of framing all governing relationships by the authority of law. In 'Fuller's Relationships' I suggested that such a conception offered a more fitting contemporary tribute to Fuller's contribution to theorising conditions necessary for the rule of law than the kind of 'checklist-style' applications of his eight principles of the 'internal morality of law' that are so often associated with that endeavour (Rundle 2019a). In support of the foregoing analysis, I want equally to suggest that this explicitly relational reading of Fuller offers the most generative 'application' of the insights of his jurisprudence to questions of administrative law.

In so urging, I am distinguishing my approach from the efforts of other scholars who have sought to bring Fuller's thought to such questions. An important recent contribution to that end is the effort of the leading American public law scholars, Cass Sunstein and Adrian Vermeule (2018), to articulate 'the morality of administrative law' (p. 1927). Though Sunstein and Vermeule do not attempt to apply each of Fuller's eight principles to specific issues in American administrative law in developing this idea, they do seek to 'examine Fuller-compatible approaches' to a number of pressing issues, including vagueness and retroactivity in the practice of administrative agencies (p. 1929). There is not space here to recount the details of this contribution that has done much to direct the attention of administrative law scholars to the promise of Fuller's thought. What requires emphasis in the present context is how, even if there is some acknowledgement of present concerns, ${ }^{23}$ Sunstein and Vermeule's project reflects a qualitatively different engagement with the idea of the 'internal morality of law' than that which I have pursued here.

The key point of difference is that Sunstein and Vermeule accept, and adopt, the 'checklist' reading of Fuller's principles that my own work has been at pains to resist. As I read them, Fuller's principles speak to an idea that is broader, and more fundamental, than the sum of eight parts. They speak to the distinctive quality of relationship that is brought into being, regulated and served, but not exhausted by, those principles (Rundle 2012, pp. 10, 92). Treating the eight principles as a 'checklist', I have therefore argued, distracts from Fuller's central concern to illuminate the relational conditions constitutive of a condition of the rule of law (Rundle 2019a, pp. 35-36). The importance of this point bears repeating in the present context. In my view, emphasising Fuller's enduring concern to illuminate the quality of governing relationships required by an order of law offers the most generative connections between his avowedly normative, authority-centred, form-sensitive, role-emphasising and subject-oriented jurisprudential commitments and the kinds of questions raised by the design and exercise of contemporary administrative power. 


\subsection{Conclusion: the promise for practice}

My aim in the foregoing has been to expand the theoretical treatment given to 'procedural fairness', 'procedural justice', or 'procedural due process' in two new directions. First, I have directed inquiry towards a different form of legal relation-administrative discretion-to that to which inquiry into the value or other significance of procedural fair treatment in decision-making settings most commonly refers. Second, I have aimed to situate this move within a jurisprudence of the rule of law understood as a practice in which governing relationships are framed by the authority of law, and in which the distinctive kind of agency supported by procedures occupies a central place.

Among the motivations for developing this analysis has been an awareness of the vulnerability of these procedural supports in practice. As Nedelsky and Cartier emphasise with respect to the American and Canadian contexts, trends in the articulation of the legal demands of procedural fairness show, starkly, the contingency of the relational promise of its conceptualisation and realisation (Nedelsky 2011, pp. 144-145, 147). The scope and content of procedural fairness in Australian administrative law have followed a similar trajectory. As with the American and Canadian experience, there have been some important moments, indeed eras, of relational promise in the conceptualisation of what procedural fairness demands as a matter of law. For example, for a period the Australian common law held that if a subject of administrative power had a 'legitimate expectation' that a particular course of action would be taken in association with its exercise, then a duty to afford procedural fairness would arise in the event that the repository proposed to depart from that course of action. Though the era of 'legitimate expectations' has now all but passed, what was striking about this idea being included among the possible triggers for a duty to afford procedural fairness was the concern it indicated for the quality of administrative relationships. That is, to insist that procedural fairness might be owed to a person whose legitimate expectation of a particular course of administrative action has been defeated, is to acknowledge that being a subject of administrative power involves a relationship with the repository of that power, and that this relationship carries demands that will be enforced by the law. ${ }^{24}$ The same might be said about the recent emphasis in the Australian case law on why the provision of an oral hearing may be necessary in certain contexts (such as when questions of credibility are at stake) if the demands of procedural fairness are to be met. ${ }^{25}$

These and other features of the Australian common law of procedural fairness - past and present - might be thought to suggest that observing this cardinal legal demand ensures 'that those governing are answerable to and should be responsive to those affected by that exercise of power' (Robertson 2016, p. 162; see also Rundle 2016, p. 168). But this, too, might be historically and institutionally contingent. In the present era, responsibility for determining the ambit of procedural fairness to be afforded to subjects of administrative power is increasingly appropriated by parliaments for their exclusive determination through the 


\section{8}

statute that establishes the authorising scheme. Moreover, contemporary practice demonstrates that administrative discretions that push furthest into the policy or political space are precisely those to which few or no procedural fairness obligations will attach. The widespread statutory exclusion of procedural fairness in the context of parole hearings, and in connection with administrative powers associated with national security measures, provide just two examples.

The framing of administrative discretion itself has also begun to take new and innovative forms. A leading Australian example is the device of the 'noncompellable' administrative discretion that can be exercised at the option of its repository. Conditioned by unspecified considerations of the 'public interest', and departing from the longstanding assumption of administrative law that a discretion reposed must be exercised upon an application to do so, procedural fairness protections will only be available in association with such powers in the event that the repository chooses to consider exercising them. ${ }^{26}$ This squarely reflects the 'authorisation' mindset analysed above, in which the very design of the scheme of power orients toward the repository and away from the subject. One can only question where these developments leave conditions for the governing relationship itself.

In administrative law these governing relationships are inherently and invariably unequal. This fact that attends the work of government in its practical expression is a perennial one. Still, there are ways of thinking about the administrative state, and about administrative law, which can promote the idea that the project of both is to mediate the governing relationships that arise between a state and its subjects. In this enterprise, ideas matter. A relational theoretical perspective on what is at stake when power is exercised by the administrative state, irrespective of the legal form through which that power might ultimately manifest, is a necessary foundation for a relational practice.

\section{Notes}

1 I am grateful to the editors, and participants in the Julius Stone Institute of Jurisprudence seminar in September 2019 at which an earlier version of this chapter was presented, especially Denise Meyerson and Jeffrey Gordon, for their helpful comments. Sincere thanks also to Emily Peck for her superb research assistance.

2 Following Denise Meyerson and Catriona Mackenzie (2018), I will treat these three terms as essentially interchangeable. For the purpose of my analysis, however, I will primarily adopt 'procedural fairness' given the prevalence of this term in the administrative law context with which my analysis is concerned.

3 I return to the administrative law treatment in Part III.

4 For an excellent review of the philosophical literature, see Meyerson and Mackenzie (2018).

5 Fuller's private correspondence explicitly affirms that 'role morality' is the primary meaning he intended for the 'morality' element of his idea of the 'internal morality of law'. For one example, see Letter from Fuller to Rolf Sartorius, 29 January 1974 in The Papers of Lon L Fuller, Harvard Law School Library, Box 7, Folder 15 (Correspondence). 
6 This was also fundamental to Fuller's objections to the concept of law presented by legal positivism. To Fuller's eyes, the picture of a unidirectional 'manifested fact of authority or social power' reflected in legal positivism might better be described in terms of 'managerial direction' than 'law (1969, p. 147). For a full treatment of Fuller's objections to legal positivism, especially those of HLA Hart, see Rundle (2012, pp. 86-140).

7 For a use of this term with compatible aims by scholars interested in questions of legal capacity in the context of disability law, for example, see Anna ArsteinKerslake and Eilionóir Flynn (2017).

8 It follows that I depart from Jeremy Waldron's assessment (2011) that 'Fuller's "procedural" theory was concerned almost entirely with the formal properties of legal rules, such as their clarity and consistency', and that the features of Fuller's internal morality of law 'all relate to the form that legal norms take, not to either the procedure of their enactment or (more important) the procedural mode of their administration' (pp. 7-8).

9 Though administrative discretion did not take a central place in the development of Fuller's claims about the principles of the 'internal morality of law' per se, those familiar with the discussion of Nazi law in the famous debate between Fuller and HLA Hart in the 1958 Harvard Law Review will recall that Fuller paid special attention to the ostensibly unbounded administrative discretions characteristic of certain Nazi statutes. Relevantly for present purposes, it was in the context of discussing Nazi law that Fuller distinguished between a 'tinsel of legal form' and the kind of conditions actually capable of supporting the relational demands of legal order, as he understood them (1958, p. 660).

10 For my own treatment of the rules of procedural fairness in the context of Australian administrative law, see Rundle (2016, p. 164).

11 See Meyerson and Mackenzie's (2018) review of the key philosophical arguments.

12 Philosophers have extended upon the connections between procedure and dignity in different ways. For example, Jeremy Waldron (2011) has argued that procedures embody 'a crucial dignitarian idea-respecting the dignity of those to whom the norms are applied as being capable of explaining themselves' (p. 16). Lawrence Solum (2004) has developed a position that recognises both the intrinsic dignitarian value of procedure alongside the 'irreducible' instrumental value of procedural participation to conferring legitimate authority on adjudicative decisions, irrespective of their substantive correctness (pp. 275, 278).

13 For a helpful explanation of the constitutional lineage and preoccupations of American 'procedural due process' thinking, see Jennifer Nedelsky (2011, pp. 139-141).

14 For an overview, see the helpful discussion of different justifications for the rules of procedural fairness in terms of 'instrumental' versus 'intrinsic' or 'non-instrumental' accounts offered by Peter Cane and Leighton McDonald (2012, p. 118).

15 My position here resonates strongly with Jennifer Nedelsky's observation, also addressing questions concerning state-subject relations in the administrative state, that ' $[\mathrm{d}]$ ignity is not necessarily about perception, competence, judgment and capacity to act', and that '[n]ot all the relations that express dignity will foster these abilities' (2011, p. 141). Though with different theoretical questions in view - in my case, theorising conditions for authority, in Nedelsky's, theorising conditions of autonomy-the common point is that more than dignitarian arguments are needed to illuminate the value of procedural fairness in administrative settings. See my discussion of Nedelksy's 'relational' approach to questions of autonomy in the administrative state in section 11.6. 
16 Ed Rubin's important analysis of law and legislation in the administrative state echoes and develops Davis's polemic in key ways. Also rejecting abstract theories of 'law' and seeking to promote the theorisation of legislation in a manner that more closely reflects its modern attributes, Rubin pointed out that the legislative form implicated in administrative authorisation rarely produces the classic rulegoverned relationship between lawgiver and citizen but is instead directed primarily to empowering officials to apply rules to or exercise discretion over subjects (see Rubin 1989).

17 Davis ultimately suggested seven 'instruments' through which this exercise of structuring discretionary power might be achieved, with different applications in different contexts: 'open plans, open policy statements, open rules, open findings, open reasons, open precedents, and fair informal procedures' $(1969$, p. 98$)$.

18 For example, established procedural demands such as that the facts of the case be enquired into and properly assessed, and that the official properly consider the circumstances of the case and its consequences for the subject (Galligan 1996, pp. 375-378).

19 Galligan highlights how this prescription runs against the position articulated by the majority of the High Court of Australia in South Australia v O'Shea (1987) 73 ALR 1, that the merits of a minister's policy on parole are matters for determination by government and should not be subject to attack in an individualised case (1996, p. 379).

20 As the French administrative law scholar Denis Baranger has astutely put the point, engaging with Martin Loughlin's Foundations of Public Law (OUP 2010), administrative law is readily assumed by public law theorists to be 'not foundational' in character (2016, p. 112).

21 It is notable for present purposes that in setting up this distinction Cartier analogises her point to Fuller's complaints about the conception of law advanced by legal positivist philosophy as 'one-way projection of authority' or a 'unidirectional assertion of control over human behaviour' (see Cartier 2005, p. 636).

22 Engaging with Cartier's account, Nedelsky suggests less optimistically that 'discretion as dialogue' might be better understood as accounting for the best of Canadian administrative law (2011 p. 147).

23 For example, in their suggestion that claims about law's internal morality 'help to underscore the serious problems ... that arise, for example, if public officials have the discretion to do whatever they want' (p. 1966)

24 For my treatment of legitimate expectations, and the corresponding loss represented in its demise, see Rundle (2016, p. 170), and (2019b, pp. 10-11).

25 See Minister for Immigration and Border Protection v WZARH (2015) 256 CLR 326.

See also my discussion of developments in the English case law in Rundle (2016, p. 172).

26 For my analysis of non-compellable powers, see Rundle (2019b).

\section{References}

Arstein-Kerslake, A \& Flynn E 2017, 'The right to legal agency: domination, disability and the protections of Article 12 of the Convention on the Rights of Persons with Disabilities', International Journal of Law in Context, vol. 13, no. 1, pp. 22-38.

Cane, P \& McDonald, L 2012, Principles of administrative law: legal regulation of governance, 2nd ed, Oxford University Press, South Melbourne.

Cartier, G 2005, 'Administrative discretion as dialogue: a response to John Willis (or: from theology to secularization)', University of Toronto Law Journal, vol. 55, no. 3, pp. 629-656. 
Davis, KC 1969, Discretionary justice: a preliminary inquiry, Louisiana State Press, Baton Rouge.

Fuller, LL 1958, 'Positivism and fidelity to law-a reply to Professor Hart', Harvard Law Review, vol. 71, no. 4, pp. 630-672.

Fuller, LL 1969, The morality of law, rev. ed, Yale University Press, New Haven/ London.

Fuller, LL 1974, 'Letter from L. L. Fuller to Rolf Sartorius, 29 January 1974', in The Papers of Lon L Fuller, Harvard Law School Library, Lon L. Fuller papers. Available at https://id.lib.harvard.edu/ead/law00074/catalog (Accessed November 03, 2019).

Galligan, DJ 1996, Due process and fair procedures: a study of administrative procedures, Clarendon Press, Oxford.

Hart, HLA 1958, 'Positivism and the separation of law and morals', Harvard Law Review, vol. 71, no. 4, pp. 593-629.

Loughlin, M 2010, Foundations of public law, Oxford University Press, Oxford.

Mashaw, JL 1985, Due process in the administrative state, Yale University Press, New Haven.

Meyerson, D \& Mackenzie, C 2018, 'Procedural justice and the law', Philosophy Compass, vol. 13, no. 12, pp. 1-11, el2548. Available at https://doi.org/10.1111/ phc3.12548

Nedelsky, J 1989, 'Reconceiving autonomy: sources, thoughts and possibilities', Yale Journal of Law and Feminism, vol. 1, pp. 7-36.

Nedelsky, J 2011, Law's relations: a relational theory of self, autonomy, and law, Oxford University Press, New York.

Robertson, A 2016, 'Natural justice or procedural fairness', Australian Journal of Administrative Law, vol. 23, no. 3, pp. 155-163.

Rubin, EL 1989, 'Law and legislation in the administrative state', Columbia Law Review, vol. 89, no. 3, pp. 369-426.

Rundle, K 2012, Forms liberate: reclaiming the jurisprudence of Lon L. Fuller, Hart Publishing, Oxford.

Rundle, K 2014, 'Legal subjects and juridical persons: developing public legal theory through Fuller and Arendt', Netherlands Journal of Legal Philosophy, vol. 43, no. 3, pp. 212-239.

Rundle, K 2016, 'The stakes of procedural fairness: reflections on the Australian position', Australian Journal of Administrative Law, vol. 23, no. 3, pp. 164-173.

Rundle, K 2019a, 'Fuller's relationships', Special Edition on 'The Rule of Law and Democracy', Archiv für Rechts- und Sozialphilosophie (The Journal for Legal and Social Philosophy), 17-40.

Rundle, K 2019b, 'Non-compellable powers: a relational analysis', Public Law Review, vol. 30, no. 4, pp. 1-14.

Solum, L 2004, 'Procedural justice', Southern California Law Review, vol. 78, no. 1, pp. 181-321.

Sunstein, CR \& Vermeule, A 2018, 'The morality of administrative law', Harvard Law Review, vol. 131, no. 7, pp. 1924-1947.

Waldron, J 2011, 'The rule of law and the importance of procedure', in J. E. Fleming (ed.), Getting to the rule of law, New York University Press, New York/London, pp. 3-31. 


\title{
12 The framing of tribunal procedures A question of balance or a participation-centred approach?
}

\author{
Therese MacDermott
}

\subsection{Introduction ${ }^{1}$}

The Australian legislative framework governing tribunals often specifies the 'just, quick, and cheap resolution' of the issues in dispute- a phrase that is increasingly finding its way into statutory schemes as an overriding purpose or guiding principle for both courts and tribunals across the spectrum. The quick and cheap aspect of this mantra has been the subject of attention directed to what procedures legal institutions should adopt to make them more accessible and affordable to litigants. Statutory phrases of this kind have been interpreted as necessitating the elimination of unnecessary delays and avoiding unduly technical and costly disputes (Black 2009). But how should we understand the meaning of 'just' in the context of tribunal procedures, and can we give effect to it in a way that can be reconciled with the quick and cheap aspects?

A common way of answering this question is to suppose that tribunals should balance the competing considerations of cost, efficiency, and justice (Mason 2017). It has been described as a 'search for that elusive point of equilibrium' (Productivity Commission, Access to justice arrangements, 2014, p. 14). In a similar vein, Rees (2006) identifies it as a tension to be resolved as a consequence of the fact that 'fairness and detachment are sometimes in conflict with efficiency and accessibility' (p. 54). This chapter explores whether the standard approach of seeking to balance these three competing dimensions provides an adequate account of the way in which the procedures of tribunals should be assessed. It argues instead for a relational justice approach that is centred on the notion that participation has an intrinsic value quite separate from questions of cost and efficiency. Giving effect to the just dimension thus requires that an opportunity for participation must be afforded to the parties before cost savings and other claimed efficiencies come into consideration. There may be circumstances where affording that opportunity is considered inefficient or costly. Nevertheless, the opportunity for participation is a fundamental requirement that must be met and cannot simply be 'balanced' away in the service of timeliness or efficiency.

In this chapter I use the concept of participation to encompass practices that afford an opportunity to have an input into how a dispute to which an individual is a party is resolved, acknowledging that an individual may not in fact take up

DOI: $10.4324 / 9780429317248-17$ 
that opportunity (Solum 2004, pp. 272-273). I argue that although participation may take different forms in various contexts in order to bring about efficiencies and timeliness, these factors do not overcome the need for regard in the first place to whether a party was afforded the opportunity for some form of participation appropriate to the nature of the dispute.

There are several arguments supporting this approach. First, is the way in which tribunals are set up to function. Most operate on the premise that parties will represent themselves and be their own advocate in resolving a dispute. To varying degrees, tribunals limit the opportunities for legal representation or make this conditional on the tribunal's assent. Therefore, a party's own involvement is set up as pivotal to the resolution of the dispute. Second, the idea that participation is a core consideration finds support in the fact that tribunals themselves are regularly subject to some form of statutory obligation to take certain measures to help parties understand the proceedings in which they are involved. Third, the importance of participation is consistent with findings in social psychology that highlight the connections between relational concerns and people's perceptions of procedural justice. These findings confirm that the opportunity to present information to a decision-maker prior to a decision being made has a positive effect on the perception of the fairness of the decision-making process (Thibaut \& Walker 1975). Tyler and Lind (1992) identified that participation in the form of the opportunity to voice one's concerns and to present evidence on one's own behalf conveys that a person is worthy of being heard (pp. 140-141), thereby supporting a sense of self-respect (Tyler \& Blader 2000, p. 171). These positive perceptions can in turn enhance the perceived legitimacy of legal institutions and foster compliance.

My focus in this chapter is on the procedures commonly utilised by Australian tribunals with a broad remit, rather than institutions that are principally involved in administrative reviews or bespoke tribunals limited to one area of specialisation, such as mental health or industrial relations. The jurisdiction of the tribunals I consider in this chapter may include reviewing administrative decision-making, and extend to areas such as consumer, commercial, and tenancy disputes; occupational regulation and professional discipline; and matters pertaining to guardianship, discrimination, or the care of children. Tribunals of this nature largely operate at the state and territory level in Australia, as this extended jurisdiction is not available to federal tribunals. My focus on tribunals is quite deliberate and is informed by several factors. First, it is very common for academic commentary to focus on criminal proceedings when exploring aspects of fair procedures, where the threat of a deprivation of liberty dictates certain types of procedural safeguards. Instead, I use the context of civil proceedings, where the subject matter of disputes is quite different, and therefore factors that do not pertain to the serious nature of criminal convictions may influence the types of procedure that are considered appropriate. Second, tribunals tend to use a greater variety of non-determinative dispute resolution processes, such as conciliation and mediation, than do other more formal legal institutions such as courts. Tribunal proceedings therefore have the potential for a more inclusive dialogue and greater 
participation of individuals. Third, it is more likely that individuals will participate in tribunal proceedings without legal representation than in court settings. This has the advantage that an assessment of the opportunity for meaningful participation is less likely to be masked by the involvement of legal representatives. Fourth, unlike courts, tribunals are often subject to a statutory obligation to assist parties to understand the available procedures.

In Section 12.2, I examine the common features of the operational set up of Australian tribunals. In Section 12.3, I explore the aspect of the statutory frameworks governing Australian tribunals that involve the obligation to help parties understand the procedures and examine the role of appropriately resourced tribunals in facilitating such participation. In Section 12.4, I examine the tension within the quick, cheap and just mantra, and the competing values that influence decisions about how to reconcile these factors. Section 12.5 offers some tentative conclusions.

\subsection{Common features of Australian tribunal procedures}

The environment in which Australian tribunals operate is one that seeks to offer what is often referred to as 'affordable' justice. Common descriptors of what tribunal processes aspire to achieve are that they are accessible, fair, just, economical, informal, quick, and proportionate to the importance and complexity of the matter. The legislative intent is that they are not designed to operate with perfect procedures. In the context of tribunal proceedings, it has been observed that 'the content of procedural fairness should take its colour from the structure of the statute and circumstances of the case' (Smyth 2010, p. 262). Procedural flexibility and the capacity of tribunals to inform themselves in any way they consider appropriate is what often sets tribunals apart from courts (Allars 1991, p. 377). The mantra of 'just, quick, and cheap' is often written into the statutory framework of a tribunal as a guiding principle or overall objective with respect to the exercise of the tribunal's functions and in relation to its approach to practices and procedures. Tribunals also aspire to accessibility, both in a geographic sense, and in the sense of less formal processes (Crekye 2012, p. 19).

Tribunals are commonly given considerable latitude by statute to determine their own procedures, to inquire into and inform themselves on any matter in such manner as they think fit, and to act with as little formality as the circumstances of the case, equity, and good conscience permit. ${ }^{2}$ As a consequence, tribunals have considerable discretion as to how proceedings are conducted in practice. For example, they are able to invoke procedures that impose time limits on the presentation of cases if appropriate, limit the number of witnesses, direct that witness evidence be given in writing or only orally, require that parties provide further information, or determine a claim based on the papers only. In addition, tribunals are not bound by the rules of evidence, but are guided by the relevance of the evidence in question.

The fact that tribunals are empowered to make their own inquiries is regarded as a basis for tribunals not to restrict their deliberations to the material put forward 
by the parties, enabling tribunal members to ask questions or raise issues that they regard as insufficiently dealt with by the parties themselves. Such features are generally interpreted as giving tribunals the capacity to operate in a manner more akin to an inquisitorial rather than an adversarial approach. Some commentators contest whether this is in fact inquisitorial in the European sense, ${ }^{3}$ and prefer to see the reliance on less formal and more user-friendly processes as an evolution in the common practices of courts and tribunals through the greater use of alternative dispute resolution (ADR) and case management, and the adoption of a less passive role (De Villiers 2014, p. 182). The operations of Australian tribunals do not reflect a strict binary divide between inquisitorial and adversarial procedures (Bedford \& Creyke 2006, p. 66). While tribunals have the discretion to make their own inquiries, courts have not interpreted this as requiring that tribunals take on such a role, nor do they impose this on tribunals as a strict duty, except in limited circumstances. ${ }^{4}$ Moreover, due to the limitations on resources available it is not common for tribunals to undertake extensive enquiries beyond the material presented by the parties themselves (Groves 2011, p. 177; Smyth 2010, p. 238). Hence the material on which a decision is made will, in the majority of disputes, be dependent on what the parties bring to the tribunal's attention through their individual input into the processes.

The statutory framework governing tribunals will often expressly encourage the use of ADR to resolve or at least narrow the issues in dispute, ${ }^{5}$ and the referral of a matter to a form of ADR, such as mediation, can be made with or without the parties' consent. ${ }^{6}$ Wright (2015) described alternative dispute resolution processes in tribunals as 'not merely an alternative to an adjudicative hearing but rather at the heart of what the Tribunal is doing' ([103]). He also characterises tribunals as offering litigants the opportunity to present their own cases 'without disadvantage', particularly where the proceedings involve smaller value claims, where it has been stated that 'resolution is not assisted by an adversarial approach' $([50]-[51])$.

The legislative framework governing tribunals may impose a positive obligation on the parties and their representatives to cooperate with or assist the tribunal to give effect to the guiding principle or overall objective. Few statutory schemes governing tribunal procedures provide for a specific obligation in this respect. However, the legislation governing the operations of the Civil and Administrative Tribunal in New South Wales (NCAT) does articulate the duty to cooperate and imposes a requirement on parties to participate in the processes of the tribunal. ${ }^{7}$ Case law and commentary both make clear that the duty to cooperate with NCAT is not considered in a vacuum, but rather in the context of giving effect to the mandate of the tribunal and as inherently tied to facilitating the overall guiding principle of 'just, quick and cheap'. ${ }^{8}$ The duty to cooperate may also be relevant to the determination of orders for costs (Maiolo $v$ Chiarelli (No 2) [2016] NSWCATAP 219 [30]). ${ }^{9}$

However, the procedural flexibility and freedom from the rules of evidence vested in tribunals by statute is usually explicitly subject to adherence to the principles of procedural fairness. As outlined in an NCAT decision, the guiding 
principle 'does not gainsay in any way the right to be accorded procedural fairness' (Su v Public Guardian [2014] NSWCATAP 32 [25]). The tribunal expressed a similar sentiment in Amad El Abmad o Imelda Reyes ([2015] NSWCATAP $50[32])$, stating,

The Tribunal is required to comply with natural justice and to ensure that parties have a reasonable opportunity to be heard. The Tribunal has not been established to operate in the same way as a court. However, while it must facilitate quick and inexpensive resolution of the real issues, it must do this in a just manner, which requires adherence to the principles of procedural fairness, which, in the circumstances of this case, meant allowing cross-examination of the applicant.

Ultimately, the restatement of the three dimensions of just, quick and cheap in conducting tribunal proceedings does not resolve how to accommodate these aspects. Despite the latitude tribunals have to determine their own procedures to enable a speedy and cost-effective resolution, the fairness of the procedures adopted still needs to be established.

\subsection{The role of tribunals in supporting participation}

A range of legislative provisions impose on tribunals a requirement to take certain measures to assist parties to understand the proceedings in which they are involved. Different statutory schemes frame the obligation in different ways. In some jurisdictions it may not be explicit in the governing legislation, ${ }^{10}$ but could form part of a tribunal's practices. The taking of reasonable measures might be directed to ensuring that the parties understand the nature of the proceeding $\mathrm{s}^{11}$ or the nature of the matter under consideration. ${ }^{12}$ In some legislative schemes it includes helping the parties to understand the nature and legal implications of any assertions made by parties before the tribunal, ${ }^{13}$ or providing an explanation where requested to do so. ${ }^{14}$

The threshold question is, what is the scope of the legislative obligation? If the legislation is worded as relating to an understanding of the nature of the proceedings, the scope of the obligation will depend on how 'proceedings' is defined. If the legislation defines 'proceedings' in a way that restricts it to the conduct of hearings, then the obligation may not arise unless there is an actual hearing, as opposed to some less formal process that disposes of the matter, such as a case conference or mediation. Some provisions have a broader reach, as they extend the obligation not only to proceedings, but also to an understanding of the 'practices and procedures of the tribunal' (Queensland Civil and Administrative Tribunal Act 2009 (Qld) s29). In addition to the question of the contexts in which the duty might arise, there is the secondary question of the nature of the obligation itself. Most of the statutory provisions refer to measures that are reasonably practicable, or to the taking of reasonable steps. Others frame the obligation more broadly by using the terminology of 'all reasonable steps' and 
the concept of 'ensuring proper understanding and regard' (Queensland Civil and Administrative Tribunal Act 2009 (Qld) s29). Thirdly, the obligation to explain to the parties any aspect of the tribunal's procedures arises in a number of jurisdictions only where requested to do so.

In reviewing the various statutory frameworks, the Queensland legislative scheme appears the most comprehensive regarding a tribunal's mandate to support parties to understand its practices and procedures, as well as the nature of the matter to which they are a party. Wilson (2013) described the Queensland Civil and Administrative Tribunal (QCAT) as planning to be 'actively fair' from its inception (p. 131). The obligation is expressed in Section 29 of the Queensland Civil and Administrative Tribunal Act 2009 (Qld) (QCAT Act) in mandatory language whereby the tribunal must take all reasonable steps to:

(a) ensure each party to a proceeding understands-

(i) the practices and procedures of the tribunal; and

(ii) the nature of assertions made in the proceeding and the legal implications of the assertions; and

(iii) any decision of the tribunal relating to the proceeding; and

(b) understands the actions, expressed views and assertions of a party to or witness in the proceeding, having regard to the party's or witness's age, any disability, and cultural, religious and socioeconomic background.

Framing the statutory obligation in this manner establishes an explicit responsibility to ensure that parties understand all the procedural aspects as well as the implications of what happens in any proceedings. But, as Matthew Groves (2011) argues, this does not 'oblige tribunals to assume control of, or responsibility for, the conduct of a party's application' (p. 184). The QCAT Act further requires the QCAT principal registrar to,

give parties and potential parties reasonable help to ensure their understanding of the tribunal's practices and procedures, including, for example, reasonable help to complete forms required under this Act or the rules (Section 30).

While the scope of statutory provisions such as Section 29 of the QCAT Act can be viewed through the lens of what would assist a self-represented party to understand the legal implications of tribunal proceedings, it is also open to a broader view. For example, in Lida Build Pty Ltd v Miller ([2010] QCAT 17 [6]), the tribunal described the obligation inherent in Section 29 as follows:

While this provision largely reflects and embodies what the courts have said in recent years is the nature of the duty owed by the judicial system to, at least, self-represented litigants, it also suggests that parties to proceedings before this Tribunal will receive, and have an entitlement to expect, assistance with the legal implications of the issues in the case [my emphasis]. ${ }^{15}$ 
The notion that parties are entitled to expect assistance clearly places an obligation on the tribunal to actively assist the parties. Without such assistance the likelihood of a party having an opportunity to participate in a meaningful way may be diminished. But tribunals have not regarded all failures in terms of information provision as automatically leading to a breach of this obligation. ${ }^{16}$

The comparable obligations in Section 38(5) of the Civil and Administrative Tribunal Act 2013 (NSW) ('CAT Act') are framed around taking such measures as are reasonably practicable:

(a) to ensure that the parties to the proceedings before it understand the nature of the proceedings, and

(b) if requested to do so- to explain to the parties any aspect of the procedure of the Tribunal, or any decision or ruling made by the Tribunal, that relates to the proceedings, and

(c) to ensure that the parties have a reasonable opportunity to be heard or otherwise have their submissions considered in the proceedings.

The CAT Act also provides in relation to matters dealt with in the consumer or commercial division, that the tribunal will have regard to 'the extent to which the party is familiar with the procedures of the Tribunal' and 'the party's capacity to understand, and act on, a direction of the Tribunal' in determining whether the conduct of a party 'unreasonably disadvantages another party in the proceedings' (Schedule 4, Part 5, Section 10(3)(a)-(b)).

The obligation to take reasonable measures to ensure that the parties have an opportunity to be heard, or otherwise have their submissions considered in the proceedings, encapsulates what is generally considered to be covered by the fair hearing rule. However, that is only one of the dimensions specified in the CAT Act. It imposes additional requirements, by extending the mandatory obligation to include taking all reasonable steps to ensure that parties understand the nature of the proceedings and to provide an explanation of the procedures where requested to do so. A good example that illustrates how these additional aspects operate is the decision of $Z D U v Z D V$ ([2017] NSWCATAP 197). The appellant (ZDU) successfully appealed a decision of the NCAT Guardianship Division on the basis that the tribunal in the first instance failed to comply with its obligations as set out above. The Panel's reasons for allowing the appeal are extracted at length below:

As directed by s 38(5)(a) of the CAT Act, the Tribunal must take such measures that are reasonably practicable to ensure that parties understand 'the nature of the proceedings'. Self-evidently, without such understanding, a party will be unable to make submissions about the key issues that arise for determination in the proceedings. It follows, that unless the Tribunal has complied with its obligations under s 38(5)(a) of the CAT Act, there is a risk it might also fail to comply with its obligation under s 38(5) (c) of the CAT Act to ensure that the parties have a reasonable opportunity to be heard... However, 
we believe the primary cause for concern was the limited nature of the measures taken by the Tribunal to ensure that ZDU and ZEF, both unrepresented parties, understood the nature of the proceedings in which they were involved ... The particular circumstances of this matter were that: ZDU and ZEF were unrepresented; they were in a spousal relationship; and both were opposed to the making of a financial management order. Given these circumstances, the Tribunal was obliged to take reasonably practical measures to ensure that ZDU and ZEF understood the nature of the proceedings. They were obliged to take steps to ensure that $Z D U$ and $Z E F$ were aware that the issue of who could be appointed as ZDU's financial manager if an order was to be made was a live issue in the proceedings so that each had an opportunity to be heard on this critical matter.

([44], [47], [49], [51], [53]-[54], emphasis added)

An interesting aspect of the $Z D U v Z D V$ decision is the reference to the interrelationship between ensuring the parties have an understanding of the proceedings and ensuring a reasonable opportunity to be heard. The decision indicates that a failure to provide for the former also potentially puts at risk the latter requirement. At the same time, it acknowledges that both are distinct statutory obligations. Hence, the duty to ensure a level of understanding can be seen as a stand-alone obligation, and not simply as part of the fair hearing rule. It is something more than a requirement that a decision-maker must 'hear' a person before making a decision affecting their interests (Kioa v West (1985) 159 CLR 550, 585 ). It is also an obligation to ensure a level of understanding that will facilitate their opportunity to be heard.

It is possible to view this decision as confined to the situation where persons are self-represented, as a result of which their circumstances warrant special attention to their understanding of what the proceedings involve and what orders are at risk of being made. However, the legislative framing of the obligations is not confined to the circumstances of self-represented persons. Moreover, even though the situation of self-represented individuals may necessitate a higher duty, this does not detract from the imposition of the obligation more generally with respect to all parties. Unless the statutory framing of the duty restricts its operation in some way, the requirement that a tribunal help parties understand the proceedings is an obligation that applies to all parties.

What this analysis confirms is that the obligation on tribunals to support the participation of parties is not a passive one, especially where the enabling statutes of tribunals are relatively comprehensive in terms of the nature and extent of the obligation to help parties understand the proceedings. Parties need to be actively supported not only in comprehending the steps involved in reaching a resolution, but also in developing an understanding of what is actually involved in pursuing or defending a claim, how to go about identifying the real issues in the dispute, and how to determine the most appropriate dispute resolution pathway for their situation. It necessitates a type and level of interaction between a party and the tribunal that facilitates a party's understanding of the conduct of the proceedings and the legal implications that arise. 
While the statutory provisions and case law referred to above acknowledge the importance of facilitating this participation, in practice few tribunals are set up or resourced to service these needs. Some institutions attempt to fill the gap through the provision of guidance materials in on-line and other forms. While this might be cost-effective, it is doubtful that such materials would assist individuals with little prior exposure to tribunals to develop a full understanding of the nature of the proceedings or an understanding of how to frame their claim in such a manner that a legal authority is likely to be receptive. The Law Council of Australia's Report on the Justice Project (2018) stated,

the capacity of courts and tribunals to resolve matters both swiftly and fairly is hampered by insufficient resources in the face of increasing demand for services ... [and that] ... sufficient resources and sustainable funding, coupled with active case management and triage, are necessary for courts and tribunals to efficiently process disputes and provide a fair outcome to participants.

The Report makes mention of the critical under-resourcing of courts and tribunals as a 'false economy' and as contributing to 'expensive societal problems over the long term' (p. 10). The Report also recorded the Council's observation that 'involvement of legal practitioners in certain tribunal proceedings can significantly enhance the efficiency and fairness of proceedings and improve the participant's experience' (p. 4). Hence, the continual emphasis on the ability of individuals to self-navigate the system and on limiting legal representation in tribunal proceedings may in fact be counterproductive in some circumstances. While one State Attorney-General has proudly described the tribunal operating in that state as a 'lean, mean, justice machine' (Queensland, Parliamentary Debates 2013, p. 1314) such 'leanness' runs the risk of impacting adversely on the opportunity parties have for input into how their dispute is resolved.

\subsection{Competing values and approaches}

The standard approach to reconciling the three dimensions of quick, cheap and just is the adoption of a balancing approach. Courts and tribunals have recognised that the objectives of speed, efficiency and fairness may give rise to tension, because a mechanism that is 'economical, informal and quick' may well not be fair or just. ${ }^{17} \mathrm{~A}$ common response to seeking to resolve this tension is the balancing approach. The Hon Michael Black AC QC, former Chief Justice of the Federal Court of Australia, articulates this approach using a mixture of references to perfection, fairness and justice in the following terms:

We should maintain the search for that elusive point of equilibrium at which the competing pulls of cost, speed, perfection and fairness are balanced in a way that produces substantial and accessible justice-not perfection, but 
nevertheless processes and outcomes readily recognisable as substantial justice according to law.

(Michael Black quoted in Productivity Commission Inquiry Report No.72 2014 p. 14, my emphasis)

This attempt at balancing competing considerations is regularly adopted in the decision-making of tribunals and by appellate courts evaluating the procedural practices of other legal institutions. For example, a decision by QCAT stated that there needs to be a balance between 'the obligation to provide procedural fairness with the tribunal's obligation to deal with matters economically and quickly' (Jennifer D Keen Pty Ltd t/as Brides of Brisbane v Barkhuizen [2013] QCATA $224,[7])$. The tribunal justified the approach on the basis that

resources for the resolution of disputes are in high demand and serve, as the High Court has recently observed in relation to court resources ... the public as a whole, not merely the parties to the proceedings.

Similarly, in considering whether a refusal to adjourn a hearing could constitute a failure to give a party an opportunity to present their case, NCAT has acknowledged that

essential to a just resolution to proceedings it is also necessary to minimize delay and expense [and that] the achievement of a just but timely and costeffective resolution of a dispute has effects not only upon the parties to the dispute but upon the court and other litigants.

(El-Saeidy $v$ NSW Land and Housing Corporation [2016] NSWCATAP 155[40])

In other proceedings, NCAT concluded that its duty to ensure that a party has a reasonable opportunity to present its case did not extend to acceding to every application for evidence to be admitted out of time, where the effect of granting the request would necessitate setting aside a further hearing date. It stated:

The Tribunal's broad inquisitorial powers do not impose upon it an obligation to inquire into every matter a party asserts might be relevant to the facts in issue. The duty of the Tribunal is to ensure that a party is given a reasonable opportunity to present its case. That duty does not extend to acceding to every application for evidence to be admitted out of time, which a party believes might assist the Tribunal's knowledge of its case. One of the directives in s 73 is that the Tribunal act as quickly as possible. The practical effect of granting this application would have been to require a further hearing day to be set aside.

(Battenberg $\mathcal{D}$ The Union Club [2004] NSW ADT $285[23]-[24])$ 


\section{Therese MacDermott}

A landmark case in this area is the High Court of Australia's decision in $A O N$ Risk Services Australia Limited v Australian National University ([2009] HCA 27) ('Aon') where the court took a strong stand with respect to a late application to amend pleadings in a litigated matter. It adopted an approach that had regard to the public interest and the interests of litigants in other cases waiting for their matters to be heard that might be affected by a further adjournment of the matter, and to the community interest in the efficient use of court resources. The court followed its earlier approach in Sali v SPC Ltd ((1993) 116 ALR 625) where Brennan, Deane and McHugh JJ stated:

What might be perceived as an injustice to a party when considered only in the context of an action between parties may not be so when considered in a context which includes the claims of other litigants and the public interest in achieving the most efficient use of court resources.

In declining to allow the late application to amend the pleadings, the High Court observed:

Where a party has had a sufficient opportunity to plead his or her case, it may be necessary for the court to make a decision which may produce a sense of injustice in that party, for the sake of doing justice to the opponent and to other litigants.

The inaugural President of QCAT attributes this broader notion of whose interests are relevant as being propelled by

the growth in individual rights, and increasing pressure from the Executive and Parliament upon courts and tribunals to be 'productive' in the sense that more services are to be provided to more citizens, but at lesser cost to society.

(Wilson 2013, p. 132)

In framing this approach, the President referenced the work of Les Arthur (2011), who states:

While justice on the merits fits well with formal access to justice, which regards justice as a commodity to enforce an essentially individualistic philosophy of rights, it is unable to give practical effect to the widespread vindication of legal rights ... Recognition of the limited resources available for the delivery of civil justice means that in order to achieve overriding objectives, community interests in the administration of justice must transcend partisan interests. 
Arthur does acknowledge that the contemporary formulation of the statutory mandate of courts and tribunals 'requires balancing justice with efficiency, not the wholesale replacement of justice by efficiency' (p. 246). Along similar lines, the case of Amad El Abmad t/as Cars for Everyone v Imelda Reyes ([2015] NSWCATAP 50), an NCAT decision on whether a refusal to allow an applicant the opportunity to cross-examine the respondent amounted to a denial of procedural fairness, included the following observation by an Appeal Panel that

speed must be tempered by the requirements of fairness. Focussing on timeliness or the potential problems posed by unpreparedness to the exclusion of fairness is not mandated by section 36 .

The prevailing approach to balancing appears to be that the broader interest in the administration of the civil justice system should be taken into account, in a way that extends the balancing approach beyond the interests of the parties themselves. Balance of this kind could be determined by factors that pertain to broader economic considerations and bear little relation to the circumstances of the parties themselves or their substantive claim. ${ }^{18}$ A party may feel a justifiable sense of injustice when it is not the balance between the parties that is determinative, but instead involves considering other factors extraneous to their dispute, for example, the efficient use of court resources and the cost to the community as a whole of certain procedural safeguards.

The balancing approach is also open to criticism on the basis that the weighing of the various considerations and their reconciling can be highly subjective. Academic commentary has pointed to the fact that speed and efficiency on the one hand, and fairness and justice on the other, have been given different weight by judges in superior courts' reviews of tribunal processes (Creyke 2006, pp. 17-18). Creyke gives the example of the High Court's approach in $S A A P$ $v$ Minister for Immigration and Multicultural and Indigenous Affairs ((2005) 215 ALR 162), where the decision at a hearing to give oral rather than written notice of material adverse to the claim, was criticised by the majority as undermining a just approach. However, the dissenting judges found that written notice would have been pointless in the circumstances, and that the objective of the hearing was 'to hear evidence and receive arguments in the most useful and efficient manner' (Crekye 2006, p. 21). In addition, Courts have accepted that in some contexts the fairness dimension can be diminished to 'nothingness' by the circumstances in which a statutory power is exercised. ${ }^{19}$ However, a reduction of this type will not occur unless there is a clear statutory direction to this effect. Finally, some of the case law lends itself to an interpretation that there is a blurring of the distinction between procedural and substantive fairness in some cases, evidenced by judicial observations to the effect that adopting a particular process would not have made any difference to the actual outcome.

If one looks at the way in which the High Court in Aon referred to doing justice in the broader sense of what serves the public interest in the administration of 
justice, it was qualified by the notion that 'a party has had a sufficient opportunity to plead his or her case'. It is important to give this qualification due weight. This could be construed as suggesting that where a party has had a genuine opportunity to have an input into the process, then it is possible to take into account other factors, such as the effect on the tribunal operations and on other litigants waiting to have their disputes dealt with in deciding whether to allow a late application to amend the pleadings. Using this approach, the opportunity that the parties were afforded to engage in a meaningful way in the processes is a precursor to considering those broader factors. It would then follow that without the initial provision of the opportunity for the parties to have input into the process, factors such as speed or efficiency do not have a role to play. This is because affording the opportunity for participation is a fundamental requirement that cannot simply be 'balanced' away to meet the need for speed and efficiency.

A participation-centred approach is justified by relational approaches to justice according to which an individual's self-identity and sense of self-respect are shaped by the nature of the interpersonal interactions they have with institutions such as legal authorities (Meyerson \& Mackenzie 2018, p. 8). Studies in psychology have established that relational factors such as voice, neutrality, dignified treatment, and trustworthiness play an important role in conveying messages of social inclusion and that individuals value interpersonal treatment from legal authorities that sends a message of equal status or value within a social group (Tyler \& Lind 1992, pp. 140-141; Tyler \& Blader 2000, p. 171). Being afforded the opportunity to have an input into how one's dispute is resolved has the potential to convey that a person is worthy of being heard. It is not simply a matter of how an individual subjectively feels about a tribunal's processes. Processes that convey to individuals that they are valued as full participants in society are more likely to be regarded as legitimate, which in turn promotes compliance with legal outcomes. The argument of this chapter is that it is not possible for messages of equal status and value to be conveyed to an individual unless they are afforded the opportunity to have an input into the processes used by tribunals to resolve matters. ${ }^{20}$

This approach is compatible with the established legal rules used to determine whether procedural fairness has been denied in the context of a hearing. The classic judicial pronouncements on procedural fairness ${ }^{21}$ are formulated in terms of the key concepts of the hearing rule and the rule against bias. An individual does not have the opportunity to participate if there is no opportunity to be heard or if the decision-maker is not open to hearing what the person has to say, due, for example, to some form of bias or partiality. An approach based on participation is also capable of dealing with the variety of ways in which tribunals actually resolve matters. As outlined earlier, much of the work of tribunals is directed to deploying alternative mechanisms for dispute resolution to assist the parties to reach a settlement, without the need for a formal hearing of the matter. A participation-focused approach can accommodate the different forms of ADR that are part of the broad dispute resolution framework of Australian tribunals, and allow the fairness of processes to be judged beyond simply the application of rules that are constructed around the typical adjudicative process of a formal hearing (MacDermott \& Meyerson 2018). 
If we accept that participation has a central role to play in assessing tribunal procedures, there is then the question of what type or extent of participation may be appropriate in a particular factual scenario. Is there some irreducible minimum' that determines the fairness or otherwise of that opportunity? The notion of proportionality serves a useful function in this context. Some legislative schemes governing tribunals specifically dictate a proportionality approach. By way of example, section 36 (4) of the CAT Act states that

the practice and procedure of the Tribunal should be implemented so as to facilitate the resolution of the issues between the parties in such a way that the cost to the parties and the Tribunal is proportionate to the importance and complexity of the subject-matter of the proceedings.

Hence processes could be seen as being on a spectrum that ranges from elaborate procedural safeguards to a form of participation that may, for example, be time-limited, judged solely 'on the papers', or take place in a truncated form. However, utilising the concept of proportionality does not involve balancing away the opportunity for participation. It acknowledges participation as a foundational requirement but allows measures to be adopted that take account of, and are appropriate for, the nature of the dispute.

Compare a claim for a refund on goods purchased to a guardianship dispute where a person's autonomy to manage their own affairs is in question. In these situations, there is scope for crafting different procedural responses and safeguards to reflect what is at stake for the parties and what investment of time and resources is therefore warranted. However, in both cases initial regard should still be paid to the opportunity to participate that is made available to the parties, albeit proportionate to the circumstances. The fact that a claim might be regarded as involving a small monetary claim, or an item of low value, does not mean it will be simple to resolve (Genn 1993, pp. 393-400). There is a risk of over-extending the category of disputes that are regarded as largely transactional in nature, simply on the basis of a monetary figure. Moreover, for the individuals who are parties to the dispute, the issues at stake for them personally are not necessarily defined only in terms of the amount of money claimed. From the perspective of the parties, the value of the processes used to resolve a dispute includes being afforded the opportunity to have their say and to have their concerns taken seriously by a legal institution.

\subsection{Conclusion}

Civil tribunals exercising jurisdiction over a broad range of subject areas offer a context in which to focus on procedural justice that is not subject to the same considerations that arise with criminal proceedings. These tribunals are also vested with considerable procedural flexibility and the discretion to inform themselves in any way they consider appropriate. How they meet the requirement that their procedures operate fairly, while subject to the pressures of efficiency and affordability, poses an interesting dilemma. A standard response in the tribunal 
context is to see it as a matter of balancing competing considerations, including broader considerations beyond the interests of the parties themselves, such as those pertaining to the administration of the civil justice system and the needs of other litigants. This chapter has argued for an approach that is less concerned with seeking to balance competing factors and instead looks first to the opportunity a party was afforded to participate in the process, before factors of cost and timeliness come into play.

Thus, this chapter has argued that from the perspective of relational justice, participation is the pivotal factor in understanding how legal institutions that are designed to offer affordable and timely justice can operate fairly. The informality with which tribunals are meant to operate is premised on the notion that parties are able to navigate the processes without requiring legal representation and that individuals can successfully advocate on their own behalf. This makes the participation of parties of primary importance. This is reinforced by the fact that many tribunals are required by statute to be actively engaged in helping parties to understand the nature of the proceedings, and thereby to facilitate that participation. However, to fulfil this important function, tribunals need to be appropriately resourced. Finally, enabling individuals to have an input into how legal institutions such as tribunals resolve disputes, can have a positive influence on how individuals view the interactions they have with such authorities. This in turn can build legitimacy in the operation of such institutions and the trust and confidence vested in them.

\section{Notes}

1 Research for this chapter was funded by the Australian Research Council's Discovery Project funding scheme (DP1701009600: 'A Relational Theory of Procedural Justice').

2 See Civil and Administrative Tribunal Act 2013 (NSW) Section 38, Queensland Civil and Administrative Tribunal Act 2009 (Qld) Section 28; Victorian Civil and Administrative Tribunal Act 1998 (Vic) Section 98; Northern Territory Civil and Administrative Tribunal Act 2014 (NT) Section 53; South Australian Civil and Administrative Tribunal Act 2013 (SA) Sections 39 and 43; ACT Civil and Administrative Tribunal Act 2008 (ACT) Section 23; State Administrative Tribunal Act 2004 (WA) Sections 9 and 32.

3 Robin Creyke describes the inquisitorial process of European based civil proceedings as 'where the adjudicator takes an active role in identifying witnesses and seeking out the evidence before reaching a conclusion' (Creyke 2006, p. 17).

4 See Minister for Immigration and Multicultural Affairs v Eshetu (1999) 197 CLR 611; KO v Commissioner of Police [2004] NSWADT 3; Chand v Rail Corporation of New South Wales(EOD) [2007] NSWADTAP 54. See also Smyth (2010) p. 241.

5 See for example Civil and Administrative Tribunal Act 3 Section 37.

6 See Queensland Civil and Administrative Tribunal Act Section 75. Victorian Civil and Administrative Tribunal Act Section 88; Northern Territory Civil and Administrative Tribunal Act Section 118; South Australian Civil and Administrative Tribunal Act Section 51; ACT Civil and Administrative Tribunal Act Sections 31 and 35; State Administrative Tribunal Act Section 54.

7 See New South Wales Civil and Administrative Tribunal Act Section 36(3). This is also present in the legislation applicable to civil proceedings more generally. See for example, Civil Procedure Act 2005 (NSW) Section 56(3)-(4). 
8 See Edmondson Rural Holdings Pty Ltd v Gordon [2017] NSWCATAP 155 [3]; Shirley Ford $v$ Conrad Meder t/as Brian's Autoscreens \& Glass [2014] NSWCATCD 156 [18]; Woodhouse v Thalis [2017] NSWCATAD 260 [43].

9 See also John Maiolo t/as M \& N Peninsular Kitchens \& Joinery v Chiarelli [2017] NSWSC 982 [51].

10 See for example, the operations of the Victorian Civil and Administrative Tribunal and the Federal Administrative Appeals Tribunal.

11 See Civil and Administrative Tribunal ActSection 38(5)(a)-(b); South Australian Civil and Administrative Tribunals Act Section 43(1)(c); State Administrative Tribunal Act Section 32(6)(b); Northern Territory Civil and Administrative Tribunal Act Section 54(c); Queensland Civil and Administrative Tribunal Act Sections 29-30.

12 See South Australian Civil and Administrative Tribunals Act Section 43(1)(a); Northern Territory Civil and Administrative Tribunal Act Section 54(a).

13 See South Australian Civil and Administrative Tribunals Act Section 43(1)(b); State Administrative Tribunal Act Section 32(6)(a); Northern Territory Civil and Administrative Tribunal Act Section 54(b); Queensland Civil and Administrative Tribunal Act Section 29(1)(a)(ii).

14 Civil and Administrative Tribunal Act Section 38(5)(b). Northern Territory Civil and Administrative Tribunal Act Section 54; State Administrative Tribunal Act Section 32; South Australian Civil and Administrative Tribunal Act Section 43.

15 See also Thorne v Toowoomba Regional Council \& Tytherleigh [2017] QCATA $128[15]-[22]$.

16 See for example, Cox Industries (Australia) Pty Ltd v Burns [2015] QCATA 9 where the QCAT Appeal Panel noted that where a party failed to appear in a matter on the basis of advice allegedly provided by the QCAT 1300 telephone information service, that issue did not constitute a failure of the tribunal' Section 29 obligations.

17 See for example, Sun Zhan Qui v Minister for Immigration and Ethnic Affairs (1997) 81 FCR 71; Minister for Immigration and Multicultural Affairs v Eshetu (1999) 197 CLR 611, 643.

18 The problem of a balancing approach not giving due weigh to a party's substantive rights is considered by Denise Meyerson (Chapter 7) in this volume.

19 See also Johnson (1985), p. 71.

20 The claim that there is a normative requirement on institutions to establish processes that express respect for citizens is explored in more detail in the contributions to this volume by Ceva (Chapter 8), Mackenzie (Chapter 9), and Stoljar (Chapter 10).

21 See Kioa v West (1985) 159 CLR 550; Annetts v McCann (1990) 170 CLR 596; Ainsworth v Criminal Justice Commission (1992) 175 CLR 564; Minister for Immigration \& Ethnic Affairs v Teoh (1995) 183 CLR 273.

\section{References}

Allars, M 1991, 'Neutrality, the judicial paradigm and tribunal procedure', Sydney Law Review, vol. 13, no. 3, pp. 377-413.

Arthur, L 2011, 'Does case management undermine the rule of law in the pursuit of access to justice?', Journal of Judicial Administration, vol. 20, no. 4, pp. 240-247.

Australian Government Productivity Commission 2014, Access to justice arrangements, vol. 1, Report No. 72, https://www.pc.gov.au/inquiries/completed/access-j ustice/report/access-justice-volumel.pdf.

Bedford, N \& Creyke, R 2006, Inquisitorial processes in Australian tribunals, Australian Institute of Judicial Administration Incorporated, Melbourne. 
Black, M 2009, 'The role of the judge in attacking endemic delays-some lessons from Fast Track', Journal of Judicial Administration, vol. 19, no. 2, pp. 88-99.

Crekye, R 2006, “Inquisitorial” practice in Australian tribunals', Administrative Review, vol. 57, pp. 17-32.

Creyke, R 2012, 'Tribunals - carving out the philosophy of their existence: the challenge for the 21st century', AIAL Forum, vol. 71, pp. 19-33.

De Villiers, B 2014, 'The State Administrative Tribunal of Western Australia-time to end the inquisitorial/accusatorial conundrum', University of Western Australia Law Review, vol. 37, no. 2, pp. 182-214.

Genn, H 1993, 'Tribunals and informal justice', Modern Law Review, vol. 56, no. 3, pp. 393-400.

Groves, M 2011, 'The duty to inquire in tribunal proceedings', Sydney Law Review, vol. 33, no. 177.

Johnson, G 1985, 'Natural justice and legitimate expectation in Australia', Federal Law Review, vol. 15, no. 1, 39-75.

Law Council of Australia 2018, The justice project final report, part 2 Courts and Tribunals, viewed 10 October 2019. Available at https://www.lawcouncil.as n.au/justice-project/final-report

MacDermott, T \& Meyerson, D 2018, 'Australian tribunals and alternative dispute resolution: a procedural justice perspective', Civil Justice Quarterly, vol. 37, no. 4, pp. 443-462.

Mason, K 2017, 'Flexibility, informality and despatch; striking the balance in tribunal decision-making', Council of Australasian Tribunal Conference, 8-9 June 2017, Sydney, viewed 11 October 2019. Available at https://coat.asn.au/ resources-library/

Meyerson, D \& MacKenzie, C 2018, 'Procedural justice and the law', Philos Compass, vol. 13, no. 12, pp. 1-11. Available at https://doi.org/10/1111/phc3.12548

Queensland, Parliamentary Debates, Legislative Assembly, 30 April 2013, 1314 (Jarrod Bleijie, Attorney-genreeal and Minister for Justice)

Rees, N. 2006, 'Procedure and evidence in "court substitute tribunals"', Australian Bar Review, vol. 28, pp. 41-87.

Smyth, M 2010, 'Inquisitorial adjudication: the duty to inquire in merits review tribunals', Melbourne University Law Review, vol. 34, pp. 230-267.

Solum, LB 2004, 'Procedural justice', Southern California Law Review, vol. 78, no. 1 , pp. 181-321.

Thibaut, J \& Walker L, 1975, Procedural justice: a psychological analysis, Lawrence Erlbaum Associates, Hillsdale.

Tyler, TR \& Blader, SL 2000, Cooperation in groups: procedural justice, social identity, and behavioral engagement, Psychology Press, Philadelphia.

Tyler, TR \& Lind, EA 1992, 'A relational model of authority in groups', Advances in Experimental Social Psychology, vol. 25, pp. 115-191.

Wilson, A 2013, 'Procedural fairness v modern tribunals: can the twain meet?', Queensland Lawyer, vol. 33, no. 2, pp. 131-136.

Wright, R, 2015, 'An overview of the NSW Civil and Administrative Tribunal', The College of Law Litigation Breakfast Series, Sydney, March 2015, viewed 9 October 2019. https://www.ncat.nsw.gov.au/Pages/about_us/news_events/speeches_a nd_presentations.aspx 


\section{Index}

administrative discretion 9, 16, 232-236, 238-241; and Australian common law 247-248; and due process 239-240, 244-245, 247; policy-based discretion 233-234, 238-248; and procedural fairness 232-241, 242-244, 247-248; and relational conditions $233-236,239$, 241-246; and relational correction of power 234, 242-3; and rule of law 233-234, 239, 241-244, 246-247 administrative law 163, 165, 232, 234, 236-238, 239, 243, 244-246

administrative tribunals see tribunal procedures

agency 3-4, 15, 16, 18, 126, 128-129, $173,187,189,203,204,235-236$, 242-245, 246-247

Allan, TRS 146-147, 155n6

alternative dispute resolution (ADR) 9 , $17 \mathrm{n} 4,255,264$

Amagnya, Moses 103

Anderson, Elizabeth 197-199

Antrobus, Emma 26

Anwar, Shamena 23

Arneson, Richard 180-181

Arnold, Helen 63, 67-68, 70-71, 75

Ashooh, Emma 92-93

authority(ies) 87-88, 94, 98-100, $102,105 \mathrm{n} 3,141-145,148-150$, 154-155, 173, 184, 194-195, 199, 200-201, 205-207, 208n4, 216-217, 260; administrative 194-195; of law 233-239

Barkworth, Julie 30, 31, 68-69, 73

Bayles, Michael 160

Beijersbergen, Karin A 68, 71, 76

Beitz, Charles 182
Bennett, Sarah 26

bias 3, 22, 32, 46, 50-51, 56, 96, 213-214, 219, 223, 225, 230n27, 264

Bickers, Ian 75

Bijleveld, Catrien 68

Bingham, Tom 123

Black, Michael 260-261

Black Lives Matter Movement 21, 35, 91-92

Blader, Steven 4, 74, 206

Boakye, Kofi E 103

Bone, Robert G 164, 166, 168-169, 172, 175nn10-11

Boonin, David 216, 218-219, 228n4, 229n6

Bottoms, Anthony 69-70, 73, 90-93

Bradford, Ben 30, 95-96

Braithwaite, Valerie 25, 73

Brunton-Smith, Ian 71-72

Butler, Michelle 69

Calavita, Kitty 74-75

Cartier, Genevieve 244-245, 247, 250n 21

Ceva, Emanuela 175n13, 196, 201-208

Chan, Janet BL 21

Cherney, Adrian 26, 31, 32

compliance $7,11,12,13,15,23-24$, $36,64-65,70-71,73-74,76,88$, $95,112-114,116-117,121,123$, $133,141-145,148-149,153-154$, 163, 195-196, 216-217, 264; of prisoners see correctional facilities, prisoner compliance in; with police see policing, compliance with consequentialism 15, 159-160, 162, $164-165,214-220,222,228$ 
correctional facilities $63-77,100-102$, 105n7; legitimacy, perceptions of 69-75; post-release offending behaviour 71; prisoner compliance in 64-65, 69-76, 77n3; prisoner wellbeing in 64-69, 77; procedural justice in $11,63-67,68-75$; psychological stress in 64-65, 67-69, 77; staffprisoner relationships in 63-75, 101-102

counter-terrorism 23, 28, 32-33, 37

courtrooms $10,46-50,54$

court(s) $45,49-54,56,148,152$, 189-190, 242, 245, 252-257,

260-263; see also courtrooms

Crewe, Ben 63, 66, 75

Creyke, Robin 263, 266n3

criminal justice system $11,16,23,45$, 57-58, 70-71, 73, 76, 85-86, 88-92, $104,154,169,218,228$

Darwall, Stephen 205-206, 208, 215-216, 220, 227

Davis, Kenneth Culp 239-241, 250n17

DeCremer, David 32

democracy $13,14,21,45,90,141$, 144-145, 146-150, 153, 155n4, 155n6, 182, 184, 196, 198-199, $208 \mathrm{n} 5,245$

deterrence-based strategies $14,23-25$, $35,36,77 \mathrm{n} 3$

dignitarianism 3-5, 16, 24, 173, 205, $232,237-238,249 \mathrm{nl} 2,249 \mathrm{nl} 5$

dignity 4-5, 126, 128, 132, 134, 141, $159,173,189,191 n 9,198,203-205$, $232,233,237,249 \mathrm{nl} 2$

Dillon, Robin 206-208

Dirkzwager, Anja JE 68, 71, 76

discrimination 15-16, 32, 99, 213-215, 220-221; see also bias; racial profiling

dispute resolution 9, 252-253, 255-256, $259,261,264-265$

domestic violence $31,32,35,153$

Dubber, Markus D 154

due process $3,14,133,146-147$, 160, 163, 171, 178-184, 203-204, 237, 239-240, 244-245, 247; inherent value of $179,181,183-190$; instrumental value of 179-183; see also procedural justice

Duff, Antony 3-4

Dworkin, Ronald 3, 14, 123, 164-172, 174
Eichelsheim, Veroni I 68, 71, 76

Eidelson, Benjamin 215, 220-224, 227, $228 \mathrm{n} 5,229 \mathrm{n} 6,230 \mathrm{n} 28$

Epp, Charles 96-97

equality $69,132-133,159$; procedural 203-204; relational 14-15, 173, 196-202, 204, 208

Factor, Roni 94-95

Feinberg, Joel 186-188

Fuller, Lon 12, 16, 113, 123-128, 134, 146-147, 189, 233-236, 241, 243, 246, 248n5, 249n6, 249nn8-9

Galligan, Denis J. 2, 13, 152, 159, 165-171, 174, 239-242, 250n19

Gau, Jacinta M 144

generics 215, 223-228, 229n24

Granovetter, Mark 93-94

group value theory $5-8,15,45,74$, 88-89, 173, 195-196, 201, 204-205, 206, 264

Groves, Matthew 257

Habermas, Jurgen 147-148

Hacin, Rok 70

Haider-Markel, Donald P 96-97

Hamilton, V Lee 143

Harris, David 213, 216-217, 222

Hart, HLA 124, 126-127

Haslanger, Sally 226, 229n24, 230n28

Hawthorn, Geoffrey 87

Hay, Will 69-70, 73

hearing rule $2-3,152,188$, 258-259, 264

Hershovitz, Scott 149

Hinds, Lyn 28, 29

Hosein, Adam Omar 226, 229n6, $229 \mathrm{n} 13$

Huo, Yuen 7

Huq, Aziz 95-96

identity: formation $4-6,63,195,204$, 206, 223, 264; group/social 213, 218-219, 224, 227; see also group value theory

impartiality 24, 51, 173; see also neutrality

inequality 4, 8, 197-200, 203-206, 218

instrumentalism 3-4, 13-14, 65, 70, 74, 86, 91-92, 105nl, 160-166, 171-174; see also procedural justice, instrumental theories of internal morality of law 236 
Jackson, Jonathan 30, 95-96, 115-117, $143-145,150,217$

Jenness, Valerie 74-75

jury(ies) 10, 44-58, 153, 155n8; and evidence management 50-56; facilities 46-49; legitimacy 56-58; neutrality $10,49-50$; participation 54-55; question and answer trails $10-11,52,53-54,56,58$; reforms and innovations $44,46,50-52,58$; trust in $10-11,45,50-52$; voice 46 , $48-49,52,53,54-55,58$; welfare of $50,53-54,58$; see also courtrooms; courts

justice $1,152,256,260,262-264$, 266; affordability of 16-17, 252, 254; distributive 11, 90-93, 197; interactive 201-205; relational conception of 196-197, 200, 252-253, see also procedural justice, relational accounts of; substantive 1, 161-166, 169-174, 232, 245, 263; see also criminal justice system; procedural justice

Kaplow, Louis 162-163

Kearns, Erin M 92-93

Kelman, Herbert C 143

Kochel, Tammy Rinehart 33

Kramer, Matthew 124

Kruttschnitt, Candace 68

law-abiding behaviour/obedience to law see compliance

legitimacy 5, 6-7, 9, 11-12, 13, 45, 64, 69-76, 85-86, 105nl, 106n8, 106n10, 106n15, 107n26, 112, 113-117, 121-123, 141-155, 184, 194-196, 200, 216-217, 228, 253, 266; basic legitimation expectations 11-12, 85-86, 88-93, 99, 104; descriptive/empirical/sociological conception of $6,104,142,194$; normative $86,91-93,102-103$, $105 \mathrm{nl}, 141-142,145,153-155$, 194, 196, 207; perceptions of 10, 11-12, 28-29, 31, 34, 41, 70-77, $88,90,92,100,103,112,114-115$, 141, 142, 149, 208n4, 253; and procedural justice 86-90, 112 , 127-128, 133, 141-143, 146-150

Leslie, Sarah-Jane 215, 224-227, $229 \mathrm{n} 24$

Lever, Annabelle 219, 229n6, 229n21
Liebling, Alison 63, 66, 67-68, $70-71,75$

Lind, Allan 5, 88, 173, 195, 201, $208 n 4,253$

Lippert-Rasmussen, Kasper 229n6, 229nl4

Loughnan, Arlie 154

Loughran, Thomas A 23

Lowrey-Kinberg, Belén 92-93

Lucas, JR 152

McCarthy, Daniel J 71-72

MacCormick, Neil 86

MacDermott, Therese 17n4

Mackenzie, Catriona 132-133, 173

McLean, Sarah J 89, 94, 98

Madon, Natasha 26, 30, 31, 32

Maruna, Shadd 69

Mashaw, Jerry L 237

Maynard-Moody, Steven 96-97

Mazerolle, Lorraine 24, 33, 35

Meares, Tracey 87-88, 100, 104

Mehozay, Yoav 94-95

Menting, Barbara 68

Mesko, Gorazd 70, 72

Meyerson, Denise 17n4, 132-133, 219

minority communities see vulnerable communities

Mitchell, Renée J 75

moral harm 3, 165-168, 170, 172, 223

Murphy, Kristina 26, 28, 29-33, 73

Muslim communities 23, 32-33, 225-227

Nagin, Daniel S 76

Nedelsky, Jennifer 244-245, 247 , 249n15, 250n22

neutrality $5,10,22,45-46,56-58$, $66,87-88,142$; see also procedural justice, four factor model of

Newburn, Tim 97-98, 107n22

Nieuwbeerta, Paul 68, 71, 76

Nussbaum, Martha 184-185, 187

partiality see bias; discrimination participation 9, 54-56, 106n18, 107n26, 181, 235-236, 241, 245, 249nl2, 252-254; and compliance 9, 141-149, 153-154; and democracy 146-150; extrinsic value of 183 , $249 \mathrm{nl} 2$; intrinsic/inherent value of $181,188,252$; in law-making processes 146-150; and legitimacy 9, 13, 58, 141-148, 151-154; 
see also jury(ies), participation; tribunal procedures, participation in

policing 1, 9, 10, 89-92, 92, 94-102,

112-116, 119-124, 154; compliance with 23-24, 29, 36; deterrencebased 23-24, 35, 36; and minority communities 1, 21-22, 31-32, 34, 35 ; procedural justice in 22-36, 89; and racial profiling see racial profiling; trust in 31-34, 144, 214, 217, 218

Posner, Richard 3, 162-164, 167, $175 \mathrm{n} 4,175 \mathrm{n} 6$

power $1,8,9,10,11-12,15,24-25$, $48,69,73,87,90-91,93,99-100$, 105n2, 106n11, 114-115, 142-145, $183,185-186,216-217,222$; and administrative discretion 236-239, 242-248

prisoner(s) see correctional facilities prisons see correctional facilities procedural due process see due process; procedural justice

procedural fairness see procedural justice proceduralism 185, 190n5, 19ln6, 202-204

procedural justice 2-9, 63-67, 85-86, 141-142, 159-162, 179-180, 184-185, 214-215, 232-234; in adjudicative contexts 10-11; and administrative discretion see administrative discretion; affordability 160-166, 167-173, 175nl0; and compliance see compliance; in correctional facilities see correctional facilities; vs. deterrence 14, 23-24, $33,35,36,196$; dignitarian accounts of $173,232,237-238,249$ nl 2 ; distributive models of 6 ; economic theories of 13-14, 162-164, see also instrumentalism; four factor model of $4-5,7-8,10,11,22-23,28$, 45-46, 55-56, 58, 66-68, 72-73, 87-88, 194-196, 201, 207-208, 264, see also neutrality; respect; trust; voice; instrumental justification for 7, 13-14, 24-25, 65, 91-92, 105nl, 126-127, 132, 137, 160-162, 174, 178-180, 182, 184, 187-188, 195-196, 202, 208n4, 216-220, 229n6, 232, 237-238, 249nl2; interactive theory of 179, 184-190, $196,201-203$; intrinsic value of 3-4, 14, 141, 160, 162, 172-173, $179,181,183,202-203,208$,
232-235; and juries see jury(ies); and legitimacy see legitimacy; normative justification for $1-3,6-8,13-15$, 21, 24, 86, 89, 105nl, 132, 160, $165,173,178-179,195-197$, 200-202, 204-205, 207-208, 208n4, 214; outcome-based accounts of 98-101, 161-173, 202, 237-238, see also instrumentalism; in policing see policing, procedural justice in; relational accounts of $1-9,14-15$, 24-25, 45, 66, 74, 132-133, 173, 195-202, 204-208, 232-235, 237-238, 241-248, 252-253; social exchange models of 5-6, 208n4; in tribunals see tribunal procedures; see also due process

procedural rights see rights, procedural

racial profiling 209n6, 213-228; consequentialist arguments for and against 216-220; and discrimination 213-215, 220-222; and disrespect 214-216, 219-223; harms of 218-220, 222-225, 228; and legitimacy 215-217, 228; and policing 9, 15-16, 213-218, 222-224, 226-227, 229nl 1

racism 21, 107n22, 215, 218; see also vulnerable communities

Rawls, John 3, 13, 170-172, 174, 178-179, 184, 186, 190n5, 19ln6, 197,202

Raz, Joseph 123-124, 126-127

Rees, Neil 252

Reisig, Michael 72

relational egalitarianism see relational equality

relational equality 14-15, 197-202, 204-208

relational theory $1,4-6,8-9,25$, 132-133, 196-202, 232-234 see also group value theory

respect $4-5,10,14-16,22,44-46$, 66-68, 70, 72, 132-134, 144, 150, 173, 198-199, 204-205, 214-216, 220-228; appraisal 205-206, 216, 224, 227; recognition 198, 205-208, 215-216, 220, 224-228; self- 4, 5, 7-8, 15, 173, 197-199, 205-208, $215,219,228,264$; see also procedural justice, four factor model of rights: procedural 163, 164, 167-170, 174, 175n10, 180-181, 187-189, 
$199,241,262$; respect for 22,88 , 143, 159, 201-204, 214, 223; substantive/ legal 3, 13-14, 161-162, 164-167, 168, 170, 171-172, 174, 232, 245, 262

Risse, Mathias 214-218, 229n6

Roberts, Benjamin 95-96

Roché, Sebastian 95-96

Roux, Guillaume 95-96

rule of law $12,16,57,90,112-113$,

132-134, 135n16, 136n23, 136n30,

$147,151,155 \mathrm{n} 4,233-234,239$, 242-244, 246-247; moral status of 123-129, 133

Rundle, Kristen 124, 128

Sargeant, Elise 26, 30, 31, 33

Sarre, Rick 35

Scheffler, Samuel 197

Schemmel, Christian 199-200

Searle, John 186

Sedikides, Constantine 32

Simmonds, Nigel 124, 128, 136n23

Skogan, Wesley 95-96

Slotboom, Anne-Marie 68

social atomism 197

social exchange theories 5-6, 208n4

social exclusion $12,25,96,198,206$; see also vulnerable communities

Sparks, Richard 69-70, 73

status 14, 15, 25, 91, 133, 179, 182, 185-190, 19ln9, 198-199, 200-201, $203,205,218,244$; in groups /social $5,8,15,74,88,96,97,144,173$, $195,205,219$; normative 14, 204, 216,227

Straub, Christina 63

Sunstein, Cass 246

Sykes, Gresham 63

Tankebe, Justice 31, 90-93, 103

Telep, Cody W 76

Thibaut, John 65-66

Törnblom, Kjell 6, 7

trials, criminal and civil 3, 45-46, 49, 50-58, 151, 153-155, 170-171, 178-182; see also jury(ies)

Tribe, Laurence 173

tribunal procedures 16-17, 159, 252-253, 254-256; balancing speed, efficiency, fairness in 260-265; conciliation and mediation in 253-254, 255; jurisdiction of 253, 257,265 ; legislative/statutory framework for 255-260; participation in $189,203,253,256-260$,

265-266; procedural flexibility and discretion in $254-255,265$; resourcing of 255, 260-263, 265; and self-representation 17,254 , 257-260

Trinkner, Richard 114-117, 119, 123,217

trust $5,10,21,31-32,34,50-51,58$, 66-69, 75, 195; see also jury(ies), trust in; policing, trust in; procedural justice, four factor model of; trustworthiness

trustworthiness $5,7,22,25,45,52$, 57, 66-67, 194, 196; of authorities 5, 54,207

Tyler, Tom 4, 5, 6, 7, 9, 11, 22, 26, $28,66-68,72-76,87-89,94,100$, 104, 105nl, 106n17, 107n19, 114, 115-117, 142-145, 150, 173, 195-196, 201, 204, 206-207, 208n $4,214,217,253$

Van der Laan, Peter H 68, 71, 76

Vermeule, Adrian 246

Vermunt, Reil 7

voice $5,11,22-23,46,49-50,52$, $53,54,55,58,66,74,87,89,188$, 194, 196, 200, 203, 253; see also juror(s), voice; participation; procedural justice, four factor model of

vulnerable communities $28,30-32$, 37, 91-92, 95-97, 99-101, 106nl2, $107 \mathrm{n} 22,133,153-154,198$, 202-203, 206, 209n14, 213-214, 216, 218-219, 226-227, 229nll

Waddington, PAJ 97-98, 107n22

Waldron, Jeremy 3-4, 149, 155n4, 173, $188-189,203$

Walker, Laurens 65-66

Weinrath, Michael, 72

Wickes, Rebecca 33

Williams, Bernard 11, 87-88, 91, 104

Williams, Kate 97-98, 107n22

Wolff, Jonathan 197-199

Woolf, Lord Justice 70

Worden, Robert E 89, 94, 98

Wright, Martin 97-98, 107n22

Wright, Robertson 255

Zeckhauser, Richard J. 214-218 


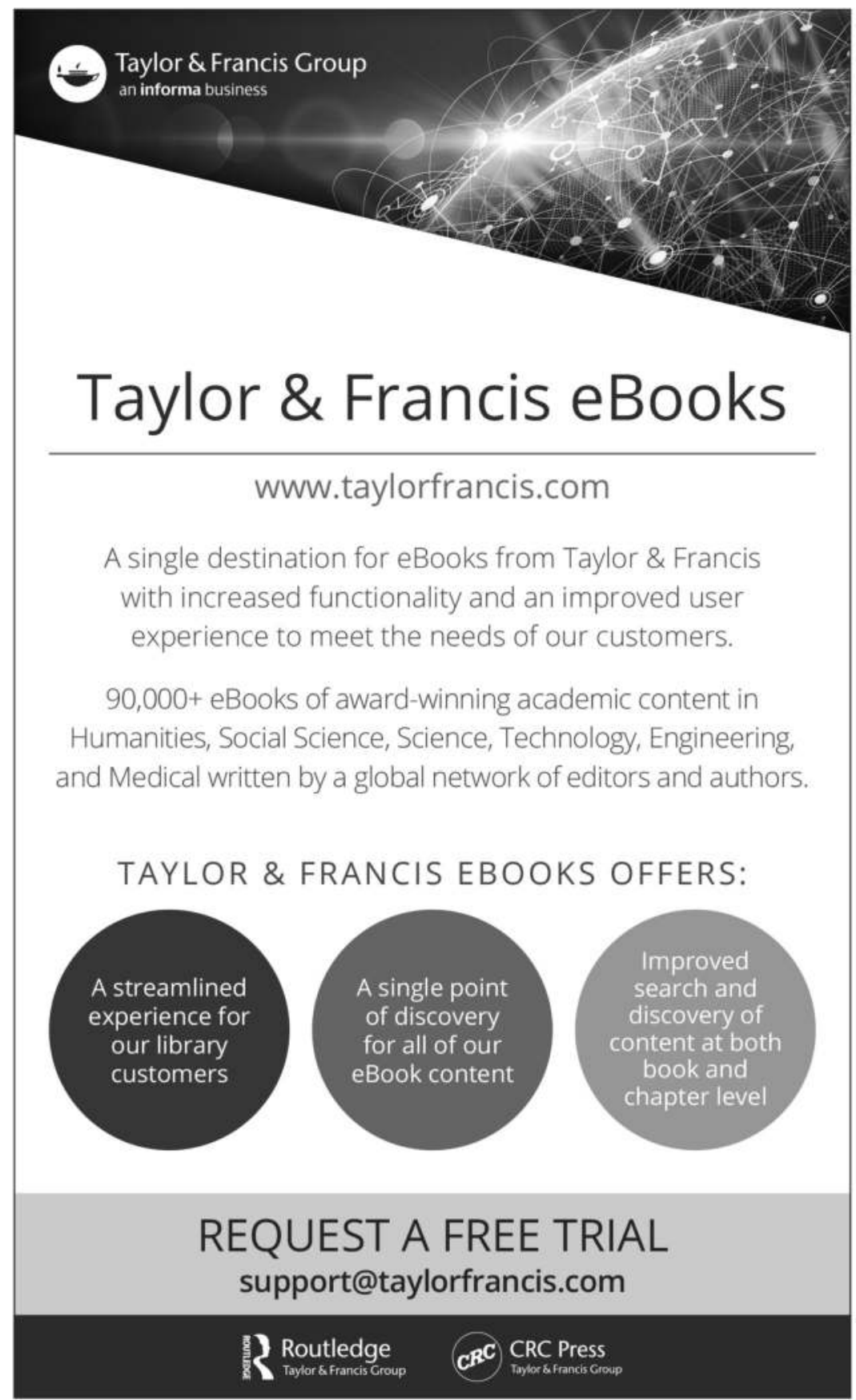

